\title{
Combustion Characteristics of n-heptane Through Temperature Variation Measurements Using Ignition Quality Tester
}

\author{
by \\ Osama Hmood \\ A thesis submitted to the \\ Faculty of Graduate Studies and Research \\ in partial fulfillment of the requirements for the degree of \\ Doctor of Philosophy \\ in \\ Mechanical Engineering \\ Ottawa-Carleton Institute for Mechanical and Aerospace Engineering \\ Department of Mechanical Engineering \\ Carleton University, \\ Ottawa, Ontario, Canada
}

December 2019

(C) Copyright

Osama Hmood , 2019 


\begin{abstract}
The constant volume combustion apparatus, known as the Ignition Quality Tester $\left(I Q T^{T M}\right)$, is increasingly used around the world to measure the ignition delay $(I D)$ of compression ignited fuels, and to calculate the derived cetane number $(D C N)$ from correlations developed with the cetane number $(\mathrm{CN})$. The $I Q T$ is widely used in research due to its capability to manipulate combustion controller parameters, including pressure, temperature, oxygen content and mass of injected fuel. Recently, the IQT has also been used to conduct experiments on fuels with a longer $I D$, such as gasoline. Most findings from previous research are based on instantaneous global pressure measurements to obtain ignition delay, whereas there are minimal spatial and temporal temperature measurements inside the combustion chamber of the IQT. This study will expand knowledge of combustion processes through temperature measurements, using a set of fine gauge thermocouples distributed at different locations inside the $I Q T$ combustion chamber.

In this study, the temperature was recorded at 46 locations inside the IQT chamber during fuel injection and combustion. The experiments were performed at the lab of Advanced Engine Technology Ltd. - Ottawa. Two sets of experiments were conducted: injection fuel into nitrogen (no chemical reaction or combustion), and injection fuel into air (chemical reaction or combustion) and the range of the charge air temperatures and pressures was $530-590^{\circ} \mathrm{C}$ and $10-21.4$ bar, respectively. The temperature variations indicated that the biggest drop in temperature was at the chamber centerline, where most of the larger droplets of the fuel spray moved to. A drop was also found to a lesser degree in the region around centerline, while there was no temperature drop near the chamber wall or tail, which means spray did not reach there.
\end{abstract}


A method developed to estimate the physical and total ignition delay based on the temperature measurements is introduced in this study. The combustion initiation location was predicted from the results of the ignition delay, and it was determined that during long periods of $I D$ the fuel-air mixture becomes pseudo-homogeneous and the combustion initiates everywhere in the main part of the IQT chamber. At higher pressure and temperature conditions, the combustion was initiated at the end of the main part of the chamber. The validation of the $I D$ by temperature method showed good agreement with the predicted $I D$ from pressure measurements. The charge air temperature did not have a significant effect on the physical ignition delay, while the charge pressure has a significant effect on the physical ID. It increased with the charge pressure. Other analysis using temperature variations or drop was conducted on the fuel spray. The estimated penetration length and velocity results of the fuel spray were compared with the empirical correlations, and they showed a good agreement. The spray cone angle was estimated to be in the range $20^{\circ}$ to $45^{\circ}$.

To better understand the fuel spray and combustion process in the IQT chamber, ANSYS Forte was utilized to develop a 3D CFD model. Four skeletal n-heptane chemical mechanisms and a detailed mechanism have been compared with the experimental work. Among these, the reduced mechanism model with 106 species and 1,738 reactions effectively predicted the combustion, and it was also in very good agreement with the experimental results, particularly close to the standard conditions of the IQT. 


\section{Acknowledgments}

I would like to greatly thank all people who either contributed to the work described with this thesis or to me personally during the working time on it. First and foremost, I would like to express my gratitude and appreciation to my supervisor professor Edgar A. Matida. His continuous support and guidance have demolished the difficulties toward gaining my $\mathrm{PhD}$.

I would like to acknowledge the Advanced Engine Technology (AET) Ltd. for allowing me to use their facilities and dedicating an IQT to do my research. The AET staff was wonderful and generous in providing everything for my research. I must thank Mr. Gary Webster, the principal of the AET for the opportunity to work in his laboratory, may he rest in peace. I also want to appreciate the unlimited technical support during experimental work from Luc Menard, Omar Ramadan, Dave Gardiner, and Aaron Wilcox.

Without a scholarship from my home country Iraq, it was impossible to achieve this work. I hope all progress and prosperity to my country and peace to all people there.

Many thanks to all friends for their emotional supports and invaluable advises. Their encouragement during difficult times of my study has inspired me and made me more productive.

Finally, I dedicate this thesis to my family; my beloved mother and father whose love continues as long as my heart is beating, my lovely wife for always standing by me and my kids, my elder brothers Assim and Yasir with respect, and to all other brothers and sisters. 


\section{Contents}

List of Symbols $\quad$ xiv

List of Acronyms $\quad$ xvi



$1.1 \quad$ Introduction . . . . . . . . . . . . . . . . . . . . . . . . 1

1.2 Motivation and Objective of the Present Work . . . . . . . . . . . . . . . 6

1.3 Thesis Outline . . . . . . . . . . . . . . . . . . . . . 7



$2.1 \quad$ Initiation and Development of Ignition Delay Theory . . . . . . . . . . . 9

2.2 Ignition Delay Definitions $\ldots \ldots \ldots \ldots$

2.3 Testing Gasoline Fuels in the IQT . . . . . . . . . . . . . . . . . . . . . . 20

$2.4 \quad$ Numerical Modeling of Combustion in $I Q T^{T M} \ldots \ldots$. . . . . . . . . . . . 21

\begin{tabular}{|lll}
\hline 3 & Experimental Apparatus and Setup & 26
\end{tabular}

$3.1 \quad$ Ignition Quality Tester . . . . . . . . . . . . . . . . . . . . . . . . . . 26

3.2 Installation of Temperature Probes in the $I Q T^{T M}$ Chamber . . . . . . . 30



3.3 .1 Thermocouple Configuration . . . . . . . . . . . . . . . . . 34

3.3 .2 Temperature Probe Fabrication . . . . . . . . . . . . . . . 36

3.4 Experimental Setup . . . . . . . . . . . . . . . . . . . . . . . 37 
$3.5 \quad I Q T^{T M}$ Calibration . . . . . . . . . . . . . . . 41

3.6 Test Procedure $\ldots \ldots \ldots \ldots$. . . . . . . . . . . . . . . . . . 43

3.7 Thermocouple Calibration and Uncertainty Analysis of Measured Temper-



3.7 .1 Thermocouple Calibration . . . . . . . . . . . . . . . 46

3.8 Uncertainty Analysis of Thermocouple Measurements . . . . . . . . . . . 49

3.9 Tested Fuel: n-heptane . . . . . . . . . . . . . . . . . . . . . . 50

3.10 Repeatability Study . . . . . . . . . . . . . . . . . . . . 51

\begin{tabular}{|lll}
\hline 4 & $I Q T^{T M}$ Chamber Temperature Measurements & 58
\end{tabular}

$4.1 \quad$ Spatial Arrangement of Thermocouples Inside the IQT Chamber . . . . . 58

4.2 Raw and Mean Results (Temperature, Pressure and Needle lift) . . . . . 60

$4.2 .1 \quad$ Pressure and Needle Lift Results . . . . . . . . . . . . . . . . 62

4.2 .2 Temperature Measurement Results _... . . . . . . . . . . 65

4.3 Mean Temperature, Pressure and Needle Lift Results at ID Period . . . . 73

4.4 Comparison of n-heptane Injection into Air and into Nitrogen . . . . . . 84

\begin{tabular}{|lll}
5 & Ignition Delay and Spray Characteristics Predictions & 87
\end{tabular}

5.1 Ignition Delay Calculations from Temperature Measurements . . . . . . . 87

5.2 Uncertainty Analysis of Ignition Delay by Temperature Variation .... . 90

5.3 Local Physical Ignition Delay by Temperature Method . . . . . . . . . . 91

$5.4 \quad$ Ignition Delay as a Ratio between Temperature and Pressure Methods . 95

$5.5 \quad$ Physical and Chemical Ignition Delay . . . . . . . . . . . . . . 107

5.6 Total Ignition Delay Based on Pressure and Temperature Variations . . . 110

$5.7 \quad$ Spray Characteristics Results . . . . . . . . . . . . . . . . . . . . . . 113

5.7.1 Estimation of Spray Penetration Length and Speed Propagation from Temperature Variation . . . . . . . . . . . . . . . . . . 113

$5.7 .2 \quad$ Spray Penetration and Propagation Speed Results . . . . . . . . . 115 
5.7.3 Spray Cone Angle Estimation from Temperature Drop during Injection Period . . . . . . . . . . . . . . . . . . . 121

\begin{tabular}{llr}
\hline & Combustion Numerical Model & 125
\end{tabular}

6.1 IQT Geometry and Meshing . . . . . . . . . . . . . . . . . . . 125

6.2 Initial and Boundary Conditions . . . . . . . . . . . . . . . . . 126

6.3 Global Mesh Size and Maximum Time Step Sensitivity Analysis . . . . . 129

6.4 Governing and Transport Equations in Combustion (Continuous Phase

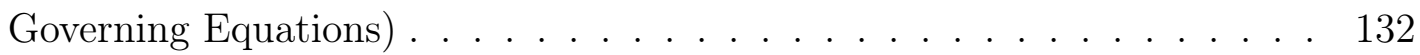

6.4 .1 Continuity Equation . . . . . . . . . . . . . . . . 133

6.4 .2 Momentum Equation . . . . . . . . . . . . . . . . . . . 133

6.4 .3 Energy Equation . . . . . . . . . . . . . . . . . . 133

6.4 .4 Species Transport Equations . . . . . . . . . . . . . . . . . 134

6.4.5 The RNG $\kappa-\varepsilon$ Turbulence Model . . . . . . . . . . . . . . . . . 135

6.5 Fuel injection and Discrete Phase Model Formulation . . . . . . . . . . . 137

6.5 .1 Primary Breakup of liquid Fuel Core . . . . . . . . . . . . . . . . 137

6.5 .2 Secondary Breakup . . . . . . . . . . . . . . . . . 138

6.6 Fuel Spray Settings . . . . . . . . . . . . . . . . . . . . . . . . . . . . 140

6.7 Chemical Kinetics Skeletal Mechanism . . . . . . . . . . . . . . . . . . . 141

\begin{tabular}{|lll}
\hline 7 & Validation of Simulation with Skeletal Mechanism & 144
\end{tabular}

7.1 Auto-ignition Analysis through Temperature, Pressure and Fuel Mass Fraction Contours . . . . . . . . . . . . . . . . . . . . . . . . 144

$7.2 \quad$ Comparison of Experimental and Numerical Ignition Delays . . . . . . . 155

8 Conclusions and Recommendations for Future Work 159

8.1 Conclusions . . . . . . . . . . . . . . . . . . . . . . . . . . . 159

8.2 Recommendations for the Future Work . . . . . . . . . . . . . . . . . . . 162 
\begin{tabular}{ll}
\hline Bibliography & 164
\end{tabular}

\begin{tabular}{ll}
\hline $\mathrm{A}$ & 183
\end{tabular}

\begin{tabular}{|ll}
\hline A Cetane Number Scale Standards & 184
\end{tabular} 


\section{List of Figures}

1.1 Cooperative Fuel Research (CFR) Engine, Standard Test Method for CN of Diesel Fuel Oil (ASTM D613) $|8|$. . . . . . . . . . . . . . . . . . . . 3

$1.2 \quad$ Ignition Quality Tester with main components $\mid 16 \|$. . . . . . . . . . . 5

2.1 Parity plot for hydrocarbon QSAR with 23 descriptors. Extracted from |30| 13

2.2 Ignition Delay data on an Arrhenius-type plot for different fuels and pure



2.3 Comparison between SOC definitions based on pressure and its derivatives $d P / d \theta, d^{2} P / d \theta^{2}$ and $H R R$. Extracted from [55] . . . . . . . . . . . . 17

2.4 A comparison of ID definitions for Sasol IPK which shows two-stage com-



2.5 A comparison of Arrhenius plots using different ID definitions for Sasol IPK $\left(I M E P=3 b a r, S O I=-3^{\circ} C A, T_{i n}=\right.$ Variable, $P_{i n j}=800 b a r$, $R s=3.77, \phi=$ const.). Extracted from $[55]$. . . . . . . . . . . . . . 18

2.6 Chamber pressure traces and needle lift profile taken at $725 \mathrm{~K}$ and $2.1 \mathrm{MPa}$ for iso-octane. Extracted from $[56] \ldots \ldots$. . . . . . . . . . 19

2.7 Correlation between DCN and RON. Extracted from $|65|$. . . . . . . . . 22

$3.1 \quad$ Section in the $I Q T^{T M}$ chamber . . . . . . . . . . . . . . . . . . 27

$3.2 \quad$ Sketch of the $I Q T^{T M}$ combustion chamber with main ports . . . . . . . 28

3.3 Connections of compressed air systems, $|99| \ldots \ldots \ldots$. . . . . . . . . . . . 29

3.4 Schematic diagram of $\left.I Q T^{T M} \mid 12\right] \ldots \ldots \ldots \ldots$. . . . . . . . . . . 31 
3.5 Sketch of TCs used in the IQT combustion chamber . . . . . . . . . .

3.6 Pressure readings from two sensors: at standard position and at intake valve 33

3.7 Temperature response from $0.003^{\prime \prime}$ in dia. and exposed junction TCs, fuel



3.8 Temperature response from 0.005 and 0.010 inch TC wires, fuel CF16 . . 36

3.9 Ceramic insulator rods, (a) $0.5 \mathrm{~mm} \times 6$ holes, $2.5 \mathrm{~mm}$ dia, $250 \mathrm{~mm}$ length, (b) $0.5 \mathrm{~mm} \times 8$ holes, $3.15 \mathrm{~mm}$ OD, $300 \mathrm{~mm}$ length $\ldots \ldots \ldots \ldots \ldots$

3.10 Connection circuit of pressure and needle lift sensors to the DAQ . . . 40

3.11 Experimental connections of sensors on IQT to the DAQ $\ldots \ldots . . .41$

3.12 Fuel mass calibration using variable displacement pump (VDP) . . . . . 43

3.13 Ignition delay starting and ending points in the IQT $\ldots \ldots \ldots . . .44$

3.14 Connections of RTD and reference TC $\ldots \ldots \ldots \ldots$

3.15 Verification of reference TC readings against resistance temperature de-

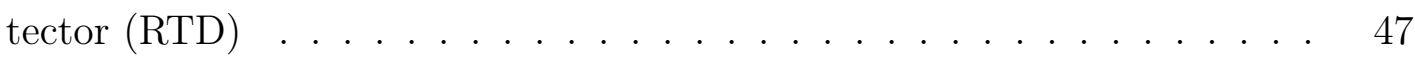

3.16 Calibration of butt welded thermocouples of type $\mathrm{K}$ with bead diameter of $0.01^{\prime \prime}$ in the range 100 to $550^{\circ} \mathrm{C} \ldots \ldots \ldots \ldots$

3.17 Uncertainty (Bias and Random) of thermocouple measurements at different conditions of set points and initial pressure . . . . . . . . . . 51

3.18 Results of the $I D_{T M}$ obtained at $550^{\circ} \mathrm{C}$ and 21.4 bar with five repeats . $\quad 54$

3.19 Results of the $I D_{T M}$ obtained at $580^{\circ} \mathrm{C}$ and 21.4 bar with five repeats . $\quad 55$

3.20 Results of the ID based on pressure obtained at $550^{\circ} \mathrm{C}$ and 21.4 bar with

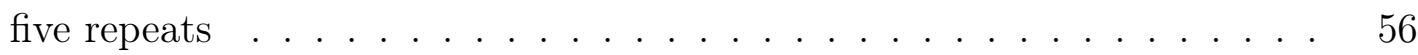

3.21 Results of the ID based on pressure obtained at $580^{\circ} \mathrm{C}$ and 21.4 bar with



4.1 Locations of temperature measurements inside the IQT $\ldots \ldots \ldots$

4.2 Raw vs. smoothing data for one injection, at $P=21$ bar and $T=580^{\circ} \mathrm{C} \quad 61$ 
4.3 Needle lift trace of 15 injections with their mean (black thick line) for two experimental extremes conditions of pressure and temperature . . . . . .

4.4 Pressure variation with time of 15 injections with their mean (black thick line) for three experimental conditions of initial pressure and temperature 64

4.5 Temperature variation of 15 test injections with mean value from the FTP,



4.6 Temperature variation of 15 test injections with mean value from the FTP, $75 \mathrm{~mm}$ from injector plane, $P_{\text {initial }}=10$ bar,$T=530^{\circ} \mathrm{C}$. . . . . . . . . 67

4.7 Temperature variation of 15 test injections with mean value from the FRONT probe, $P_{\text {initial }}=21.4$ bar,$T=590^{\circ} \mathrm{C} \ldots$. . . . . . . . . . .

4.8 Temperature variation of 15 test injections with mean value from the FRONT probe, $P_{\text {initial }}=10 \mathrm{bar}, \mathrm{T}=530^{\circ} \mathrm{C} \ldots \ldots$. . . . . . . . 70

4.9 Temperature variation of 15 test injections with mean value from the BACK probe, $P_{\text {initial }}=21.4 \mathrm{bar}, \mathrm{T}=590^{\circ} \mathrm{C} \ldots \ldots$. . . . . . . . . 71

4.10 Temperature variation of 15 test injections with mean value from the BACK probe, $P_{\text {initial }}=10 \mathrm{bar}, \mathrm{T}=530^{\circ} \mathrm{C} \ldots \ldots$. . . . . . . . . 72

4.11 Temperature variations with time at chamber centerline $(r=0 \mathrm{~mm})$ with different locations from injector plane, and at different initial pressure and temperature . . . . . . . . . . . . . . . . 76

4.12 Temperature variations with time at $r=8 \mathrm{~mm}$ with different locations from injector plane, and at different initial pressure and temperature . . 78

4.13 Temperature variations with time at $r=16 \mathrm{~mm}$ with different locations from injector plane, and at different initial pressure and temperature . . 80

4.14 Temperature variations with time at $r=24 \mathrm{~mm}$ with different locations from injector plane, and at different initial pressure and temperature . . 81

4.15 Temperature variations with time at FRONT port with different initial pressure and temperature . . . . . . . . . . . . . . 
4.16 Temperature variations with time at BACK port with different initial pressure and temperature . . . . . . . . . . . . . . . . . . 83

4.17 Comparison of temperature and pressure variations at chamber centerline and $85 \mathrm{~mm}$ from injector for heptane injection into air and into nitrogen 86

5.1 Temperature method for calculating ignition delay from temperature variation at chamber centerline, and ID by pressure; $P=21.4$ bar, and $T=$ $584^{\circ} \mathrm{C}$; and TC is located at chamber centerline with $75 \mathrm{~mm}$ from injector 88

5.2 Local physical ignition delay at different locations inside the IQT chamber at 10 bar and different initial temperatures . . . . . . . . . . . . . . . 92

5.3 Local physical ignition delay at different locations inside the IQT chamber at 15 bar and different initial temperatures . . . . . . . . . . . . . . . 93

5.4 Local physical ignition delay at different locations inside the IQT chamber at 21 bar and different initial temperatures . . . . . . . . . . . . . . . . . 94

5.5 Ignition delay ratio $\left(I D_{T M} / I D_{I Q T}\right)$ at different locations inside the IQT chamber at $10 \mathrm{bar}$. . . . . . . . . . . . . . . . . . . . . . . . . 97

5.6 Ignition delay ratio $\left(I D_{T M} / I D_{I Q T}\right)$ at different locations inside the IQT



5.7 Ignition delay ratio $\left(I D_{T M} / I D_{I Q T}\right)$ at different locations inside the IQT chamber at $21 \mathrm{bar}$. . . . . . . . . . . . . . . . . . . . . 99

5.8 Ignition delay ratio $\left(I D_{T M} / I D_{\text {Bogin }}\right)$ at different locations inside the IQT chamber at $10 \mathrm{bar}$. . . . . . . . . . . . . . . . . . . . . 101

5.9 Ignition delay ratio $\left(I D_{T M} / I D_{B o g i n}\right)$ at different locations inside the IQT chamber at $15 \mathrm{bar}$. . . . . . . . . . . . . . . . . . . . . . . . 102

5.10 Ignition delay ratio $\left(I D_{T M} / I D_{\text {Bogin }}\right)$ at different locations inside the IQT chamber at 21 bar . . . . . . . . . . . . . . . . . . 103

5.11 Ignition delay ratio $\left(I D_{T M} / I D_{D M}\right)$ at different locations inside the IQT




5.12 Ignition delay ratio $\left(I D_{T M} / I D_{D M}\right)$ at different locations inside the IQT chamber at 15 bar . . . . . . . . . . . . . . . . . . . . 105

5.13 Ignition delay ratio $\left(I D_{T M} / I D_{D M}\right)$ at different locations inside the IQT chamber at 21 bar . . . . . . . . . . . . . . . . . . 106

5.14 The average physical and chemical ignition delay for all tested conditions 109

5.15 Comparison of the ignition delay based on pressure and temperature meth-



5.16 Comparison of the ignition delay based on pressure and temperature meth-



5.17 Comparison of the ignition delay based on pressure and temperature meth-



5.18 Explanation of the estimation of spray penetration and speed from temperature variation during spraying period, all locations are for TCs on the IQT chamber centerline, with 10 bar and $570^{\circ} \mathrm{C} \ldots \ldots \ldots \ldots$

5.19 Comparison of experimental results of spray penetration length with Eqs 5.1 $\mid$ and $5.2 \mid P_{i n j}=17.93 \mathrm{MPa}$ and $P_{a m b}=1.0 \mathrm{MPa} \ldots \ldots \ldots \ldots$

5.20 Comparison of experimental results of spray penetration length with Eqs $5.1 \mid$ and $|5.2| P_{i n j}=17.93 \mathrm{MPa}$ and $P_{a m b}=1.5 \mathrm{MPa} \ldots \ldots \ldots \ldots$

5.21 Comparison of experimental results of spray penetration length with Eqs 5.1 and $5.2 \mid P_{i n j}=17.93 \mathrm{MPa}$ and $P_{a m b}=2.14 \mathrm{MPa} \ldots \ldots \ldots$

5.22 Spray penetration velocity profiles at $P_{a m b}=1.0 \mathrm{MPa} \ldots \ldots$

5.23 Spray penetration velocity profiles at $P_{a m b}=1.5 \mathrm{MPa} \ldots \ldots$

5.24 Spray penetration velocity profiles at $P_{a m b}=2.14 \mathrm{MPa} \ldots \ldots \ldots$

5.25 Spray presented through temperature drop measurements, initial condi-



5.26 Spray presented through temperature drop measurements, initial conditions: $570^{\circ} \mathrm{C}$ and $15 \mathrm{bar} \ldots \ldots \ldots \ldots \ldots \ldots \ldots$ 
5.27 Spray presented through temperature drop measurements, initial conditions: $590^{\circ} \mathrm{C}$ and $21.4 \mathrm{bar}$. . . . . . . . . . . . . . . . . . . . . . . . . 124

$6.1 \quad I Q T$ combustion chamber isometric view with partitions . . . . . . . . 126

6.2 Initial structured mesh of the IQT . . . . . . . . . . . . . . . . . . 127

6.3 Temperature distribution measurements at chamber centerline at pressure 21.4 bar and set point $580^{\circ} \mathrm{C}$. . . . . . . . . . . . . . . 128

6.4 Mesh automatic refinement at milestones of simulation process of fuel injection and combustion . . . . . . . . . . . . . . . . . . . . . . . 130

6.5 Comparison of total simulation run-time and Maximum number of cells at different values of mts and gms . . . . . . . . . . . . . . . . 131

$6.6 \quad$ Verification of global mesh size and maximum time step . . . . . . . . . . 132

6.7 The four primary breakup regimes with diesel direct injection zone. Extracted from $\mid 142\rceil \ldots \ldots \ldots$. . . . . . . . . . . . . . . 139

6.8 Comparison of total simulation run-time and maximum number of cells at four skeletal chemical kinetics . . . . . . . . . . . . . . . . . . . . . . . . 142

6.9 Effects of skeletal and detailed mechanisms on the ignition delay at two



7.1 Temperature contour plots at different instances during injection and combustion processes for conditions 10 bar and $530^{\circ} \mathrm{C}$. . . . . . . . . . . . 146

7.2 Temperature contour plots at different instances during injection and combustion processes for conditions 15 bar and $570^{\circ} \mathrm{C}$. . . . . . . . . . . . . 147

7.3 Temperature contour plots at different instances during injection and combustion processes for conditions 21.4 bar and $590^{\circ} \mathrm{C}$. . . . . . . . . . . . 148

7.4 Pressure contour plots at different instances during injection and combustion processes for conditions 10 bar and $530^{\circ} \mathrm{C} \ldots$. . . . . . . . . . . . 149 
7.5 Pressure contour plots at different instances during injection and combus-



7.6 Pressure contour plots at different instances during injection and combustion processes for conditions 21.4 bar and $590{ }^{\circ} \mathrm{C}$. . . . . . . . . . . . . . 151

7.7 n-heptane mass fraction contour plots at different instances during injection and combustion processes for conditions 10 bar and $530^{\circ} \mathrm{C}$. . . . . . 152

7.8 n-heptane mass fraction contour plots at different instances during injection and combustion processes for conditions 15 bar and $570^{\circ} \mathrm{C}$. . . . . 153

7.9 n heptane mass fraction contour plots at different instances during injection and combustion processes for conditions 21.4 bar and $590^{\circ} \mathrm{C}$. . . . . 154

7.10 Ignition delay prediction by temperature method on numerical and experimental data extracted from a point at chamber centerline and $105 \mathrm{~mm}$ from injector . . . . . . . . . . . . . . . . . 156

7.11 Comparison of ignition delay experimentally (curves and lines with red colors) and numerically (curves and lines with blue colors). The solid markers $(\boldsymbol{\square}, \boldsymbol{\Lambda}, \boldsymbol{\vee})$ are for $I D_{T M}$ at chamber centerline, and open markers $(\square, \triangle, \diamond)$ are for $I D_{I Q T}$. Markers $(\boldsymbol{\square}, \square)$ for $10 \mathrm{bar},(\boldsymbol{\Delta}, \triangle)$ for $15 \mathrm{bar}$ and $(\diamond, \diamond)$ for 21.4 bar. . . . . . . . . . . . . . . . . . . . 158 


\section{List of Tables}

$3.1 \quad$ Sources of bias uncertainties with total bias uncertainty . . . . . . . . . 50

$4.1 \quad$ Initial conditions (Pressure and Temperature) used in the project . . . . 74

5.1 Numeric of the IDs for the analysis shown in Figure 5.1 . . . . . . . . . . 89

5.2 Uncertainty of the $I D_{T M}$ for two conditions of pressure and temperature, and at two locations inside the IQT . . . . . . . . . . . . . . . . . . . 90

$6.1 \quad$ Fuel spray parameters for combustion modeling . . . . . . . . . . . . . . 141

A.1 Characteristics of Cetane Number Scales, |120]] . . . . . . . . . . . . . . 184

A.1 Characteristics of Cetane Number Scales, [120] . . . . . . . . . . . . . . . 185

A.1 Characteristics of Cetane Number Scales, $\mid 120]$. . . . . . . . . . . . . . . 186 


\section{Nomenclature}

\begin{tabular}{|c|c|c|}
\hline Symbol & Definition & Units \\
\hline$A$ & Pre-exponential constant of Arrhenius model & $s^{-1}$ \\
\hline$C_{N L}$ & Needle lift sensor proportional constant & $m m$ \\
\hline$d_{i}$ & Nozzle inner diameter & $m m$ \\
\hline$D_{i, m}$ & Mass diffusivity coefficient & $m m^{2} / s$ \\
\hline$d_{o}$ & Nozzle outer diameter & $m m$ \\
\hline$D_{\text {Therm, } i}$ & Thermal diffusivity coefficient & $m m^{2} / s$ \\
\hline$E$ & Mixture internal energy & $J / k g$ \\
\hline$E_{a}$ & Activation energy of Arrhenius model & $J / m o l$ \\
\hline$g$ & Acceleration due to gravity & $m / s^{2}$ \\
\hline$h_{j}$ & Specific enthalpy of species $\mathrm{j}$ & $J / k g$ \\
\hline$J_{j}$ & Diffusion flux of species $\mathrm{j}$ & $k g / s . m^{2}$ \\
\hline$k_{e}$ & Effective thermal conductivity & $W / m . K$ \\
\hline$N$ & Engine rotational speed & rpm \\
\hline Oh & Ohnesorge number & {$[-]$} \\
\hline$P$ & Pressure & bar, $M P a$, \\
\hline$R$ & Universal gas constant & $J / m o l . K$ \\
\hline$R_{i}$ & Net chemical reaction rate source of species i & $\mathrm{mol} / \mathrm{m}^{3} \cdot \mathrm{s}$ \\
\hline$R e$ & Reynolds number & {$[-]$} \\
\hline$S$ & $\begin{array}{l}\text { Spray penetration length based on environmental } \\
\text { and nozzle specifications }\end{array}$ & $m m$ \\
\hline$S_{i}$ & $\begin{array}{l}\text { Source of heat that comes from liquid droplets } \\
\text { evaporation }\end{array}$ & $\mathrm{mol} / \mathrm{m}^{3} . \mathrm{s}$ \\
\hline$S_{s e}$ & $\begin{array}{l}\text { Any defined volumetric heat source such as heat } \\
\text { released from chemical reaction }\end{array}$ & $J / s$ \\
\hline$S c_{t}$ & Turbulent Schmidt number & {$[-]$} \\
\hline$S_{m}$ & Mass source & $\mathrm{kg} / \mathrm{s}$ \\
\hline$T$ & Temperature & ${ }^{o} \mathrm{C}$ \\
\hline$U_{s}$ & Spray propagation speed & $m / s$ \\
\hline$W e$ & Weber number & {$[-]$} \\
\hline$Y_{j}$ & Mass fraction of species j & \\
\hline \multicolumn{2}{|c|}{ Directional Definition } & Units \\
\hline
\end{tabular}




\begin{tabular}{|c|c|c|}
\hline Symbol & Definition & Units \\
\hline$\vec{F}$ & External body force & $N$ \\
\hline$u, v, w$ & Instantaneous directional velocities & $\mathrm{m} / \mathrm{s}$ \\
\hline$\vec{v}$ & Fluid velocity vector & $m / s$ \\
\hline '́ & Fluctuation component of fluid velocity & $\mathrm{m} / \mathrm{s}$ \\
\hline$x, y, z$ & Cartesian coordinates & $m$ \\
\hline $\begin{array}{l}\text { Greek } \\
\text { symbol }\end{array}$ & Definition & Units \\
\hline$\alpha_{\varepsilon}$ & Inverse effective Prandtle number for $\varepsilon$ & {$[-]$} \\
\hline$\alpha_{\kappa}$ & Inverse effective Prandtle number for $\kappa$ & {$[-]$} \\
\hline$\varepsilon$ & Dissipation of kinetic energy & $J / k g$ \\
\hline$\kappa$ & Turbulent kinetic energy & $J / k g$ \\
\hline$\mu$ & Dynamic viscosity of mixture gases & $\mathrm{kg} / \mathrm{m} . \mathrm{s}$ \\
\hline$\mu_{e f f}$ & Effective viscosity for $\kappa-\varepsilon R N G$ model & $\mathrm{kg} / \mathrm{m} . \mathrm{s}$ \\
\hline$\mu_{t}$ & Turbulent viscosity & $\mathrm{kg} / \mathrm{m} . \mathrm{s}$ \\
\hline$\rho_{\text {air }}$ & Air density & $k g / m^{3}$ \\
\hline$\rho_{f}$ & Fuel density & $k g / m^{3}$ \\
\hline$\tau$ & Viscous stress tensor & $N / m^{2}$ \\
\hline
\end{tabular}




\section{List of Acronyms}

\begin{tabular}{|c|c|}
\hline Acronym & Definition \\
\hline $\mathrm{AET}$ & Advance Engine Technology \\
\hline ANSYS & Analysis System \\
\hline ASTM & American Society for Testing and Materials \\
\hline ASME & American Society of Mechanical Engineers \\
\hline$B_{T}$ & Total Bias Uncertainty \\
\hline $\mathrm{BDCN}$ & Blending Derived Cetane Number \\
\hline BTDC & Before Top Dead Center \\
\hline CAD & Crank Angle in Degree \\
\hline CF16 & Diesel Check Fuel 16 \\
\hline CF18 & Diesel Check Fuel 18 \\
\hline CFD & Computational Fluid Dynamics \\
\hline CFR & Cooperative Fuel Research \\
\hline $\mathrm{CN}$ & Cetane Number \\
\hline $\mathrm{CR}$ & Compression Ratio \\
\hline $\mathrm{CuHRR}$ & Cumulative Heat Release Rate \\
\hline CVCA & Constant Volume Combustion Apparatus \\
\hline CVCC & Constant Volume Combustion Chamber \\
\hline DAQ & Data Acquisition \\
\hline $\mathrm{DCN}$ & Derived Cetane Number \\
\hline $\mathrm{Ea}$ & Activation Energy \\
\hline EGR & Exhaust Gas Recirculation \\
\hline EIA & Energy Information Administration \\
\hline FACE & Fuels for Advanced Combustion Engines \\
\hline
\end{tabular}




\begin{tabular}{|c|c|}
\hline Acronym & Definition \\
\hline FIT & Fuel Ignition Tester \\
\hline FTP & Flower Temperature Probe \\
\hline gms & global mesh size \\
\hline HRR & Heat Release Rate \\
\hline$I D$ & Ignition Delay \\
\hline$I D_{\text {Bogin }}$ & Ignition Delay based on Bogin et al. method \\
\hline$I D_{D M}$ & Ignition Delay by differential method \\
\hline$I D_{e}$ & Engine Ignition Delay \\
\hline$I D_{I Q T}$ & Ignition Delay by standard method (ASTM D6890) \\
\hline$I D_{T M}$ & Ignition Delay based on temperature measurements \\
\hline$I D_{\text {phys }}$ & $\begin{array}{l}\text { total physical Ignition Delay based on temperature } \\
\text { measurements }\end{array}$ \\
\hline$\left(I D_{\text {phys }}\right)_{\text {local }}$ & $\begin{array}{l}\text { local physical Ignition Delay based on temperature } \\
\text { measurements }\end{array}$ \\
\hline$I D_{\text {chem }}$ & $\begin{array}{l}\text { total chemical Ignition Delay based on temperature } \\
\text { measurements }\end{array}$ \\
\hline$I D_{v}$ & Vessel Ignition Delay \\
\hline IQT & Ignition Quality Tester \\
\hline KH-RT & Kelvin-Helmholtz/Rayleigh-Taylor \\
\hline LANL & Los Alamos National Laboratory \\
\hline $\mathrm{MCH}$ & Methylcyclohexane \\
\hline MFI & Mass of Fuel Injected \\
\hline $\mathrm{MON}$ & Motor Octane Number \\
\hline MTBE & Methyl Tertiary Butyl Ether \\
\hline $\mathrm{mts}$ & maximum time step \\
\hline NL & Needle Lift \\
\hline
\end{tabular}




\begin{tabular}{|c|c|}
\hline Acronym & Definition \\
\hline NTC & Negative Temperature Coefficient \\
\hline OI & Octane Index \\
\hline $\mathrm{PM}$ & Particulate Matter \\
\hline $\mathrm{PMH}$ & Pentamethyleheptane \\
\hline PRF & Primary Reference Fuel \\
\hline QSAR & Quantitative Structure Activity Relationship \\
\hline RNG & Renormalization Group \\
\hline $\mathrm{RON}$ & Research Octane Number \\
\hline RTD & Resistance Temperature Detector \\
\hline$R_{T}$ & Total random uncertainty \\
\hline SG & Specific Gravity \\
\hline $\mathrm{SOC}$ & Start Of Combustion \\
\hline SOI & Start Of Injection \\
\hline $\mathrm{TC}$ & Thermocouple \\
\hline TDC & Top Dead Center \\
\hline $\mathrm{TR}$ & Temperature ratio $\left(T(t) / T_{\text {initial }}\right)$ \\
\hline$T U_{A S M E}$ & Total Uncertainty of measurement \\
\hline UDF & User defined function \\
\hline
\end{tabular}




\section{Chapter 1}

\section{Introduction and Motivation}

\subsection{Introduction}

Combustion is the main process of releasing energy from fuels. Most of the energy used over the world comes mainly from fossil fuel combustion. This energy is utilized for ground, sea or air transportation, operating factories (industry) and several other applications. Almost 40\% of the energy used nowadays is extracted from liquid fuels [1], [2]. Despite their value in transportation and other applications, the burning of diesel and gasoline has a great impact on the environment through emissions of greenhouse gases, like carbon dioxide $\mathrm{CO}_{2}$. Based on U.S. Energy Information Administration (EIA, 2015), about $83 \%$ of the $\mathrm{CO}_{2}$ released in the transportation sector is produced from burning diesel and gasoline in engines [3].

Diesel engines are more economical than gasoline engines but at the same time the pollutants in the diesel exhaust gases, like particulate matter $(P M)$, carbon monoxide $(C O)$, nitrogen oxides $(N O x)$, and hydrocarbons, have more drawbacks on both health and environment. Extensive work has been conducted on combustion of diesel fuel and its influence on the performance of compression ignition engines [4]. Most studies include the period from fuel injection until combustion. This period, which is called ignition delay 
$(I D)$, is a very short period of time in milliseconds and it varies based on the fuel type and depends greatly on the environmental conditions of combustion, like temperature and pressure [5]. Further, the new engine technology uses high fuel injection pressure to reduce ID period and improve combustion efficiency, but at the same time the NOx is increased whereas soot formation is reduced [6], [7].

A scale to measure the ignition quality of diesel fuels called cetane rating or Cetane Number $(C N)$ was first determined experimentally in a Cooperative Fuel Research $(C F R)$ test engine (Figure 1.1) and it was adopted in 1941 under the designation number ASMT D613 method [8]. Cetane number is an inverse analogous to the octane number for gasoline. Both scales measure the tendency of the fuel to a spontaneous ignition but with opposite conceptual consequences [9]. The compression ratio $(C R)$ of the 4 stroke, single cylinder $C F R$ engine is controlled manually through the variable compression plug hand-wheel (Figure 1.1) to get the required ignition delay. The engine is running at a constant rotational speed of $900 \mathrm{rpm}$, and the tested fuel is injected at 13 Crank Angle in Degree (CAD) before top dead center (BTDC) to be ignited at the top dead center $(T D C)$. The $C R$ is adjusted for the $I D$ to be $2.407 \mathrm{~ms}$. Then, the combustion characteristics of the tested fuel are tabulated and compared with those for the blends by volume of the two reference fuels, n-hexadecane (cetane) with $C N=100$ and 2,2,4,4,6,8,8-heptamethylnonane (isocetane) with $C N=15$, to determine the $C N$ of the tested fuel. The CFR engine is considered as a reference method (ASMT D613) to measure $C N$. However, the high capital cost, long testing time, large fuel sample quantity, and high reproducibility errors of this method led to the development of alternative methods for rating diesel and non diesel fuels. Those methods are based on injecting and igniting fuel into a constant volume vessel or chamber.

The first attempts of testing compression ignition fuels in a pressurized and heated constant volume chamber was started with a single-shot injector to measure the $I D$ and to observe the effect of $C N$ on it [10]. Studies of the constant volume combustion have been 



A- Fuel tanks
B- Air heater housing
C- Air intake silencer
D- Fuel flow rate buret
E- Combustion pickup
F- Safety guard
G- Variable compression plug handwheel
H- V.C.P. Locking handwheel
I- Oil filter cap
J- Injection pump safety shut-off solenoid
$\mathrm{K}$ - Injector assembly
L- Fuel injection pump
M- Fuel selector-valve
$\mathrm{N}$ - Oil filter
O- Crankcase oil heater control
P- Air heater switch
Q- Engine start-stop switch
R- Instrument panel

Figure 1.1: Cooperative Fuel Research (CFR) Engine, Standard Test Method for CN of Diesel Fuel Oil (ASTM D613) [8 
developed greatly and their results have showed an excellent agreement with engine tests [11]. As a result, three standard test methods [12]-[14 using constant volume combustion chamber were developed and used to test diesel fuels and obtain $I D$ or Derived Cetane Number $(D C N)$. The features of these standards with ASTM D613 are summarized in Appendix A. One of the instruments that used to test diesel fuels and their alternatives is manufactured in Ottawa by Advanced Engine Technology Ltd. (AET). It is called the ignition quality tester $\left(I Q T^{T M}\right)$, as shown in Figure 1.2 with designation number ASTM D6890. The $I Q T^{T M}$ is a constant volume combustion chamber and it is considered as the most precise device used to rate diesel fuels in the present because of its lower reproducibility errors $\left[15\right.$. The predicted $I D$ by the $I Q T^{T M}$ is experimentally correlated to the $D C N$, where two standard equations based on the limits of ID are used to obtain $D C N[12-14$.

$$
\begin{gathered}
D C N=4.46+\frac{186.6}{I D} \text { for } 3.1 \leq I D \leq 6.5 \\
D C N=83.99 \times(I D-1.512)^{(-0.658)}+3.547 \text { for ID outside the range in eq } 1.1
\end{gathered}
$$

Despite considerable experimental and theoretical work conducted on different fuels by using the $I Q T^{T M}$, there is still need to know more about the IQT combustion, especially in the part related to temperature measurements. Most of the experimental data involving the $I Q T^{T M}$ are related to pressure measurements. Whereas temperature measurements are presented either experimentally by visualization or numerically by simulation. The present work aims to analyze fuel combustion in the IQT through temperature measurements using fine gauge thermocouples. In addition to that, the combustion process is numerically modeled and the experimental temperature measurements prior to the fuel injection were applied as an actual initial condition in the numerical 




Figure 1.2: Ignition Quality Tester with main components 16 
combustion model.

This chapter will review mainly the work related to the $I D$ period in the $I Q T^{T M}$ and other machines and engines. In addition to that, it will also highlight the objectives and describe this proposal outline.

\subsection{Motivation and Objective of the Present Work}

The rapidly increasing reliance on the $I Q T^{T M}$ for fuel testing, with more than 190 petroleum and additive companies and research centers around the world using it [16], means studying the combustion in the $I Q T^{T M}$ highly important. The main objective of the this work is to develop and enhance knowledge of fuel spray and ignition in the ignition quality tester through temperature measurements. Although the pressure variations of the overall gas mixture indicate the spray breakup and evaporation at the onset of combustion, it is also important to know the spatial and temporal variations by monitoring the temperature at different locations inside the chamber. In order to achieve this, a set of fine gauge temperature probes were inserted into the $I Q T^{T M}$ chamber at different per-selected locations; the temperature measurements highlight the spray and ignition characteristics in greater details. The experimental aspect is conducted on an $I Q T^{T M}$ at Advanced Engine Technology Ltd. which was specifically tailored for this purpose.

The objective is accomplished in four main steps:

1. Prepare and test the required fine gauge temperature probes from butt-welded thermocouple wires and adjust the $I Q T^{T M}$ to the new test settings. The selected $T C$ should meet two requirements: 1) Be robust enough to withstand the harsh conditions of high temperatures and pressure and, 2) provide efficient response to temperature variations. 
2. Conduct the first set of experiments on the primary reference fuel n-heptane, by applying different conditions of pressure, temperature and injected mass. In this set, the fuel is injected into a chamber charged with air (reacting conditions).

3. Conduct a second set of experiments by applying the same conditions as the first set, but with the chamber charged with an inert gas such as nitrogen (nonreacting conditions).

4. Develop a three-dimensional numerical model to reproduce n-heptane spraying and ignition behavior, and validate it against experimental results.

\subsection{Thesis Outline}

The thesis consists of eight chapters organized as follows:

In Chapter 2, compression combustion is reviewed through the ignition delay theory. The milestones of the $I D$ theory initiation are stated first, then the $I D$ definitions in the engines and constant volume apparatus are presented. This is followed by a review of the work on using the $I Q T^{T M}$ for testing gasoline fuels. Finally, the chapter summarizes the conducted numerical combustion work using the $I Q T^{T M}$ geometry and settings.

The experiment settings and results are presented in Chapters 3 to 5 . The setup, which includes fabrication and testing of the temperature probes, adapting the $I Q T^{T M}$ for temperature settings and the final setup, are detailed in Chapter 3. The results of the experiments are presented and discussed in Chapters 4 and 5. The raw, filtered, and mean data for the measured parameters (i.e. temperature, pressure, and needle lift) are first presented in Chapter 4, to provide information regarding the temporal temperature variations at different locations inside the $I Q T^{T M}$ chamber. Detailed analyses of the $I D$ based on the temperature and pressure measurements are covered in Chapter 5, as well as the heptane spray characteristics from temperature measurements. 
Chapters 6 and 7 focus for the combustion numerical CFD modeling. Chapter 6 illustrates the 3D geometry and meshing of the $I Q T^{T M}$ and the CFD model setup, after which the primary and secondary spray break up are explained. Several skeletal mechanisms are compared, and the results are reported in Chapter 6. Results of the final adjusted settings of the numerical model and comparisons with the experimental work are presented in Chapter 7 .

Finally, the thesis findings, conclusions, and recommendations for future work are summarized in Chapter 8. 


\section{Chapter 2}

\section{Background and Literature Review}

\subsection{Initiation and Development of Ignition Delay The- ory}

The ignition delay in the fuel combustion mainly comes from two interrelated effects comprising of physical and chemical delays. The physical delay period represents the time required for the injected fuel to be atomized, vaporized, mixed with air and have its temperature initially dropped (due to evaporation) and then elevated (heated) to the point where the chemical reactions start. Whereas the chemical delay attributes to precombustion reactions. There are many parameters affecting the ignition delay period. They have been studied and presented through research conducted on constant volume combustion chambers and engines [4], [17]-[19].

The idea of physical delay period was established in the 1920s [20]. Two sets of experiments at constant and varying pressures were performed on seven types of available liquid fuels. All results proved that the fuel cannot be ignited in liquid phase, it should be evaporated and mixed with oxidant before combustion. Whereas the chemical delay was indicated for the first time in 1936 by Holfelder [21] through watching the ignition of injected spray into a confined heated air in a constant volume vessel equipped with a large 
window. Photographs with a frequency of 500 frames/sec traced the combustion process. Pictures have shown the hot spots initiation and combustion processes for different fuels.

Later on, several formulae for the ID have been proposed. In 1949, cetane and methylnaphthalene fuels were tested in a diesel engine and two formulae for the $I D$ have been presented in the results $[22$. The concept of the $I D$ was expressed as the summation of physical and chemical delay as stated in the Equations 2.1 and 2.2 .

$$
\begin{gathered}
\text { For Cetane fuel }: I D=0.71 e^{\frac{1070}{T}}+3.47\left(10^{-14}\right) e^{\frac{17620}{T}} \\
\text { For methylnaphthalene fuel }: I D=0.977 e^{\frac{1070}{T}}+2.18\left(10^{-8}\right) e^{\frac{14510}{T}}
\end{gathered}
$$

Tsao et al. 23 have recorded gas temperature inside Cooperative Fuel Research (CFR) engine [8] by using an infrared technique explained by Burrows [24]. A mixture of normal cetane and alpha-methyl naphthalene was used in the experiments. Gas temperature was traced for different operating variables: pressure, intake temperature and engine rotational speed. A formula for $I D$ as a function of the three variables: pressure $(P)$, temperature $(T)$ and rotational speed $(N)$ has been proposed as shown in Equation 2.3 ,

$$
\begin{aligned}
I D & =\left(\frac{123}{P}+0.415\right)\left[\left(\frac{-36.3}{T}+0.0222\right) N+\left(\frac{47.45 \times 10^{3}}{T}-26.66\right)+\right. \\
& \left.\left(\frac{T}{1000}-1.45\right)\left(\frac{1000-N}{60}\right)\right]
\end{aligned}
$$

Ryan 25] has determined the physical and chemical ignition delay by conducting two sets of experiments in a constant volume combustion chamber (CVCC). In both sets, the fuel was injected into the same environmental conditions of quiescent, high temperature $\left(538^{\circ} \mathrm{C}\right)$ and high pressure $(\approx 4 M P a)$. In the first set, the fuel was injected into the 
chamber charged with heated air and combustion occurred. Whereas in the second set the fuel was injected into a chamber charged with nitrogen where the fuel was only evaporated. An accurate pressure measuring system was used to trace pressure variation in the chamber. In both cases, the pressure has the same trend of decreasing levels due to fuel vaporization. This matching has started from fuel injection until a point where the chemical reactions between fuel vapour and air started and pressure increased whereas in the nitrogen case, the pressure remained unchanged. This point was defined as the end of physical delay and start of chemical delay. Blends of primary reference fuels were used with different cetane numbers. The results showed that the physical delay is longer for high $C N$ fuel. Also, it was found that the $I D$ is a strong function of temperature.

In 1987, Ryan and Stapper [26] used the same combustion chamber and procedure to obtain the $I D$ values of 42 different fuels with wide range of $C N$ and at 3 different initial temperatures. The results showed that the chemical delay is affected greatly by temperature and fuel type $(C N)$ while the physical delay did not show a significant effect on those factors. Also, a formula for the total ID was developed which is based on the Arrhenius equation [27. In another work by Ryan and Callahan 11, the ID time for blends of primary reference fuels and various distilled fuels was measured using both the constant combustion chamber and a standard ASTM D613 engine which is designated for cetane number measurements. This study aimed to develop a method for diesel fuel rating by using a constant volume combustion chamber. The effects of air temperature and pressure, air-fuel ratio and $O_{2}$ concentration were investigated by using this constant volume combustion chamber. It was found that air temperature was the most dominant parameter on the ignition process and it was inversely proportional to the $I D$. Comparison of the $I D$ results for distilled fuels have showed good agreement between two methods (i.e., CVCC and CFR engine). Han et al. 28 studied the differences between measured $I D s$ using engine ignition delay $(I D e)$ and constant volume vessels ignition delay $(I D v)$ and presented a correlation for $I D e$ for cold starting condition. 
Kwon et al. 29 showed that the $I D$ in engine was shorter than that in constant volume combustion chamber.

In 2004, a comprehensive work by Taylor et al. [30 has collected and analyzed $C N$ data for 275 pure compounds by using a Quantitative Structure Activity Relationship (QSAR) software to investigate the effects of molecular structure on compression ignition, where 147 compounds were hydrocarbons and the rest oxygenates. Most data from the QSAR model were in good agreement with a database as shown in Figure 2.1. In addition to data analysis, the $I D$ of 9 pure fuel compounds and 5 real fuel mixtures were measured at $310 \mathrm{psig}$ and different temperature in the range $\left(360-580^{\circ} \mathrm{C}\right)$ by using the Ignition Quality Tester $\left(I Q T^{T M}\right)$. The log scale of the $I D$ curves for all fuels were inversely proportional to the temperature as a non-linear relationship as shown in Figure 2.2. In another work, Taylor $\left[31\right.$ has investigated the pressure, temperature and $\mathrm{O}_{2}$ concentration effects on $I D$ for heptane by using the $I Q T$. The $I D$ has been measured at 27 different conditions $\left(P=10,20\right.$, and $30 \mathrm{bar} ; \mathrm{T}=450,500$, and $550^{\circ} \mathrm{C}$; and $\mathrm{O}_{2}=$ 15\%,18\%, and 21\%). An Arrhenius like model was developed to correlate ID with temperature as shown in the Equation 2.4. Where $A$ is a pre-exponential constant and can be calculated from derived cetane number $(D C N), E_{a}$ is the activation energy, $b$ is the oxygen concentration exponent, $R$ is the universal gas constant and $T$ is the ambient temperature in $K$. Where for heptane, the measured values were: $D C N=52.5, E_{a}=$ $50.2 \mathrm{~kJ} / \mathrm{mol}$, and $b=0.74$.

$$
\text { Rate }=\frac{1}{I D}=A \exp \left(\frac{E_{a}}{R T}\right)\left(O_{2}\right)^{b}
$$

Saravanan et al. [32 have developed and validated two ID correlations based on Wolfer's equation [33] for diesel and biodiesel combustion in engine. One equation at a no load condition and the other at a load condition as shown in Equations 2.5 and 2.6. where $C N$ is the fuel cetane number, $P_{i}$ and $T_{i}$ are pressure and temperature at the start of injection respectively, and $T_{L}$ is the temperature at loaded condition. 


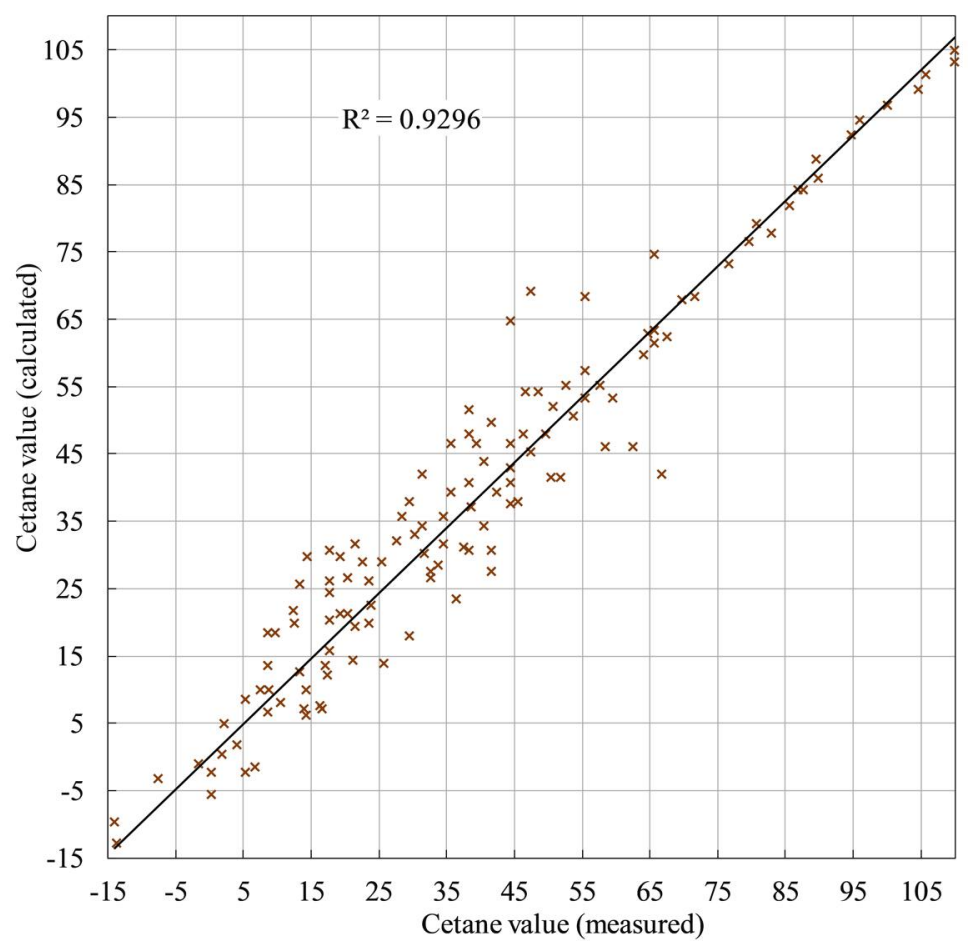

Figure 2.1: Parity plot for hydrocarbon QSAR with 23 descriptors. Extracted from $|30|$



Figure 2.2: Ignition Delay data on an Arrhenius-type plot for different fuels and pure compounds. Extracted from 30$]$ 
No loadcondition $: \quad I D(m s)=\exp (-(0.0187 C N+8.551)) P_{i}^{0.7352} \exp \left(4626.44 / T_{i}\right)$

Loaded condition $: \quad I D(m s)=\exp (-(0.0187 C N+8.551)) P_{i}^{0.7352} \exp \left(4626.44 / T_{L}\right)$

Several investigations [34]-36] have also been used in compression ignition engines to test and model different biodiesel or alternative diesel fuels when they are blended with diesel fuels or alone. Using constant volume combustion chambers (CVCC), like the $I Q T^{T M}$, to analyze compression ignition has been expanded greatly after their results were validated against engines. For the last two decades, IQT $T^{T M}$ usage in testing conventional fuels with and without fuel cetane improvers and alternative fuels like biodiesel has been increased greatly. The $I Q T^{T M}$ is reliable and well convenient to test fuels for a wide range of $C N$.

In 2009, Berkhous [37 measured DCN of five fuel samples by using CVCC. Three samples were JP-8 fuels and the other two were Jet A fuels. Effects of two types of cetane improvers (2-EHN and DTBP) on the tested fuels were also investigated and presented. The cetane improver levels used in the experiments were 250, 500, 1500, 3000, and $5000 \mathrm{ppm}$. The results of $D C N$ from CVCC were compared with the predicted cetane number from engine test of ASTM D613 method. Maximum deviation was $\pm 2 C N$. Both types of the cetane improvers have significant effects on the $D C N$ up to level $500 \mathrm{ppm}$, where there was rapid increase in $D C N$. After that level, the response of CN to the additives diminishes greatly.

In addition to temperature and $\mathrm{O}_{2}$ concentration, pressure was presented in the $I D$ correlation proposed by [38, [39] as shown in the Equation 2.7. Kook et al. [38 has investigated the $I D$ using a small-bore single-cylinder diesel engine with diluted air by 
adding $\mathrm{N}_{2}$ and $\mathrm{CO}_{2}$ in the range $0-65 \%$ to simulate exhaust gas re-circulation (EGR) and get the required variations in the $T, P$ and $\mathrm{O}_{2}$ concentration. On the other hand, Bogin et al. [39] used the IQT to measure the ID of nine diesel fuels (FD1A through FD9A) designated for Advanced Combustion Engine (FACE) at pressure, temperature and $\mathrm{O}_{2}$ concentration in the ranges $15-30 \mathrm{bar}, 450-550{ }^{\circ} \mathrm{C}$ and $15-20.9 \%$ respectively.

$$
I D=A P^{b} X_{O_{2}}^{c} \exp \left(\frac{E_{a}}{R T}\right)
$$

Nine n-alkanes with low to high volatility were tested at different conditions by using the IQT [40], 41]. The ID measurements were conducted at a wide range of pressures and temperatures 0.1 to $3 \mathrm{MPa}$ and 650 to $1023 \mathrm{~K}$ respectively and two $\mathrm{O}_{2}$ concentrations of $15 \%$ and $21 \%$. Negative Temperature Coefficient (NTC) region [42], in which an unusual behavior for fuel ignition occurs where the $I D$ increases as the temperature increases, was observed for the first time in the $I Q T^{T M}$ and especially at reduced conditions of temperature and pressure which produces a longer ID. Also, at a low temperature heat release condition, it is observed that a two stage ignition process from monitoring the chamber pressure. First stage is called the cool flame and the second one is called the main ignition. These stages were also observed in rapid compression machines 43].

In 2013, Zheng et al. [17] followed the same procedure applied by Ryan [25], 26] to get physical and chemical ID of four fuels: ultra low sulfur diesel (ULSD), jet propellant8 (JP-8), and two synthetic fuels of Sasol IPK and F-T SPK (S-8). The experiments were conducted in the range of charge air temperatures from 778 to $848 K$ and at a standard IQT pressure of 21.3 bar. Physical delay was more sensitive to temperature variations than chemical delay. Activation energy of each fuel has been calculated from the developed Arrhenius plots of the experimental data. Two models were proposed for Arrhenius based on $I D$. The first model was for total (physical and chemical $I D$ ) and the second one was based on the chemical delay only. A year later, Zheng et al. 44 studied the effect of adding 0.1 to $0.4 \%$ of Lubrizol 8090 (cetane improver) on the ID of Sasol IPK 
fuel by using the $I Q T^{T M}$ under the same conditions of their previous work [17]. Results have shown that as the cetane improver level increases in the fuel, the chemical delay period decreases and this cetane improver has no influence on the physical delay period. Also, the apparent activation energy decreases when there is more cetane improver in the fuel. Whereas in another work by Yang et al. [45], adding MTBE, which is an octane improver with negative impact on humans [46], to the diesel fuel has increased the $I D$ linearly.

\subsection{Ignition Delay Definitions}

All ID definitions have common starting point which is called start of injection (SOI) but the end point of the $I D$ which is called start of combustion (SOC) has different definitions. Some researchers define SOC point based on the variation in the pressure values and their first and second order derivatives [47]-49] and others are based on the point where the heat release rate (HRR) curve changes from negative to positive [50]-55] as shown in Figure 2.3 .

In 2015, Joshi et al. 55 have tackled the comparison between different definitions of ID through an experimental study on a single cylinder high speed direct injection engine using two types of fuels: Ultra-low sulfur diesel (ULSD) and iso paraffinic kerosene (IPK), where five different $I D$ definitions have been calculated from pressure measurements and analyzed to see their discrepancy effects on the activation energy as shown in Figures 2.4 and 2.5. Where $I D_{R}$ : delay between $S O I$ and $H R R$ curve crossing zero, $I D_{R P}$ : delay between $S O I$ and cumulative heat release rate $(C u H R R)$ curve crossing zero, $I D_{C A 5}$ : delay between $S O I$ and $5 \%$ of $C u H R R$ curve, $I D_{C A 10}$ : delay between $S O I$ and $10 \%$ of $C u H R R$ curve, and $I D_{P}$ : delay between $S O I$ and a detectable start of pressure rise. 




Figure 2.3: Comparison between SOC definitions based on pressure and its derivatives $d P / d \theta, d^{2} P / d \theta^{2}$ and $H R R$. Extracted from $[55$



Figure 2.4: A comparison of ID definitions for Sasol IPK which shows two-stage combustion. Extracted from 55 




Figure 2.5: A comparison of Arrhenius plots using different ID definitions for Sasol IPK ( $I M E P=3$ bar, $S O I=-3{ }^{\circ} C A, T_{i n}=$ Variable, $P_{i n j}=800$ bar $, R s=3.77, \phi=$ const.$)$. Extracted from 55 




Figure 2.6: Chamber pressure traces and needle lift profile taken at $725 \mathrm{~K}$ and $2.1 \mathrm{MPa}$ for iso-octane. Extracted from [56]

Two months later from Joshi's work, a detailed experimental study on the $I D$ measurements at low temperature conditions was reported by Yang et al. [56 using diesel, $\mathrm{n} \_$heptane and iso-Octane fuels. The effects of three parameters (temperature, pressure and equivalence ratio) were investigated in the ranges 698 to $860 \mathrm{~K}, 1.5$ to $2.1 \mathrm{MPa}$ and 0.5 to 1.7 , respectively. A new way of $I D$ estimation, it is the SOC definitions like in Figure 2.3. called gradient method was introduced which is based on the intersection point of two line tangents extracted from the pressure variation curve as shown in Figure 2.6. The first tangent (slope I) was taken at the pressure recovery point [57] and the other one (slope II) was at the maximum pressure rise when combustion starts. Kuti et al. [58 applied a gradient method to see the effects of lubricant oil on gasoline-like fuel combustion using the $I Q T^{T M}$. 


\subsection{Testing Gasoline Fuels in the IQT}

Although the IQT is mainly designed to test diesel-like (high reactivity) fuels, lately it has been notably used to test gasoline-like (low reactivity) fuels and their blends. In 2016, Waqas et al. [59] utilized the $I Q T^{T M}$ to elucidate the effect of ethanol blending with three FACE gasoline fuels and two primary reference fuels (PRFs) and a blending derived cetane number $(\mathrm{BDCN})$ was introduced. The gradient method $[56]$ was used to get all the $I D$ values and a similar equation to that used in octane number calculations [60], [61] was introduced to get $D C N_{m i x}$ (Equation 2.8). Where $D C N_{\text {base }}$ is the $D C N$ of base fuel without ethanol, $C_{b a s e}$ as the base fuel concentration, $C_{b o o s t e r}$ is the booster (ethanol) concentration and $D C N_{m i x}$ is the $D C N$ of the blends. Blending ethanol with fuels has increased $B D C N$.

$$
D C N_{\text {mix }}=D C N_{\text {base }} \times C_{\text {base }}+B D C N \times C_{\text {booster }}
$$

Bogin et al. [62 studied the existence of the Negative Temperature Coefficient $(N T C)$ regions in the combustion of iso-octane/ethanol with volumetric blends (100/0, 90/10, $80 / 20,50 / 50$, and $0 / 100)$ by using the $I Q T^{T M}$. The ranges of pressure, temperature and equivalence ratio used in the test were 0.5 to $1.5 \mathrm{MPa}, 623$ to $993 \mathrm{~K}$ and 0.7 to 1.0 , respectively. The $N T C$ region was observed at 1 and $1.5 \mathrm{MPa}$ from $0 \%$ to $20 \%$ ethanol while it was not observed at low pressure $(0.5 \mathrm{MPa})$ and ethanol concentration higher than $50 \%$ because the $I D s$ became very long $(>700 \mathrm{~ms})$. Another work on iso-octane was conducted by Osecky et al. 63] using the IQT and applying almost the same $T$ and $\phi$ ranges used in ref. 62 with two pressure values, 1 and $1.5 \mathrm{MPa}$. The $I D$ values of isooctane were measured through experiments and predicted from three modeling methods. The NTC regions have been observed from the experimental and modeling results but there was a significant discrepancy in the $I D$ values between the two studies. Fisher et al. 64 has also noticed the $N T C$ at $0.5 \mathrm{MPa}$ and higher of $\mathrm{n}$ - heptane ignition using 
a CVCC called the CetaneID 510. The percentage of liquid fuel that impinged on the chamber wall was increased when the pressure was lowered.

In 2017, the study of gasoline like fuels in the IQT has continued to correlate the ID measurements and $D C N$ to the octane numbers. Naser et al. 65 tested four sets of gasoline like fuel samples: 1. PRFs (primary reference fuels: blends of iso-octane and n_heptane), 2. TRFs (toluene ref. fuels: blends of toluene and $n \_$heptane), 3. TPRFs (toluene, iso-octane and $\mathrm{n}_{-}$heptane blends), and 4. FACE gasoline 66 real fuels. All tests were made at $P=21.3 \mathrm{bar}$, equivalence ratio $\phi=0.7$ and temperature in the range 770 to $850 \mathrm{~K}$. The measured $I D$ in $m s$ by gradient method $[56$ was correlated to the Octane index $(O I)$, the anti-knock indicator of a fuel [67], [68], as shown in Equation 2.9. Where $a$ and $b$ are functions of initial charge temperature with a second order polynomial form. In addition to that, research and motor octane numbers ( $R O N$ and $M O N)$ were extracted from $O I$ results and validated well with the conventional data from CFR tests [69]. Because of fuels' sensitivity, only $R O N$ has been correlated to $D C N$ as shown in the Figure 2.7 .

$$
O I=a(\ln (I D))^{-2.4}+b
$$

\subsection{Numerical Modeling of Combustion in $I Q T^{T M}$}

Numerical modeling is used widely to investigate and understand the spray and ignition of fuels in an enclosed vessels like $I Q T^{T M}$. Several methods of computational fluid dynamics $(C F D)$ and chemical kinetic mechanisms have been developed to simulate the experimental studies of combustion in the $I Q T^{T M}$.

A number of commercial softwares have been developed to simulate the reacting fuel spray in the $I Q T^{T M}$. KIVA-3V, a Fortran based software by Los Alamos National Laboratory (LANL), is the most common code that manipulates the two and three dimensional 




Figure 2.7: Correlation between DCN and RON. Extracted from 65 
CFD model of the fuel spray evaporation and combustion [70], [71]. It has been used to simulate n-heptane combustion in the $I Q T^{T M}[40],[72-[74]$. The other software is ANSYS Fluent package, which is modeled to simulate fuel injection and combustion. In addition to the built-in utility for creating injections and discrete phase transport, Fluent could be used to determine the ignition delay based on Douaud et al. model [75]. Metcalf et al. $[76 \mid$ modeled heptane by Fluent through solving the governing equations over two dimensional axisymmetric boundaries to reduce computational time. The third software is called CONVERGE. It has been used to model Iso-octane and n-Dodecane combustion in the $I Q T^{T M}$ and a constant volume combustion chamber [63], [77], respectively. Lately, ANSYS Forte 778 is increasingly utilized in the combustion CFD simulation of the constant combustion chamber $[79]-81]$. The features of ANSYS Forte make it more convenient and effective in manipulating the advanced fuel spray models and their chemical kinetics through ANSYS Chemkin pro solver. With less attention, Open FOAM has been used to simulate n-heptane combustion by analyzing a 40 wedge sector of cylindrical domain in a constant volume combustion chamber 82 .

The grid domain of the $I Q T^{T M}$ combustion chamber $\left(213 \mathrm{~cm}^{3}\right)$ is usually meshed by using the software ANSYS ICEM. The structured grid is used in meshing instead of an unstructured one because the chamber geometry allows straight forward meshing. The number of generated cells for the 3D domain of the $I Q T^{T M}$ chamber is around 60,000 72 74 and an automatic mesh refinement could be used whenever there is a notable change in the designated variables like temperature and velocity 63 .

Different turbulence modeling and chemical kinetic skeletal mechanisms were adopted and developed for combustion simulation. The two-equation $k-\varepsilon$ and its developed form, Renormalization Group (RNG) models are the most widely selected turbulent models for simulating combustion in the $I Q T$ [73], [74], [76], |77], [82]. All codes use the Lagrangian-Eulerian approach to determine fluid properties, wherein the liquid fuel spray droplets are tracked through a Lagrangian formulation while the carrier field (hot gases 
in the chamber) is expressed in an Eulerian formulation and the fluid flow is governed by Navier-Stokes equations [83]. The Kelvin-Helmholtz/Rayleigh-Taylor (KH-RT) is the most common adopted model for the spray atomization, breakup, and vaporization of the injected fuel [84, 85].

It is well known that after fuel vaporization, the chemical reaction (combustion) starts. Based on fuel type, mixing and ambient conditions, thousands of chemical reactions take place and hundreds of species exist during combustion process [86]. The reactions and species are modeled through a detailed chemical kinetic reaction mechanism to describe the ignition behavior [87], [88. Simulation work depends on the reduced skeletal mechanism by taking the significant species and reactions and eliminating the unimportant ones. The detailed mechanism needs high cost computational capabilities.

Heptane as a reference and surrogate diesel fuel has been investigated extensively. Bogin et al. [72], |73] compared the ignition delay of three reduced n-heptane mechanisms included 60,42, and 33 species at single step chemistry with the experimental data from the $I Q T^{T M}$ at standard conditions $(\approx 861 \mathrm{~K}$ and $2.1 \mathrm{MPa})$. The total $I D$ of 42 species n-heptane mechanism was the closest to the experimental data with longer $I D$ than an experimental one by about $0.6 \mathrm{~ms}$. Tsai et al. [74 has obtained the 144 species skeletal mechanism from Lawrence Livermore National Laboratory (LLNL) detailed n-heptane mechanism 88 by using CARM code [89]. The resulted mechanism has been validated against experimental data 90 and a further reduction was made by using QSSA code 91 to end with 62 species. Both mechanisms were applied in the $3 D$ simulation of three different combustion applications (IQT, diesel engine and CFR) and validated against experimental data.

Som et al. 777 developed a reduced skeletal mechanism of 103 species and 370 reactions for n-Dodecane from a detailed mechanism 87] which consists of 2, 115 species and 8, 157 elementary reactions. The validation of the skeletal mechanism against a detailed one and experimental data showed good agreement in the prediction of combustion charac- 
teristics. In another work, a reduced mechanism of 89 species from a detailed 874 species of iso-octane mechanism [92 was used with three modeling methods 63].

The precise selection of initial and boundary conditions that applied in the combustion modeling makes the simulation more realistic. The spray specifications (the initial droplet size and velocity) in the reference [76] were determined based on the mass of fuel (heptane 0.087 grams and hexadecane (cetane) 0.098 grams) per injection and injector specifications. Other simulations [63, $[72]-74$ used the observation of high-speed imaging of fuel spray under atmospheric pressure to estimate spray specifications.

The initial values of other parameters like pressure and temperature are selected in different ways. The air pressure inside the $I Q T^{T M}$ chamber and before fuel injection is the same for all of the chamber but the temperature of hot air prior to the fuel injection is not the same for all of the chamber due to the presence of cooling jackets used on both ends of the $I Q T^{T M}$ chamber [12]. However, most investigations assume that the whole chamber has the same initial temperature and the chamber wall (boundaries) temperatures are equal to the initial temperature [40], [63], [73], [74], [82]. Metcalf et al. 76 defined the initial temperature through two quadratic equations extracted from thermocouple measurements on the chamber centerline. 


\section{Chapter 3}

\section{Experimental Apparatus and Setup}

\subsection{Ignition Quality Tester}

The $I Q T^{T M}$ is at first created by the Southwest Research Institute (SwRI) and it was called constant volume combustion apparatus (CVCA) [11], 25], [26], [93]. Then it has been developed and automated by Advanced Engine Technology Ltd. (AET) [16] to make it highly precise and accurate for the oil industry as well as research applications [39], [57], [94]-|96]. The $I Q T^{T M}$ is a bench-scale device that is mainly utilized to determine the ignition quality of diesel and alternative diesel fuels. It is comprised of a constant volume combustion chamber with intake and exhaust systems, a fuel injection system, and temperature/pressure sensors and a data-acquisition system.

The combustion chamber of the $I Q T^{T M}$ is made from stainless steel where its longitudinal cross section is shown in Figure 3.1. There are six ports and holes on the wall of chamber as shown in Figure 3.2 nozzle body port on one end of the chamber, pressure transducer port on the other end, air inlet valve, exhaust outlet valve, front and back thermocouples holes. Nine electrical heaters of cartridge-type are embedded in the chamber skin and used to heat the chamber walls up to approximately $600^{\circ} \mathrm{C}$. The combustion chamber is a cavity of cylindrical and conical shapes with total size of $0.213 \pm 0.002$ liters. 
The charge-air gains heat from the hot walls of the chamber. Both ends of the $I Q T^{T M}$ chamber are maintained at a lower temperature compared to the temperature of main portion of the chamber. The flow of the liquid coolant transfers heat from the chamber walls surrounding the injector nozzle and pressure transducer, and maintains them at a lower constant temperatures $50 \pm 4^{\circ} \mathrm{C}$ and $130 \pm 20^{\circ} \mathrm{C}$, respectively. The chamber is charged with air $\left(\mathrm{O}_{2}, 20.9 \pm 1.0 \mathrm{vol} . \%\right)$ under a pressure of $21.37 \pm 0.07 \mathrm{bar}$.



Figure 3.1: Section in the $I Q T^{T M}$ chamber

The fuel is injected with a pneumatically actuated, mechanical fuel injection pump and a fixed fuel volume is released from the injector nozzle at each injection. The fuel is injected into the chamber as a hollow spray cone from an inward opening singlehole pintle-type nozzle. The spray characteristics from this nozzle design and others are well studied by [97], [98]. The nozzle needle, which moves against a loaded spring, starts to lift and the fuel flows out when the pressure of the liquid fuel behind the nozzle reaches $17.92 \mathrm{MPa}(2,600 \mathrm{psi})$ or higher. The main injection duration lasts for 




Figure 3.2: Sketch of the $I Q T^{T M}$ combustion chamber with main ports

approximately $2 \mathrm{~ms}[99$, where a compressed air with pressure $1.206 \pm 0.3 \mathrm{MPa}$ is used to pressurize the fuel in the pump. The pneumatic connections of charge air and injection air systems are shown in Figure 3.3 .

The $I Q T^{T M}$ is equipped with a set of sensors that are connected to the data acquisition system to monitor test conditions and read the required data for the $I D$ calculations. The chamber gas pressure during the test is measured by a piezo-electric pressure transducer [100] installed in a coolant adapter to protect it against overheating, where it is located at the end of the chamber that is opposite the nozzle end. The pressure sensor is made of quartz with high sensitivity (rise time of $2 \mu s$ ) and it can work with a maximum pressure of 18,000 psi without damage. The position of the nozzle needle is traced through a proximity transducer system [101. The voltage signal from the system is linearly proportional to the gap between the nozzle needle and probe tip. There are eleven grounded thermocouples of type $\mathrm{K}$ connected to the $I Q T^{T M}$ at different locations 




Figure 3.3: Connections of compressed air systems, [99 
for control and temperature measurements purposes as shown in Figure 3.4. The set point temperature is determined by a thermocouple embedded in the chamber wall (T1, Figure 3.4). Two thermocouples (front and back) are located at the inside wall and exposed to the chamber volume (T-4 and T-5). The front thermocouple is close to the injector nozzle where the chamber diameter is $36 \mathrm{~mm}$ and it is used to measure the charge air temperature. The back thermocouple is $7 \mathrm{~cm}$ (in the axial direction) from the front one setting, at the main portion of the chamber where the diameter is $50.8 \mathrm{~mm}$.

\subsection{Installation of Temperature Probes in the $I Q T^{T M}$ Chamber}

As mentioned earlier, the $I Q T^{T M}$ chamber has six ports and holes that lead to the interior of the chamber. Only three of them could be used to install temperature probes that would protrude into the chamber: front and back TC ports and the pressure transducer port. Slight modifications have been made on the $I Q T^{T M}$ chamber to permit adjustment of the temperature probes.

The 1/8 inch probe could be used with either front or back TC ports because those ports are already fitted for $1 / 8$ inch temperature probes and they do not need any modifications. The port of the pressure transducer was used to insert a probe with 4 TCs, which is called a flower temperature probe $(\mathrm{FTP})$. The coolant adapter of the pressure sensor has been modified to accommodate the $3 / 16$ inch probe diameter. Also, fittings and a Teflon ferrule were used with the coolant adapter for sealing purposes and traversing the probe longitudinally inside the chamber. Thus, a total of 10 TCs were fitted inside and near the wall of combustion chamber. The configuration of thermocouples inside the chamber are shown in Figure 3.5.

The pressure sensor has been moved and fitted in intake valve port created on the 




Figure 3.4: Schematic diagram of $I Q T^{T M}$ 




Figure 3.5: Sketch of TCs used in the IQT combustion chamber

inlet valve. For this location, the temperature is low enough that there is no need for coolant to be circulated in the cooling adapter. The data from the pressure sensor at the new location was verified against the standard location, where the two pressure sensors were connected to 1-MHz, 16-Bit USB Data Acquisition Module from Omega 102 and data were collected from an experiment on an internal check fuel CF18. The results of sixteen test injections are averaged and presented in Figure 3.6. The delay in response from the pressure sensor at intake valve can be attributed to a combination of three reasons: the sensor at intake valve is not exposed directly to the chamber space and the pressure wave created in the chamber space should transfer through intake pipe line to be detected by the relocated pressure sensor, the temperature of gases around the sensor at the intake valve is much lower than that at the standard location, and the rapid motion and collisions of gas molecules within the chamber walls as well as the pipe to the intake valve may cause a difference in pressure signals. 




Figure 3.6: Pressure readings from two sensors: at standard position and at intake valve

\subsection{Temperature Measurements}

The temperature of gases inside the combustion chamber varies greatly (several hundreds of degrees) during combustion process which lasts just few milliseconds depending on the fuel type. Therefore, a robust and fast response temperature probe is required in order to withstand the harsh combustion environment presented by the high temperature and pressure, and to track and record the momentary variation in the temperature. Gas temperature in a combustion chamber can be detected and measured through different techniques [103]. The measurements of the present work are based on thermocouples (TC) because they are very robust and have a wide temperature range [104, [105 compared to other temperature sensors like some fiber optic probes. First of all, a decision should be made on the specifications of the TC used in the experiments. Then, the proper temperature probes will be produced to get the designated temperature measurements. 


\subsubsection{Thermocouple Configuration}

The response of a TC to the temperature variation depends on parameters, i.e., size of a $\mathrm{TC}$ hot junction and conditions of the working fluid. Conduction and radiation along fine TC wires have a small or negligible effects on the time response [106]. TC of type $\mathrm{K}$ has been selected to be used in all experiments due to its wide range of temperatures $\left(>0-1300^{\circ} C\right)$, high sensitivity $(41 \mu V / C)$ and availability [104. Different sizes of TC wires have been tested in combustion chambers to achieve a compromise between the response and durability.

Temporal variation of pressure inside the combustion chamber gives an indication on the temperature variation and it could be used to check how fast the response of a TC on this pressure variation. The TC tests have been started with an available temperature probe from Omega (model number: TJFT72-T-INC-116G-6-SMPW-M). The fine tip transition joint (TJ) probe (0.5 mm in dia.) has showed a delay in comparison with the response of the pressure signal. In addition to that, only several injections could be made before it burned. A plan was then made to prepare probes from fine TC wires. Three wires with sizes $0.003^{\prime \prime}, 0.005^{\prime \prime}$ and $0.010^{\prime \prime}$ of a butt welded hot junction end were selected to be used in the probes. The preparation of the probes is explained in Section 3.3.2.

Experiments on $0.003^{\prime \prime} \mathrm{TC}$ wire were repeated many times due to wire breaking, either during warming-up of the combustion chamber or after fuel injection. The data for only one complete injection could be recorded without breaking the TC. Although the response for this wire is much faster when compared to the previous one (TJ probe) as shown in Figure 3.7, it was not durable enough to remain intact for a complete run of 47 or at least 20 injections. The same procedure has been repeated on 0.005 " and 0.010 " TC wires but this time a probe with three TCs $\left(0.003^{\prime \prime}, 0.005^{\prime \prime}\right.$, and $\left.0.010^{\prime \prime}\right)$ has been inserted axially from the pressure transducer port up to the main portion of the chamber. The $0.003^{\prime \prime} \mathrm{TC}$ broke first during warming up time and the $0.005^{\prime \prime} \mathrm{TC}$ failed to resist the sudden increase in temperature due to fuel combustion. The data showed that $0.005^{\prime \prime} \mathrm{TC}$ 




Figure 3.7: Temperature response from $0.003^{\prime \prime}$ in dia. and exposed junction TCs , fuel CF16

was broken during fuel ignition, whereas the $0.010^{\prime \prime}$ TC remained intact throughout the test and showed high durability. It became obvious from Figure 3.8 that the variations in temperature was recorded well by the $0.010^{\prime \prime} \mathrm{TC}$ especially at discriminatory points (start of fuel injection and ignition). Thus, it was decided to use $0.010^{\prime \prime}$ butt welded TC wires of type $\mathrm{K}$ from Omega in all experiments of the project. 




Figure 3.8: Temperature response from 0.005 and 0.010 inch TC wires, fuel CF16

\subsubsection{Temperature Probe Fabrication}

In order to get a robust temperature probe, the thermocouple wire inside the combustion chamber should be insulated by a material of particular properties, which are chemically and thermally stable, also having high electrical insulation and sufficient strength. Thermocouple assemblies are fabricated by using a sheath usually made from stainless steel to protect the brittle insulating material while providing the required probe dimensions.

Three ports on the $I Q T^{T M}$ combustion chamber could be used to insert the temperature probe: front and back TC ports (radial insertion), and pressure transducer port (longitudinal axial insertion). Based on the dimensions of those ports, a probe with diameter $1 / 8$ inch could be used for front and back ports, and it could be up to $3 / 16$ inch for the pressure transducer port. Thus, two sizes $(1 / 8$ and $3 / 16$ inch) of stainless steel 
sheath tubes were used to encase and fabricate the probes.

Despite its brittleness, an alumina ceramic insulator is the most appropriate material that could be used with TCs for high temperature applications because of their other physical and thermo-mechanical properties [107. The outside diameter of a ceramic insulator rod is restricted to the inside diameter of sheath tube and there should be a sufficient clearance between them for the rod to slide inside the sheath. The $1 / 8$ inch

probe contains three thermocouples and the $3 / 16^{\prime \prime}$ probe contains four thermocouples. Each thermocouple requires two holes in the ceramic insulator rod. A maximum of 6 holes (3 TCs) and 8 holes (4 TCs) could be created on the face of a $2.5 \mathrm{~mm}$ and $3.2 \mathrm{~mm}$ in diameter of ceramic rods, respectively as shown in Figure 3.9. The diameter of each hole is $0.5 \pm 0.05 \mathrm{~mm}$. After fabricating the probe, a high-temperature cement and J-B weld high-heat epoxy were applied on the hot and cold ends of the probe, respectively for sealing purposes.

\subsection{Experimental Setup}

All tests were conducted in the laboratory of the AET with average ambient conditions of $20^{\circ} \mathrm{C}$ and $1 \mathrm{~atm}$. The test procedure was repeated at different conditions of charge air pressure, set point temperature and injected mass fuel. All sensors were fitted to the chamber and connected to the data logger before the test. The following points explain that:

1. Two temperature probes with 3 TCs were fitted in the front and back TC ports, where the hot junctions are located as shown in Figure 3.5. A permanent stainless steel ferrule-on-probe sheath was used with a fitting for sealing purposes.

2. The flower temperature probe (FTP) with 4 TCs or 3 TCs was inserted into the chamber from pressure transducer port through a bored coolant adapter. All TC 




Figure 3.9: Ceramic insulator rods, (a) $0.5 \mathrm{~mm} \times 6$ holes, $2.5 \mathrm{~mm}$ dia, $250 \mathrm{~mm}$ length, (b) $0.5 \mathrm{~mm} \times 8$ holes, $3.15 \mathrm{~mm}$ OD, $300 \mathrm{~mm}$ length 
wires of the hot junction side were kept straight in the axial direction at first. Then, they were bent inside the chamber by $90^{\circ}$ to be distributed radially (see Figure 3.5). TC wires inside the IQT chamber were bent with the help of video inspection borescope 3.5 endoscope with $3.9 \mathrm{~mm}$ camera by getting an access to them from nozzle injector side. For sealing purposes, a reusable Teflon ferrule with stainless steel fittings were used here for the probe to be traversed inside the chamber.

3. The pressure transducer was fitted to the chamber space through an adapter created on the intake valve wall.

4. The chamber was pressurized with air to make sure that there was no leak from points of probes and connections with the chamber by applying liquid soap water solution.

5. A circuit was created to connect the terminals of the pressure and needle lift sensors on the $I Q T^{T M}$ to the DAQ system as shown in Figure 3.10 .

6. All TCs (10 TCs or 9 TCs) from probes were connected directly to the DAQ board which is connected to the laptop through a USB cable.

Figure 3.11 shows the $I Q T^{T M}$ with all sensor connections. At this point the IQT $T^{T M}$ with this connections is ready to be used. The procedure of the test is explained in Appendix C. 


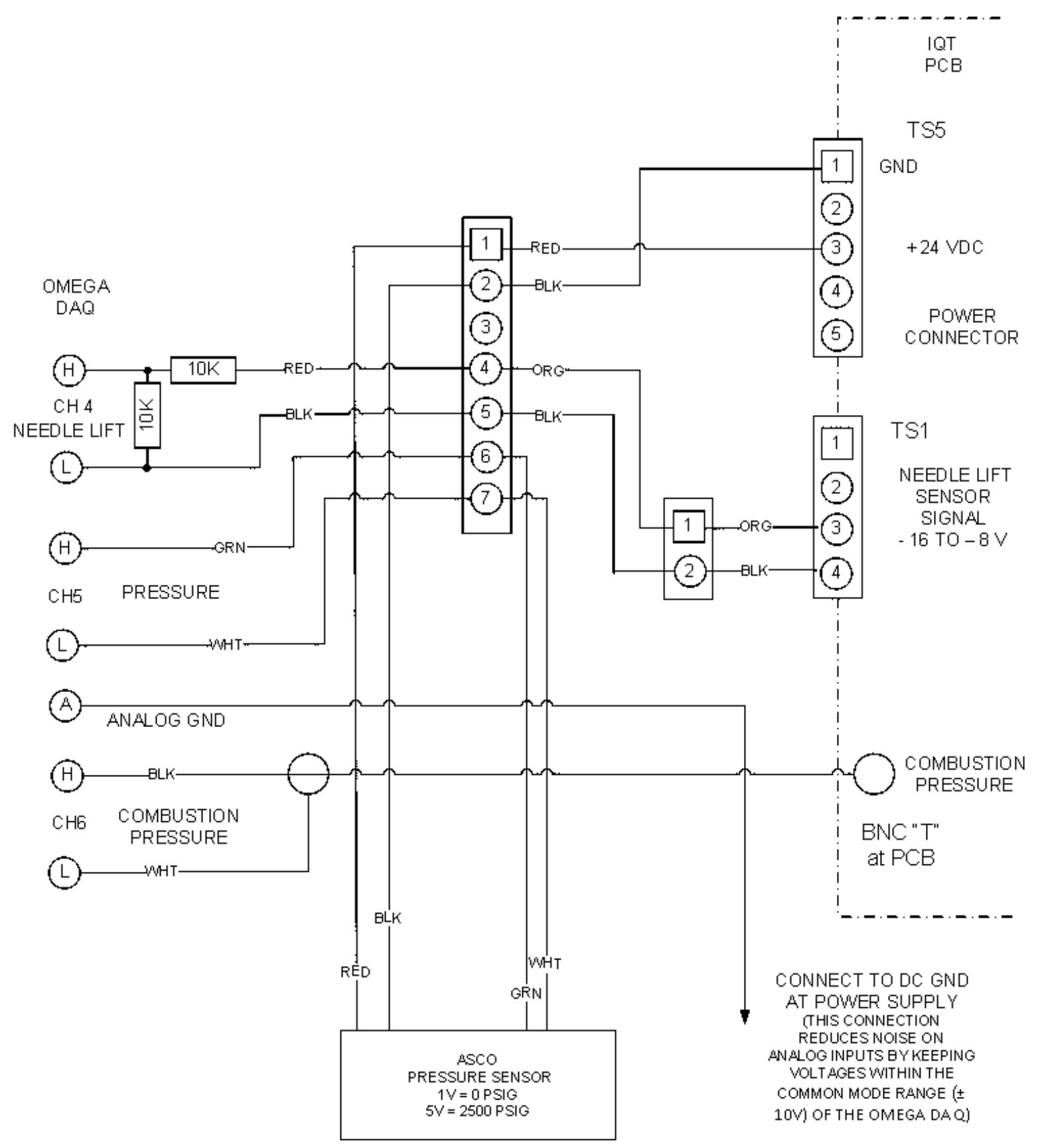

Figure 3.10: Connection circuit of pressure and needle lift sensors to the DAQ 




Figure 3.11: Experimental connections of sensors on IQT to the DAQ

1. Laptop to store the recorded data

2. USB cable to transfer the data from

DAQ to the laptop

3. 1-MHz, 16-Bit USB Data Acquisition Module OMB-DAQ-3000 Series (8 differential analog inputs)

4. Analog Input Expansion Module for OMB-DAQ-3000 Series (24 differential analog inputs adds to OMB-DAQ-3000)

5. Thermocouple wires

6. Flower temperature probe

7. Back port temperature probe

8. Pressure sensor at inlet valve
9. Inlet valve

10. Needle lift sensor

11. Fuel pump

12. Exhaust vaccum duct

13. Power button

14. Pressure regulator panel

15. Combustion chamber

16. Fuel reservoir

\subsection{IQT $T^{T M}$ Calibration}

Each $I Q T^{T M}$ unit is calibrated according to the ASTM D6890 standard before using 
it for fuel testing. The fuel injection system has two component settings that should be adjusted according to the instruction manual of the manufacturer before calibration of the ignition delay of a reference fuel. The first setting is the nozzle opening pressure. It should be adjusted to open at $17.92 \pm 0.2 \mathrm{MPa}$. The nozzle body is connected to a fuel line equipped with a pressure transducer and the pressure is applied manually to the fuel.

After that, the second setting, mass of fuel injected (MFI), is adjusted using hexadecane followed by heptane reference fuels. Based on the ASTM D6980 mass calibration procedure, the average of the MFI for 20 injections of hexadecane should be in the range $0.098 \pm 0.001$ grams and the fuel pump should be adjusted when the mass is outside this range. The same procedure is repeated on n-Heptane, where the accepted MFI will be within the range $0.077-0.084$ grams/injection. The length of the plunger stroke within fuel pump should be adjusted to get the required amount of MFI by adding or removing fuel injection pump shims. Adding shims decreases the effective length of the plunger stroke and the mass of injected fuel and vice-versa. A variable displacement pump (VDP) is used for research applications to provide rapid and easy adjustments of injected mass, as shown in Figure 3.12. In addition to the calibration fuels (cetane and heptane), the mass injected of five other fuels of different properties have been tested and presented. As stated earlier in Section 3.1, the fuel pump is adjusted to deliver a fixed volume of fuel. Therefore, the MFI depends on the fuel type and it is mainly sensitive to density, and to a lesser extent the fuel viscosity as a result of very tight clearances between the small elements.

After completing mass calibration, the ignition delays of two reference fuels are calibrated by adjustment of the temperature set-point controller. The $I D$ of three consecutive acceptable runs of n-Heptane are averaged and it is required to be within $3.78 \pm$ $0.01 \mathrm{~ms}$, followed by that two consecutive acceptable runs of methylcyclohexane (MCH) with an average $I D$ in the limit $10.4 \pm 0.5 \mathrm{~ms}$. A complete run of the standard $I Q T^{T M}$ fuel test consists of 47 injections. The first 15 pre-injections are not included in the ID 


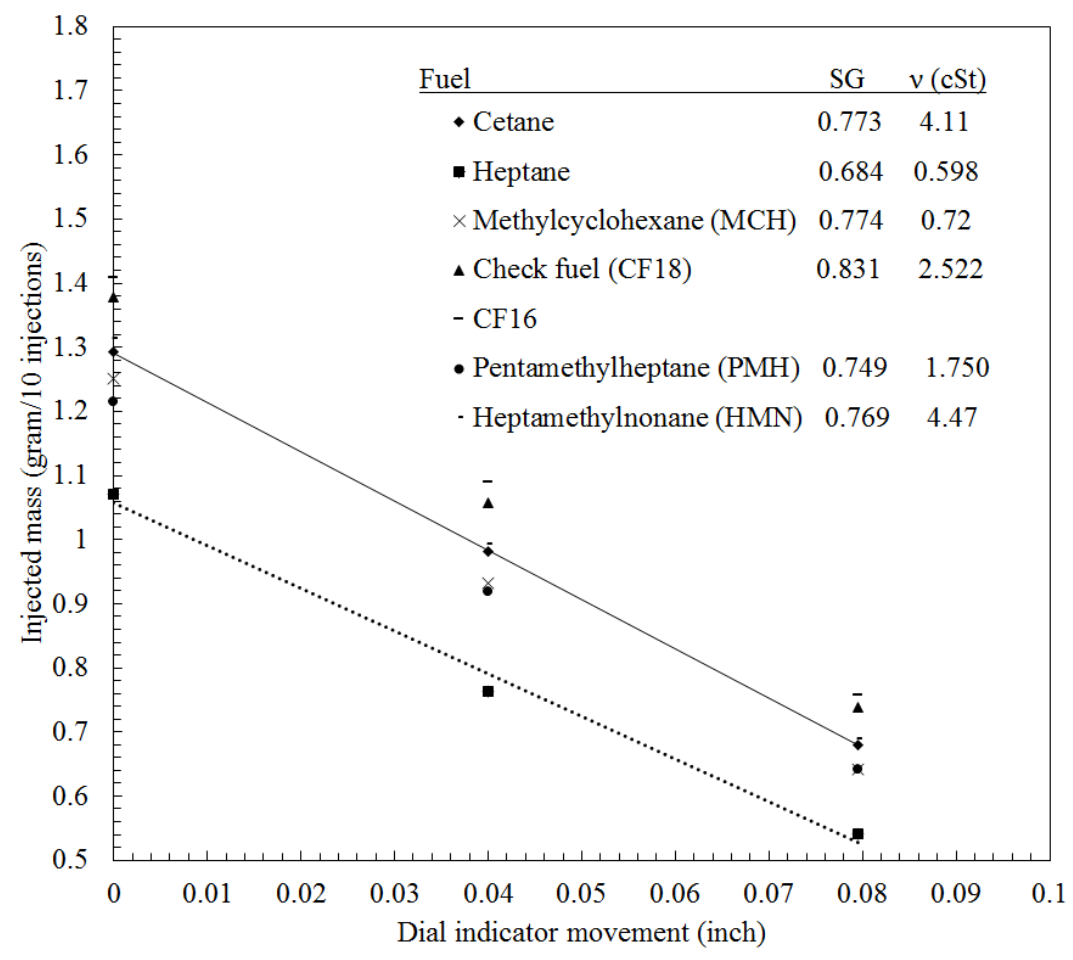

Figure 3.12: Fuel mass calibration using variable displacement pump (VDP)

calculations and they are just introduced to thermally stabilize the device. The $I D$ of the remaining 32 injections are averaged to get the $I D$ of the run. The $I D$ in the $I Q T^{T M}$ is defined as the time period starting from needle lift (start of injection SOI) up to and above the pressure recovery point, which is called start of combustion (SOC), as shown in Figure 3.13. This point is determined when the chamber pressure reaches a certain pressure above the initial pressure prior to the fuel injection. If the $I D$ of a run is outside the specified range, the set point temperature (T1) is changed to adjust it. The set point is inversely proportional to the $I D$.

\subsection{Test Procedure}

The procedure of the test is explained in the following steps:

1. The $I Q T^{T M}$ computer workstation is switched on and the Run Flexible Research $I Q T^{T M}$ System software is started. 


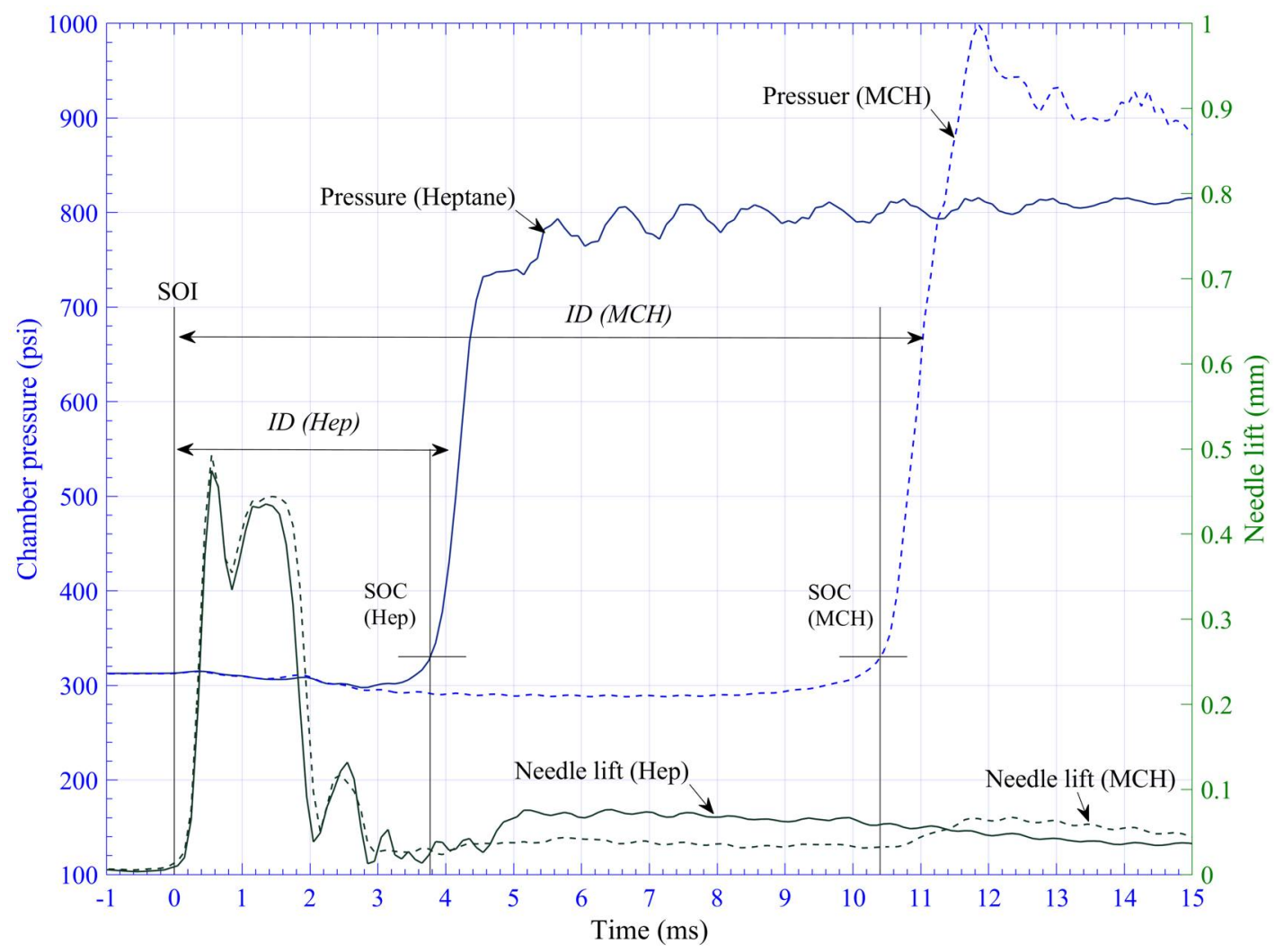

Figure 3.13: Ignition delay starting and ending points in the IQT 
2. The laptop connected to the DAQ is switched on and the DAQ software (DAQ view) is started-up to make sure that all sensors are working well and giving the correct signals before starting the test. In order to capture all combustion events, the DAQ view is adjusted to trigger the data prior to needle lift by a few milliseconds $(\approx 10$ ms) up to the end of combustion. The data from each of the injections are saved automatically to separate files when the test run is done.

3. The unit is powered on. It is necessary to make sure that the coolant liquid is circulating in the coolant system.

4. Three valves are opened to supply the unit with: 1) charge air to the combustion chamber, 2) air to actuator utility injection, and 3) nitrogen to fuel reservoir.

5. The combustion chamber is pressurized with air to make sure again that there are no leaks at connection points with temperature and pressure sensors.

6. The heaters around the chamber are activated to start the warming up process which usually takes about 30 min.

7. The fuel reservoir is filled with the filtered test fuel and then residual fuel in the system flushed out. Then the reservoir is filled again with the same fuel and the fuel system is purged to make sure that there are no air bubbles.

8. The operating conditions (pressure and temperature) are adjusted and the number of injections are selected (20 injections are used for present work: 5 pre-injections and 15 test injections).

9. The command is given to start the run where the fuel is injected, the mixture is ignited, the exhaust valve is opened to release exhaust gases and the chamber is purged with air. Then, the next injection starts and so on. 


\subsection{Thermocouple Calibration and Uncertainty Anal- ysis of Measured Temperature}

Experimental measurements cannot be performed without errors. Thus, measurement tools should be calibrated first and then the uncertainty analysis of the measured data should be achieved to make sure that the results are precise and accurate enough to be adopted.

\subsubsection{Thermocouple Calibration}

The thermocouples that have been used in the experiments, type $\mathrm{K}$ with bead diameter of 0.01 " butt welded hot junction, were calibrated against a reference thermocouple in the AET laboratories by using dry block calibrator $(C L-790 A)$ from Omega [108]. The readings of reference thermocouple were verified first against the resistance temperature detector (RTD - PT100), (see Figure 3.14) of higher accuracy compared to TCs 103 in the range $100-400^{\circ} \mathrm{C}$ as shown in Figure 3.15. It is clear that the temperature varies linearly with the resistance of the $R T D$ platinum wire. The intersect point of the fitted line is almost at $0{ }^{\circ} \mathrm{C}, 0.1 \mathrm{k} \Omega$, where this is the value of platinum resistance at $0^{\circ} \mathrm{C}$ for calibration purposes.

Followed by reference thermocouple reading verification, the thermocouples used in the experiments were calibrated against the reference $T C$. The flower temperature probe (FTP) with $4 T C s$, front, and back temperature probes with $3 T C s$ each along with the reference $T C$ were inserted into slots on the face of cylindrical stainless steel block. The stainless steel block is heated uniformly by the dry block calibrator and its temperature is controlled through a regulator settings. The temperature was recorded at six points between $100^{\circ} \mathrm{C}$ and $550^{\circ} \mathrm{C}$ and presented in Figure 3.16. The readings from the TCs were very close to that of reference $T C$ with maximum error less than $1 \%$. 




Figure 3.14: Connections of RTD and reference TC



Figure 3.15: Verification of reference TC readings against resistance temperature detector (RTD) 


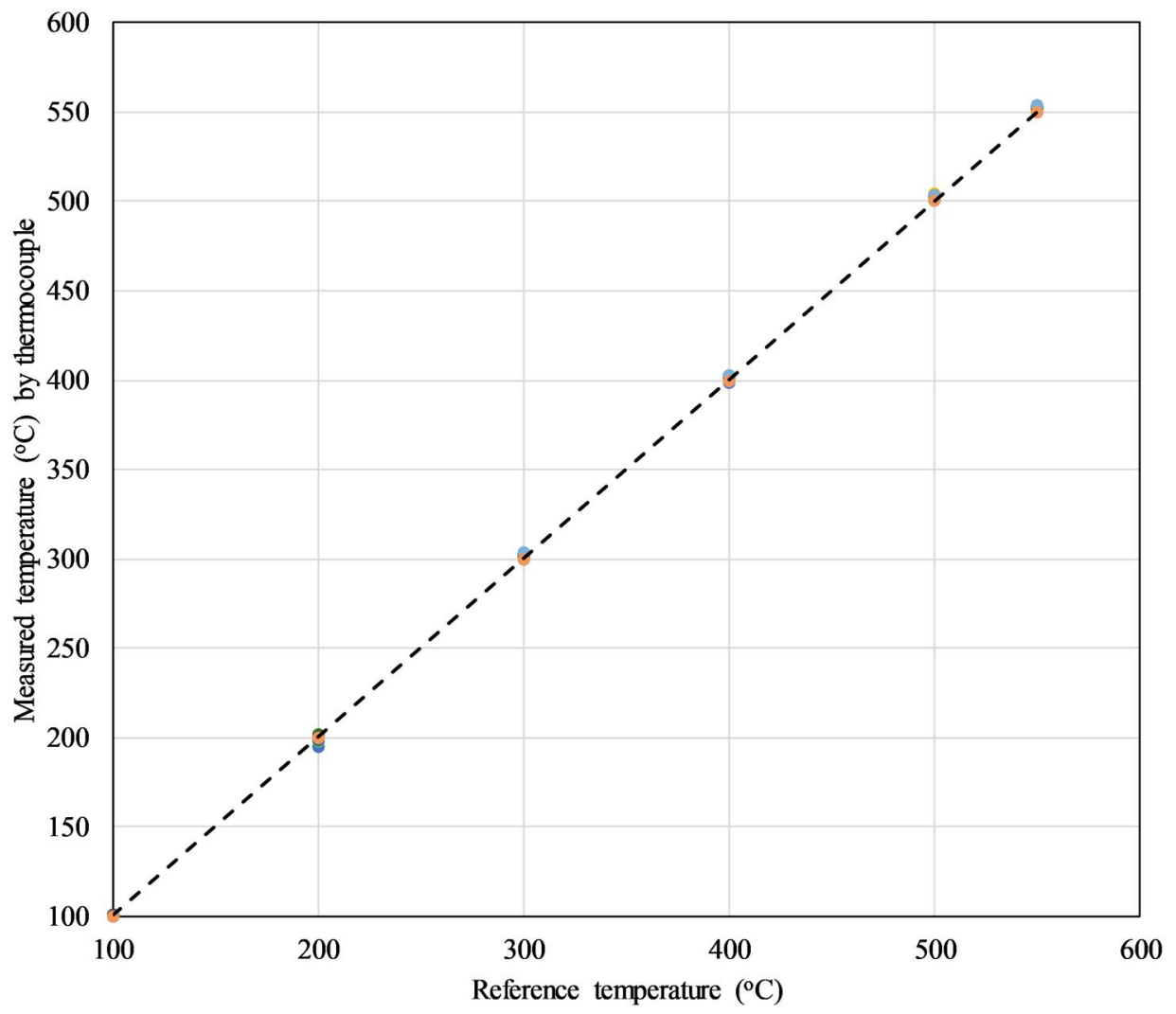

Figure 3.16: Calibration of butt welded thermocouples of type $\mathrm{K}$ with bead diameter of $0.01^{\prime \prime}$ in the range 100 to $550^{\circ} \mathrm{C}$

Although the main concern of temperature measurements is the variation in temperature and not the absolute value, the time constant and response time of TC to an instantaneous change in temperature should be analyzed and reported. The hot junction size and type in addition to the media type are the most influence factors affecting TC time constant (the time required for the sensor (TC) to respond to $63.2 \%$ of its total output signal when subjected to sudden change in temperature) and response time (the time required for TC to reach its full output). The TC used is of butt welded hot junction and its size is the wire diameter (0.001 inch). The media is gases and some spray. A simple experiment has been conducted to obtain the TC time constant and response by dipping the TC into a hot water. The results showed that the time constant of $0.01 \mathrm{TC}$ 
of type $\mathrm{K}$ is $0.02 \mathrm{sec}$ while this value is much higher (around $0.23 \mathrm{sec}$ ) for the case of exposing TC to moving air with a velocity of $65 \mathrm{ft} / \mathrm{s}$ under atmospheric conditions 109.

\subsection{Uncertainty Analysis of Thermocouple Measure- ments}

The total calculated uncertainty for TC measurements at high temperature is greater than that at normal low conditions [110]. The uncertainty of any measurement comes from two sources of errors [111]; first: systematic (unavoidable or bias) errors related to the hardware used to acquire data, such as data acquisition system, TC junction, extension wires, and connectors. This type of error is usually constant throughout the experiment. The second source is called random error which is proportional inversely to the number of experiment repeats at the same condition. This section explains the method used to calculate random uncertainty and presents types of bias errors considered to get bias uncertainty.

There are number of methods used to calculate total uncertainty and they are well explained in the reference [112]. However, the method recommended by ASME is used here to get uncertainty of thermocouple measurements. This method is presented by Equation 3.1 .

$$
T U_{A S M E}= \pm t_{95}\left[\left(B_{T} / 2\right)^{2}+\left(R_{T}\right)^{2}\right]^{0.5}
$$

Where $T U_{A S M E}$ is the total uncertainty of the measurement, $B_{T}$ is the total bias uncertainty, $R_{T}$ is the total random uncertainty, and $t_{95}$ is the student's $t$ value at $95 \%$

confidence. For number of repeats equals 15 (15 injections per run) (with degree of freedom $N-1=14), t_{95}=2.145$. The errors used to get the total bias uncertainty are explained in Table 3.1 . The total bias uncertainty $\left(B_{T}\right)$ is calculated by using root sum 


\begin{tabular}{|c|l|c|}
\hline Hardware name & Type of source error & Bias uncertainty \% \\
\hline \hline \multirow{2}{*}{ Data acquisition system 102} & offset error $\left(B_{1}\right)$ & 0.011 \\
\cline { 3 - 4 } & gain error $\left(B_{2}\right)$ & 0.010 \\
\hline \multirow{2}{*}{ Thermocouple (TC) 113} & TC accuracy $\left(B_{3}\right)$ & 0.750 \\
\cline { 3 - 4 } & TC extension wire $\left(B_{4}\right)$ & 0.330 \\
\hline TC connector $[113$ & connector $\left(B_{5}\right)$ & 0.077 \\
\hline \multicolumn{2}{|c|}{ Total bias uncertainty } & 0.823 \\
\hline
\end{tabular}

Table 3.1: Sources of bias uncertainties with total bias uncertainty

squared as shown in the Equation 3.2 .

$$
B_{T}=\sqrt{B_{1}^{2}+B_{2}^{2}+B_{3}^{2}+B_{4}^{2}+B_{5}^{2}}
$$

The total random uncertainty $\left(R_{T}\right)$ is found by using standard deviation method defined by Equation 3.3 .

$$
R_{T}=\sqrt{\frac{\sum_{i=1}^{N}\left(T_{i}-\bar{T}\right)^{2}}{N-1}}
$$

Where $N$ is the number of repeats which equals number of injections per run (15 injections), $T_{i}$ is thermocouple reading prior to fuel injection, and $\bar{T}$ is the mean of thermocouple readings prior to fuel injection for 15 injections. The total uncertainty was calculated in the range of temperature $350{ }^{\circ} \mathrm{C}$ to $590{ }^{\circ} \mathrm{C}$, as shown in Figure 3.17 . Each point in Figure 3.17 represents the total uncertainty of TC readings at a particular location in the IQT under particular conditions of set point temperature and initial pressure. Most points were around $1 \%$ which is in good agreement with the uncertainty work on several TCs of type K at high temperature conditions [110].

\subsection{Tested Fuel: n-heptane}

n-heptane has been selected to be tested to obtain the temperature measurements under different conditions of charge pressure and temperature. The selection was based on the 


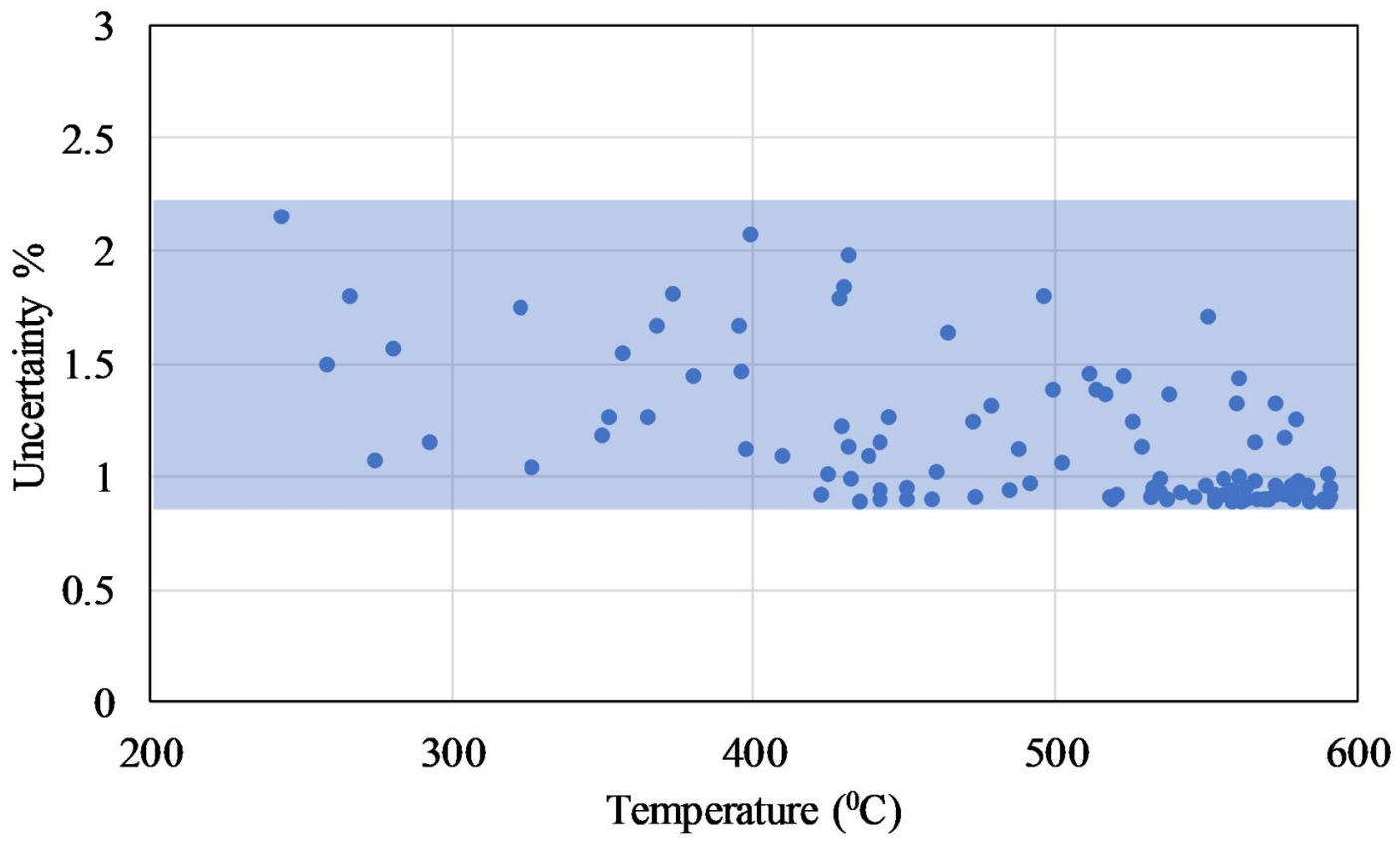

Figure 3.17: Uncertainty (Bias and Random) of thermocouple measurements at different conditions of set points and initial pressure

fuel physical and chemical properties. n-heptane is one of the primary reference fuels which is used to calibrate the IQT and it is also used with other apparatus for the same purpose. It is also important to know the detailed and skeletal chemical kinetic reaction mechanisms of the fuel to be used in the CFD modeling. Therefore, heptane was used experimentally and its chemical kinetics was used in the numerical modeling.

\subsection{Repeatability Study}

The modifications made on the $I Q T^{T M}$ by adding more controllers on measurements like totally automated laboratory model (TALM) technology have improved the $I Q T^{T M}$ test accuracy, reproducibility and repeatability 114 -116 and made it less intervention with the operator. The repeatability or test-retest reliability is used to show the accuracy of the results when the test or experiment is repeated several times and measurements taken under same operating conditions. Thus, the goal of this section is to conduct a 
repeatability study for the sake of reliability and precision for our experimental data. Two operating conditions (initial temperature) $\left(550^{\circ} \mathrm{C}\right.$ and $\left.580^{\circ} \mathrm{C}\right)$ at $21.4 \mathrm{bar}$ were selected to conduct the repeatability study. At each set point, the temperature measurements by the FTP were collected at two planes (6 and 10)(65 and $105 \mathrm{~mm}$ from injector, respectively). The tests were repeated four times on different days in addition to the main test. Thus, the data of five repeats were compared and presented. In each repeat, same procedure of the $I Q T^{T M}$ warming up to the designated set point with setting the charge air pressure at 21.4 bar (310 psi) followed by that 20 injections are used to complete the run. At each repeat, a new tested and calibrated FTP was inserted inside the IQT $T^{T M}$ and used to get temperature measurements. The TCs of the FTP are positioned well inside the IQT by using the endoscope camera as explained in Section 3.4. The FTP was remaining inside the IQT after warming up for few hours before starting the test for the TCs to acquire annealing effects. Annealing TCs may reduce the measurement error [117], [118].

The result data from the repeated tests were analyzed by following the same procedure of analyzing the results of the main test. Same matlab codes that were used with the results of main test were also used here. Where each run consisted of 20 injections and the data of the last 15 injections were filtered and averaged. The ignition delay by temperature method $\left(I D_{T M}\right)$ and pressure methods $\left(I D_{I Q T}, I D_{\text {Bogin }}\right.$, and $\left.I D_{D M}\right)$ [see Section 5.1] were calculated and presented in this study. The results of the $I D_{T M}$ are presented in Figures 3.18 and 3.19 and the results of the ID by pressure methods are presented in Figures 3.20 and 3.21 . The ignition delay predictions by temperature method on each of the Figures 3.18 and 3.19 were presented at four locations of the FTP thermocouples. Those locations are distributed radially at plane 6 (65 $\mathrm{mm}$ from injector) or plane 10 (105 mm from injector).

The average for each set of repeats is also presented on the figures with a table for standard deviation (STDev) at each radial location. The averages give an indication on the location of the main test results among the repeat results whereas the STDev enables 
to measure the size of the measurement error. For both conditions and at two planes, the $I D_{T M}$ for the main test were close to the $\left(I D_{T M}\right)_{\text {average }}$ and the maximum STDev was $0.1139 \mathrm{~ms}$ for the TC with $r=24 \mathrm{~mm}$ near chamber wall (Figure 3.18a).

The ID calculated from pressure measurements are presented in Figures 3.20 and 3.21. In general, the STDev here is less than that for the ignition delay by temperature method, with a maximum value of 0.0512 for condition shown in Figure 3.20a. The highest variance in the ID results was recorded at condition of $550^{\circ} \mathrm{C}$ and $21.4 \mathrm{bar}$ when the FTP is at the plane 6. 


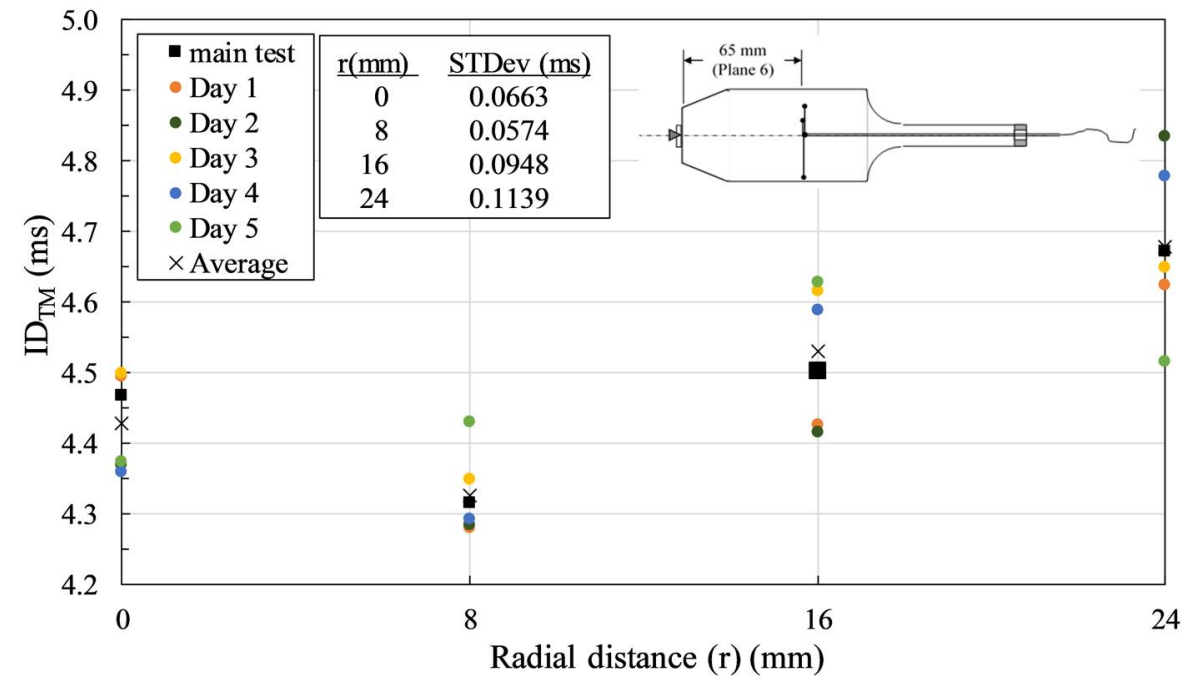

(a) The FTP at plane 6 (65 $\mathrm{mm}$ from injector)

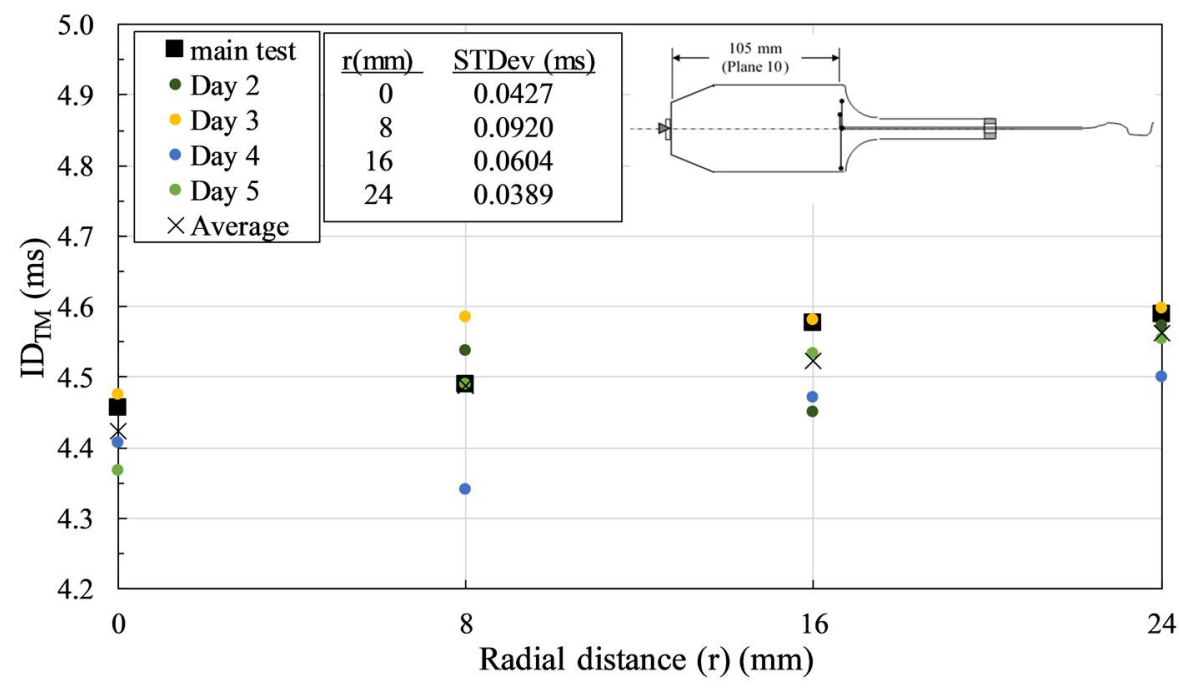

(b) The FTP at plane 10 (105 mm from injector)

Figure 3.18: Results of the $I D_{T M}$ obtained at $550^{\circ} \mathrm{C}$ and 21.4 bar with five repeats 


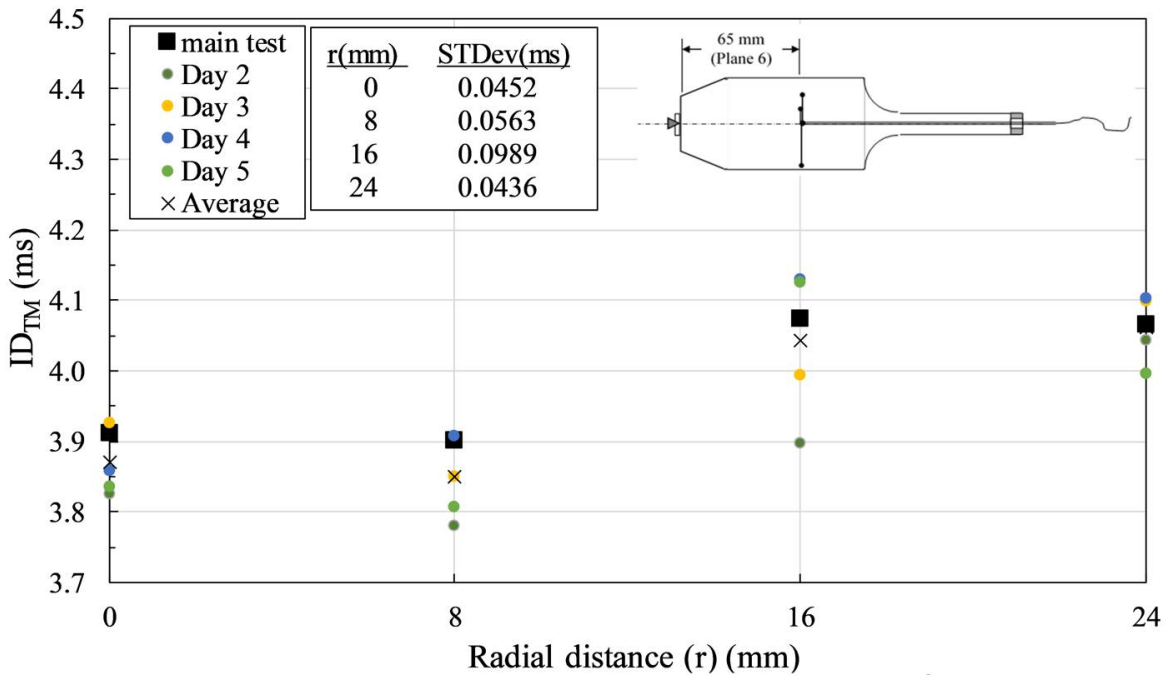

(a) The FTP at plane 6 (65 $\mathrm{mm}$ from injector)



(b) The FTP at plane 10 (105 $\mathrm{mm}$ from injector)

Figure 3.19: Results of the $I D_{T M}$ obtained at $580^{\circ} \mathrm{C}$ and 21.4 bar with five repeats 


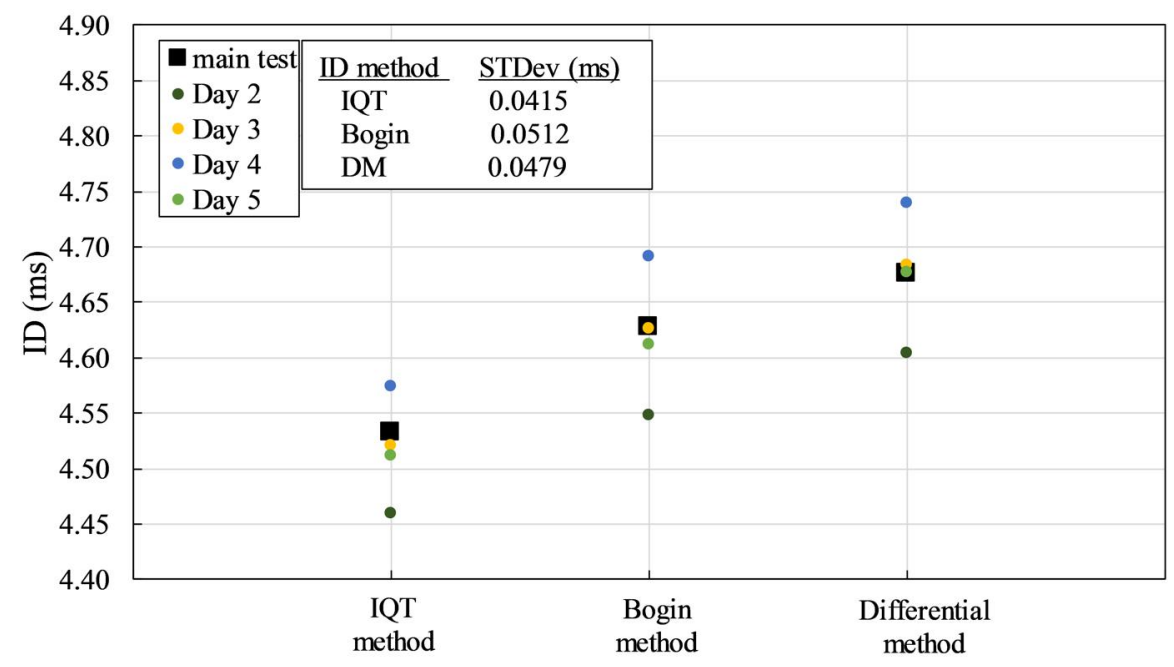

(a) When FTP at plane 6 (65 $\mathrm{mm}$ from injector)

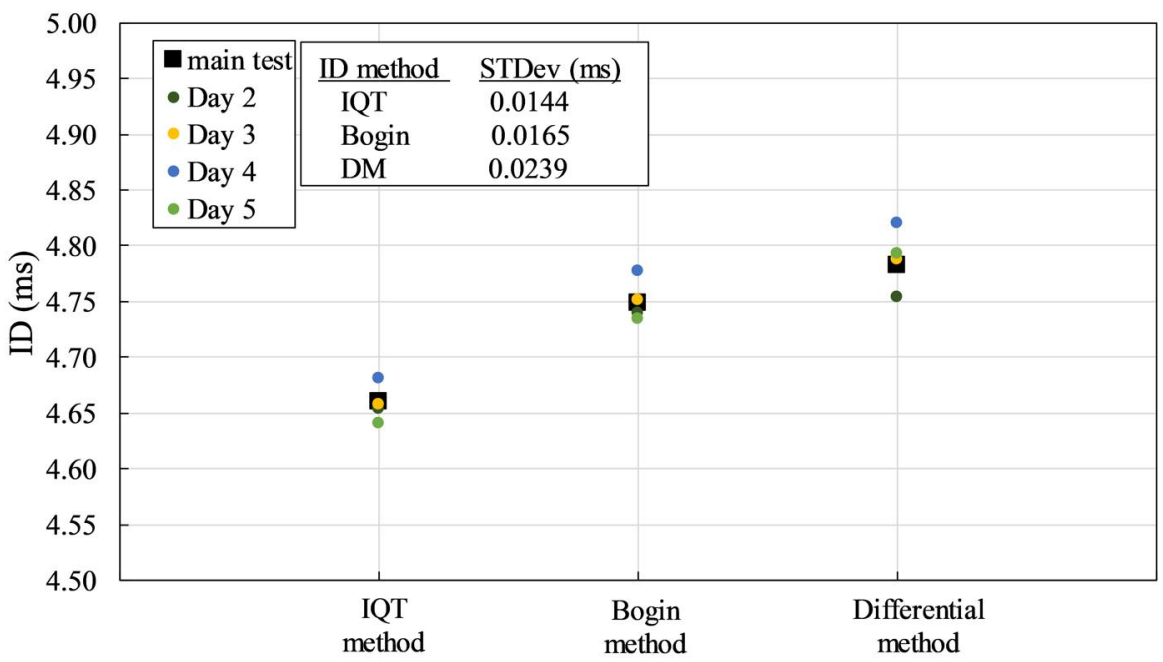

(b) When FTP at plane 10 (105 mm from injector)

Figure 3.20: Results of the ID based on pressure obtained at $550{ }^{\circ} \mathrm{C}$ and $21.4 \mathrm{bar}$ with five repeats 


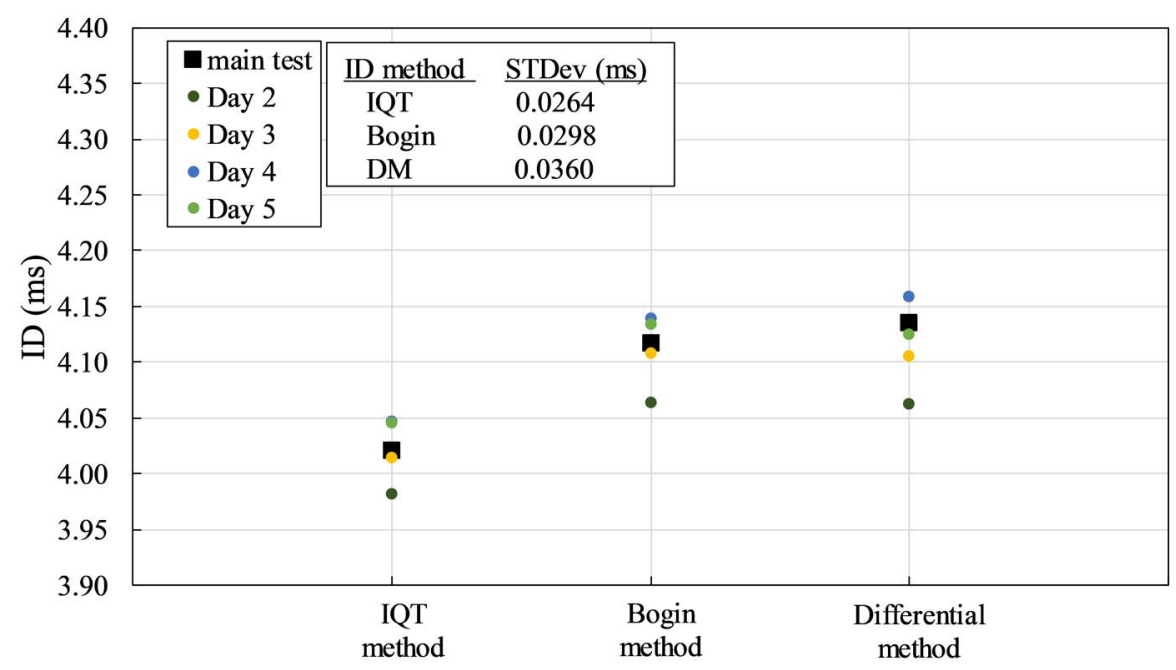

(a) When FTP at plane 6 (65 $\mathrm{mm}$ from injector)

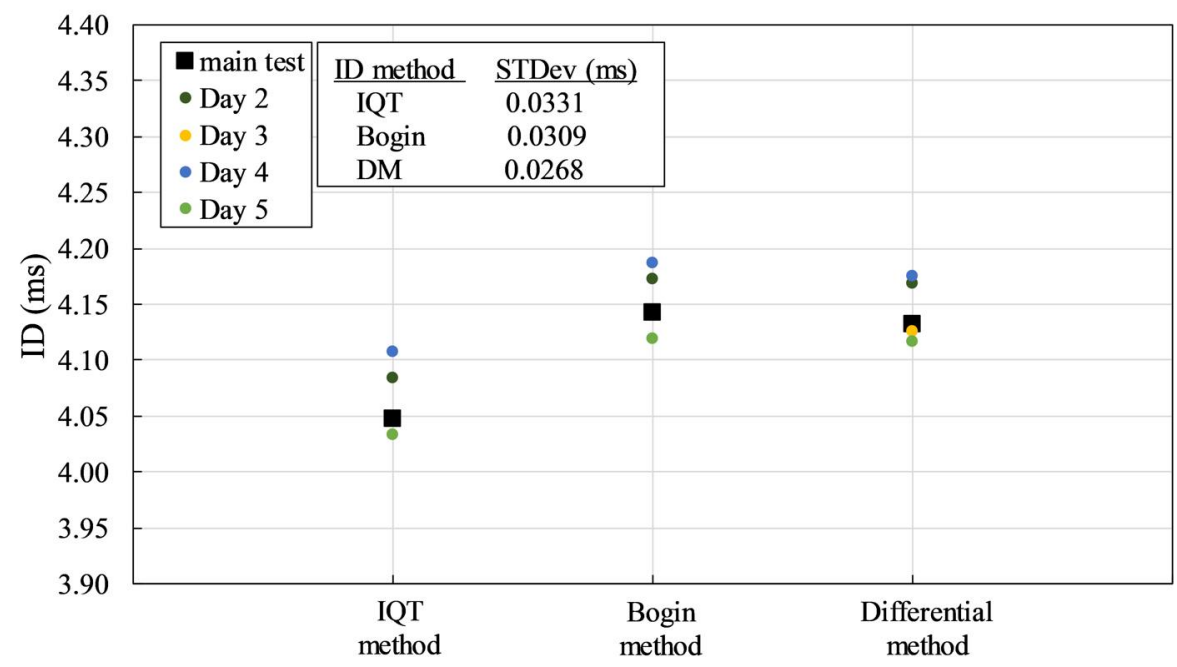

(b) When FTP at plane 10 (105 mm from injector)

Figure 3.21: Results of the ID based on pressure obtained at $580{ }^{\circ} \mathrm{C}$ and 21.4 bar with five repeats 


\section{Chapter 4}

\section{$I Q T^{T M}$ Chamber Temperature Measurements}

In this chapter the results of temperature measurements inside the IQT combustion chamber using heptane has been presented. The main concern was with the response of the TCs to the temperature variations in the period starting from fuel injection up to the mixture combustion (ignition delay period).

\subsection{Spatial Arrangement of Thermocouples Inside the IQT Chamber}

As stated earlier, there will be $10 T C s$ or $9 T C s$ inside the combustion chamber capturing temporally the variation in the temperature at different locations throughout the combustion process. The three $T C s$ of the front port temperature probe are distributed as following: the first $T C$ is positioned at chamber wall plane, the second $T C$ is $8 \mathrm{~mm}$ from chamber wall and $8 \mathrm{~mm}$ from chamber centerline, and the third $T C$ is $16 \mathrm{~mm}$ from wall and $3 \mathrm{~mm}$ from centerline. The other three $T C s$ of the back port temperature probe are 
distributed as following: the first $T C$ is positioned at the chamber wall plane, the second $T C$ is $9 \mathrm{~mm}$ from chamber wall and $16 \mathrm{~mm}$ from centerline, and the third $T C$ is $16 \mathrm{~mm}$ from chamber wall and $9 \mathrm{~mm}$ from centerline.

The third temperature probe, which is called flower temperature probe $(F T P)$, is inserted axially from pressure transducer port. The FTP is fabricated with two arrangements based on the number of $T C s$ on each probe and the radial locations of hot junctions inside the $I Q T^{T M}$. The first arrangement of the FTP has four TCs. They are spread out radially on the same radial plane as following: the first $T C$ is located at chamber centerline, the second $T C$ is $8 \mathrm{~mm}$ from centerline, the third $T C$ is $16 \mathrm{~mm}$ from the centerline and the last $T C$ is very close to the chamber wall (25 $\mathrm{mm}$ from centerline). The second arrangement of the FTP has three TCs. The first TC is located at chamber centerline, the second $T C$ is $3 \mathrm{~mm}$ from centerline, the third $T C$ is $6 \mathrm{~mm}$ from the centerline.

To get full scan of the temperature variation within the chamber during combustion process, the distance from injector to the plane of the FTP could be chosen for each run by traversing the probe axially within the main part of the chamber, where the diameter is $50 \mathrm{~mm}$, and within both ends of chamber (injector and pressure transducer ends). Also, the probe could be rotated by an angle to get the temperature at the same plane and radius with different angles. The locations of TCs are selected based on the characteristics of the fuel spray from experimental work and the features of fuel combustion from simulations. The FTP is traversed at thirteen planes as shown in Figure 4.1. Temperature variations are recorded at 46 different locations inside the $I Q T^{T M}$ chamber by using the FTP. The FTP with 3 TCs is used at planes 1,2 (injector end), and $10,11,12, \& 13$ (chamber tail or pressure transducer end). The FTP with 4 TCs is used at planes $3,4,5,6,7,8, \& 9$ (main part of chamber). In addition to that, the front and back temperature probes are used to record temperature variation at 6 different locations, three for each probe. 


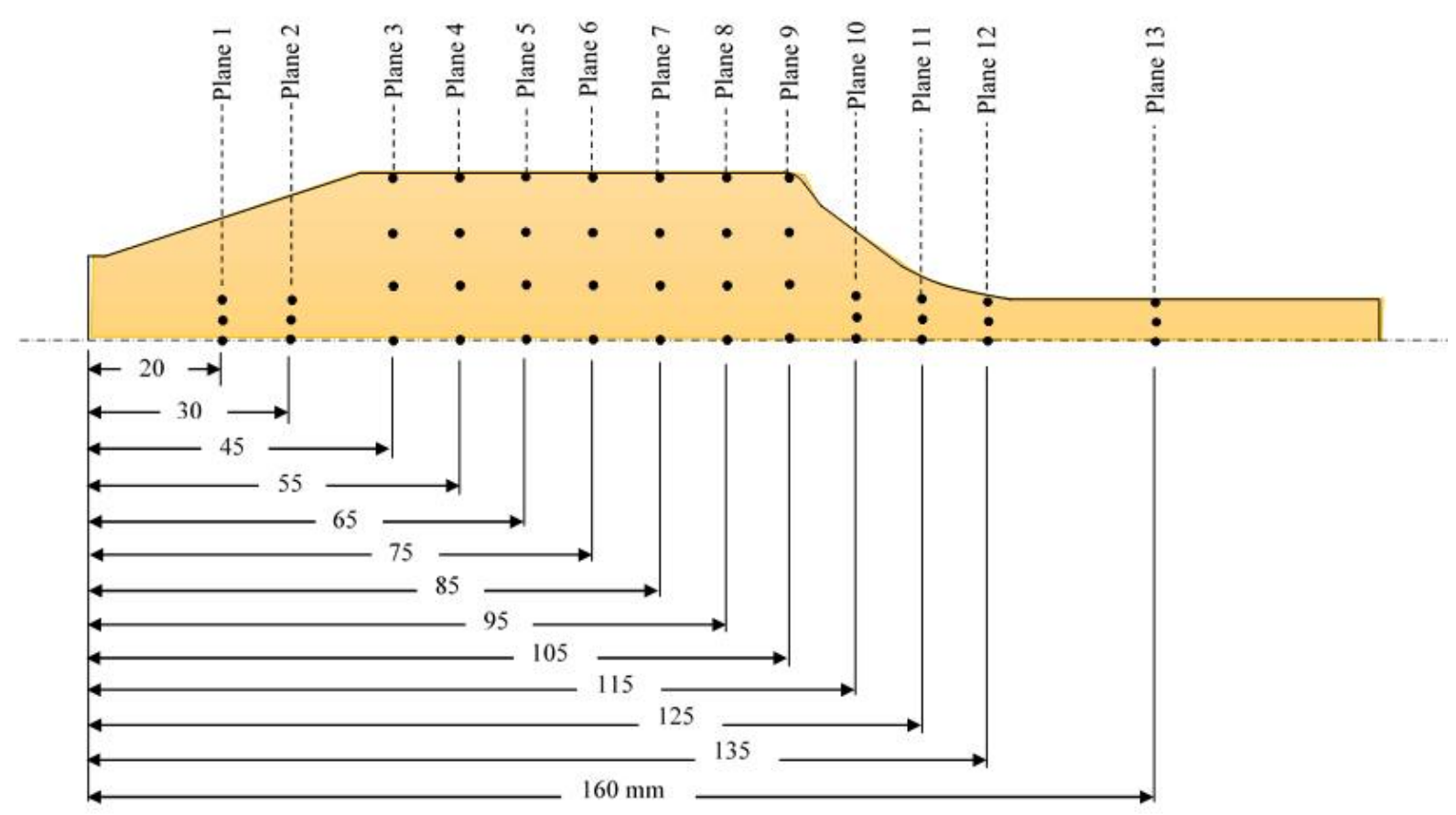

Figure 4.1: Locations of temperature measurements inside the IQT

\subsection{Raw and Mean Results (Temperature, Pressure and Needle lift)}

The IQT was calibrated first and the test conditions were $584.5^{\circ} \mathrm{C}$ for set point, $310 \mathrm{psi}$ (21.4 bar ) for charge air pressure and $0.8 \mathrm{gram} / 10$ injections of n-heptane. Later on, the experiments at different conditions of initial pressure and temperature are conducted.

The three main parameters: nozzle needle position, combustion chamber pressure and spatial gas temperature are collected from needle lift sensor, pressure transducer at new position and TC probes, respectively. All sensors are connected to a laptop through data acquisition system from Omega of model OMB-DAQ-3005. DAQ software (Daq view) settings are adjusted to get the feedback from the sensors. Needle lift sensor has been selected as a reference to start data synchronization process. The data are collected for the period just before needle lift by $10 \mathrm{~ms}$ until the end of combustion with a time interval of $0.1 \mathrm{~ms}$. The recorded data for all injections are saved automatically into the 


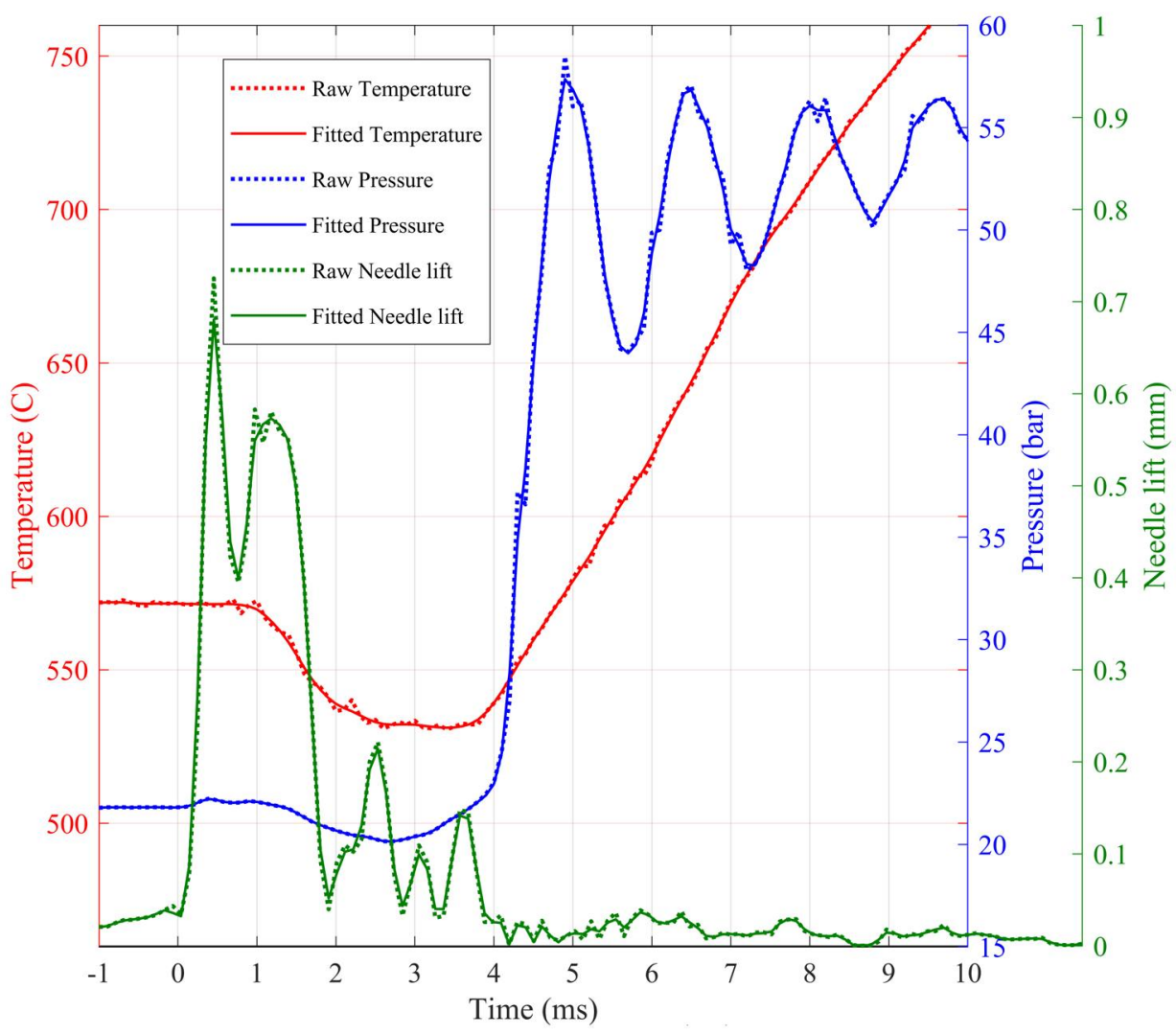

Figure 4.2: Raw vs. smoothing data for one injection, at $P=21 \mathrm{bar}$ and $T=580^{\circ} \mathrm{C}$

pre-selected file names. For present study, a complete run of fuel test consists of 20 injections instead of 47 injections for fuel saving purposes. The first 5 pre-injections are not included in the results and the $I D$ calculations. They are just introduced to thermally stabilize the device. The data of the remaining (last) 15 injections are fitted by using smoothing spline model $[119]$. A matlab code is created to smooth noise with the data and then the mean values of 15 injections were calculated for temperatures, pressure and needle lift as shown in the Figures 4.3-4.10. The smoothing-spline method along with the goodness of fit functions are used in the matlab code for the purpose of noise cancellation of the recorded data. To show the effectiveness of the smoothing on data, the results of one injection is presented in Figure 4.2. The dashed dotted lines are for raw signal (temperature, pressure, or needle lift) and the solid lines are after applying the smoothing-spline method. 


\subsubsection{Pressure and Needle Lift Results}

The voltage signals from pressure and needle lift sensors are converted into the pressure and length units by using Equations 4.1 and 4.2 [120, respectively. The pressure and needle lift are proportional linearly to the voltage signals from the sensors.

Needle lift sensor conversion equation:

$$
N L=a b s\left(\frac{\left(N L_{v}-N L_{\text {init }}\right)}{N L_{\text {init }}}\right) * C_{N L}
$$

Where $N L$ is the gap (in $\mathrm{mm}$ ) between the sensing surface of the injector nozzle needle motion sensor and the end of injector nozzle needle extension pin, $N L_{v}$ is the instantaneous needle sensor signal in volts, $N L_{\text {init }}$ is the average signal of needle sensor before needle motion, and $C_{N L}$ is the linear proportional constant which equals 1 .

Two resistances of $10 k \Omega$ were connected to the circuit of needle lift sensor (see Figure 3.10 to divide the signal and make it within the range of the OMB-DAQ-3005.

Pressure sensor conversion equation is based on the specifications of pressure transducer 100 as shown in Equation 4.2.

$$
P=\frac{2000 \text { psi }}{10 \text { volts }} * P_{v}+P_{\text {init }}
$$

Where $P$ is the instantaneous chamber pressure in $p s i, P_{v}$ is the instantaneous pressure signal in volts, and $P_{\text {init }}$ is the average initial chamber pressure before fuel injection in psi.

Figure 4.3, shows the needle lift position with time for the raw data of 15 injections with their mean fitted value (black thick line). The nozzle starts to lift and discharge fuel of the injector sac into the pressurized chamber when the pressure in the fuel line reaches the nozzle opening pressure (around $18 \mathrm{MPa}$ ) or higher. This point is known as start of injection or the beginning time of ignition delay period. All injections have the

same starting point and the peak of needle lift is around $0.6 \mathrm{~mm}$. The main injection 


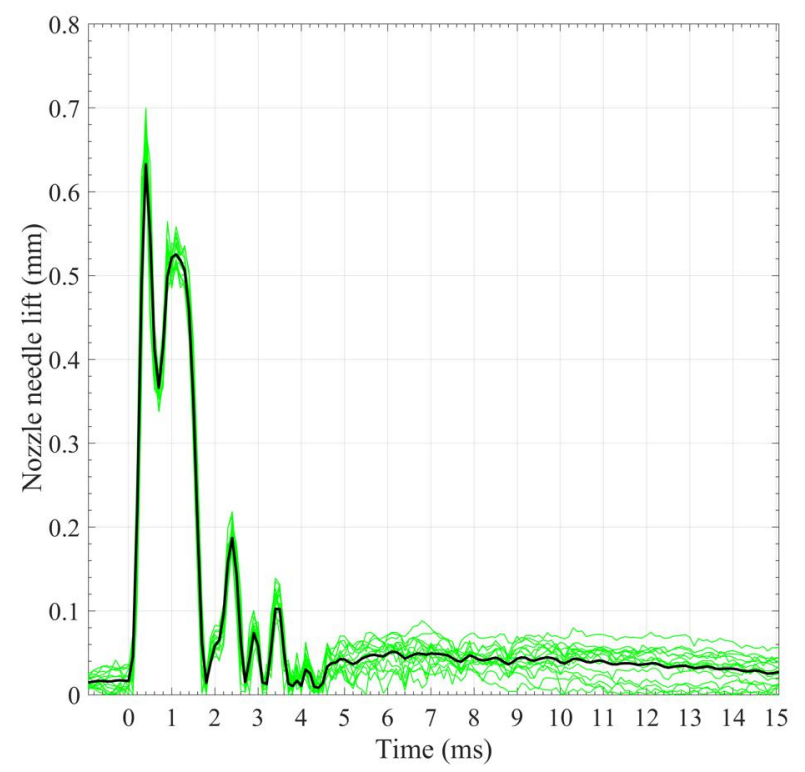

(a) $P_{\text {initial }}=21.4 \mathrm{bar}$ and $\mathrm{T}=590^{\circ} \mathrm{C}$

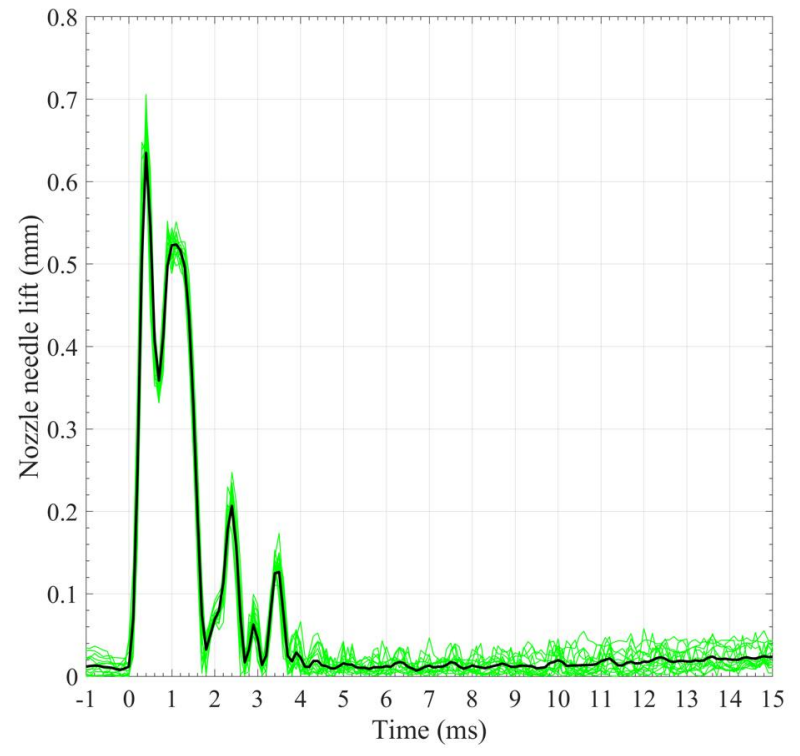

(b) $P_{\text {initial }}=10 \mathrm{bar}$ and $\mathrm{T}=530^{\circ} \mathrm{C}$

Figure 4.3: Needle lift trace of 15 injections with their mean (black thick line) for two experimental extremes conditions of pressure and temperature

duration lasts in about $2 \mathrm{~ms}$. The small spikes after that might come from the vibrations in injector needle because of the spring force effects which lead to some leak in fuel. The needle trace are presented at two chamber initial conditions of pressure and temperature. They look almost identical and chamber conditions has no effects on needle lift trace or profile of injected fuel.

The global variation of pressure inside the $I Q T^{T M}$ chamber is presented in Figure 4.4 . After fuel has been injected, the pressure drops due to cooling effects of evaporative spray. The required time for atomization, vaporization, mixing and heating of the injected fuel is called physical ignition delay period as discussed before. At this period, the pressure and temperature inside the chamber decrease. Followed by that drop in pressure is a gradual increase presenting the commencement of the chemical ignition delay. The combustion is noticed at the sudden increase in pressure and temperature due to heat released from the chemical reactions. 


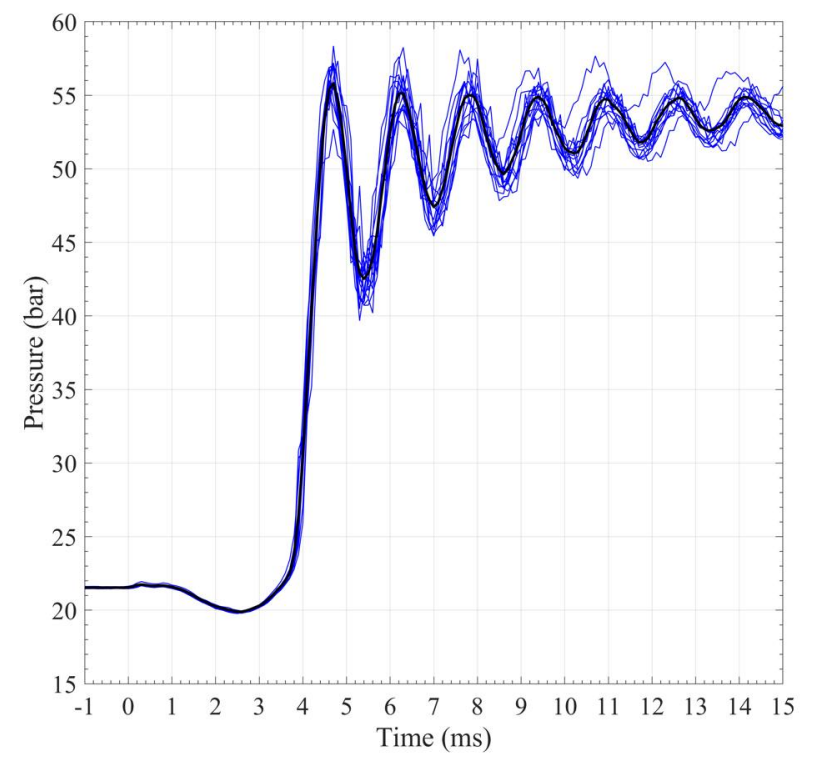

(a) $P_{\text {initial }}=21.4 \mathrm{bar}$ and $\mathrm{T}=590^{\circ} \mathrm{C}$



(b) $P_{\text {initial }}=15 \mathrm{bar}$ and $\mathrm{T}=550^{\circ} \mathrm{C}$

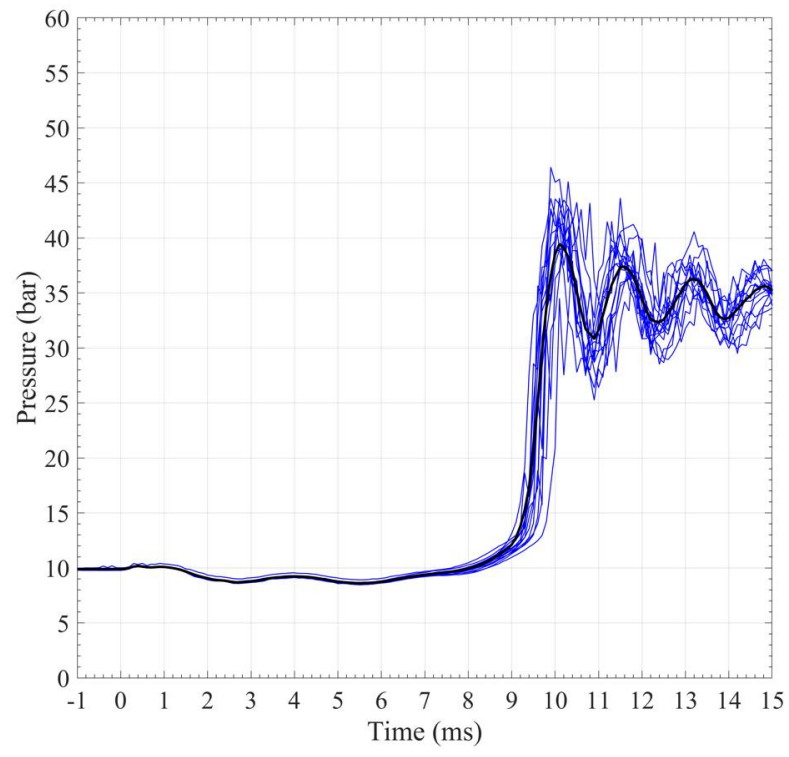

(c) $P_{\text {initial }}=10 \mathrm{bar}$ and $\mathrm{T}=530^{\circ} \mathrm{C}$

Figure 4.4: Pressure variation with time of 15 injections with their mean (black thick line) for three experimental conditions of initial pressure and temperature 


\subsubsection{Temperature Measurement Results}

The temperature variations are recorded at the locations that aforementioned in Figure 4.1. At each run, there are $10 \mathrm{TCs}$ inside the chamber measuring the temperature variation and in total the temperature are measured at 52 different locations inside the chamber. The temperature variation at 10 locations with two different conditions of pressure and temperature are selected to be presented in this section: 3 at front port (by front temperature probe), 3 at back port (by back temperature probe), and 4 locations at plane 7 ( $85 \mathrm{~mm}$ from injector plane) by using the FTP.

The time history of the gas temperature measured by the FTP (4TCs) is given in Figures 4.5 and 4.6 . The trend of temperature variations are similar for all locations except near chamber wall (Figure 4.5d), where there is no drop in temperature after fuel injection. The other three locations of the FTP (Figure 4.5, a,b, and c) have showed a significant drop in temperature due to the cooling effect of the injected fuel. Prior to fuel injection, temperature lines for all injections show consistency and there is a slight deviation due to the accuracy of TCs. The lines become closer to each other at the point of sudden increase in temperature which represents the onset of combustion. At the other condition $\left(P_{\text {initial }}=10 \mathrm{bar}\right.$ and $\left.T=530^{\circ} \mathrm{C}\right)$, Figure 4.6, the temperature has dropped significantly at chamber centerline only. The temperature has dropped slightly at the other three locations.

At the first presented condition $\left(21.4 \mathrm{bar}, 590^{\circ} \mathrm{C}\right)$, temperature profiles at the front port of chamber (Figure 4.7) are greatly different to that at the main part of the chamber (Figure 4.5). A slight increase in temperature (less than $30^{\circ} \mathrm{C}$ ) were noticed from the readings of the TC at chamber wall (Figure 4.8a), with maximum temperature of about $590{ }^{\circ} \mathrm{C}$ which is very close to the test set point $\left(590^{\circ} \mathrm{C}\right)$. The fuel spray direction away from the front area and the cooling effects of the coolant around the injector make this wall far from combustion effects. A higher temperature was measured by the second TC of the front probe (Figure $4.7 \mathrm{~b}$ ). However, there was not a sudden increase in the temperature 


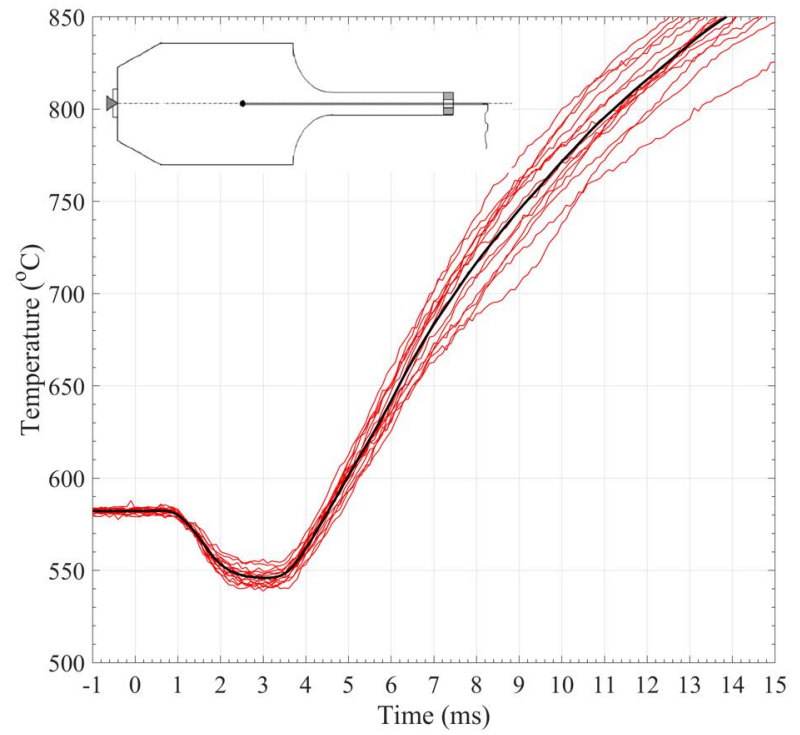

(a) At chamber centerline $(\mathrm{r}=0 \mathrm{~mm})$

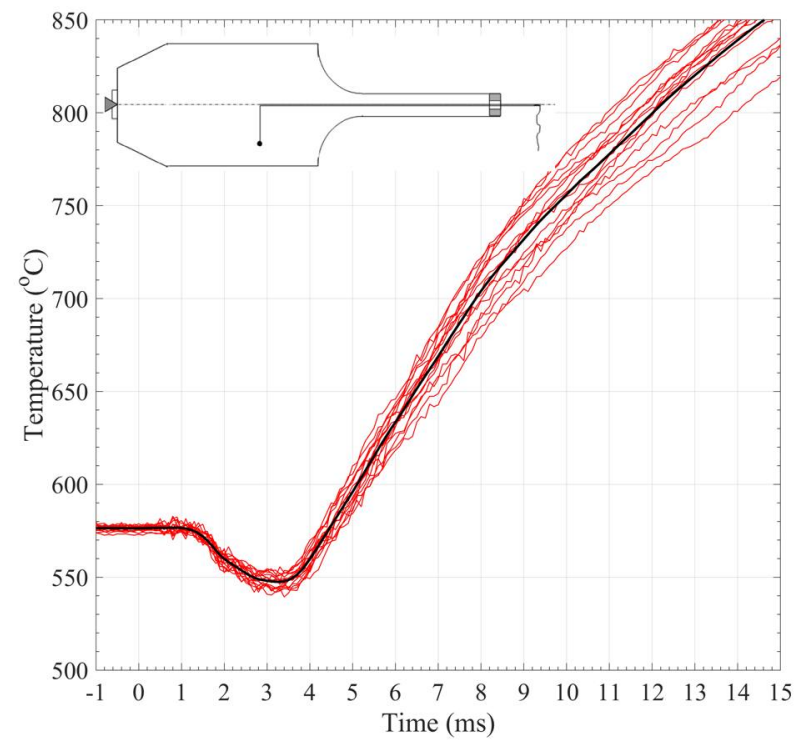

(c) $\mathrm{r}=16 \mathrm{~mm}$

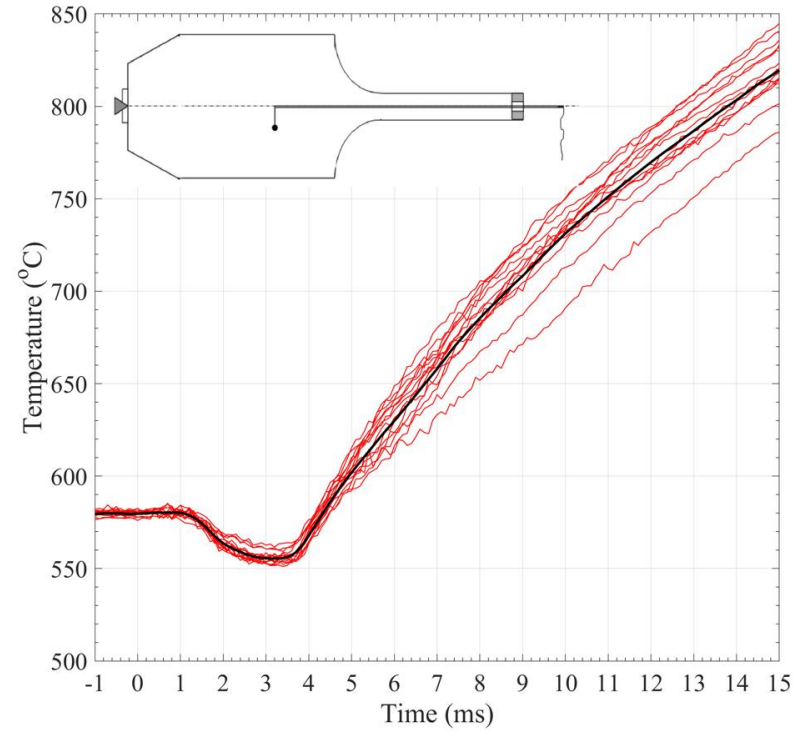

(b) $\mathrm{r}=8 \mathrm{~mm}$

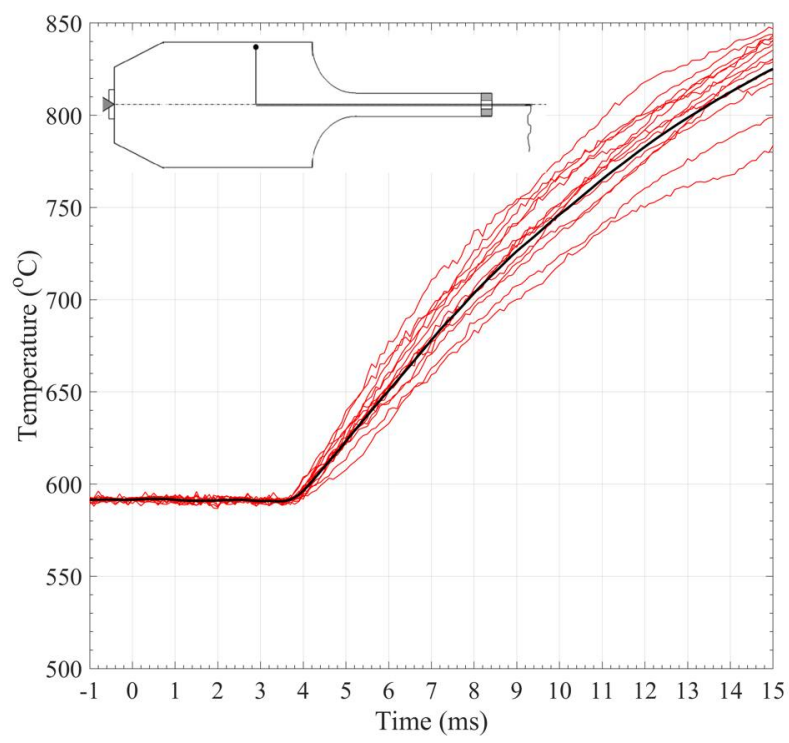

(d) $\mathrm{r}=24 \mathrm{~mm}$

Figure 4.5: Temperature variation of 15 test injections with mean value from the $F T P$, $75 \mathrm{~mm}$ from injector plane, $P_{\text {initial }}=21.4 \mathrm{bar}, \mathrm{T}=590^{\circ} \mathrm{C}$ 


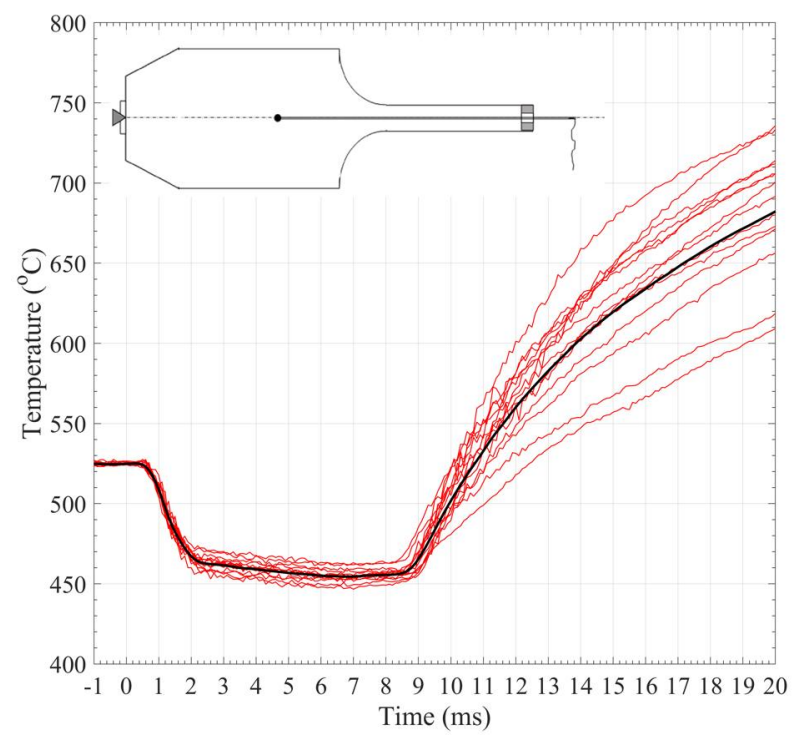

(a) At chamber centerline $(\mathrm{r}=0 \mathrm{~mm})$

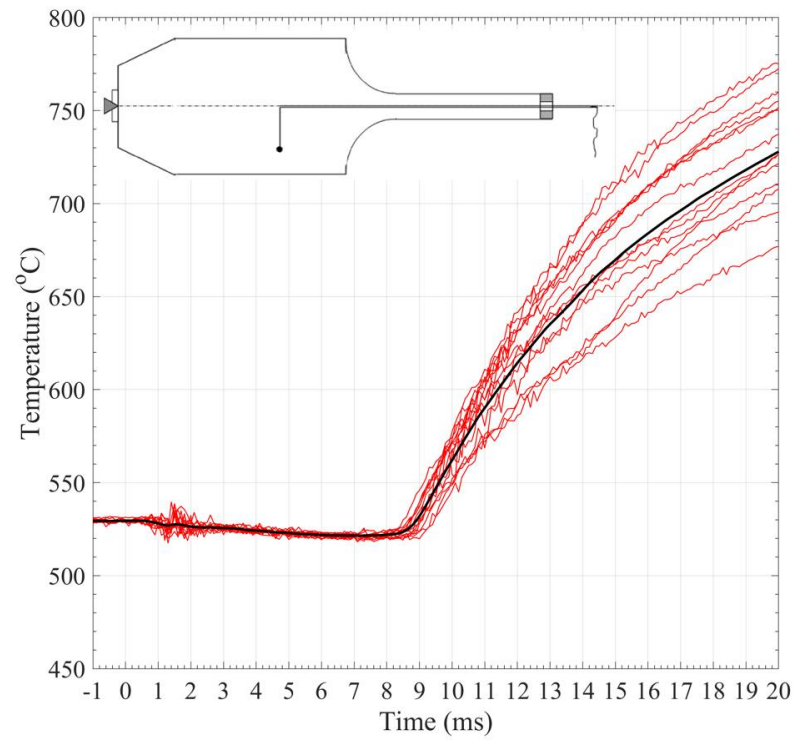

(c) $\mathrm{r}=16 \mathrm{~mm}$

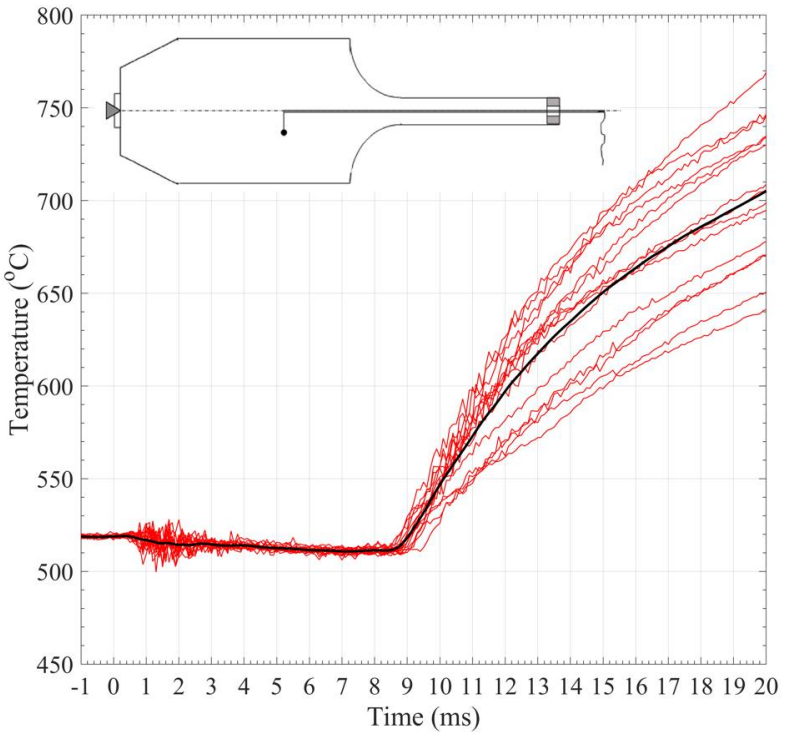

(b) $\mathrm{r}=8 \mathrm{~mm}$

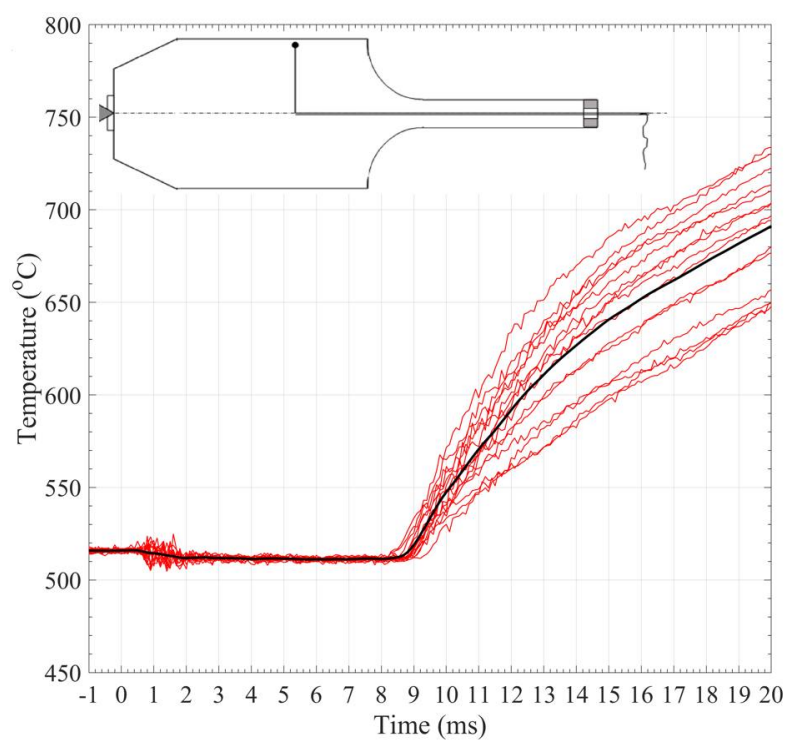

(d) $\mathrm{r}=24 \mathrm{~mm}$

Figure 4.6: Temperature variation of 15 test injections with mean value from the FTP, $75 \mathrm{~mm}$ from injector plane, $P_{\text {initial }}=10 \mathrm{bar}, \mathrm{T}=530^{\circ} \mathrm{C}$ 
and the maximum temperature is recorded by the TC closer to chamber centerline. That means the flame propagated to that area and no combustion was initiated there. The relatively high initial pressure and temperature $\left(21.4 \mathrm{bar}, 590^{\circ} \mathrm{C}\right)$ reduce greatly the spray droplet lifetime, and most of the fuel spray is evaporated and mixed rapidly with air during its propagation towards the other end of chamber. Thus, the rich fuel air mixture is concentrated far from chamber front port. At the other end, where the conditions $\left(10 \mathrm{bar}, 530^{\circ} \mathrm{C}\right)$ are relatively low, there is enough time for the spray to evaporate and mix with air before ignition. The mixture hits the chamber wall and moves backward toward the injector or the front portion side. The temperature profiles at this conditions are close from each other (Figures 4.6 and 4.8), except at chamber centerline (Figure 4.6a). The temperature measurements at the chamber front wall, (Figure 4.8a), show a lot of inconsistencies at the time of temperature rise. That is a consequence of high turbulence coming from other end of chamber and at the same time from the mixture combusting near the chamber front wall.

The results of the third probe (at back port) is given in Figures 4.9 and 4.10 . No temperature drop was recorded at high conditions $\left(21.4 \mathrm{bar}, 590^{\circ} \mathrm{C}\right)$ and a slight drop was recorded at low conditions $\left(10 \mathrm{bar}, 530^{\circ} \mathrm{C}\right)$. Two different temperature profiles existed. The temperature rise at chamber wall (Figures $4.9 \mathrm{a}$ and $4.10 \mathrm{a}$ ) continues for a very short period of time and then the slopes become moderate with time, whereas at other two locations ( $8 \mathrm{~mm}$ and $16 \mathrm{~mm}$ ) from the wall (Figure $4.9 \mathrm{~b}, 4.9 \mathrm{c}$ and $4.10 \mathrm{~b}, 4.10 \mathrm{c}$ ) a higher temperature was measured (around $1200^{\circ} \mathrm{C}$ ) and it continued for a longer period of time. 




(a) Near chamber wall



(b) $8 \mathrm{~mm}$ from wall



(c) $16 \mathrm{~mm}$ from wall

Figure 4.7: Temperature variation of 15 test injections with mean value from the FRONT probe, $P_{\text {initial }}=21.4 \mathrm{bar}, \mathrm{T}=590^{\circ} \mathrm{C}$ 


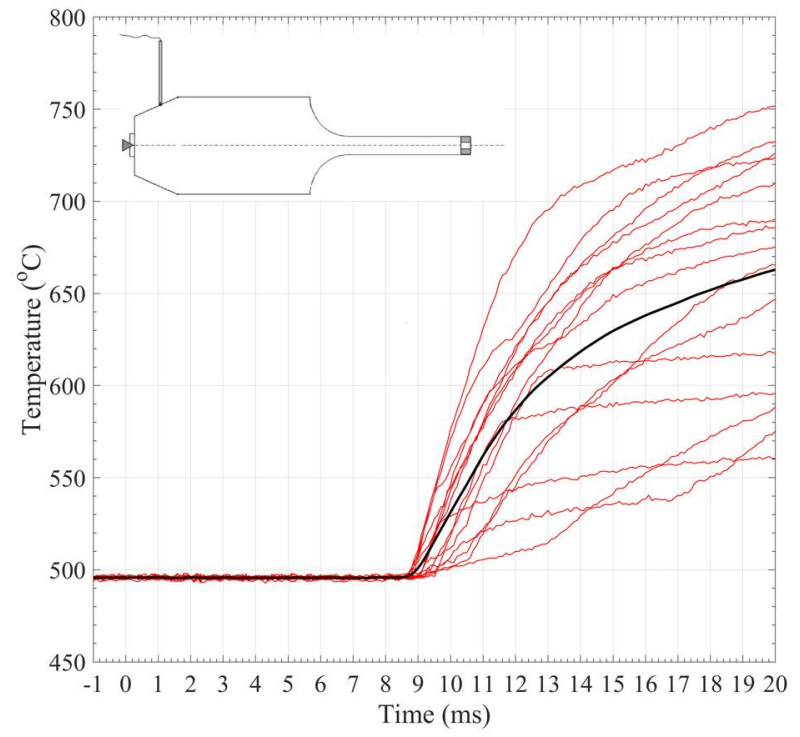

(a) Near chamber wall

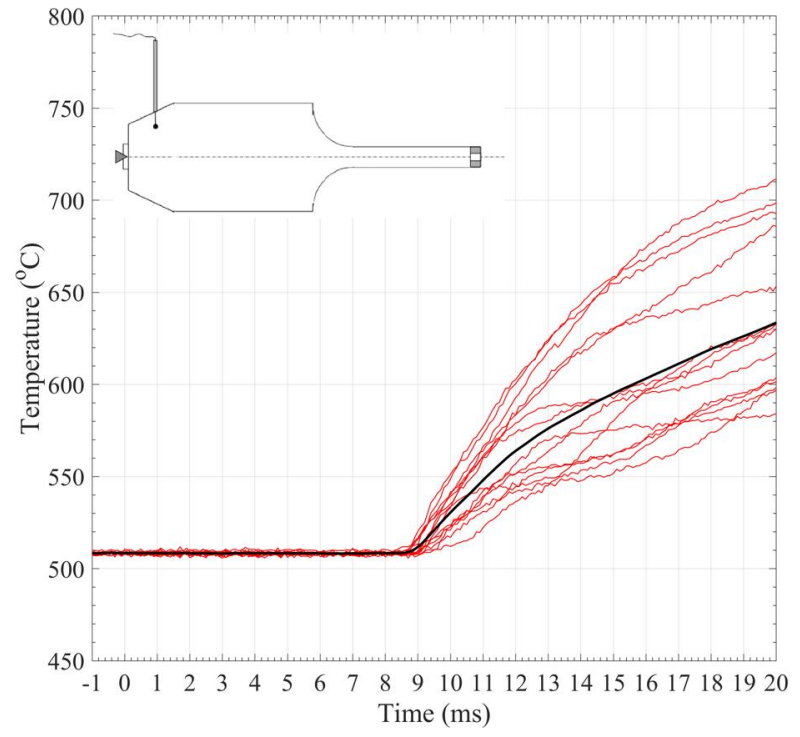

(b) $8 \mathrm{~mm}$ from wall

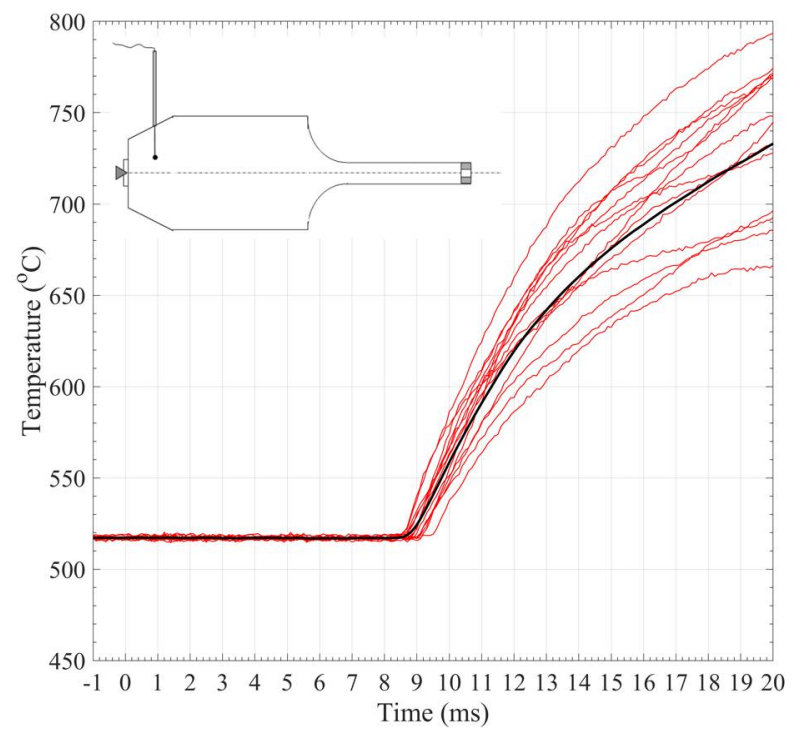

(c) $16 \mathrm{~mm}$ from wall

Figure 4.8: Temperature variation of 15 test injections with mean value from the FRONT probe, $P_{\text {initial }}=10 \mathrm{bar}, \mathrm{T}=530^{\circ} \mathrm{C}$ 


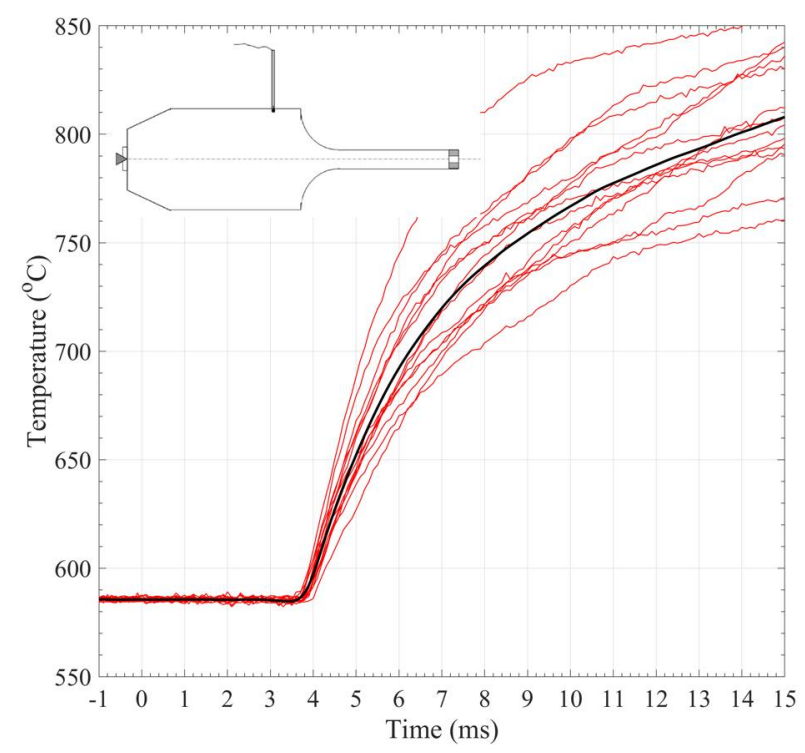

(a) Near chamber wall

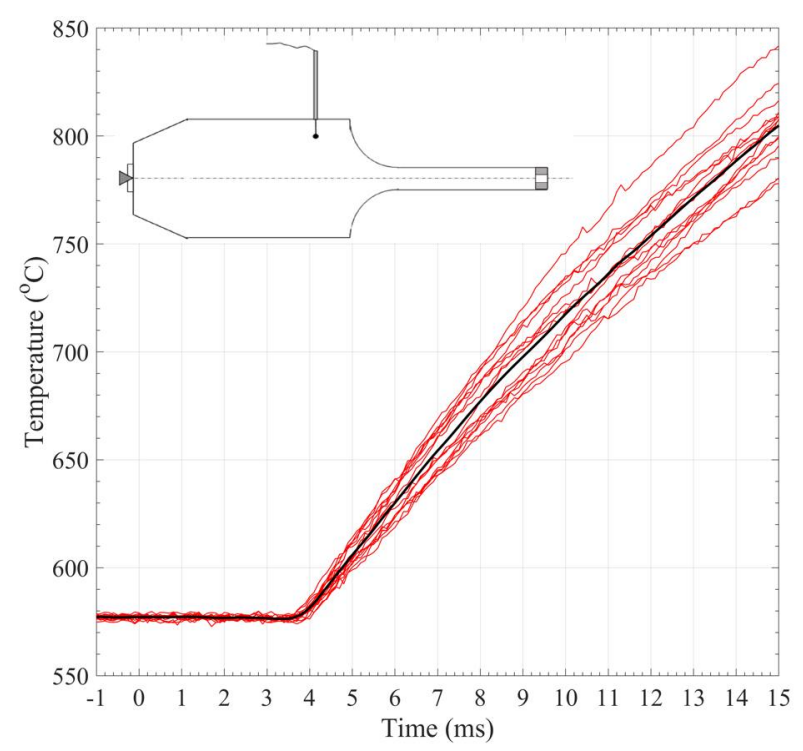

(b) $8 \mathrm{~mm}$ from wall

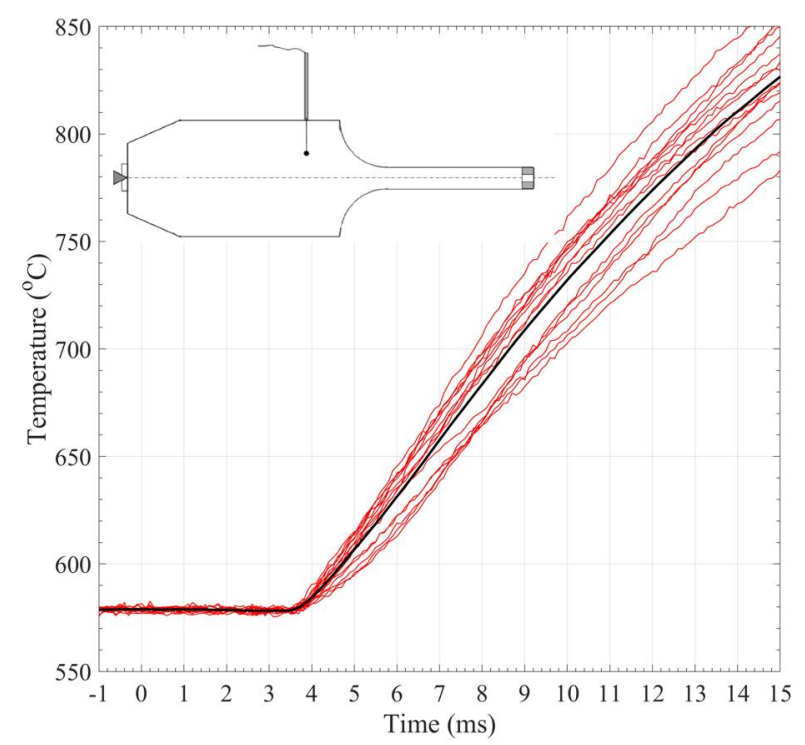

(c) $16 \mathrm{~mm}$ from wall

Figure 4.9: Temperature variation of 15 test injections with mean value from the BACK probe, $P_{\text {initial }}=21.4 \mathrm{bar}, \mathrm{T}=590^{\circ} \mathrm{C}$ 


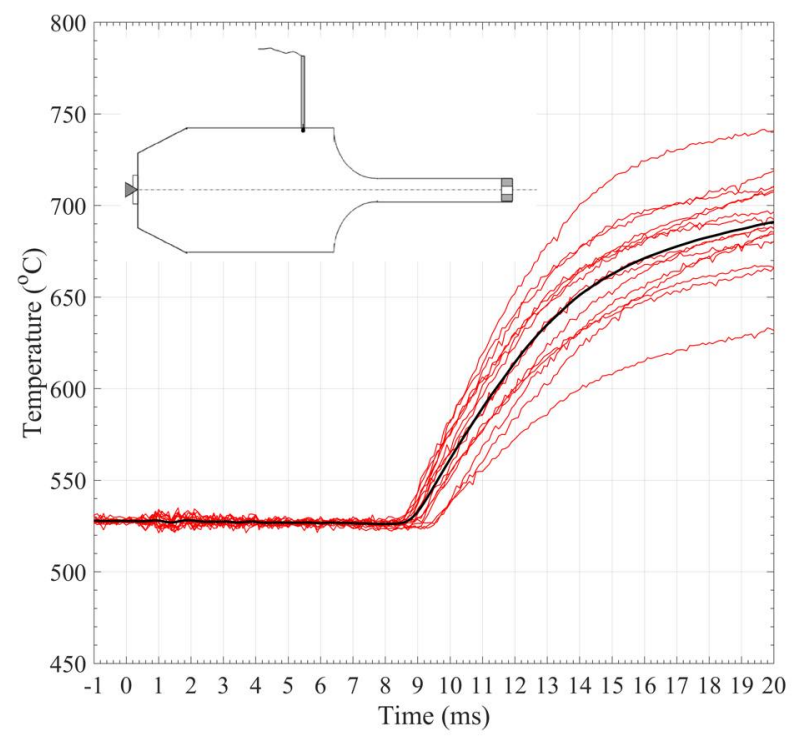

(a) Near chamber wall

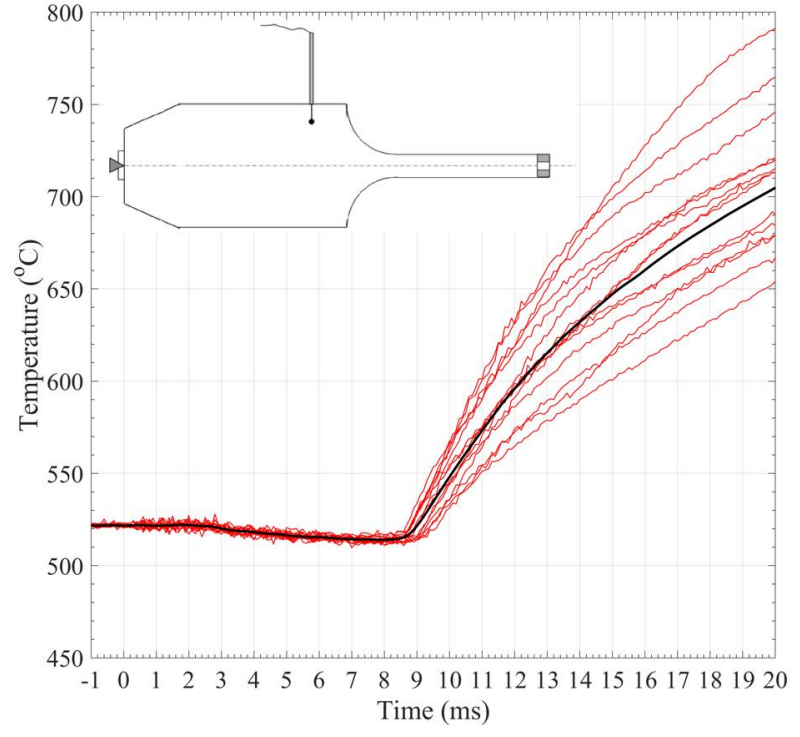

(b) $8 \mathrm{~mm}$ from wall

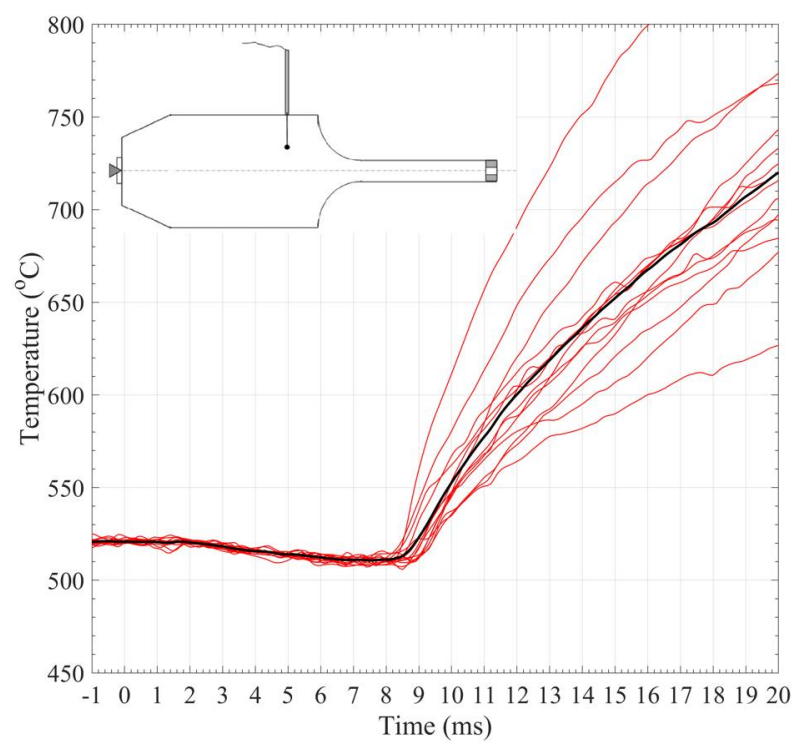

(c) $16 \mathrm{~mm}$ from wall

Figure 4.10: Temperature variation of 15 test injections with mean value from the BACK probe, $P_{\text {initial }}=10 \mathrm{bar}, \mathrm{T}=530^{\circ} \mathrm{C}$ 


\subsection{Mean Temperature, Pressure and Needle Lift Re- sults at ID Period}

To observe clearly temperature variation with pressure at the ignition delay period, the mean values of 15 test injections are presented for the time prior to the fuel injection up to the fuel ignition as shown in Figures 4.11 to 4.16 , where three parameters (temperature ratio $\left(T R=T(t) / T_{\text {initial }}\right)$, pressure, and needle lift $)$ are shown on the each figure. The start of fuel injection is pointed at $0 \mathrm{~ms}$ on time axis and same needle tracing line. Due to the gradient in temperature along the IQT chamber prior to fuel injection, it is decided to present temperature variation as a ratio of the momentary temperature readings $T(t)$ to the initial temperature (prior to fuel injection) $T_{\text {initial }}$ instead of temperature. In total, the test on n-heptane were conducted under 15 different conditions of initial pressure and temperature as shown in the Table 4.1 with a standard amount of injected fuel at $80 \mathrm{mg} /$ injection. The results of just 3 conditions out of 15 are selected to be presented on each figure at this section. Those conditions are: 1) $10 \mathrm{bar}$ and $\left.530{ }^{\circ} \mathrm{C}, 2\right) 15 \mathrm{bar}$ and $570^{\circ} \mathrm{C}$, and 3) $21.4 \mathrm{bar}$ and $590^{\circ} \mathrm{C}$. 


\begin{tabular}{|c|c|c|}
\hline condition number & $P_{\text {initial }}($ bar $)$ & $T_{\text {initial }}\left({ }^{\circ} \mathrm{C}\right)$ \\
\hline \hline 1 & 10 & 530 \\
\hline 2 & 10 & 550 \\
\hline 3 & 10 & 570 \\
\hline 4 & 10 & 580 \\
\hline 5 & 10 & 590 \\
\hline 6 & 15 & 530 \\
\hline 7 & 15 & 550 \\
\hline 8 & 15 & 570 \\
\hline 9 & 15 & 580 \\
\hline 10 & 15 & 590 \\
\hline 11 & 21.4 & 530 \\
\hline 12 & 21.4 & 550 \\
\hline 13 & 21.4 & 570 \\
\hline 14 & 21.4 & 580 \\
\hline 15 & 21.4 & 590 \\
\hline
\end{tabular}

Table 4.1: Initial conditions (Pressure and Temperature) used in the project

Figure 4.11 shows the $T R$ variations at seven locations along chamber centerline. All those locations have experienced different amount of drop in temperature after fuel injection except the last location at $160 \mathrm{~mm}$ from injector, where there was no drop in temperature. The maximum drop in temperature was recorded by TCs at chamber centerline compared to other locations in the chamber. The drop occurs when the released spray from injector reaches and hits the TCs. The drop is due to high vaporization rate which absorbs heat at a certain time. In the Figure 4.11a and 4.11b, the temperature variations at the first three locations from injector side have almost similar trend, where the temperature did not increase significantly after combustion. This gives an indication that this zone has a weak fuel-air mixture ratio. The variations at the other three locations at the main part of chamber showed rapid increase during combustion process and maximum temperature was recorded by TC at chamber centerline $(95 \mathrm{~mm}$ from injector) which is around $1300^{\circ} \mathrm{C}$. At low IQT conditions (Figure 4.11c), the temperature drops first after fuel injection and remains unchanged for a while before the initiation of 
ignition. This period will be adequate for the fuel to evaporate and mix with air and also spread out in the chamber. 




(a) $21.4 \mathrm{bar}$ and $590^{\circ} \mathrm{C}$



(b) 15 bar and $570^{\circ} \mathrm{C}$

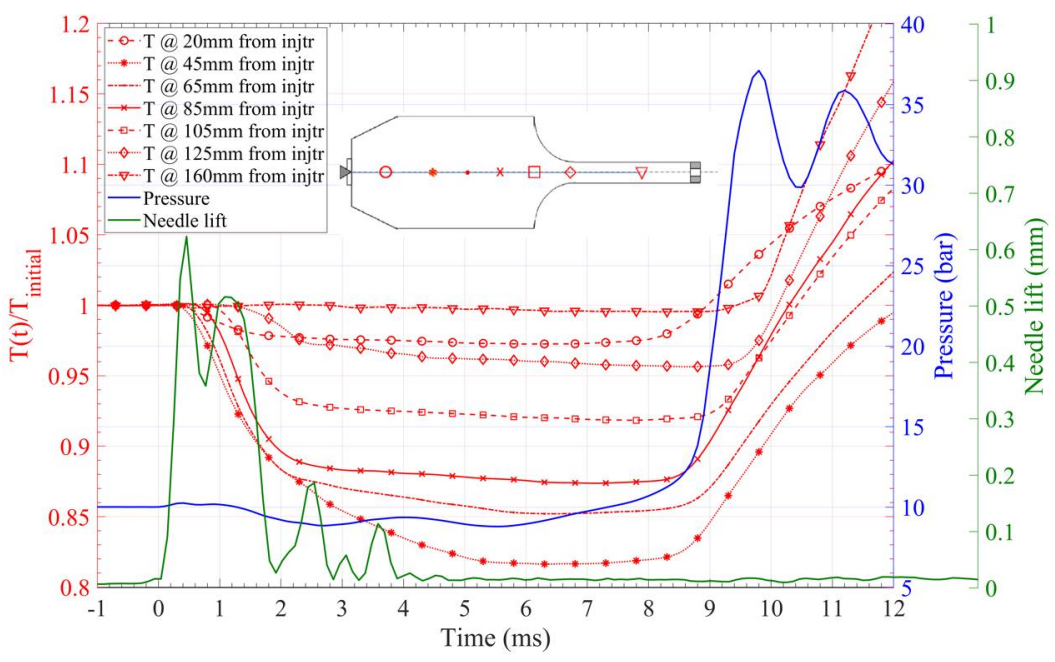

(c) $10 \mathrm{bar}$ and $530^{\circ} \mathrm{C}$

Figure 4.11: Temperature variations with time at chamber centerline $(r=0 \mathrm{~mm})$ with different locations from injector plane, and at different initial pressure and temperature 
The other set of TC locations $(r=8 \mathrm{~mm})$, Figure 4.12 , have experienced less drop in temperature when it compared to the set at chamber centerline. At high IQT conditions, Figure $4.12 \mathrm{a}$, the temperature rise profiles are similar for all locations, except at the first two TCs. Significant drop in temperature was recorded at two locations shown in Figure $4.12 \mathrm{~b}$ and a slight drop recorded on the other locations on the same figure. Most $T R$ lines on Figures $4.12 \mathrm{a}$ and $4.12 \mathrm{~b}$ cross at a particular point on the time axis. A slight drop was noticed on the Figure $4.12 \mathrm{c}$ and all locations have similar temperature rise except at the first location which is close to the injector side. The first location did not show any drop in temperature.

Figures 4.13 and 4.14 show the $T R$ variations at seven different locations on the main part of the chamber with two radius, $r=16 \mathrm{~mm}$ and $r=24 \mathrm{~mm}$, respectively. It is observed that the $T R$ lines remain closer to each other and have similar trend after fuel injection up to the fuel combustion. The significant drop was recorded at high IQT conditions of Figure $4.13 \mathrm{a}$ only whereas at the other two conditions (Figures $4.13 \mathrm{~b}$ and 4.13c), a slight drop in temperature was noticed. The $T R$ lines are almost parallel at the temperature rise portion. The locations near the chamber wall (Figure 4.14) did not show significant drop in temperature. The rate of increase in the TR at the last four locations on the Figure 4.14a is higher than that at the first three locations, where the increase in temperature is slower. As conditions lowered, as shown in Figures 4.14b and 4.14c all TR lines have experienced rapid increase when combustion occurs. 


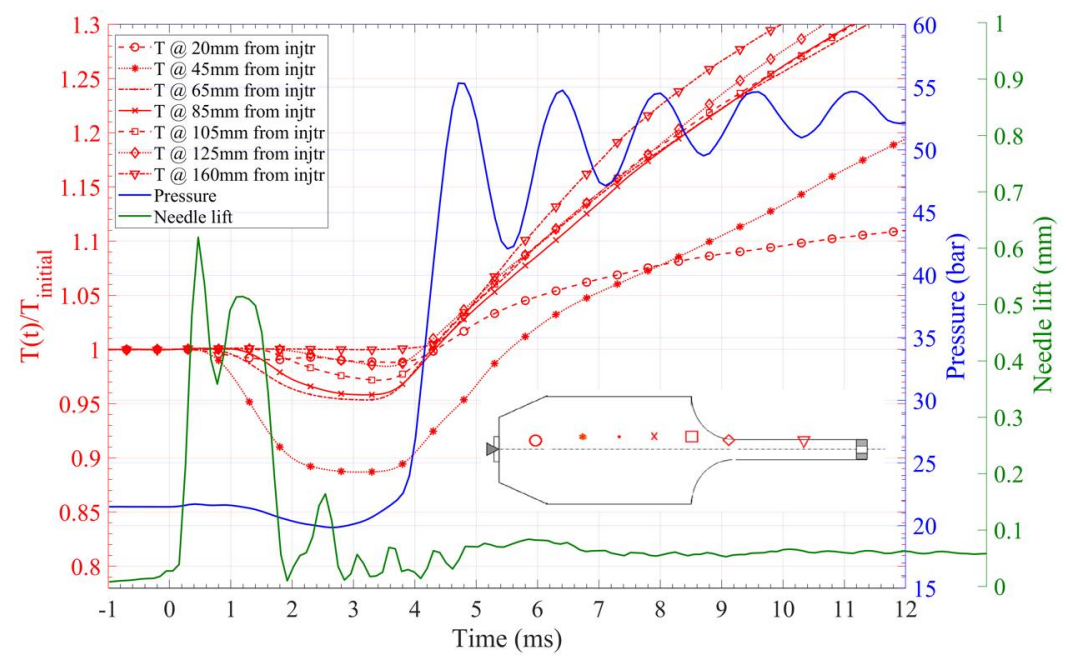

(a) 21.4 bar and $590^{\circ} \mathrm{C}$

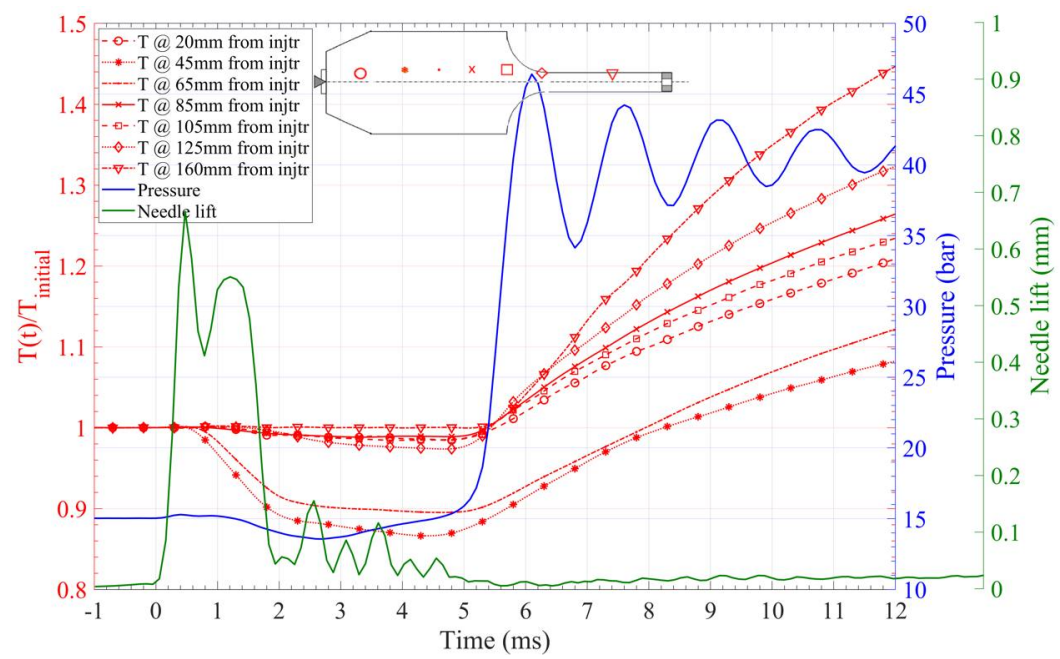

(b) 15 bar and $570^{\circ} \mathrm{C}$

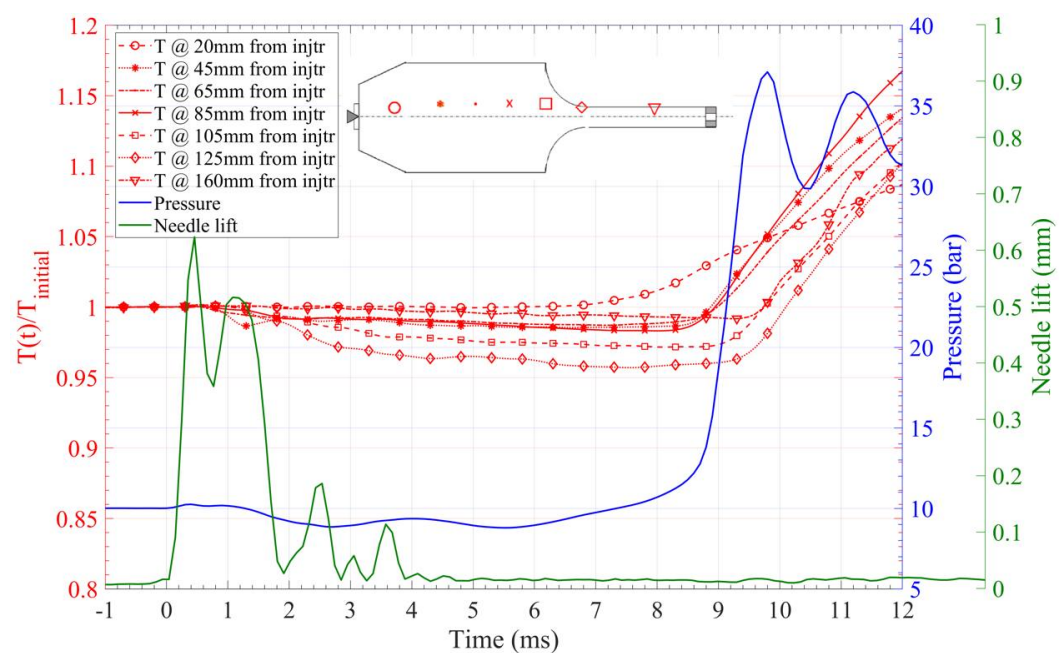

(c) $10 \mathrm{bar}$ and $530^{\circ} \mathrm{C}$

Figure 4.12: Temperature variations with time at $r=8 \mathrm{~mm}$ with different locations from injector plane, and at different initial pressure and temperature 
The results of front and back TCs are presented on the Figures 4.15 and 4.16 . The TCs at front did not record any drop in temperature during injection time. The sharp or rapid increase in temperature was mentioned at low pressure and temperature conditions (Figure 4.15c) only which again gives an evidence of fuel vapor moving back to the front port of chamber before combustion initiation. The temperature at the other two higher pressure and temperature conditions shown on the Figures $4.15 \mathrm{a}$ and $4.15 \mathrm{~b}$ did not vary significantly and there is a moderate increase after ignition. The trend of the TR lines shown in Figure 4.16 are similar and the conditions have no significant effect on them. 


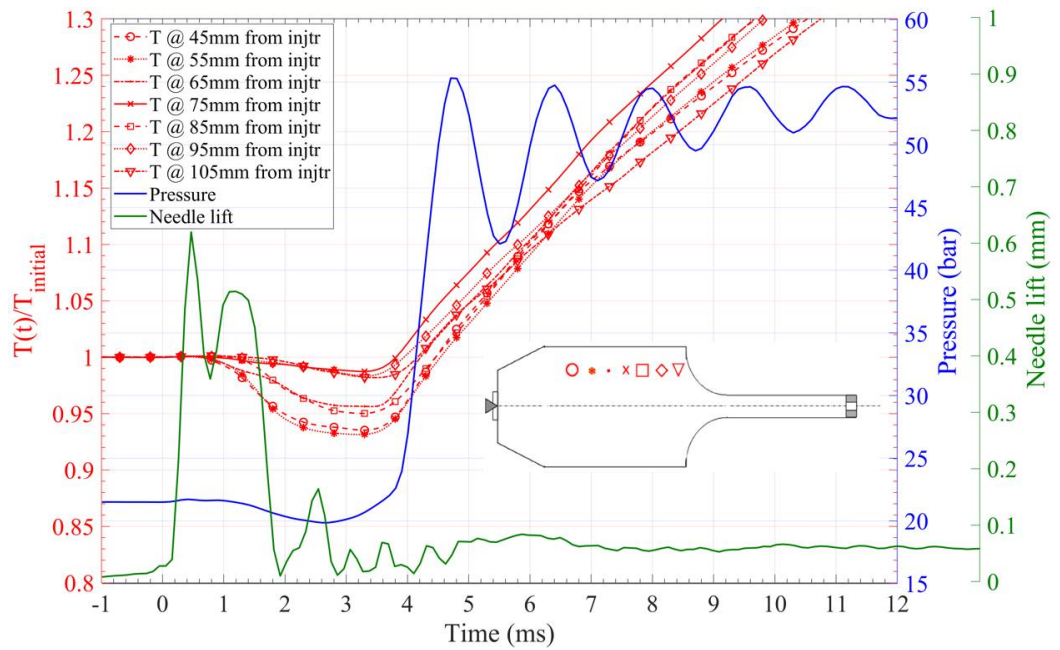

(a) 21.4 bar and $590^{\circ} \mathrm{C}$

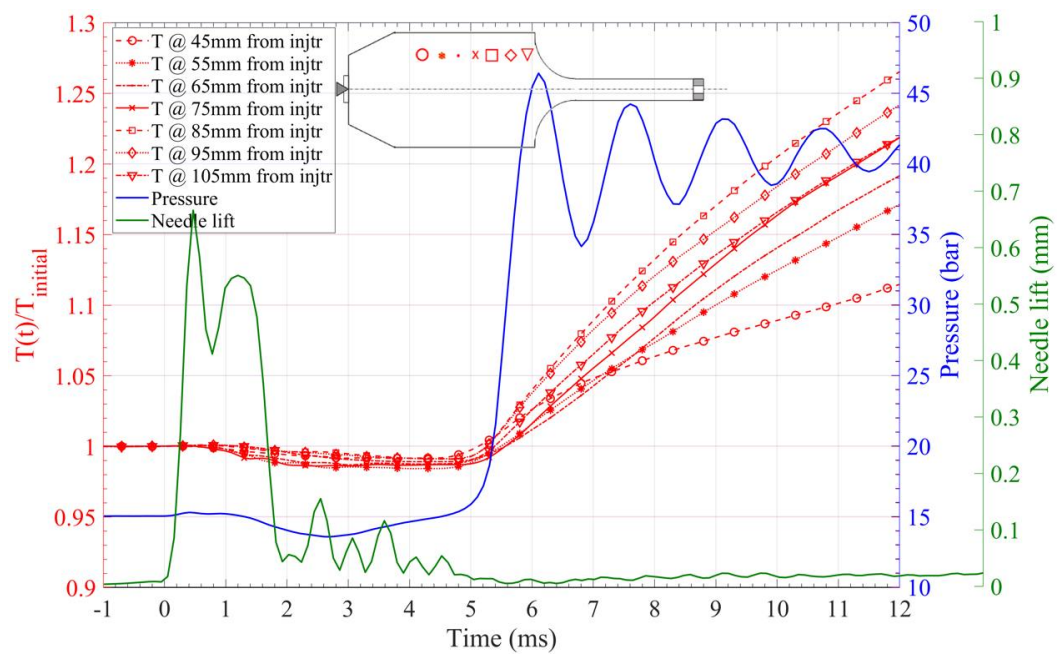

(b) 15 bar and $570^{\circ} \mathrm{C}$

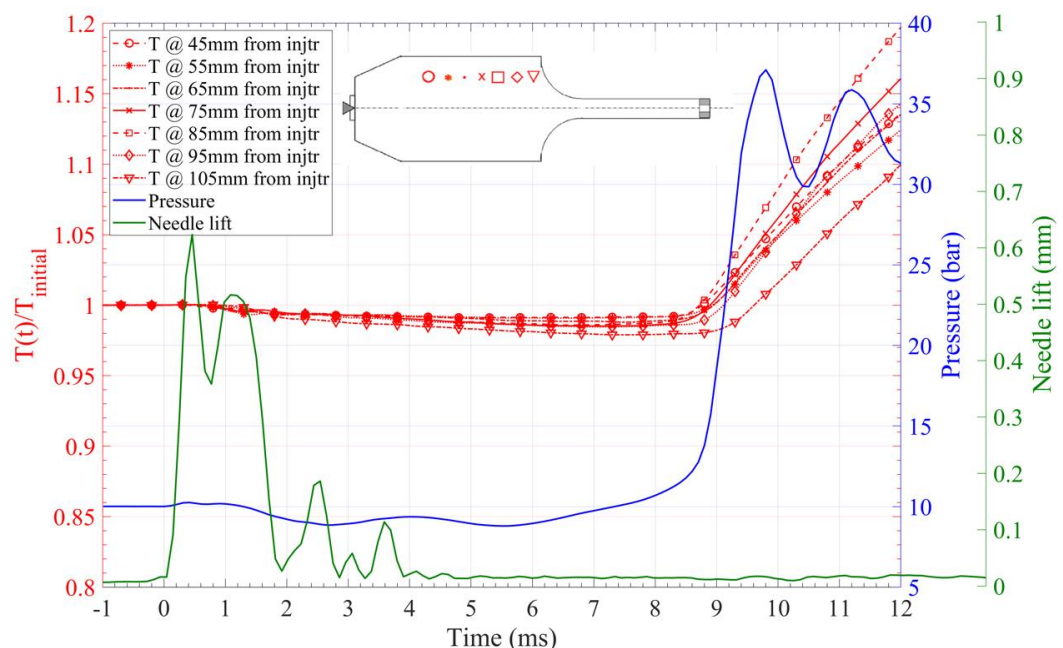

(c) $10 \mathrm{bar}$ and $530^{\circ} \mathrm{C}$

Figure 4.13: Temperature variations with time at $r=16 \mathrm{~mm}$ with different locations from injector plane, and at different initial pressure and temperature 


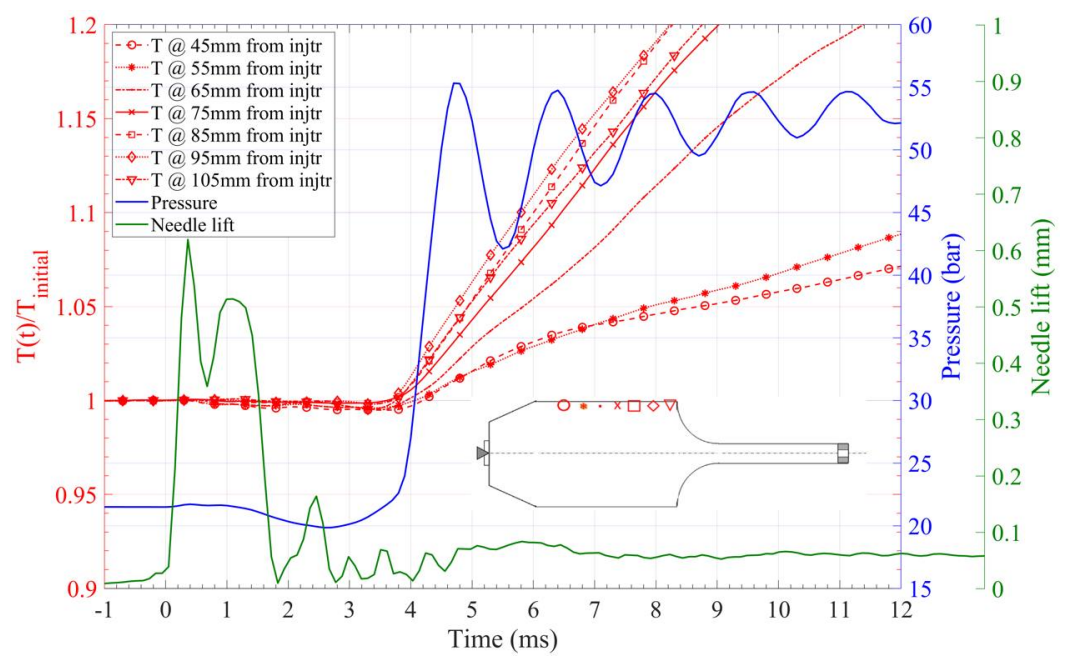

(a) 21.4 bar and $590^{\circ} \mathrm{C}$

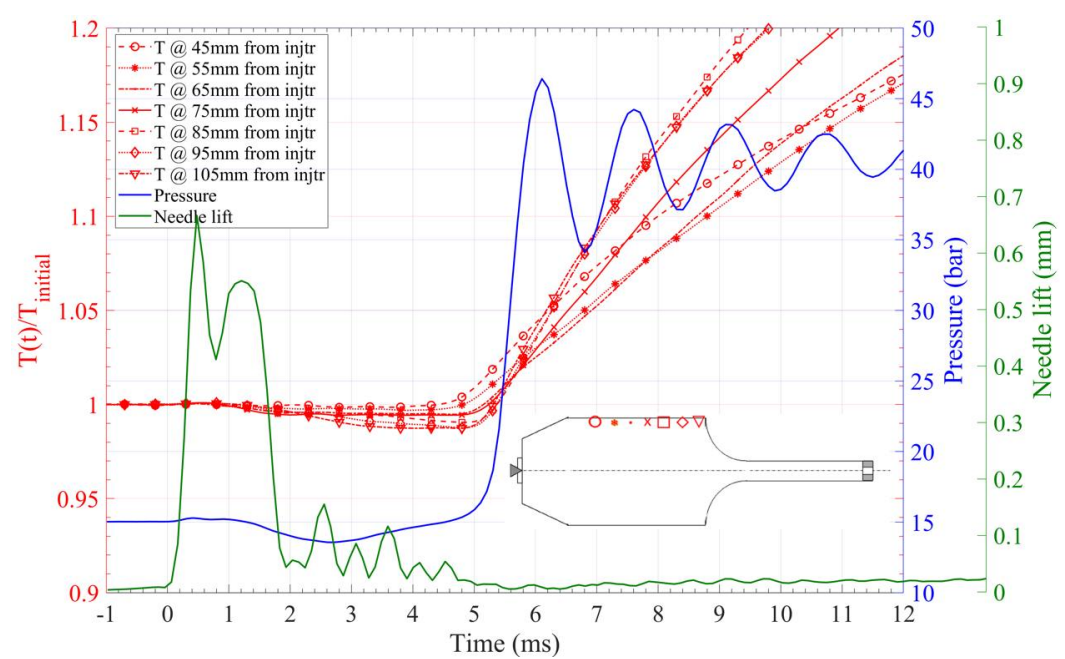

(b) 15 bar and $570{ }^{\circ} \mathrm{C}$

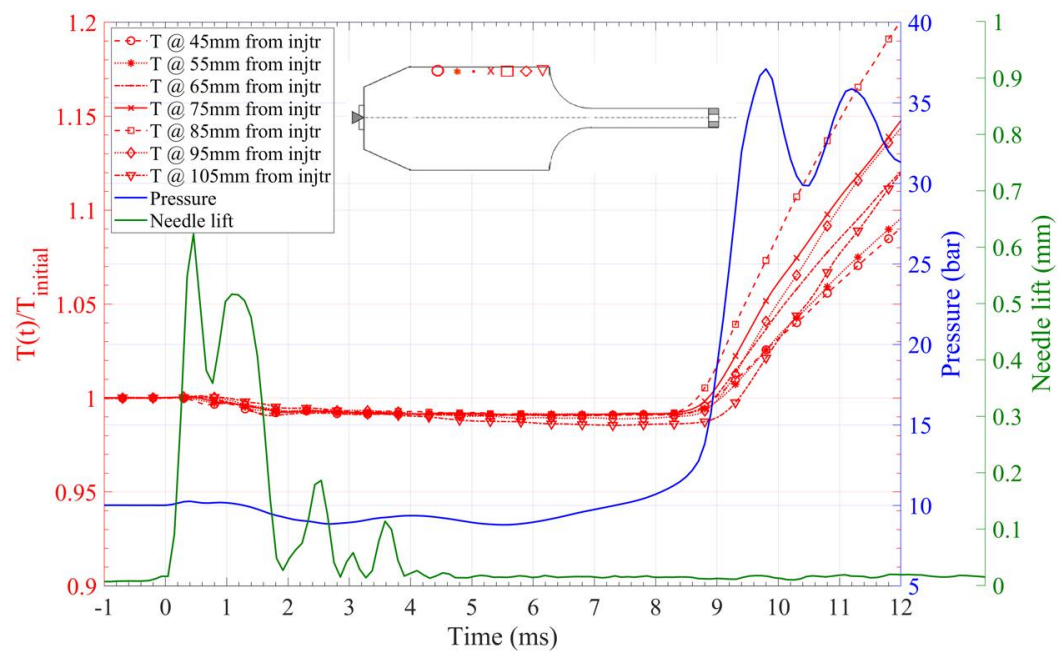

(c) 10 bar and $530^{\circ} \mathrm{C}$

Figure 4.14: Temperature variations with time at $r=24 \mathrm{~mm}$ with different locations from injector plane, and at different initial pressure and temperature 


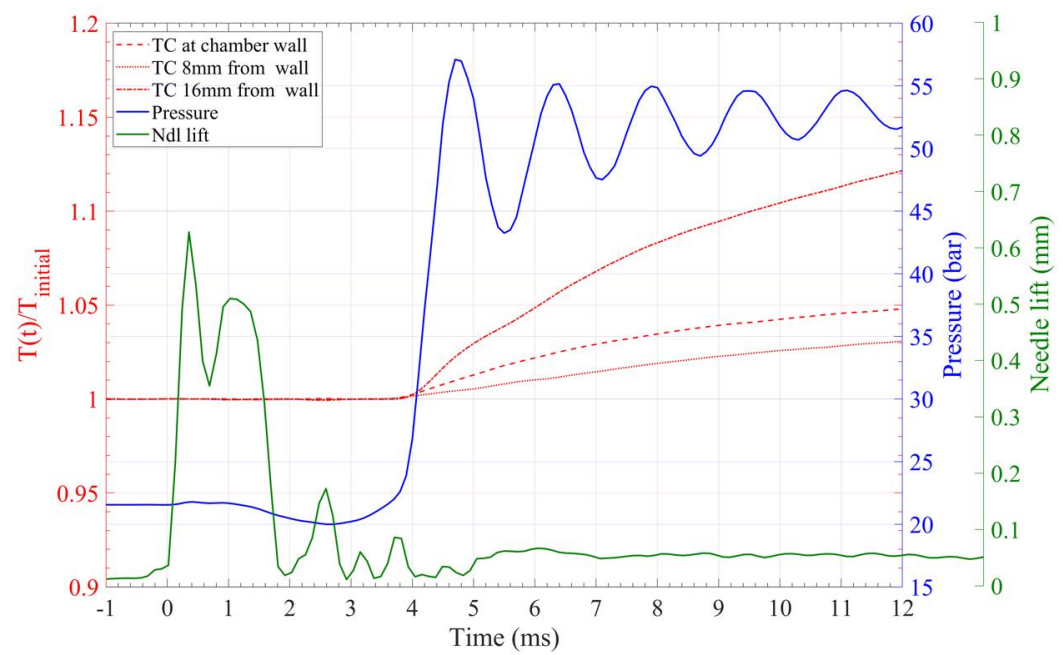

(a) 21.4 bar and $590^{\circ} \mathrm{C}$

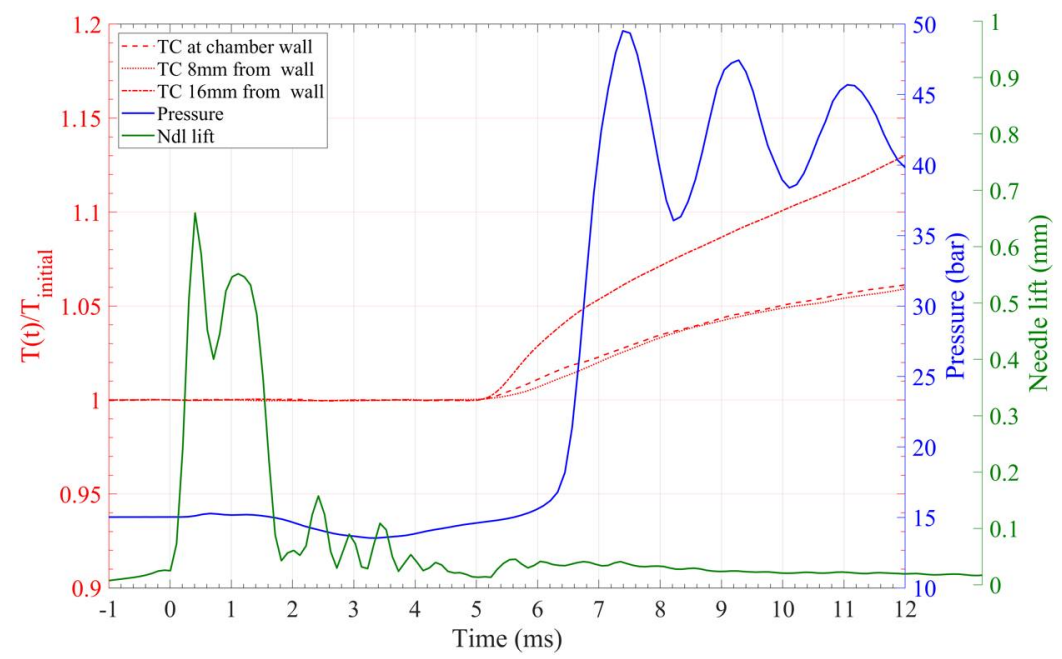

(b) $15 \mathrm{bar}$ and $570^{\circ} \mathrm{C}$

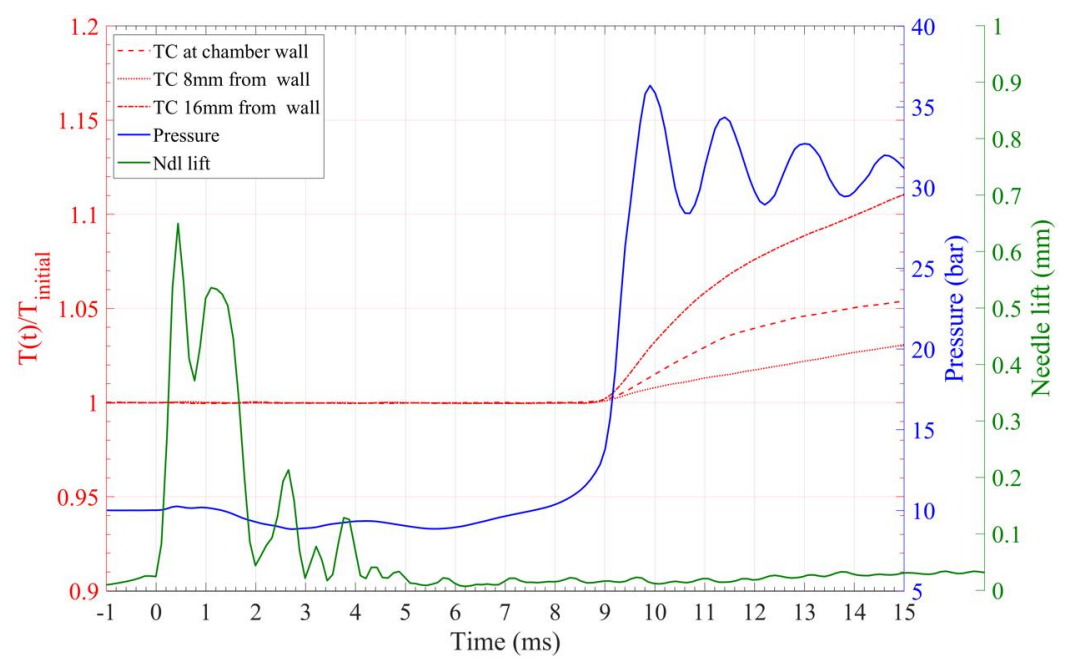

(c) 10 bar and $530^{\circ} \mathrm{C}$

Figure 4.15: Temperature variations with time at FRONT port with different initial pressure and temperature 


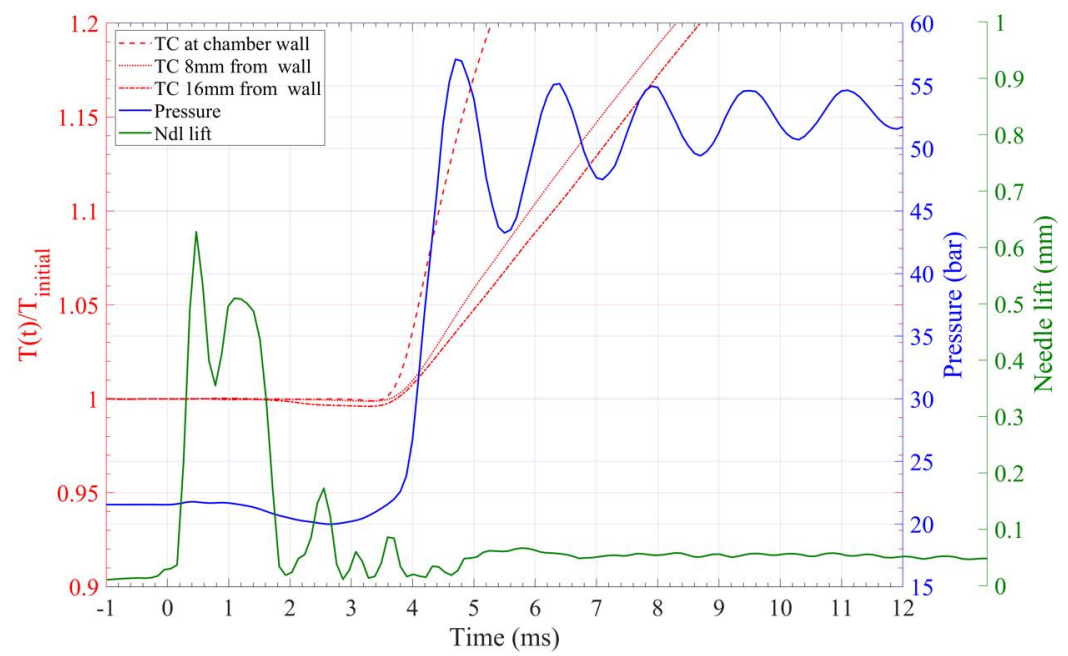

(a) $21.4 \mathrm{bar}$ and $590^{\circ} \mathrm{C}$

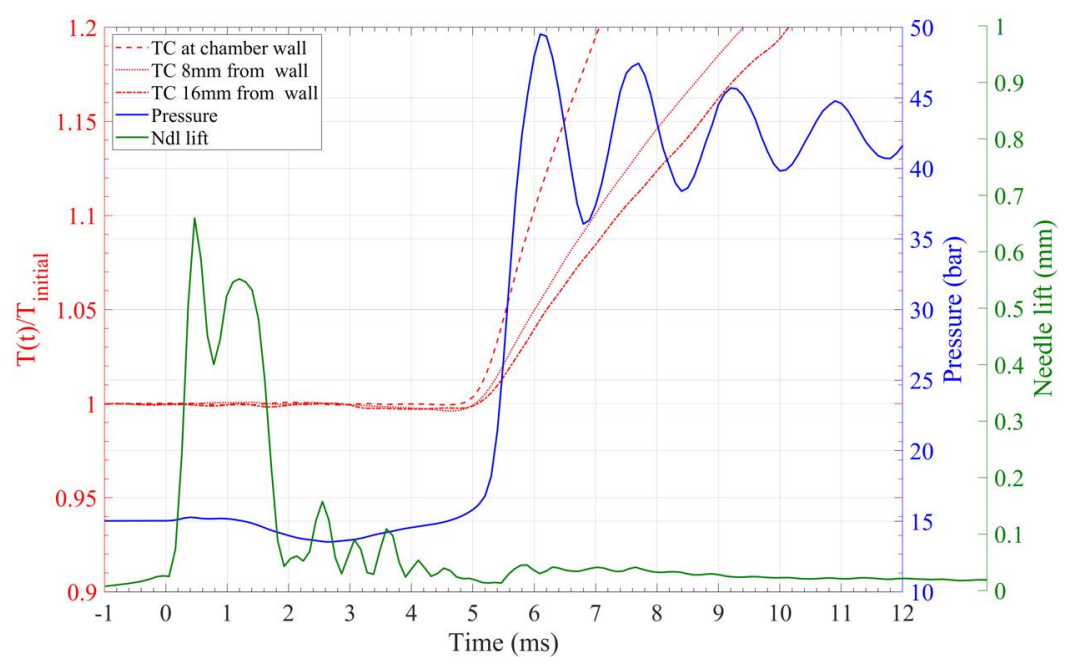

(b) 15 bar and $570^{\circ} \mathrm{C}$

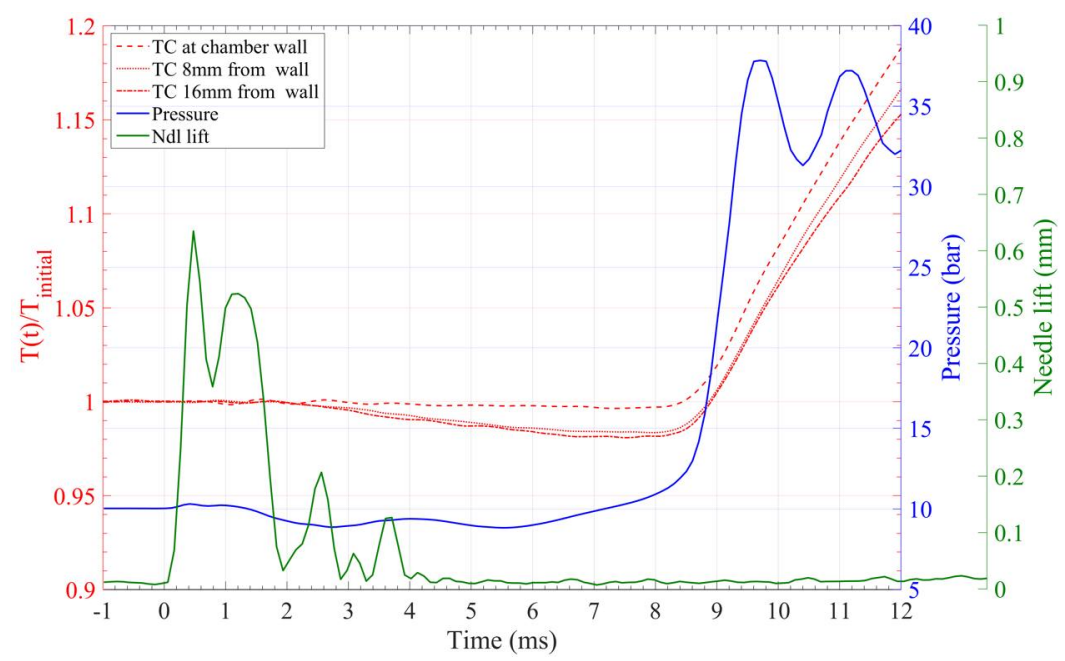

(c) 10 bar and $530^{\circ} \mathrm{C}$

Figure 4.16: Temperature variations with time at BACK port with different initial pressure and temperature 


\subsection{Comparison of $\mathrm{n}$-heptane Injection into Air and into Nitrogen}

The second set of experiments involved injecting n-heptane into nitrogen with no combustion. These tests were conducted to monitor the temperature and pressure variations for a period equal to the correspondence ignition delay time of the same initial pressure and temperature conditions. The same procedure of heptane injection into air was repeated here, except into nitrogen rather than air and for the number of injections per run. The run of 20 injections stops after the first injection and generates a run-time error message, as there is no combustion so the system cannot continue. A command is immediately sent to the exhaust valve to release the trapped $N_{2}$ and heptane, and chamber is purged. Thus, the data of one injection could be collected by the data acquisition system. This process is repeated three times, to ensure the chamber is thermally stable between the repeats. The data of three injections into $N_{2}$ were collected and analyzed. The same Matlab codes used with the air injections (i.e. combustion case) are applied here. The data of the three injections is filtered and averaged in this section.

The experiments were conducted for all 15 conditions, at 13 planes per condition. However, the results of one location (the chamber centerline $85 \mathrm{~mm}$ from the injector) were selected to compare the temperature and pressure variations when injecting heptane into air or $N_{2}$, as shown in Figure 4.17. The solid red and dashed lines in the figure represent the temperature ratio $\left(T(t) / T_{\text {initial }}\right)$ variation for n-heptane injection into air and $N_{2}$, respectively. The representation is also applied for the pressure using a blue line.

With injection into $N_{2}$ case, the temperature profiles showed a sharp drop due to the cooling effect of the spray droplets. The temperature remained unchanged or had slight drop over time. The period from fuel injection to the end of the temperature drop is 
defined here as the fuel evaporation and mixing with $N_{2}$ (physical ignition delay). With the injection into the air case, the temperature had a similar profile up to the point of sudden increase, which is defined as the end of the total ignition delay. 


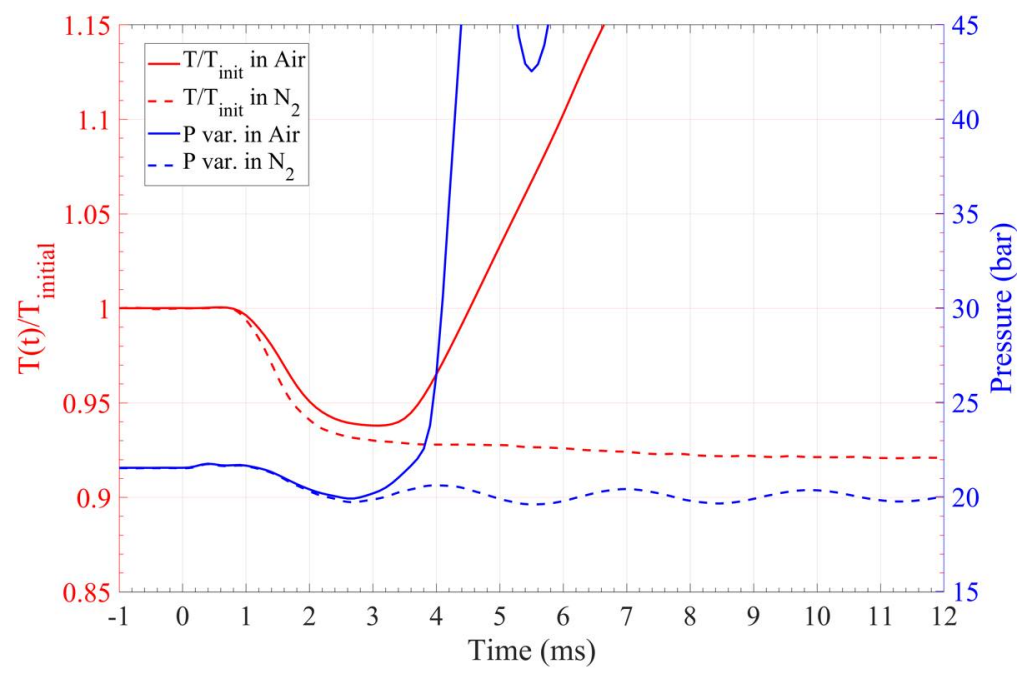

(a) $21.4 \mathrm{bar}$ and $590^{\circ} \mathrm{C}$

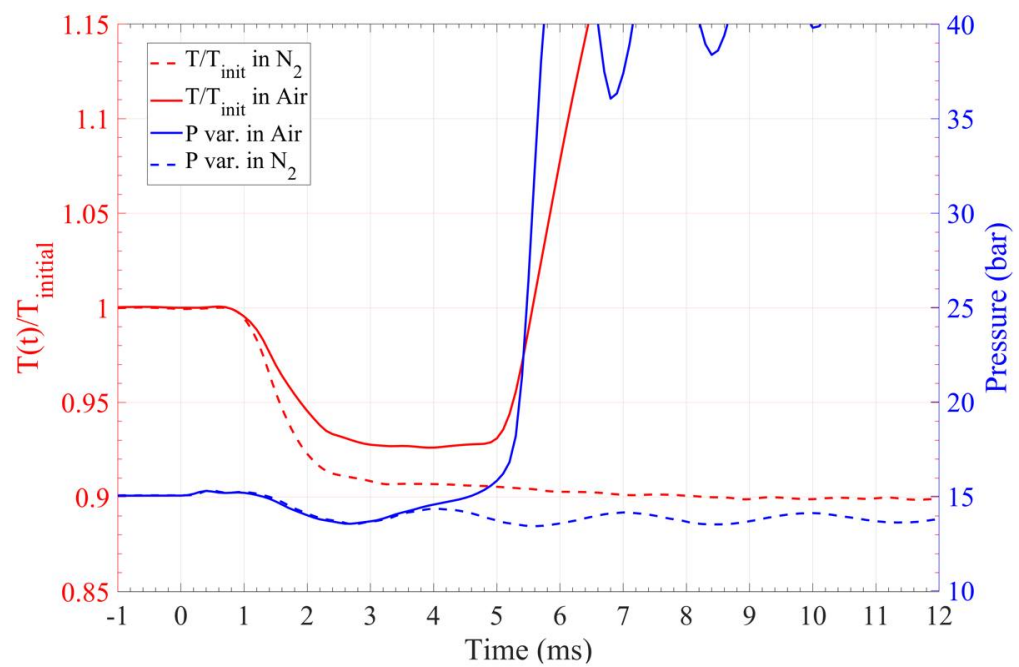

(b) 15 bar and $570^{\circ} \mathrm{C}$

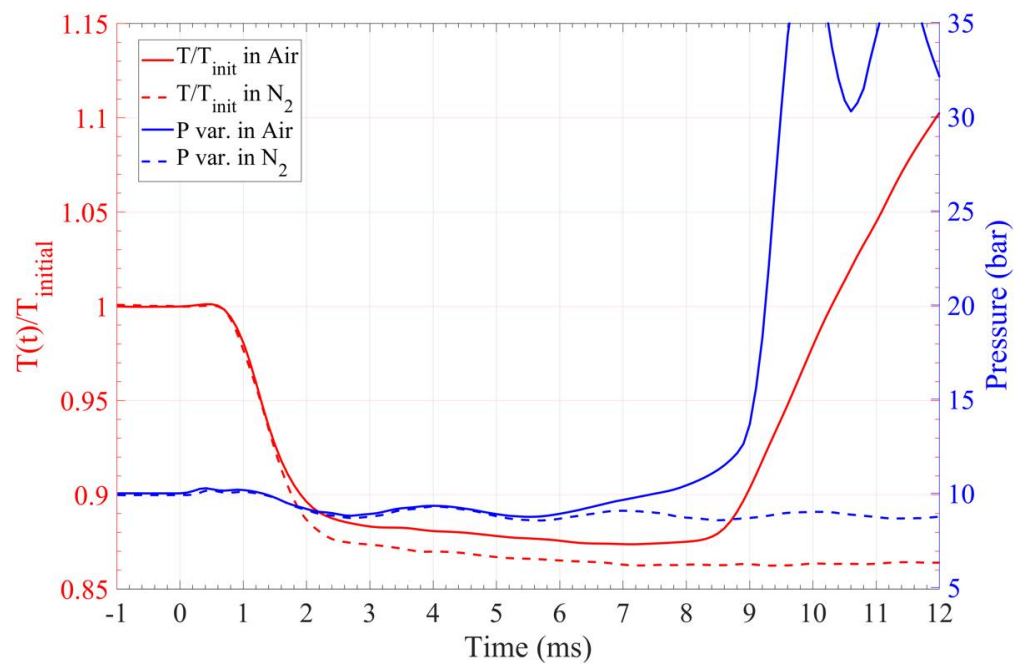

(c) $10 \mathrm{bar}$ and $530{ }^{\circ} \mathrm{C}$

Figure 4.17: Comparison of temperature and pressure variations at chamber centerline and $85 \mathrm{~mm}$ from injector for heptane injection into air and into nitrogen 


\section{Chapter 5}

\section{Ignition Delay and Spray \\ Characteristics Predictions}

In this chapter, the temperature measurement data from Chapter 4 is used to analyze the spray injection and combustion of n-heptane. A newly developed method of ignition delay based on temperature variation is introduced here and the results are compared to the pressure base ignition delay. The spray characteristics (i.e. spray penetration length and velocity, and spray cone angle) are also predicted from the temperature variations.

\subsection{Ignition Delay Calculations from Temperature Mea- surements}

Ignition delay calculations in the $I Q T^{T M}$ and other apparatus are based on pressure measurements. In this section, temperature measurement is introduced to obtain the ignition delay, as shown in Figure 5.1. The temperature measured by a TC at the chamber centerline $75 \mathrm{~mm}$ from injector plane was used to explain this method of ID calculation which is known as the temperature method $\left(I D_{T M}\right)$. The $I D_{T M}$ period is 
divided into three main periods (t1, t2, and $\mathrm{t} 3$ ), from which $\mathrm{t} 4$ and $\mathrm{t} 5$ are calculated.

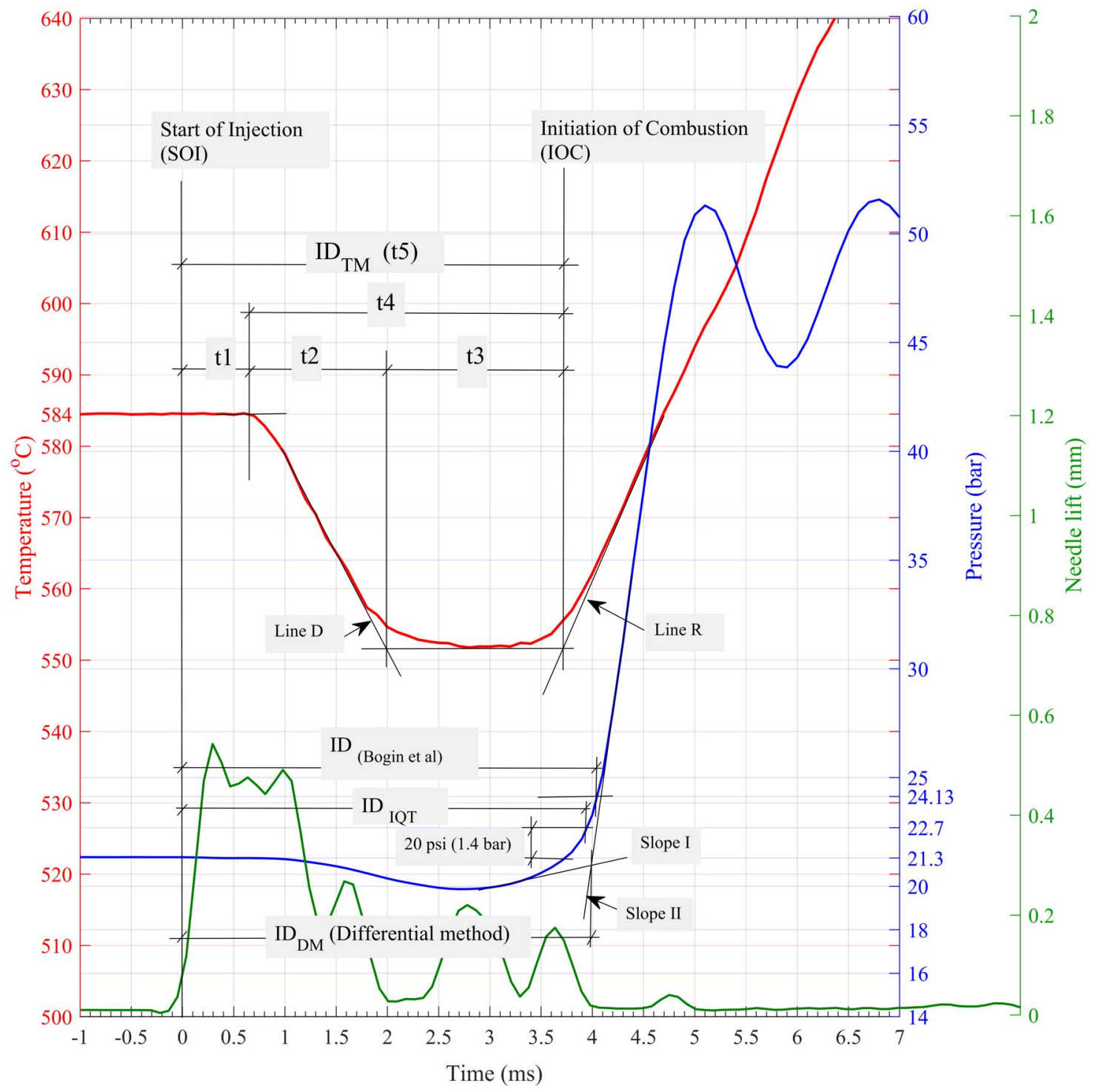

Figure 5.1: Temperature method for calculating ignition delay from temperature variation at chamber centerline, and ID by pressure; $P=21.4 \mathrm{bar}$, and $T=584^{\circ} \mathrm{C}$; and TC is located at chamber centerline with $75 \mathrm{~mm}$ from injector

t1 is the period from the start of injection (SOI) to the point where the temperature starts to drop due to the cooling effects of the fuel spray. This is followed by the t2 period, 
which represents the local physical ID at the corresponding location of measurement. The end of $\mathrm{t} 2$ is determined at the intersection point between line $\mathrm{D}$, which represents the best fit line of the data during the temperature drop, and the horizontal line that passes through a point of minimum temperature. With t3, the chemical ID at the corresponding location of measurement, is the last period prior to mixture ignition. The initiation of combustion (IOC) at the end of $\mathrm{t} 3$ is at the intersection point between the horizontal line of minimum temperature, and line $\mathrm{R}$ which represents the best fit line of the data during temperature rise. $t 5$ is the total ID from the temperature method and it is equal to the total of $\mathrm{t} 1$, local physical ID (t2), and chemical ID (t3). $\mathrm{t} 4$ is defined as a local ID at the measurement point.

The ID is also calculated in the other three methods (i.e. IQT, Bogin et al, and differential method) using a pressure variation curve as shown in Figure 5.1 and explained in reference [56]. The ignition delays and time periods shown in Figure 5.1 are presented numerically in Table 5.1. A MATLAB code was created to manage all the ignition delay calculations, in both the temperature and pressure methods. A linear least-squares fitting with robust least-squares built in functions of MATLAB were used in the code to get the best linear fit from the data during temperature drop and temperature rise.

\begin{tabular}{|l|l|c|}
\hline & Period name & time $(\mathrm{ms})$ \\
\hline \multirow{5}{*}{ Temperature based ID method } & $\mathrm{t} 1$ & 0.66 \\
\cline { 2 - 3 } & $\mathrm{t} 2:\left(I D_{\text {phys }}\right)_{\text {local }}$ & 1.32 \\
\cline { 2 - 3 } & $\mathrm{t} 1+\mathrm{t} 2: I D_{\text {phys }}$ & 1.98 \\
\cline { 2 - 3 } & $\mathrm{t} 3: I D_{\text {chem }}$ & 1.74 \\
\cline { 2 - 3 } & $\mathrm{t} 4$ & 3.06 \\
\cline { 2 - 3 } & $\mathrm{t} 5: I D_{T M}$ & 3.72 \\
\cline { 2 - 3 } & $I D_{T M}=I D_{\text {phys }}+I D_{\text {chem }}$ & 3.72 \\
\hline \multirow{4}{*}{ Pressure based ID methods } & $I D_{I Q T}$ & 3.98 \\
\cline { 2 - 3 } & $I D_{\text {Bogin }}$ & 4.09 \\
\cline { 2 - 3 } & $I D_{D M}$ & 4.03 \\
\hline
\end{tabular}

Table 5.1: Numeric of the IDs for the analysis shown in Figure 5.1 


\subsection{Uncertainty Analysis of Ignition Delay by Temper- ature Variation}

The uncertainty analysis of the TCs shown in Section 3.8 was for a steady state temperature measurements prior to the fuel injection. The uncertainty analysis of the estimated ignition delay from temperature measurements is presented in this section. The analyses were conducted at two initial conditions (10 bar and $530^{\circ} \mathrm{C}$, and $21.4 \mathrm{bar}$ and $590^{\circ} \mathrm{C}$ ) on the data at two locations inside the IQT chamber: both were $105 \mathrm{~mm}$ from the injector and one location was on the chamber centerline and the other location was $16 \mathrm{~mm}$ in radial direction. Same procedure and equations were used, where the total bias uncertainty from Equation 3.2 and data in Table 3.1 equals $0.823 \%$. The total random uncertainty of the $I D_{T M}$ was calculated from the estimated $I D_{T M}$ for each injection. The total number of repeats (injections) is 15 . The temperature data of each injection was filtered first by using a MATLAB code and then the $I D_{T M}$ is estimated. The standard deviation equation (Equation 3.3) was used to obtain the total random uncertainty. Table 5.2 summarizes the total uncertainty as a percentage and in ms. The total uncertainty is around $5 \%$ which is relatively high compared to the total uncertainty of TCs. That is because the process of fuel injection and ignition is not identical for all injections and the combustion does not onset (initiate) at the same location for all injections. Also, the amount of the injected fuel is not exactly the same for all injections.

\begin{tabular}{|c|c|c|c|}
\hline Pressure and temperature & Radial location (mm) & Total uncert. (\%) & Total uncert. (ms) \\
\hline \hline \multirow{2}{*}{10 bar and $530{ }^{\circ} \mathrm{C}$} & 0 & 5.07 & 0.46 \\
\cline { 2 - 4 } & 16 & 5.59 & 0.51 \\
\hline \multirow{2}{*}{21.4 bar and $590^{\circ} \mathrm{C}$} & 0 & 5.42 & 0.20 \\
\cline { 2 - 4 } & 16 & 4.97 & 0.19 \\
\hline
\end{tabular}

Table 5.2: Uncertainty of the $I D_{T M}$ for two conditions of pressure and temperature, and at two locations inside the IQT 


\subsection{Local Physical Ignition Delay by Temperature Method}

The results of the local physical ignition delay $\left(\left(I D_{\text {phys }}\right)_{\text {local }}\right)$ by the temperature method explained in Section 5.1, are illustrated in Figures 5.2 to 5.4. The results of 9 conditions of 15 are presented here. The height of the gray strip at chamber boundaries represents the total ignition delay based on the pressure measurements for the corresponding initial conditions in the figure title.

The $\left(I D_{\text {phys }}\right)_{\text {local }}$ is presented as colored columns on the $3 \mathrm{~d}$ plots. The axes of the horizontal plane are the longitudinal (axial) and radial directions, and are used to indicate the locations of measurements. The height of the columns represents the estimated lifetime of the spray at the corresponding locations or simply $\left(I D_{\text {phys }}\right)_{\text {local }}$.

In general, the $\left(I D_{\text {phys }}\right)_{\text {local }}$ values decrease as the temperature and pressure increase, as shown in Figures $5.2 \mathrm{a}$ and $5.4 \mathrm{c}$. The $\left(I D_{\text {phys }}\right)_{\text {local }}$ values decrease in the direction of the spray propagation along the chamber centerline up to the end of main part of the chamber (i.e. between 100 and $110 \mathrm{~mm}$ ); they then increase in the converging part of the chamber. No temperature drop was recorded by the last 3 TCs at $160 \mathrm{~mm}$ from the injector in all conditions, so the $\left(I D_{\text {phys }}\right)_{\text {local }}$ has zero values there. Although there was a slight temperature drop recorded near the chamber wall, the $\left(I D_{\text {phys }}\right)_{\text {local }}$ exists near chamber wall (at $r=24 \mathrm{~mm}$ ), particularly at low pressure conditions (Figures 5.2 and 5.3 , and it disappeared gradually at 21 bar, as shown in Figure 5.4 .

It is worth noticing that, compared to other locations, the $\left(I D_{\text {phys }}\right)_{\text {local }}$ values are relatively high at locations around $100 \mathrm{~mm}$ of axial direction. This could be due to the turbulence and collisions between the spray traveling around the chamber centerline with the radial dispersed spray droplets. The locations at $r=8 \mathrm{~mm}$ (the $2^{\text {nd }}$ longitudinal row in the main part of chamber) have the lowest values of $\left(I D_{\text {phys }}\right)_{\text {local }}$ compared to the other two rows at $r=0 \mathrm{~mm}$ and $r=16 \mathrm{~mm}$, as shown in Figures 5.4a and 5.4b. This means that less fuel spray passes through this area, indicating that the spray has a hollow shape. Figure $5.4 \mathrm{c}$ did not show any $\left(I D_{\text {phys }}\right)_{\text {local }}$ near the chamber wall, or at the end 
of converging part of the chamber.

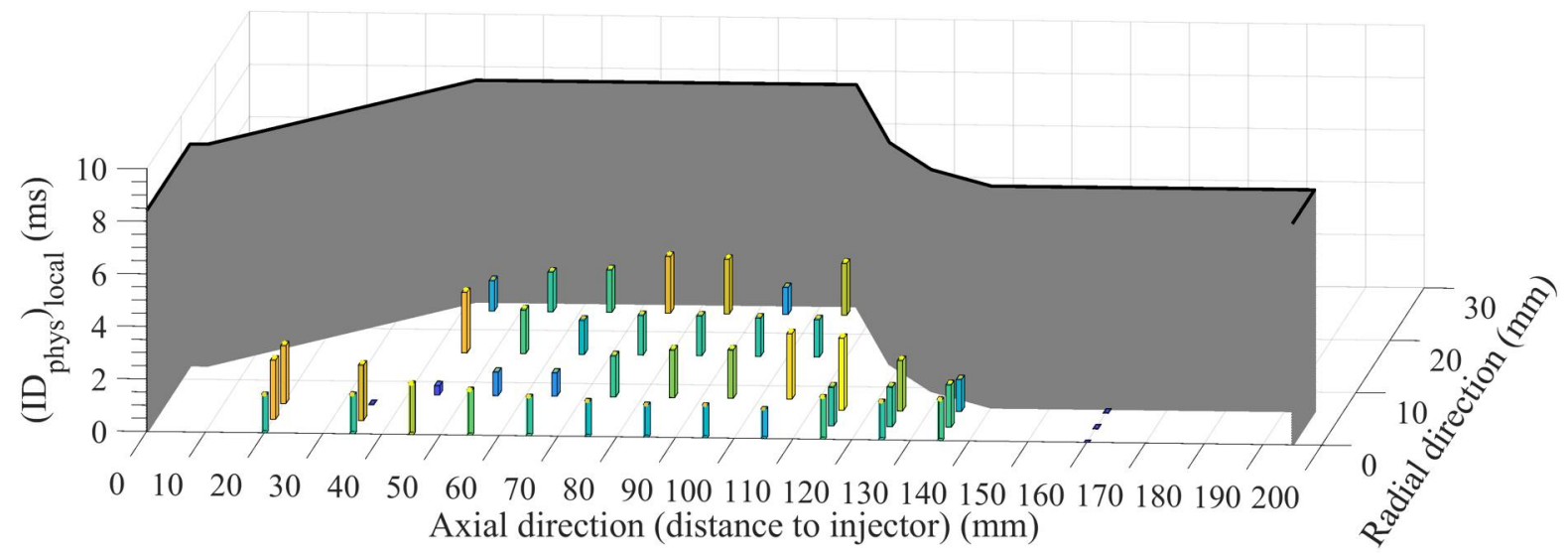

(a) $P=10$ bar, and $T=530^{\circ} \mathrm{C}$

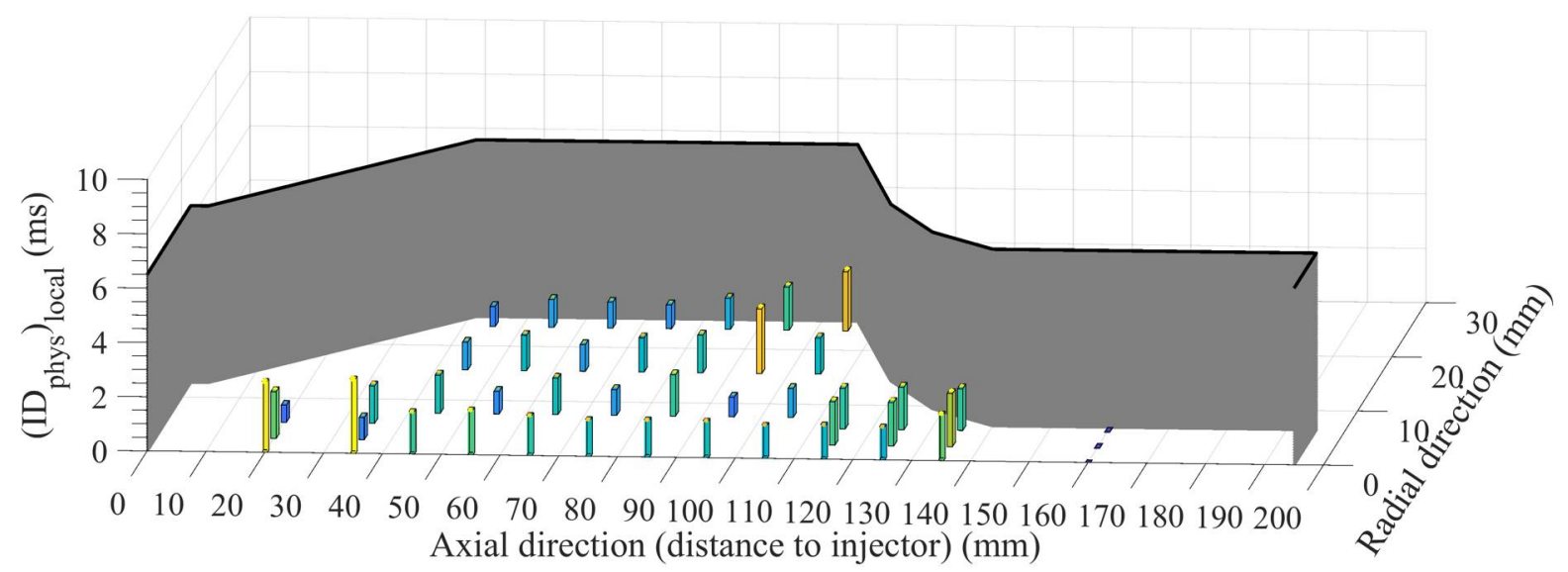

(b) $P=10$ bar, and $T=570^{\circ} \mathrm{C}$

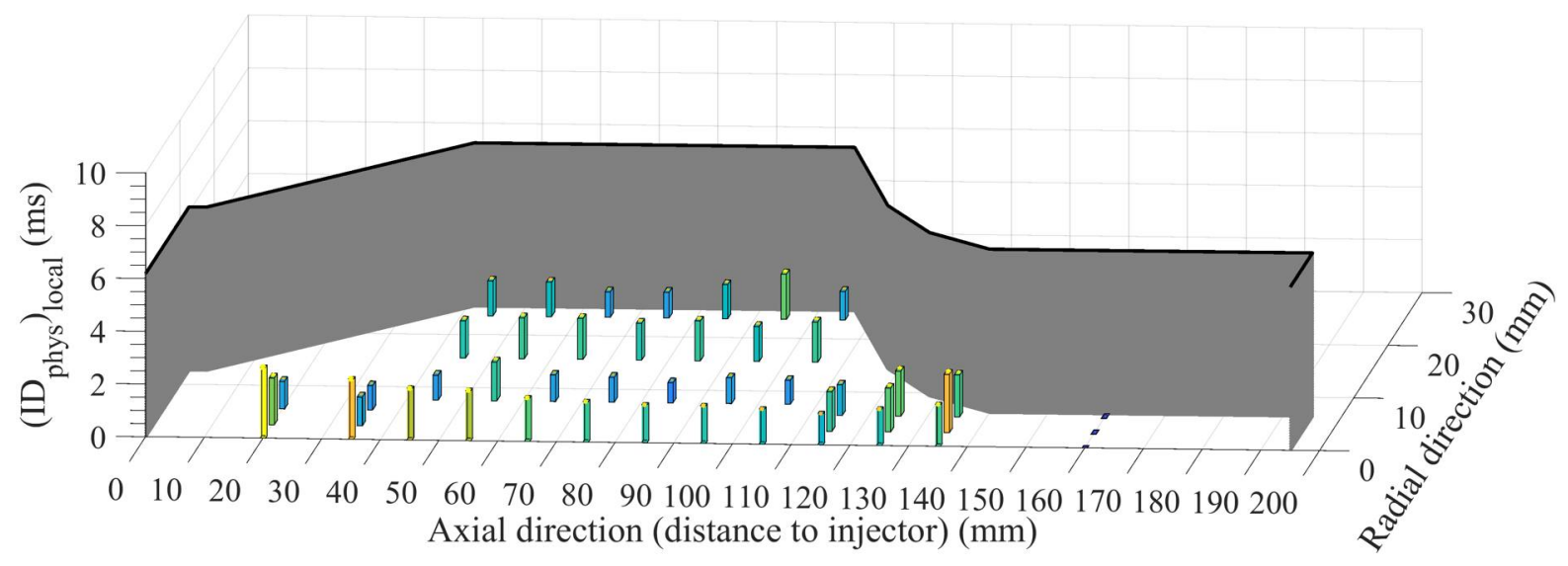

(c) $P=10$ bar, and $T=590^{\circ} \mathrm{C}$

Figure 5.2: Local physical ignition delay at different locations inside the IQT chamber at 10 bar and different initial temperatures 


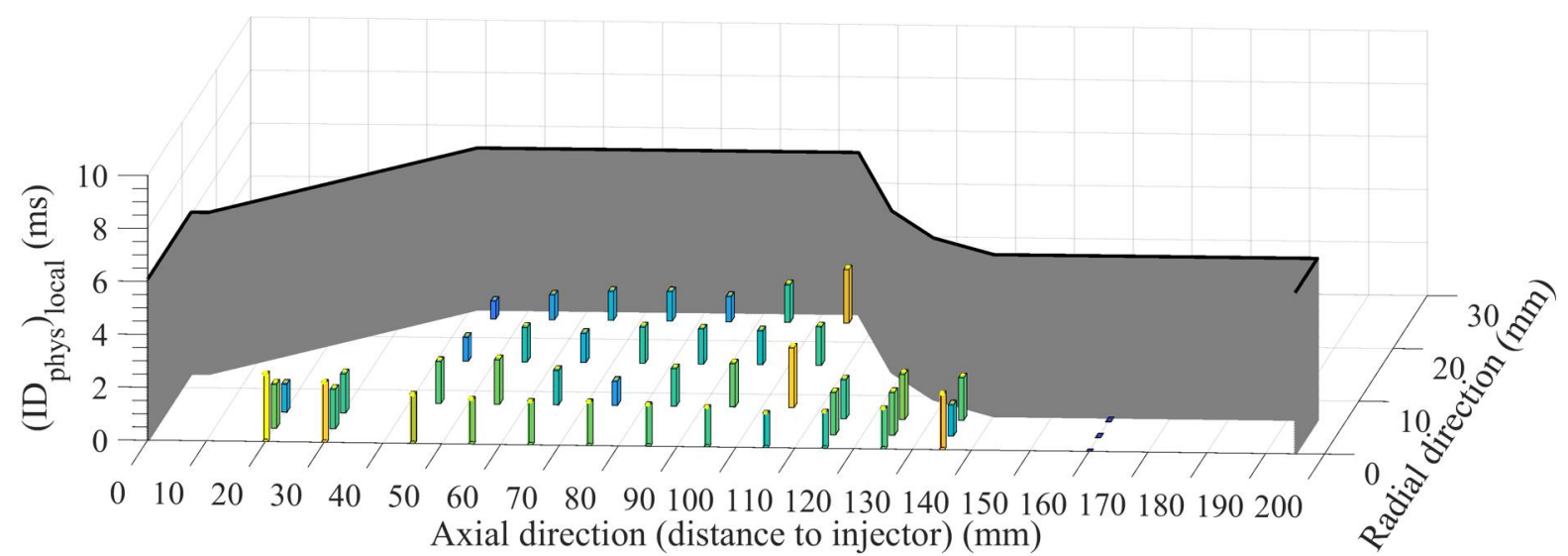

(a) $P=15$ bar , and $T=530^{\circ} \mathrm{C}$

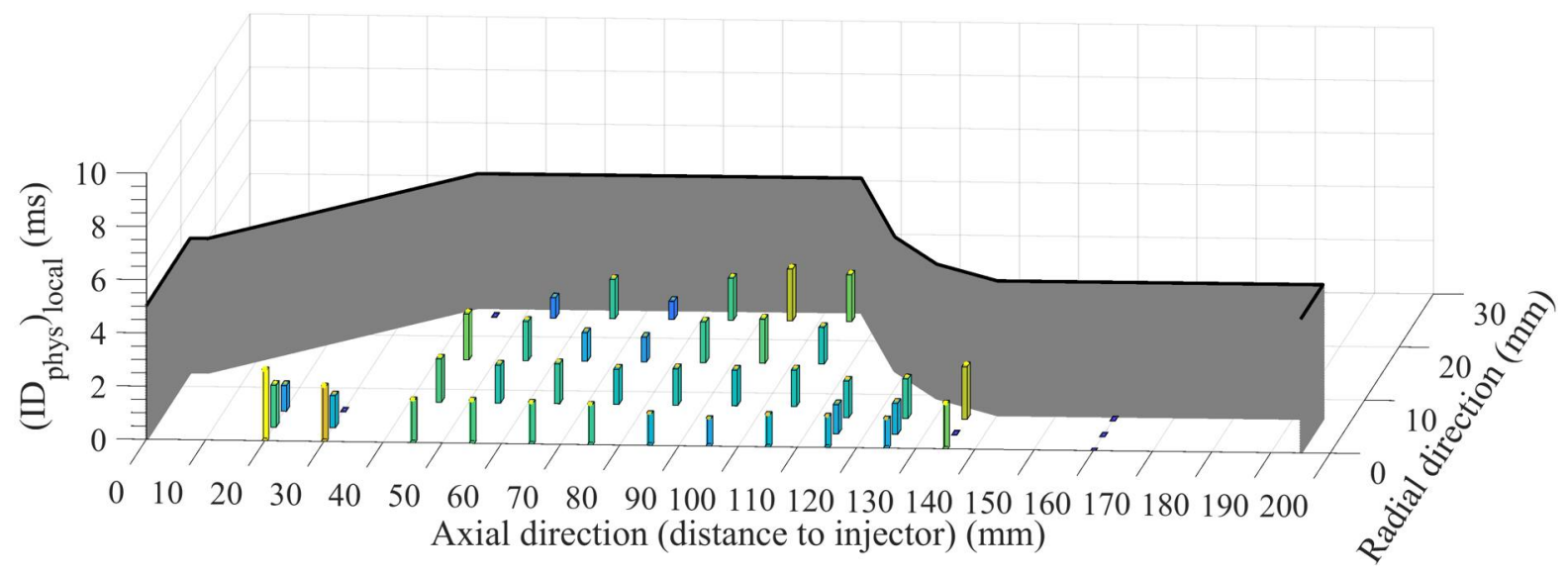

(b) $P=15$ bar, and $T=570^{\circ} \mathrm{C}$

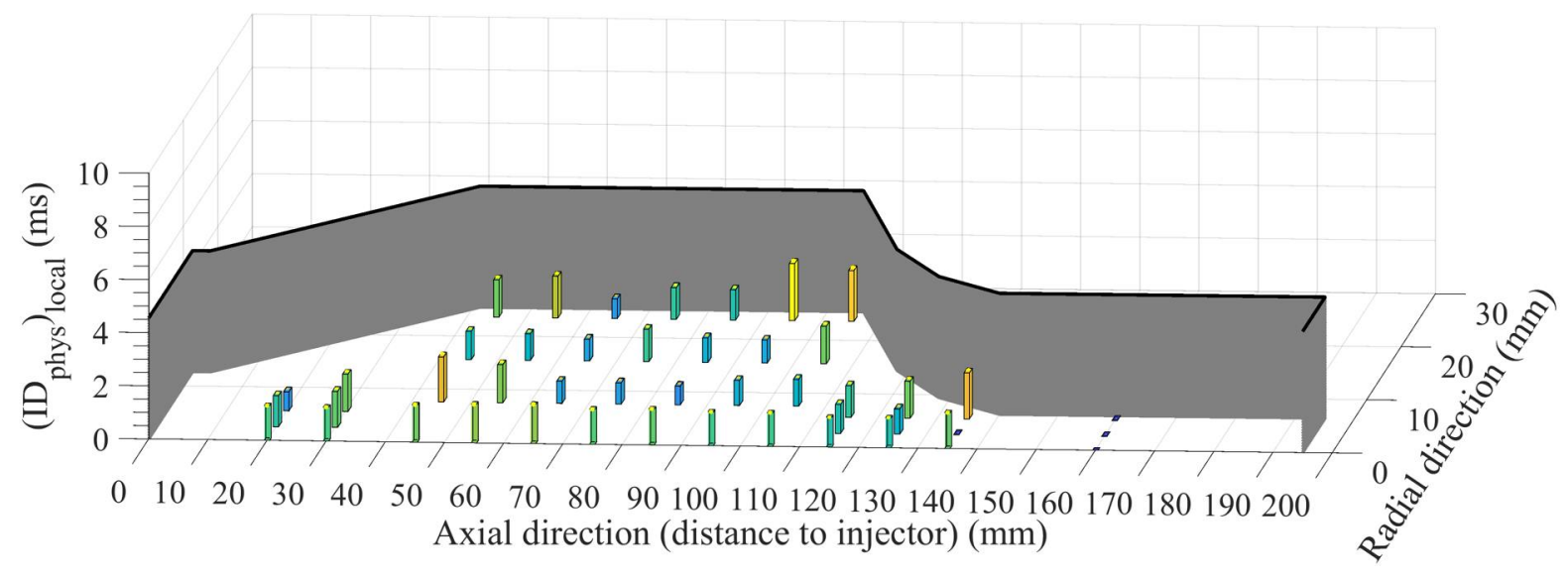

(c) $P=15$ bar, and $T=590^{\circ} \mathrm{C}$

Figure 5.3: Local physical ignition delay at different locations inside the IQT chamber at 15 bar and different initial temperatures 


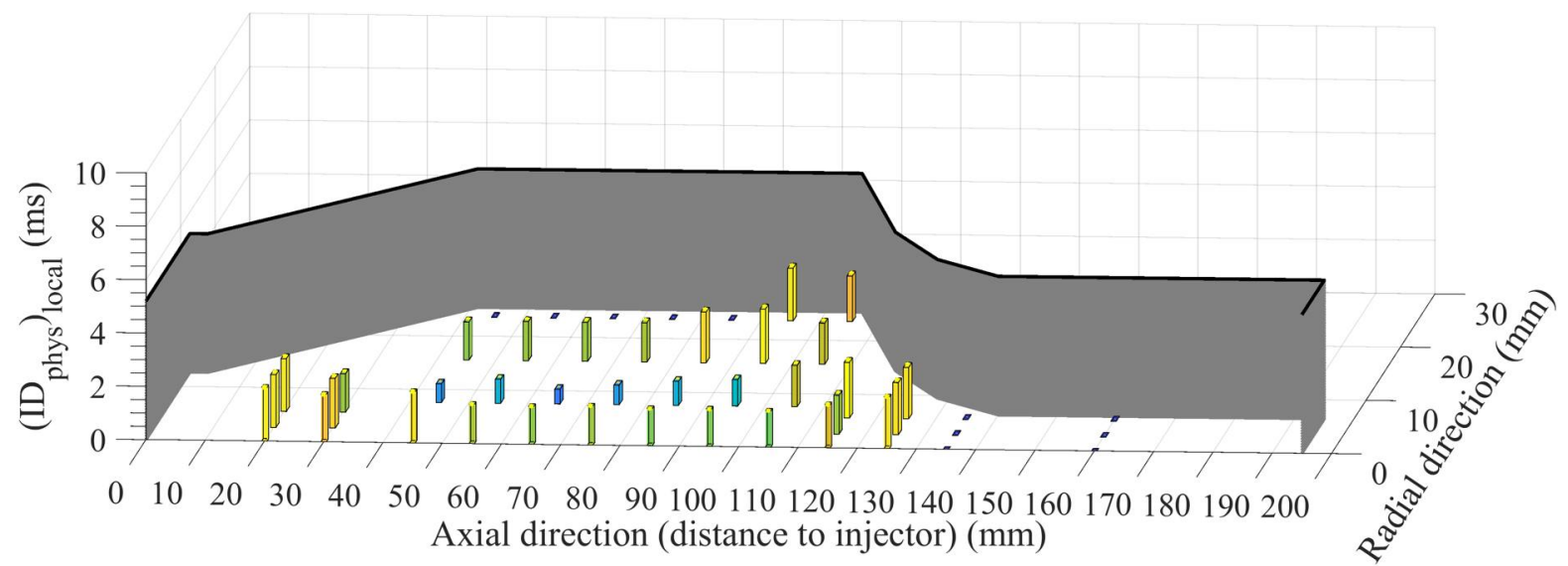

(a) $P=21$ bar, and $T=530^{\circ} \mathrm{C}$



(b) $P=21$ bar, and $T=570^{\circ} \mathrm{C}$

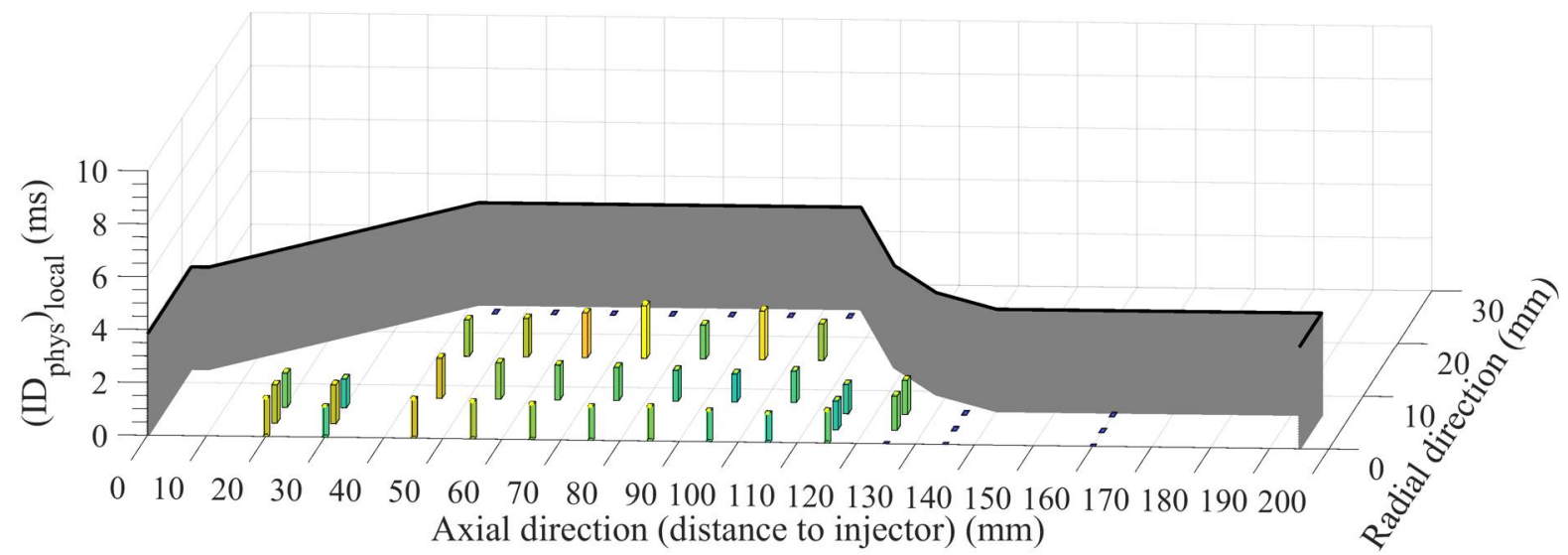

(c) $P=21$ bar, and $T=590^{\circ} \mathrm{C}$

Figure 5.4: Local physical ignition delay at different locations inside the IQT chamber at 21 bar and different initial temperatures 


\subsection{Ignition Delay as a Ratio between Temperature and Pressure Methods}

The ignition delay by the temperature method $I D_{T M}$ that was estimated from the spatial temperature variation during combustion process (see Section 5.1), is presented in this section as a ratio of the $I D_{T M}$ to the ignition delay calculated from the global pressure variations by three different methods [56] (named as $I D_{I Q T}, I D_{B o g i n}$, and $I D_{D M}$ ).

The 3D plots in Figures 5.5 to 5.13 illustrate the ignition delay ratio at different pressure and temperature conditions. Again, the axes on the base plane are used to allocate the position of measurement, and the vertical axis is the $I D$ ratio. The yellow plane at the $I D$ ratio equal to one is a reference for comparison, and the columns or bars with the colored bulbs (from blue for early combustion to yellow for late combustion) at the ends are for the ID ratio. In general, the combustion initiates at the locations with lower $I D_{T M}$ values.

As shown in Figure 5.5, at low pressure conditions almost all $I D_{T M}$ values are greater than the $I D_{I Q T}$, which means the combustion is first detected by pressure variation. Based on the $I D_{T M}$ values, the combustion initiates everywhere in the chamber, regardless of the initial temperature, which agrees with the observations in the compression ignition diesel engines. The combustion spreads from the main part of the chamber, with relatively lower values of $I D_{T M}$, to the tail and side wall areas which have relatively higher $I D_{T M}$ values. The values of the $I D_{T M}$ increase gradually toward the chamber tail area. Figure 5.6 shows the $I D_{T M} / I D_{I Q T}$ at 15 bar with three initial temperatures $\left(530,570\right.$, and $590^{\circ} \mathrm{C}$ ). At $530^{\circ} \mathrm{C}$ (Figure 5.6a), the $I D_{T M} / I D_{I Q T}$ values are still somewhat higher than one, and the values at the main part of the chamber are close to each

other; thus the combustion is initiated in the main part of the chamber. With the other 
two conditions (Figures $5.6 \mathrm{~b}$ and $5.6 \mathrm{c}$, most $I D_{T M} / I D_{I Q T}$ ratios are less than one, and they decrease as temperature increases; the highest $I D_{T M} / I D_{I Q T}$ values were found in the chamber tail. At the third pressure condition, shown in Figure 5.7, combustion initiation was indicated first by temperature where most $I D_{T M} / I D_{I Q T}$ ratios are less than one, particularly at higher temperature conditions (Figure 5.7c). However, there are still locations near the chamber wall and at the end of chamber with $I D_{T M} / I D_{I Q T}$ ratios greater than one.

The second set of $I D_{T M}$ results, which are based on the Bogin et al [40] method of ID calculation, are shown in Figures 5.8, 5.9 and 5.10. With the Bogin method, ignition starts at the point where the chamber pressure rises above the initial value by 40 psi $(\approx 2.76$ bar $)$ rather than 20 psi $(\approx 1.38$ bar $)$ as in the standard IQT method. The method is proposed to be used with the longer ignition delay cases, such as lower pressure and temperature conditions, or fuels with high ID values. The $I D_{T M} / I D_{B o g i n}$ ratios are close to one at $10 \mathrm{bar}$ and $530{ }^{\circ} \mathrm{C}$ conditions (Figure 5.8a) where the ID is relatively high, then the ratio decreases to less than one as the temperature increases. At the 15 bar and 21 bar pressure conditions shown in Figures 5.9 and 5.10 , the $I D_{T M} / I D_{\text {Bogin }}$, ratios are significantly lower than one, particularly in the main part of the chamber. In the third set, the $I D_{T M}$ results are compared with the ignition delay calculated using the differential method $(D M)$, as shown in Figures 5.11, 5.12 and 5.13. The $D M$ is used to accommodate the effect of low temperature heat release behavior [56]. The start of combustion (i.e. the end of the ID period) with this method is located at the intersection point of two slopes, as shown in Figure 5.1. The ignition delay results of both the Bogin and DM methods are very close; thus, the $I D_{T M} / I D_{D M}$ results are very similar to $I D_{T M} / I D_{\text {Bogin }}$. 


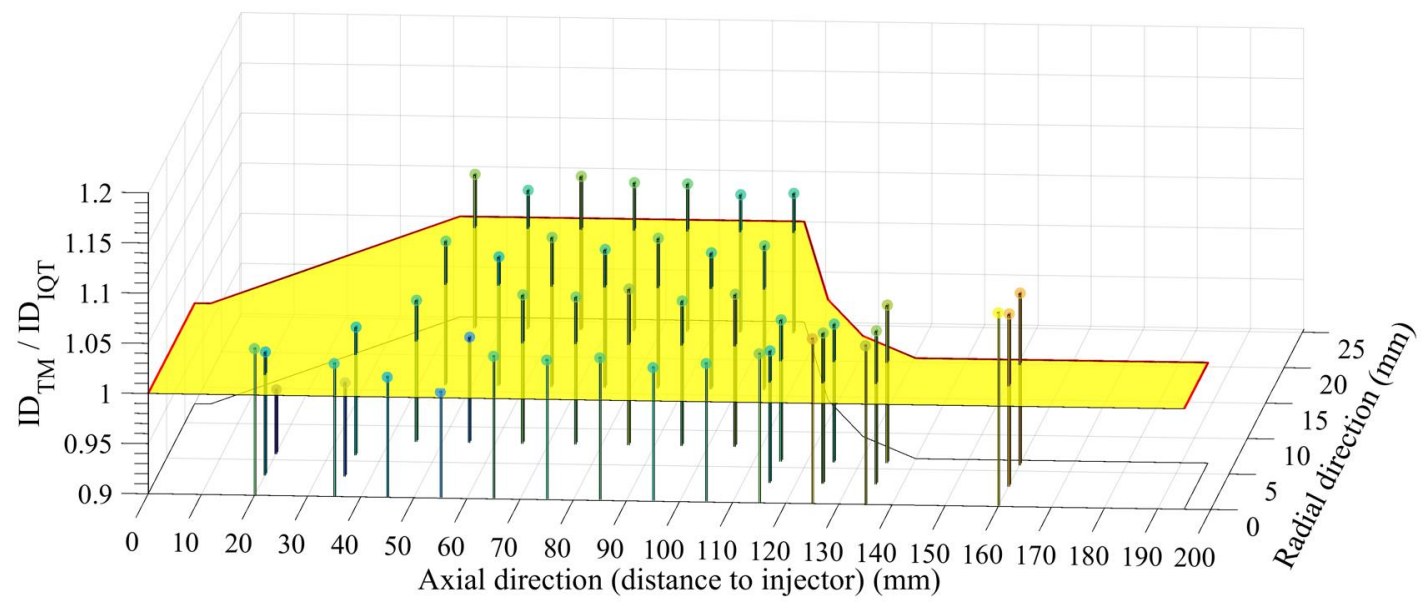

(a) $530{ }^{\circ} \mathrm{C}, I D_{I Q T}=8.41 \mathrm{~ms}$

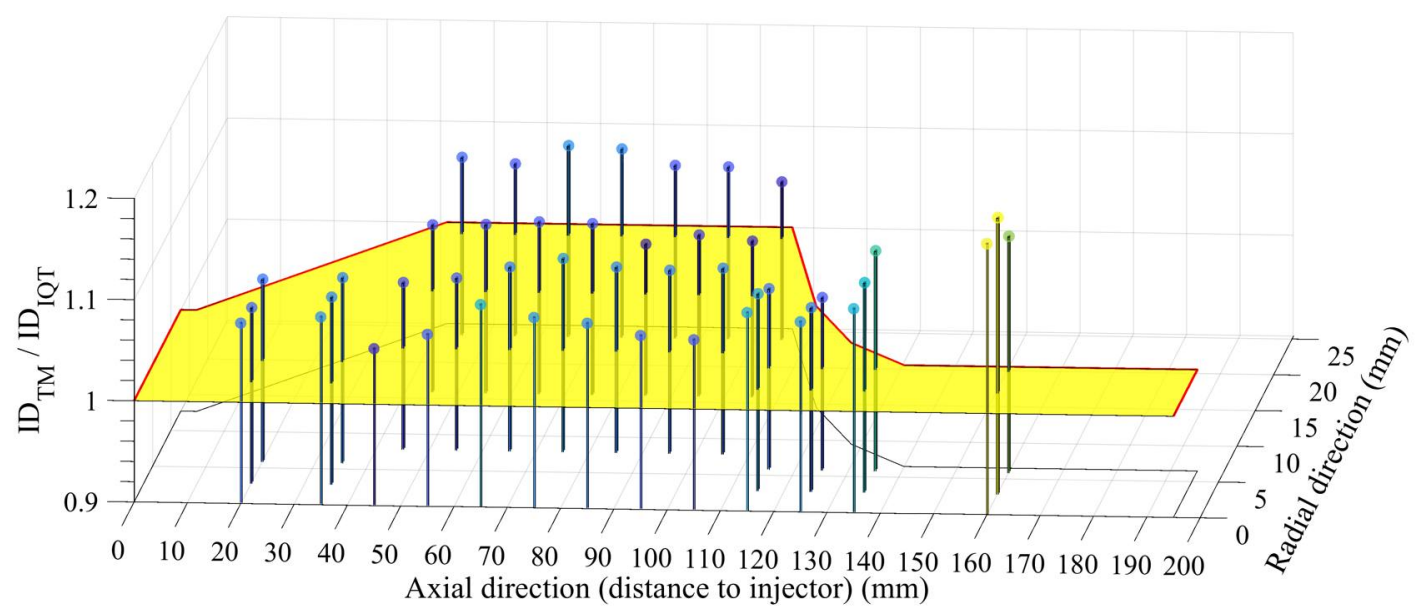

(b) $570{ }^{\circ} \mathrm{C}, I D_{I Q T}=6.50 \mathrm{~ms}$

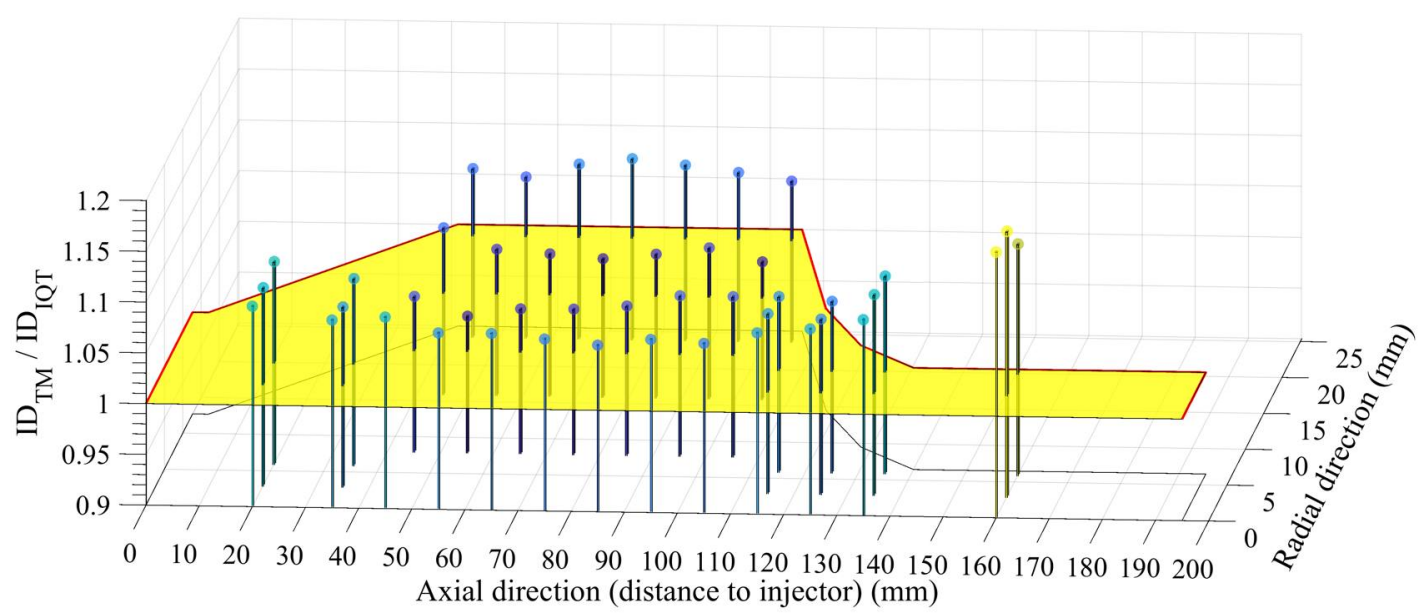

(c) $590{ }^{\circ} \mathrm{C}, I D_{I Q T}=6.18 \mathrm{~ms}$

Figure 5.5: Ignition delay ratio $\left(I D_{T M} / I D_{I Q T}\right)$ at different locations inside the IQT chamber at 10 bar 


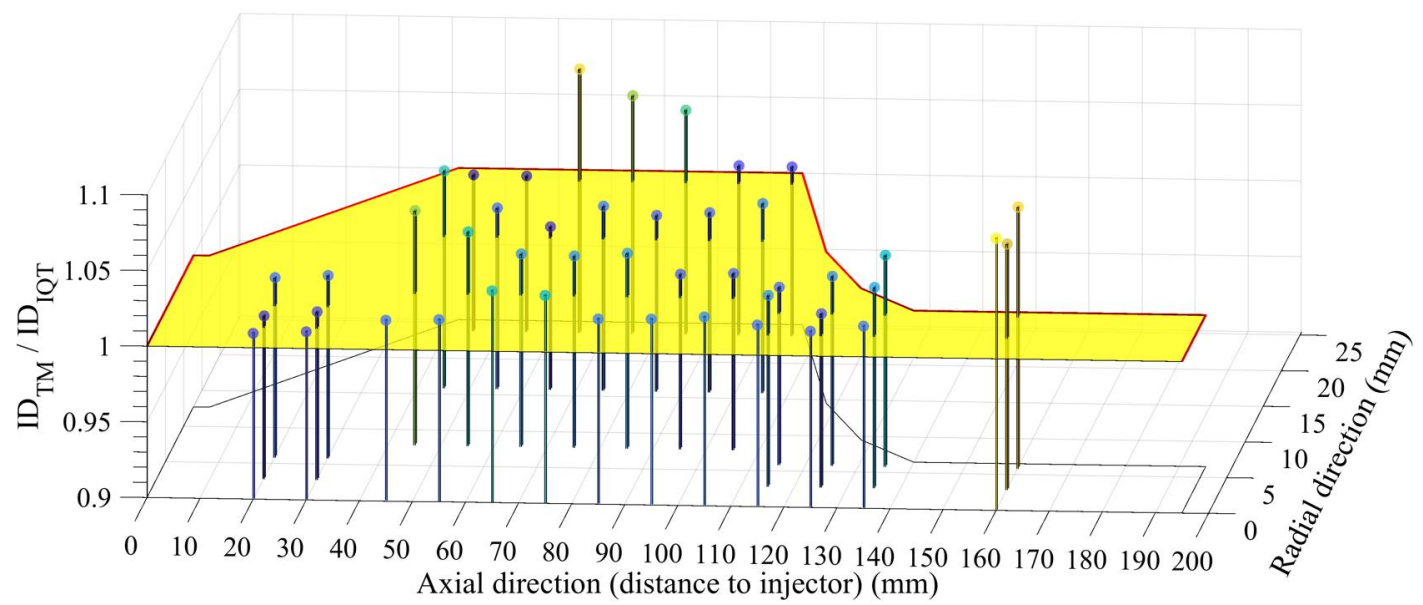

(a) $530{ }^{\circ} \mathrm{C}, I D_{I Q T}=6.09 \mathrm{~ms}$

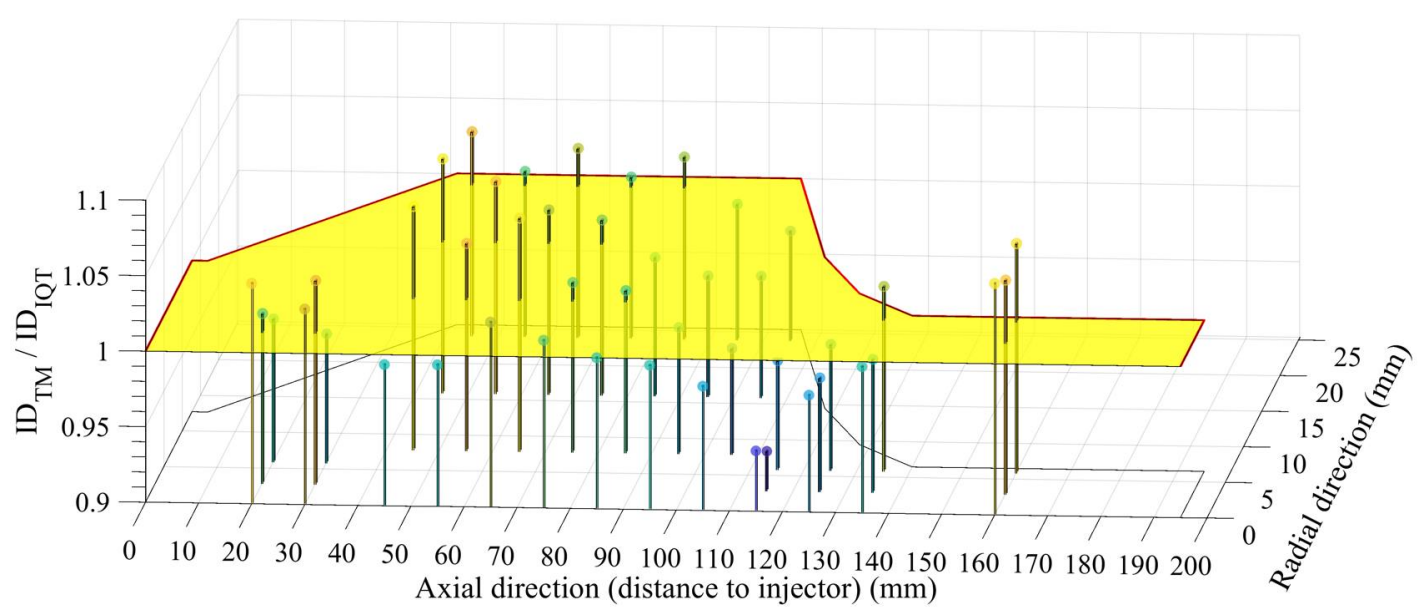

(b) $570{ }^{\circ} \mathrm{C}, I D_{I Q T}=5.04 \mathrm{~ms}$

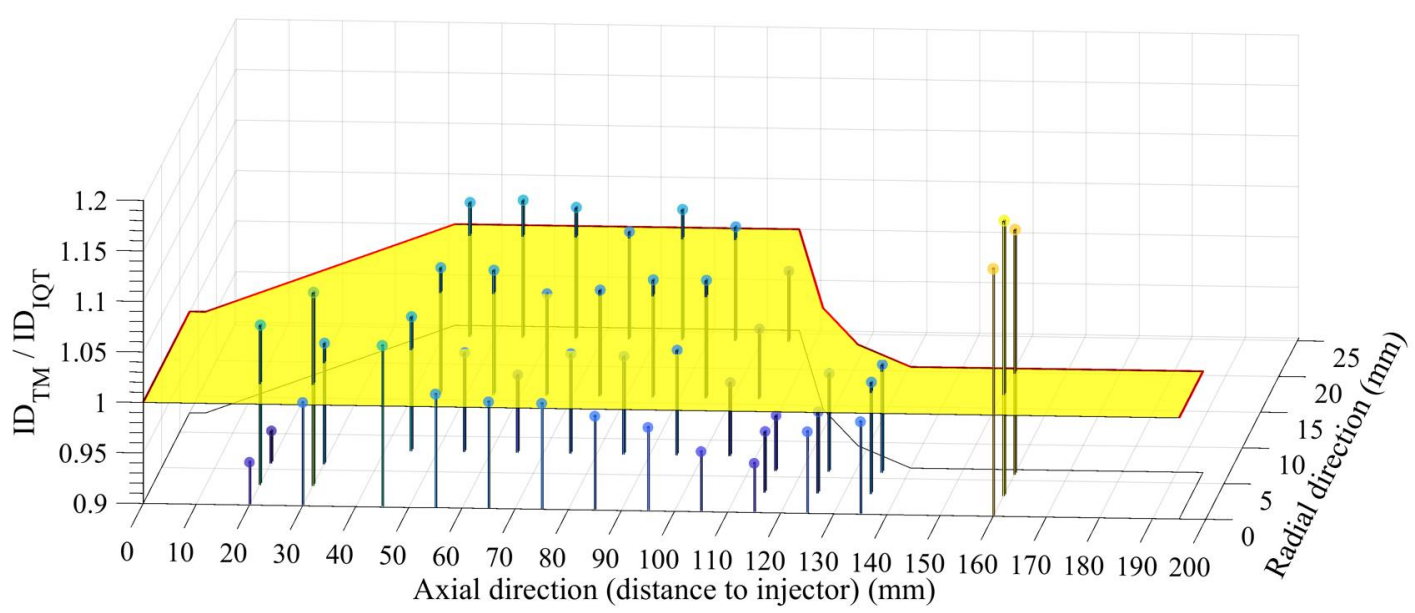

(c) $590^{\circ} \mathrm{C}, I D_{I Q T}=4.55 \mathrm{~ms}$

Figure 5.6: Ignition delay ratio $\left(I D_{T M} / I D_{I Q T}\right)$ at different locations inside the IQT chamber at 15 bar 


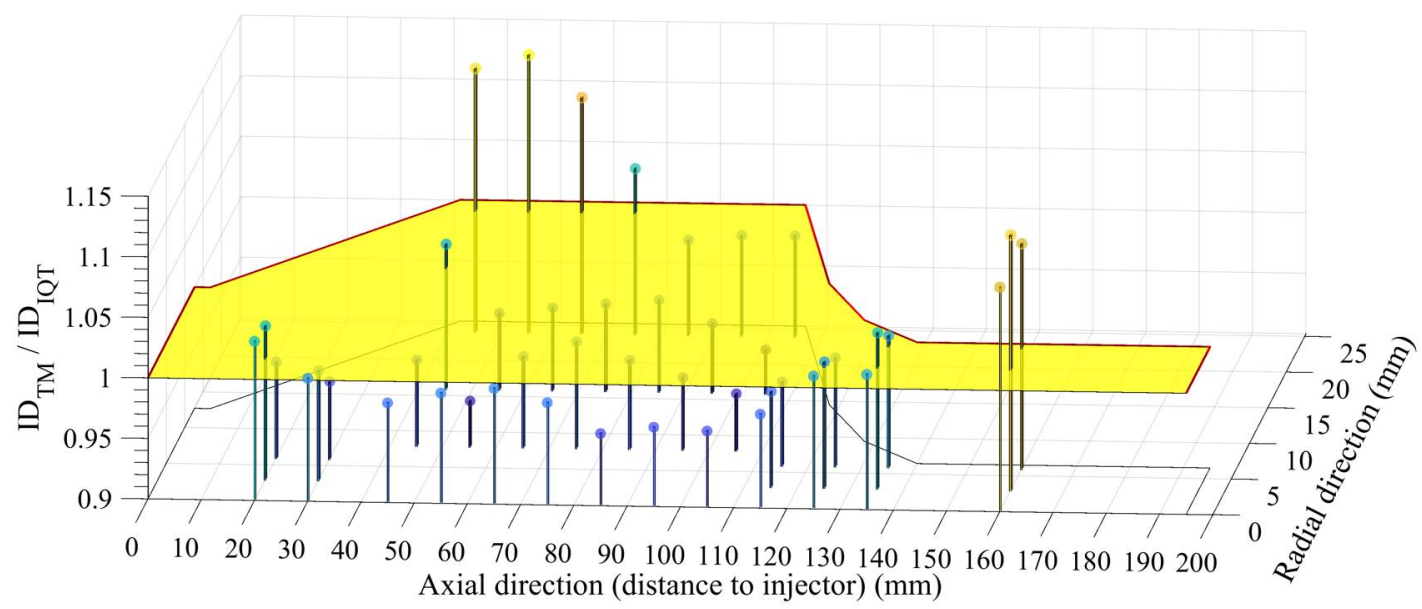

(a) $530{ }^{\circ} \mathrm{C}, I D_{I Q T}=5.21 \mathrm{~ms}$

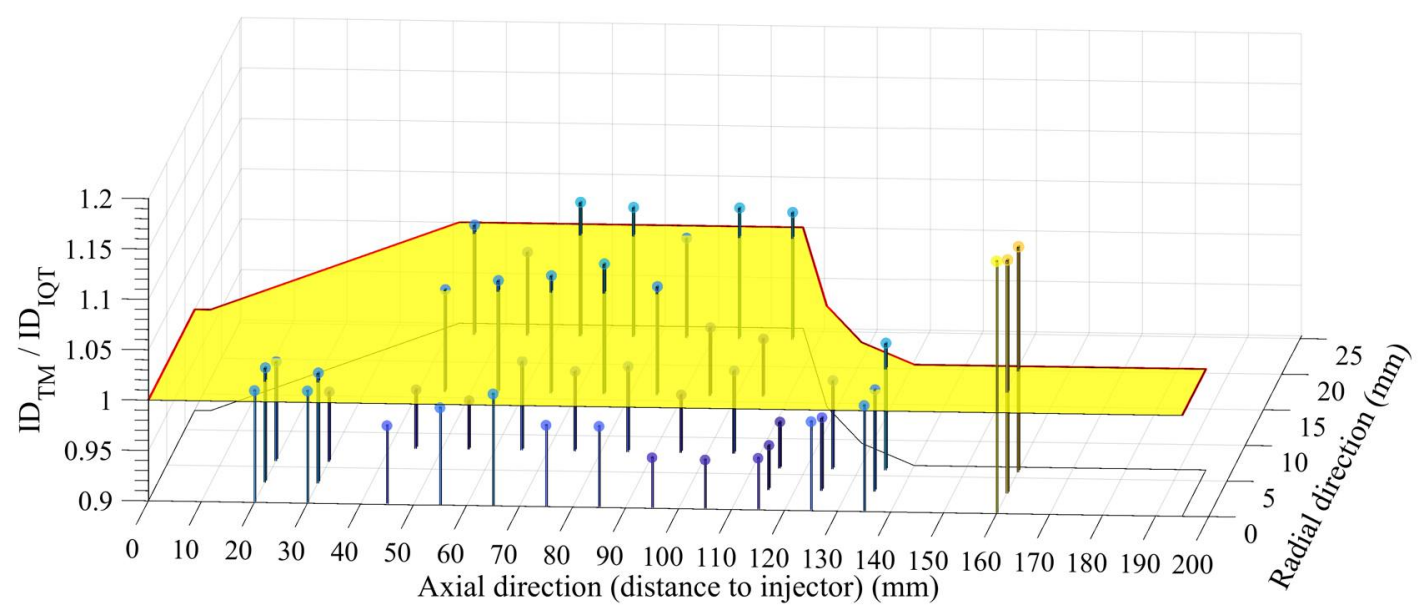

(b) $570{ }^{\circ} \mathrm{C}, I D_{I Q T}=4.15 \mathrm{~ms}$

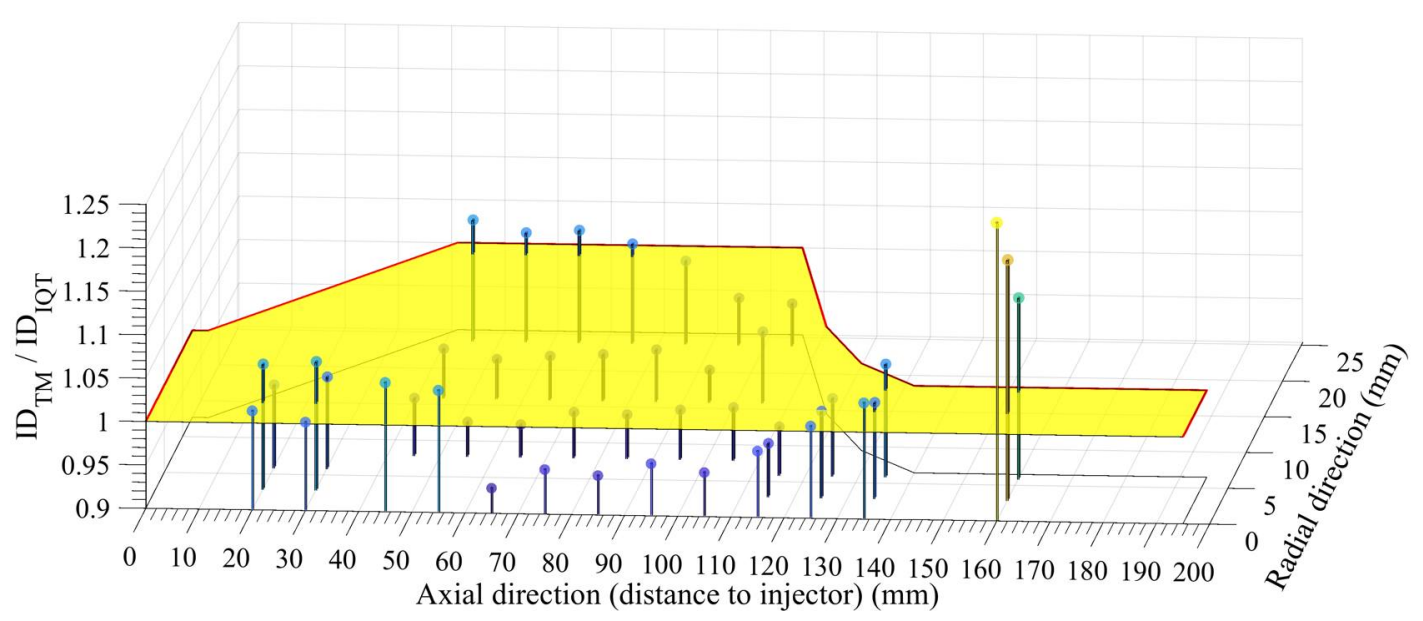

(c) $590{ }^{\circ} \mathrm{C}, I D_{I Q T}=3.83 \mathrm{~ms}$

Figure 5.7: Ignition delay ratio $\left(I D_{T M} / I D_{I Q T}\right)$ at different locations inside the IQT chamber at 21 bar 


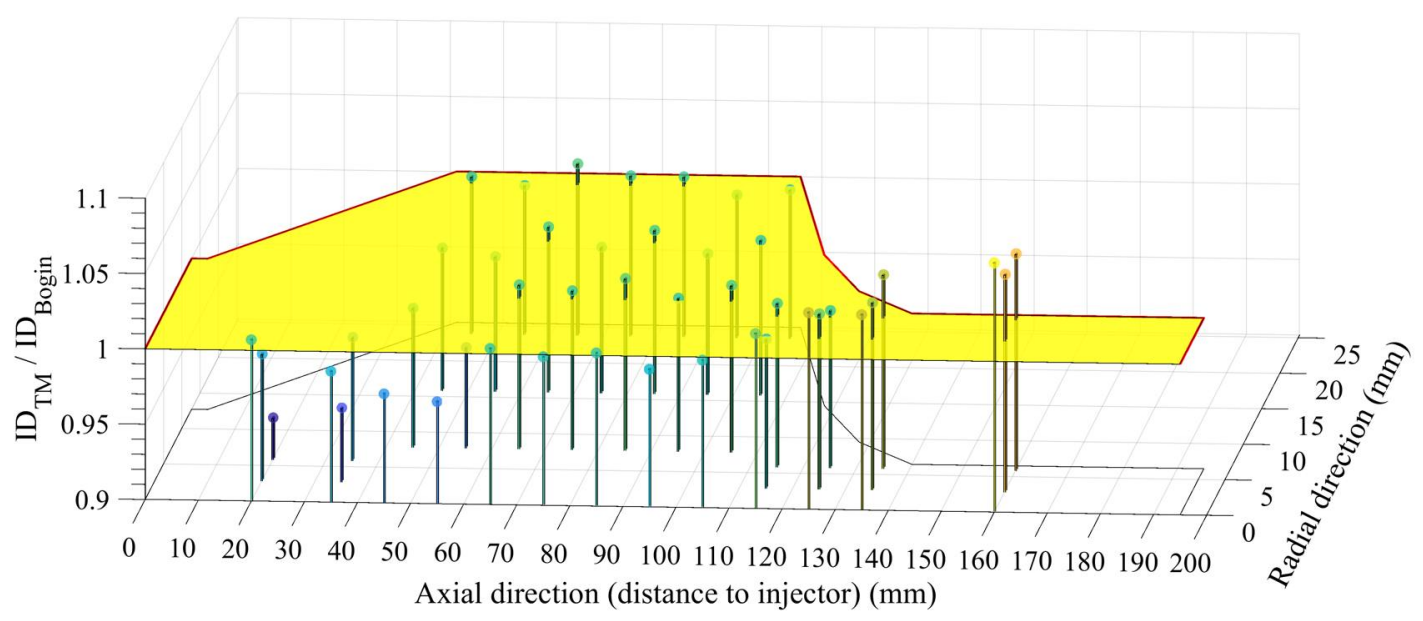

(a) $530^{\circ} \mathrm{C}, I D_{\text {Bogin }}=8.74 \mathrm{~ms}$

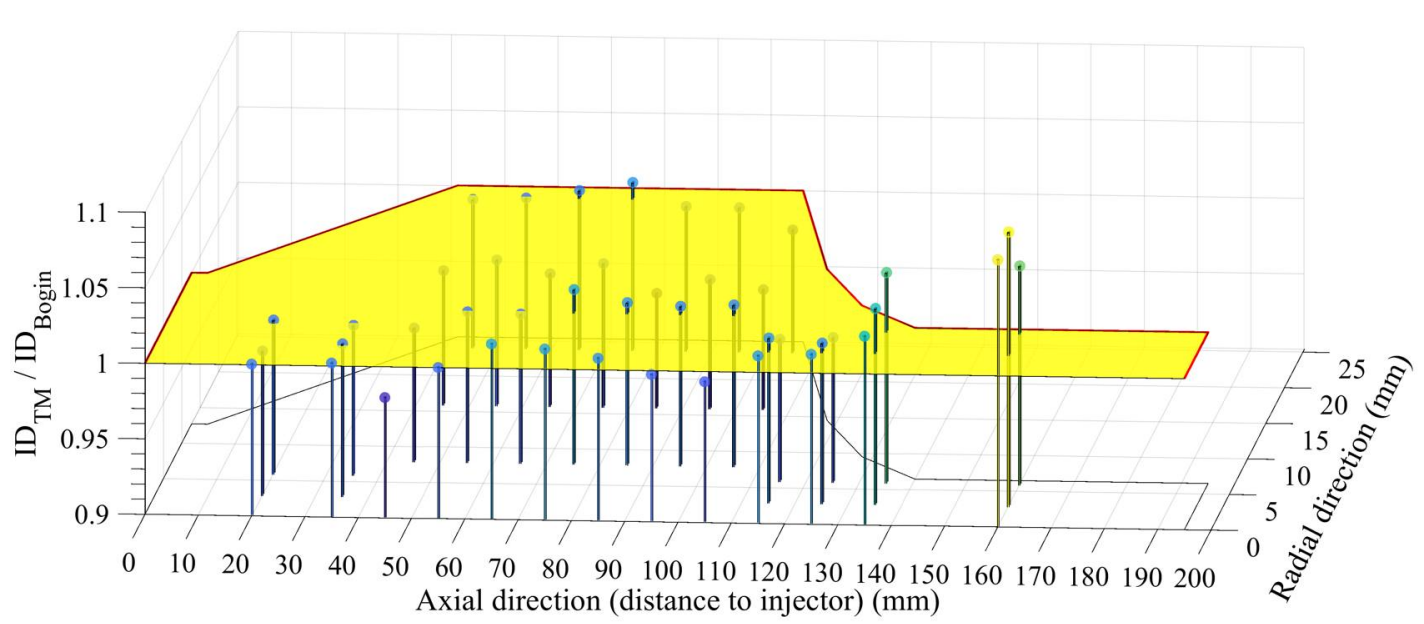

(b) $570^{\circ} \mathrm{C}, I D_{\text {Bogin }}=6.99 \mathrm{~ms}$

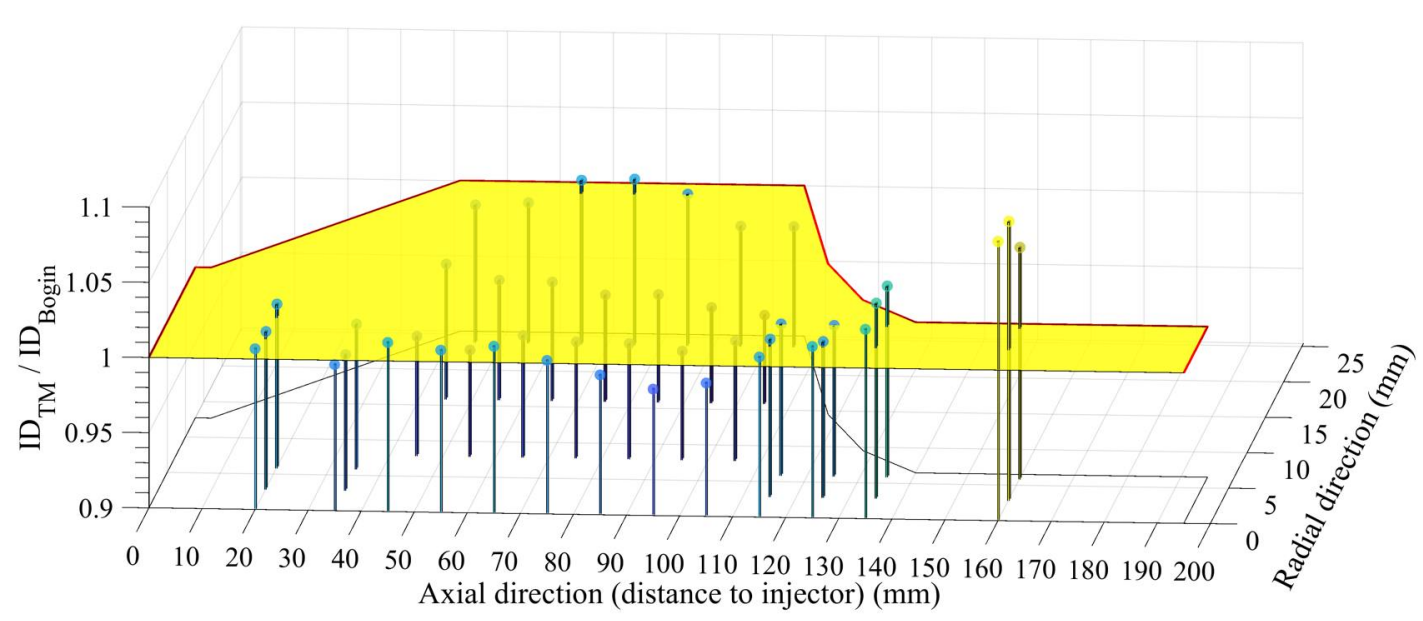

(c) $590{ }^{\circ} \mathrm{C}, I D_{\text {Bogin }}=6.62 \mathrm{~ms}$

Figure 5.8: Ignition delay ratio $\left(I D_{T M} / I D_{\text {Bogin }}\right)$ at different locations inside the IQT chamber at $10 \mathrm{bar}$ 


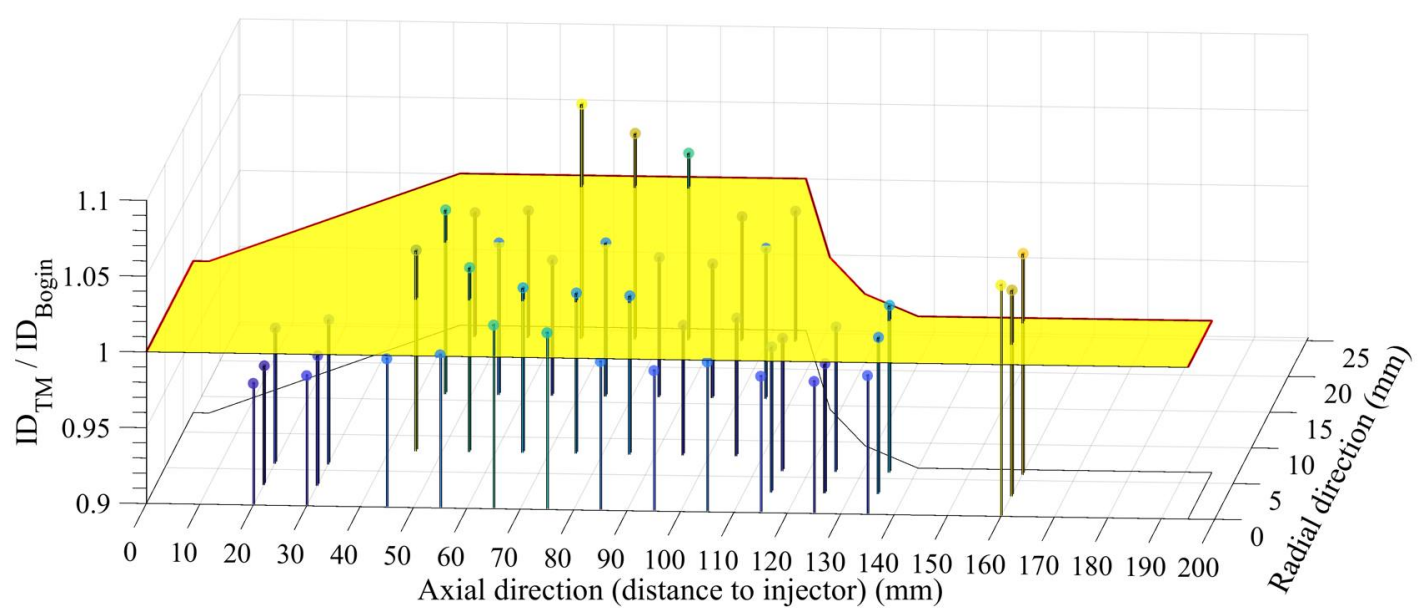

(a) $530^{\circ} \mathrm{C}, I D_{\text {Bogin }}=6.22 \mathrm{~ms}$

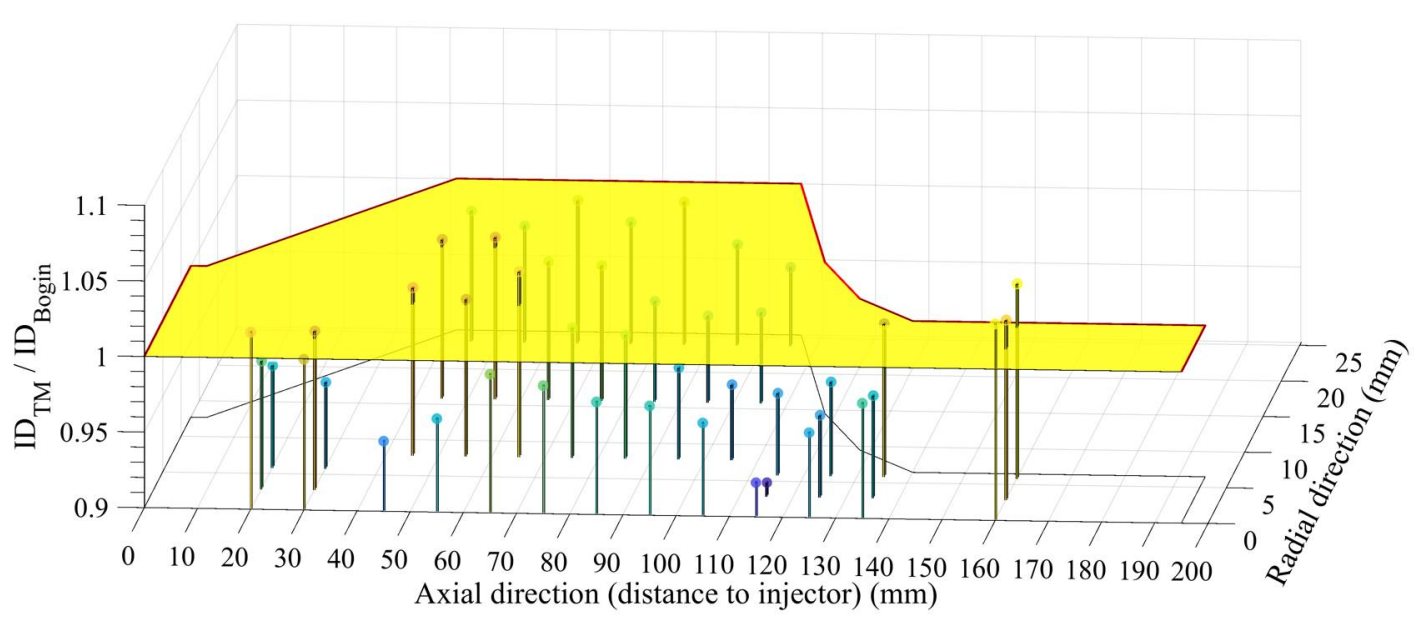

(b) $570{ }^{\circ} \mathrm{C}, I D_{\text {Bogin }}=5.16 \mathrm{~ms}$

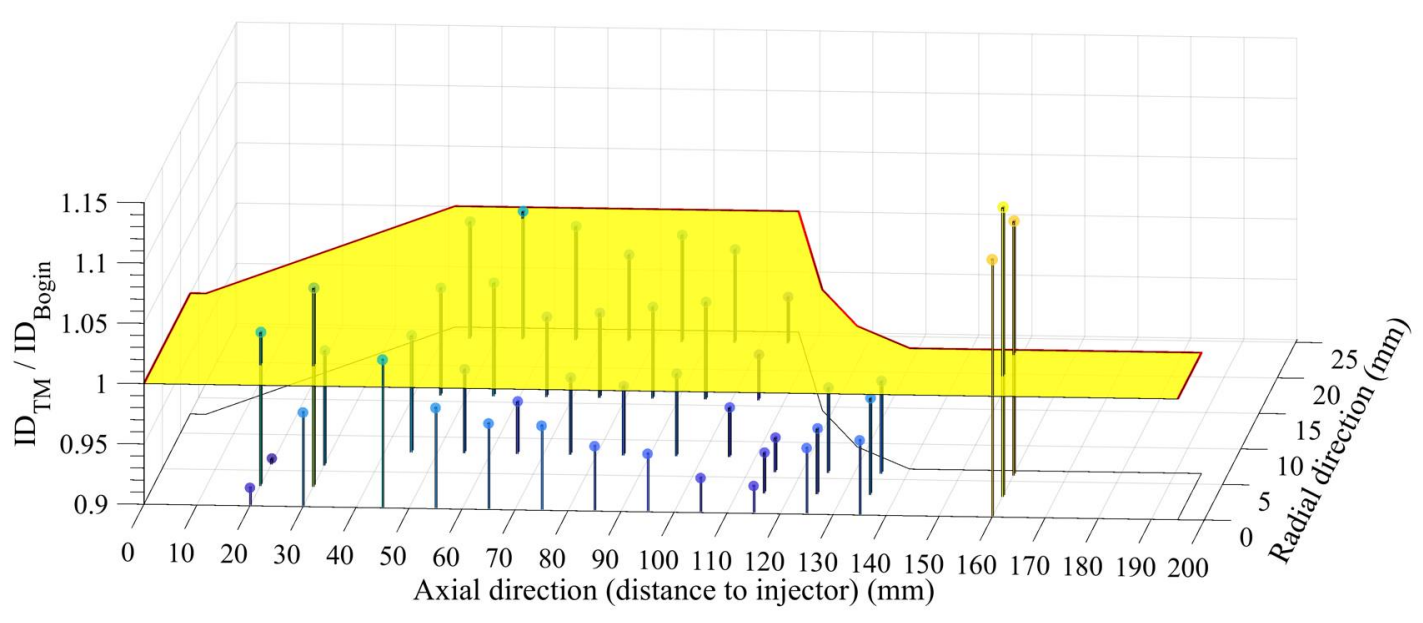

(c) $590^{\circ} \mathrm{C}, I D_{\text {Bogin }}=4.71 \mathrm{~ms}$

Figure 5.9: Ignition delay ratio $\left(I D_{T M} / I D_{\text {Bogin }}\right)$ at different locations inside the IQT chamber at 15 bar 


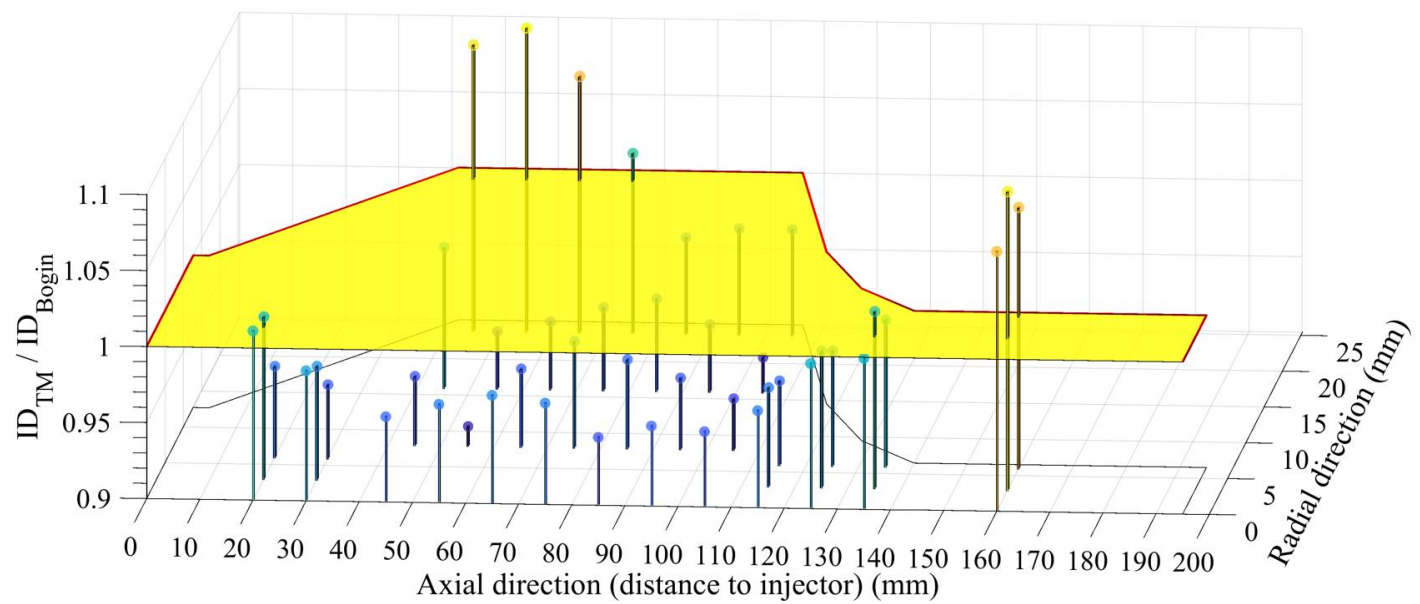

(a) $530^{\circ} \mathrm{C}, I D_{\text {Bogin }}=5.30 \mathrm{~ms}$

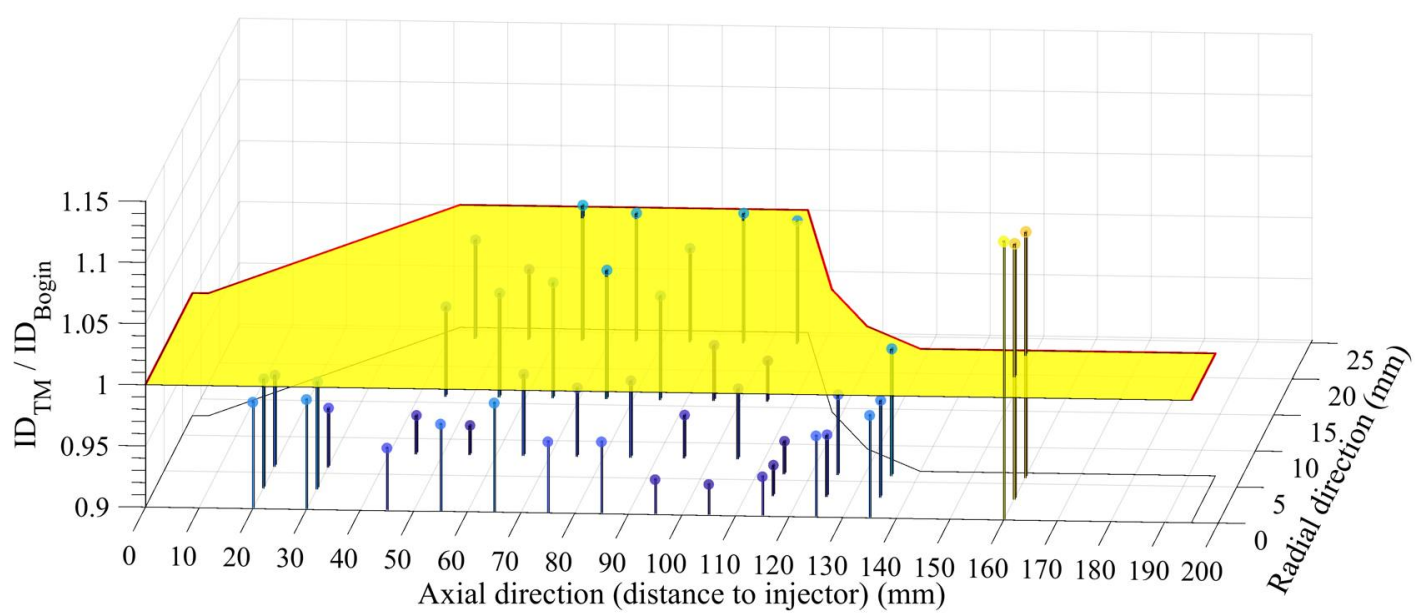

(b) $570{ }^{\circ} \mathrm{C}, I D_{\text {Bogin }}=4.25 \mathrm{~ms}$

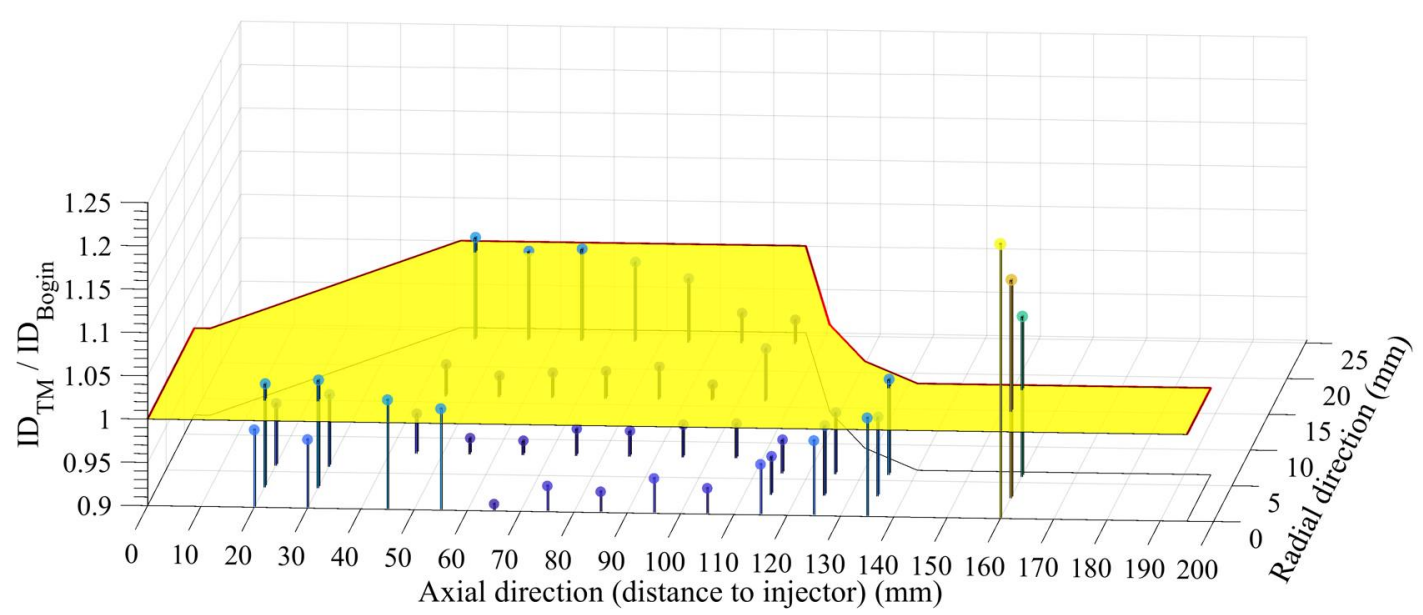

(c) $590^{\circ} \mathrm{C}, I D_{\text {Bogin }}=3.92 \mathrm{~ms}$

Figure 5.10: Ignition delay ratio $\left(I D_{T M} / I D_{\text {Bogin }}\right)$ at different locations inside the IQT chamber at 21 bar 


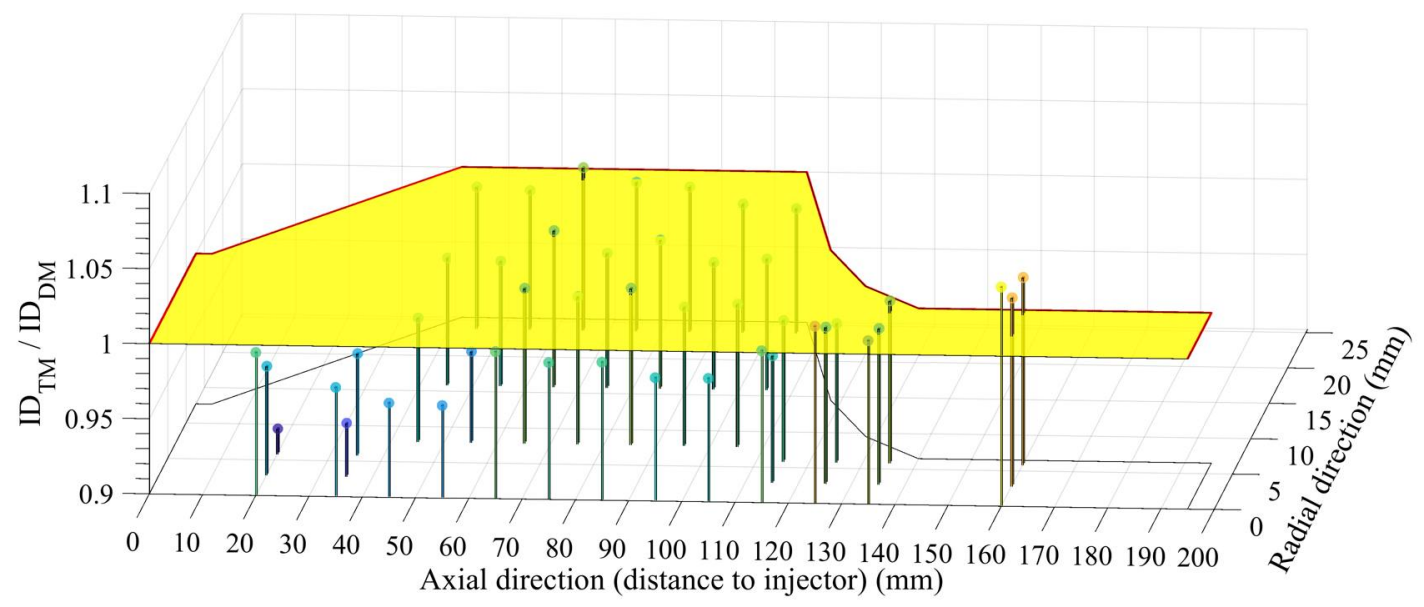

(a) $530{ }^{\circ} \mathrm{C}, I D_{D M}=8.81 \mathrm{~ms}$

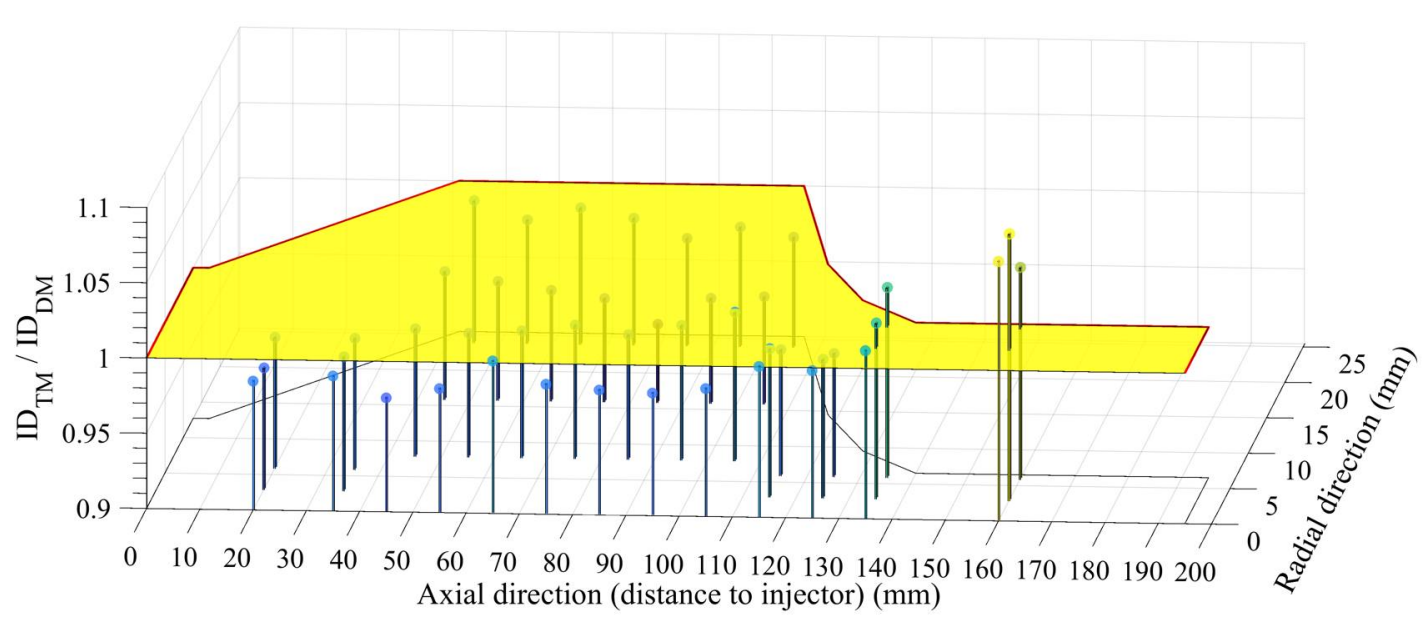

(b) $570^{\circ} \mathrm{C}, I D_{D M}=7.13 \mathrm{~ms}$

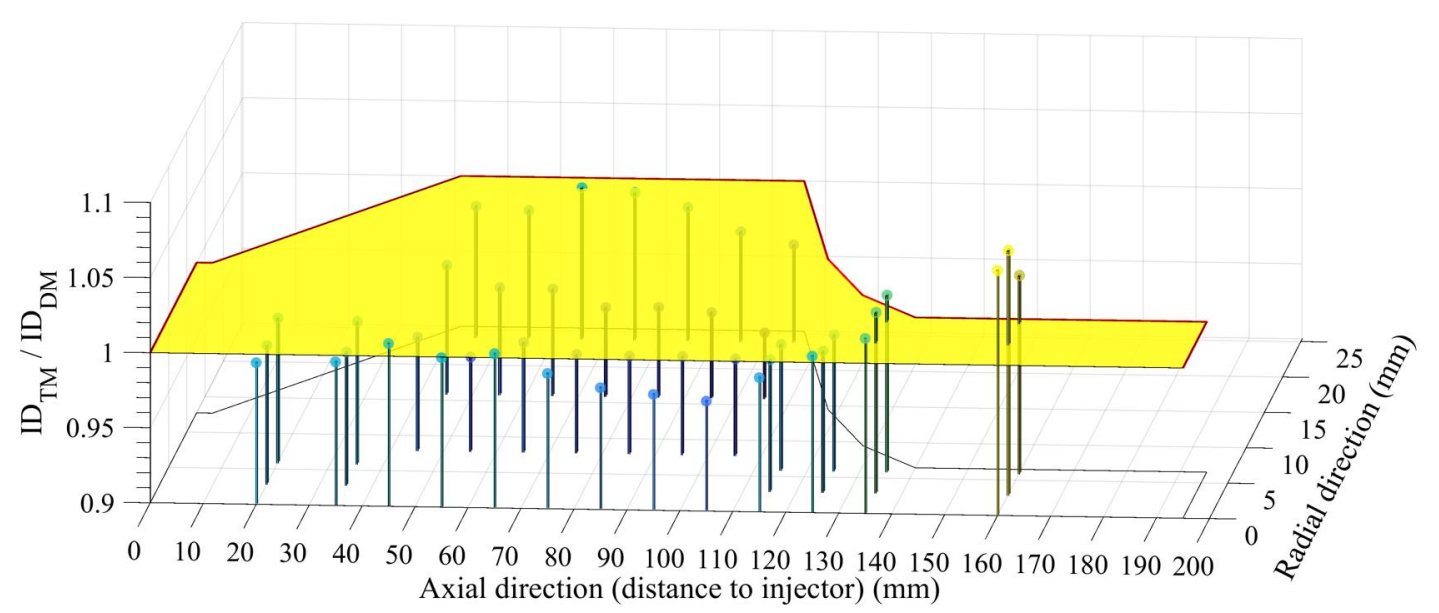

(c) $590^{\circ} \mathrm{C}, I D_{D M}=6.68 \mathrm{~ms}$

Figure 5.11: Ignition delay ratio $\left(I D_{T M} / I D_{D M}\right)$ at different locations inside the IQT chamber at 10 bar 


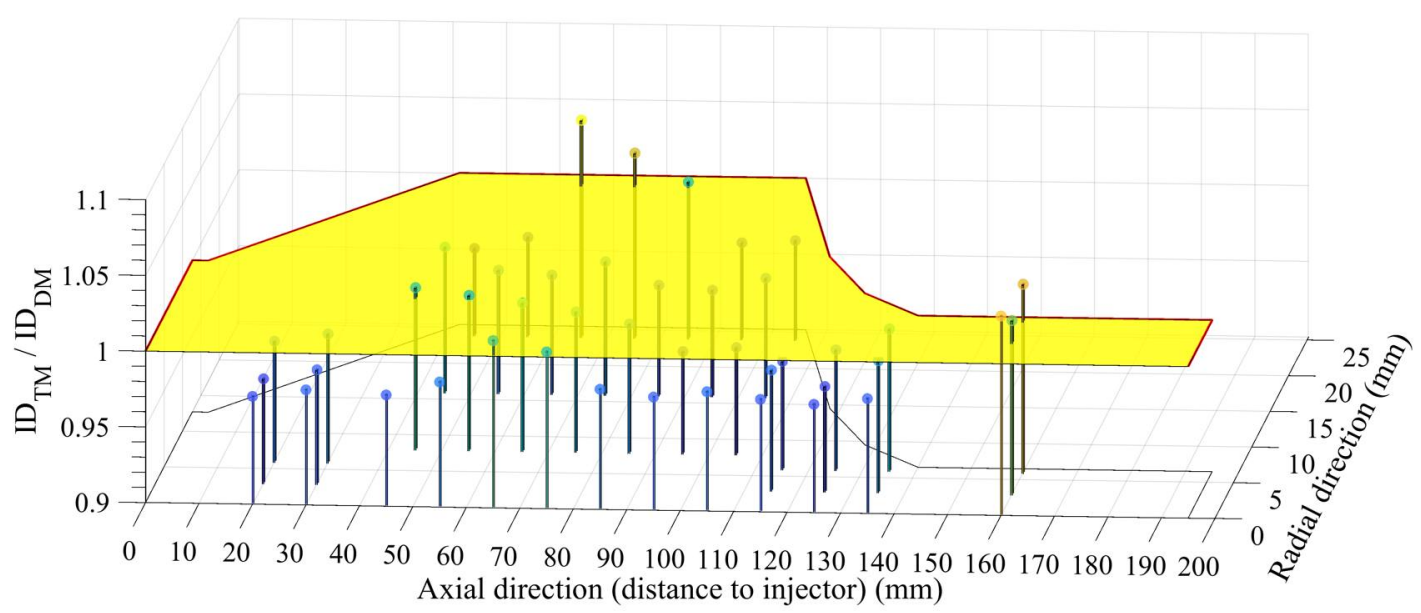

(a) $530^{\circ} \mathrm{C}, I D_{D M}=6.32 \mathrm{~ms}$

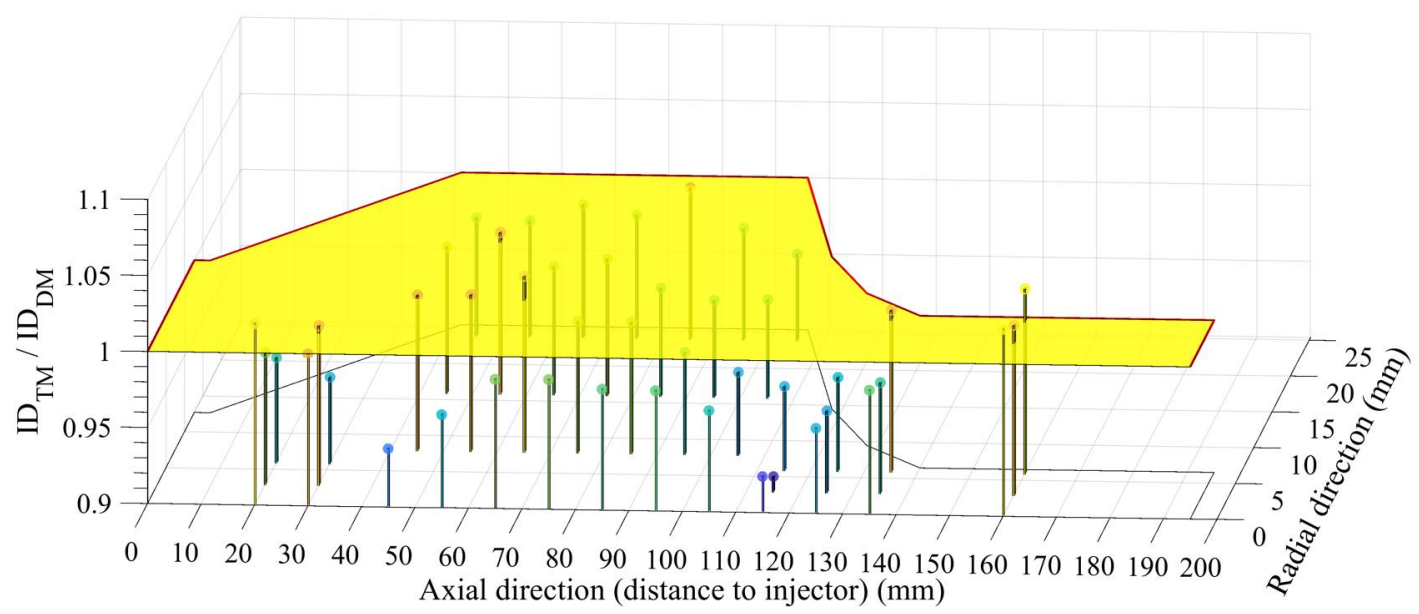

(b) $570{ }^{\circ} \mathrm{C}, I D_{D M}=5.16 \mathrm{~ms}$

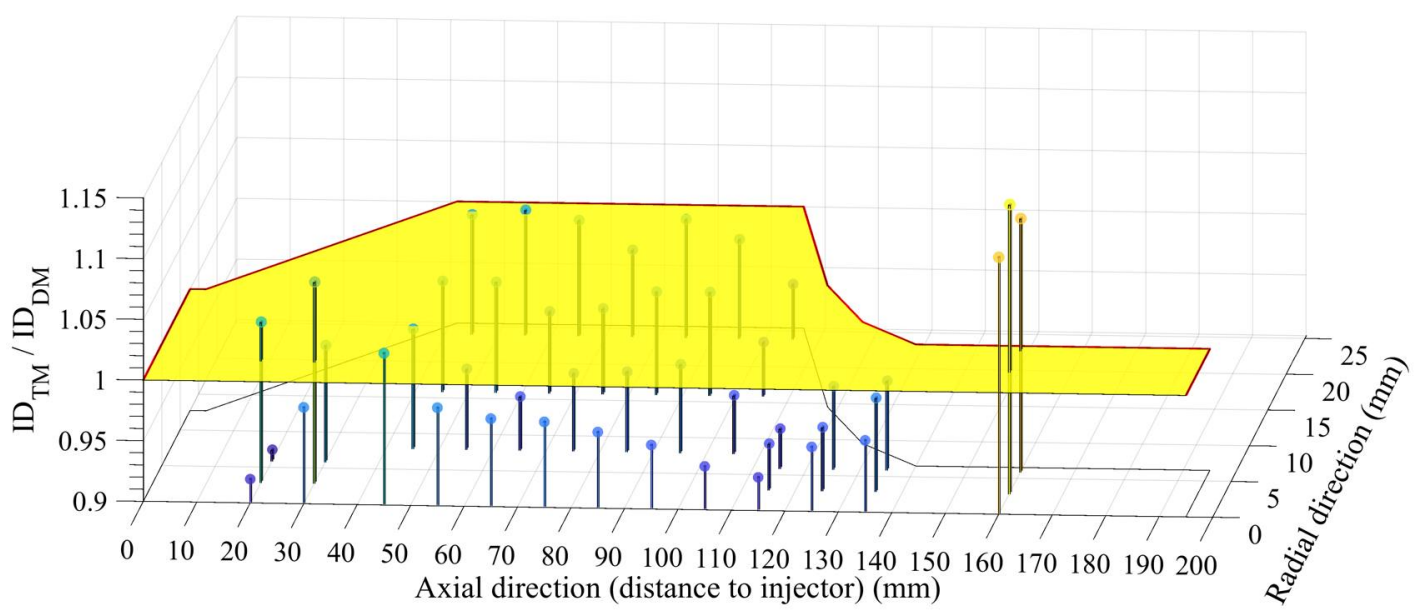

(c) $590^{\circ} \mathrm{C}, I D_{D M}=4.70 \mathrm{~ms}$

Figure 5.12: Ignition delay ratio $\left(I D_{T M} / I D_{D M}\right)$ at different locations inside the IQT chamber at 15 bar 


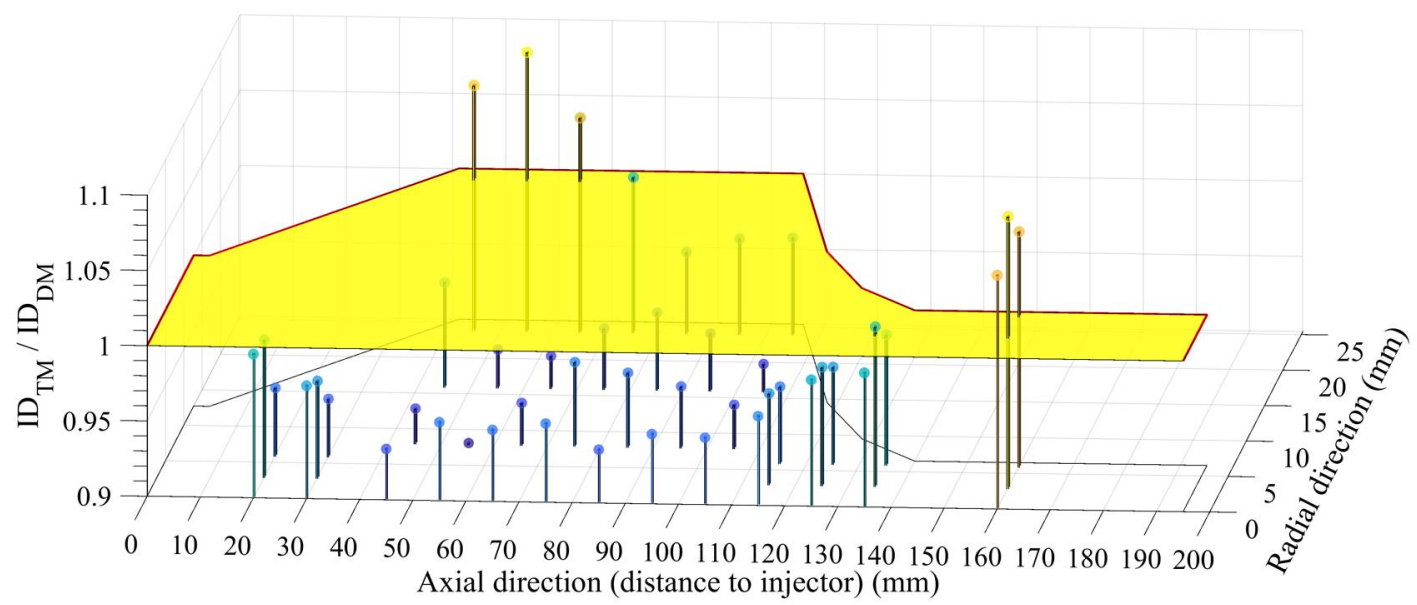

(a) $530^{\circ} \mathrm{C}, I D_{D M}=5.37 \mathrm{~ms}$

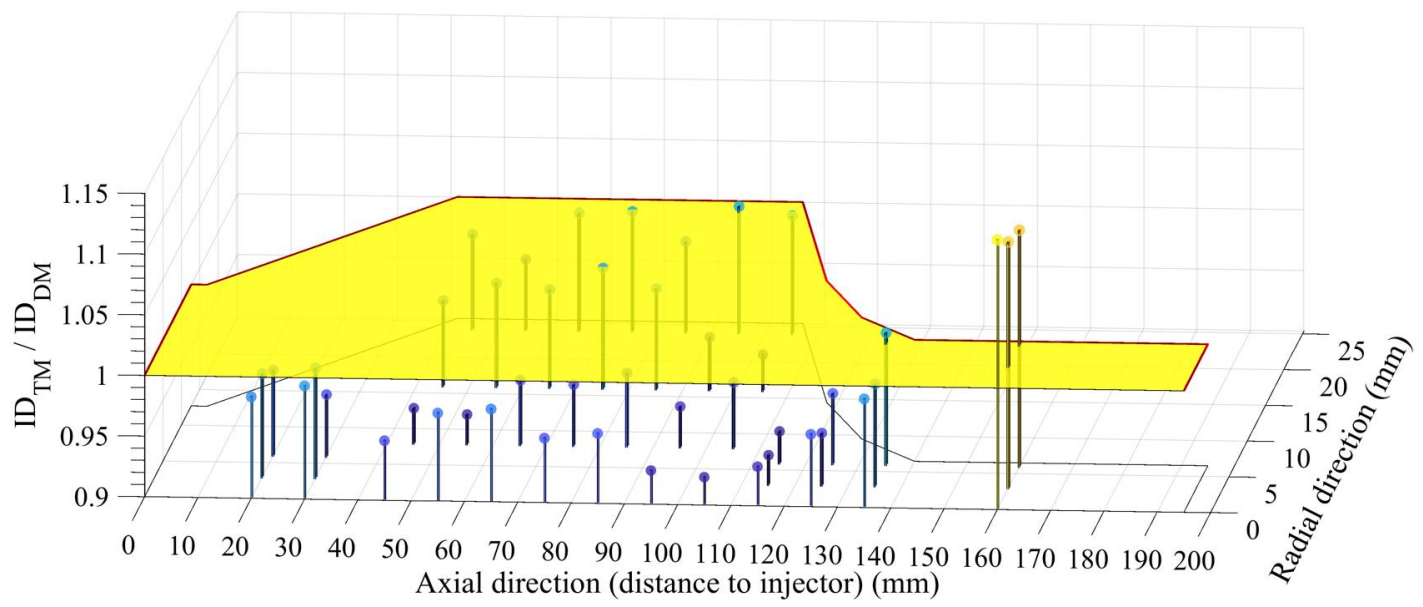

(b) $570^{\circ} \mathrm{C}, I D_{D M}=4.27 \mathrm{~ms}$

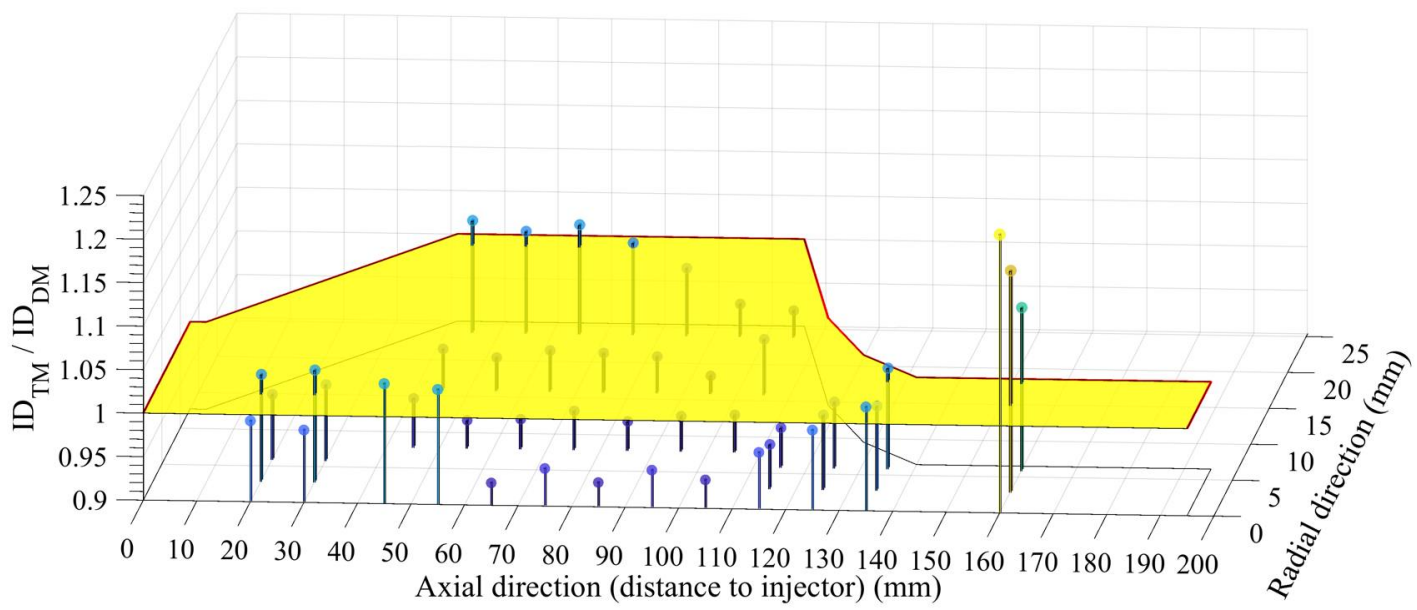

(c) $590^{\circ} \mathrm{C}, I D_{D M}=3.88 \mathrm{~ms}$

Figure 5.13: Ignition delay ratio $\left(I D_{T M} / I D_{D M}\right)$ at different locations inside the IQT chamber at 21 bar 


\subsection{Physical and Chemical Ignition Delay}

Most empirical studies on compression combustion incorporate the overall ignition delay, which comprises both the physical ignition delay caused by the fuel spray break up, evaporation and mixing with air, as well as the chemical ignition delay due to chemical reactions in the fuel-air mixture. Here, the separation between the physical and chemical delays is estimated using temperature variations, as shown in Figure 5.1. The physical delay $\left(I D_{\text {phys }}\right)$ at each location with significant temperature drop is partitioned into two periods. The first period is between the SOI and the start of temperature drop at the location (t1), which represents the required time for the spray to reach the particular location. The second period, which was previously defined as the local physical ignition delay $\left(\left(I D_{\text {phys }}\right)_{\text {local }}\right)$, starts at the point of temperature decrease up to the end of the drop temperature line. The chemical delay period $\left(I D_{\text {chem }}\right)$ can be easily calculated as the difference between the $I D_{T M}$ and $I D_{\text {phys }}$.

Each of the three periods $\left(\mathrm{t} 1,\left(I D_{\text {phys }}\right)_{\text {local }}\right.$, and $\left.I D_{\text {chem }}\right)$ mentioned above was divided by the $I D_{T M}$ at each location that showed physical delay, then averaged over all locations and presented as a percentage of the total ID time on the three bar chart plots in Figure 5.14, where each bar represents three partitions. The lower dark blue part of the bar is the average percentage time for the spray droplets to spread out in the chamber after the SOI,

the intermediate light blue represents the average percentage time of the $\left(I D_{\text {phys }}\right)_{\text {local }}$, and the upper part with gradient from yellow to red represents the average percentage time of the $I D_{\text {chem }}$.

The average percentage time of the spray to spread out in the chamber becomes higher as the charge air pressure increases, whereas the charge air temperature at the same pressure has a minimal effect on the time for the spray to spread out. It is approximately 
$12 \%(0.87 \mathrm{~ms})$ at $10 \mathrm{bar}$, and $21 \%(1.05 \mathrm{~ms})$ at $21.4 \mathrm{bar}$. Denser air at higher pressure also restricts the propagation and break up of the spray droplets. The average $\left(I D_{\text {phys }}\right)_{\text {local }} \%$ is relatively longer than the first period as time is spent on the secondary breakup of the bigger droplets and the evaporation process, and it takes 18 to $26 \%$ of the total $I D$. The average percentage of the total physical ignition delay is approximately $31 \%$ at $10 \mathrm{bar}$ and $47 \%$ at 21.4 bar. The rest of the time percentage is used for chemical ignition delay. 


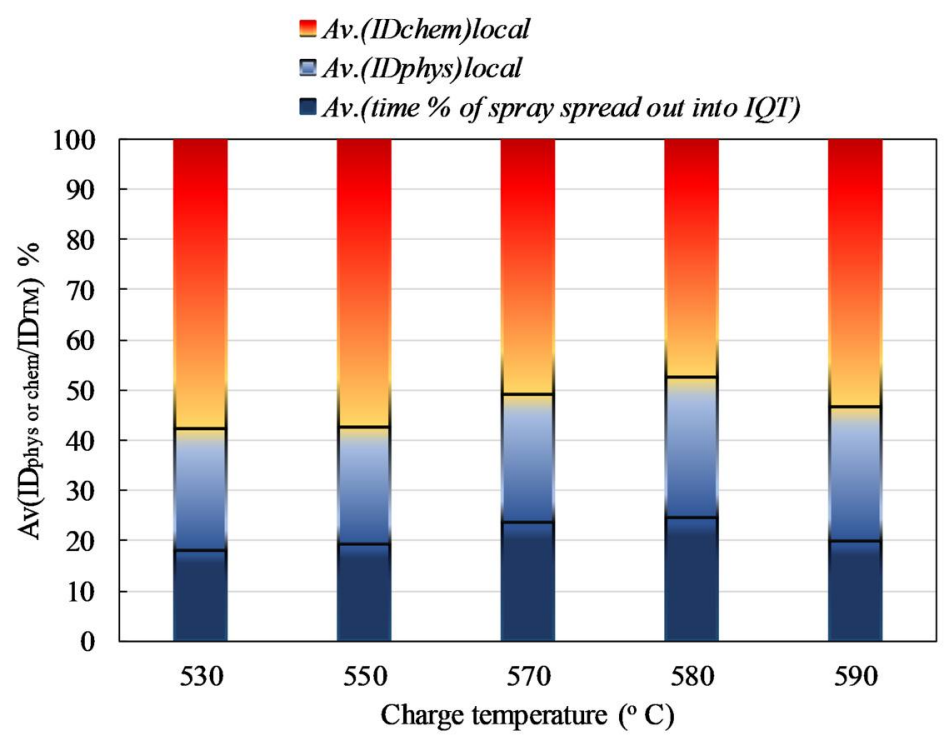

(a) 21.4 bar

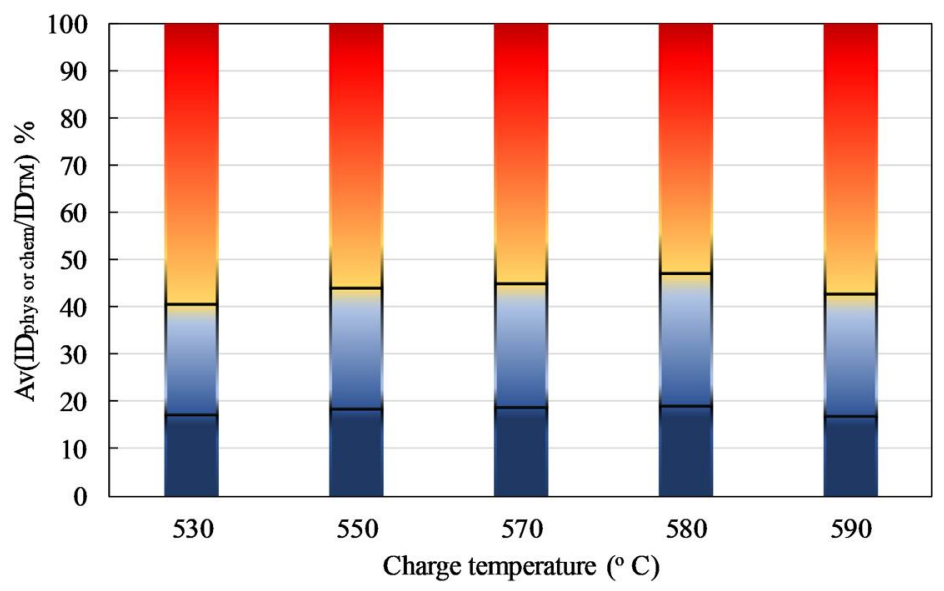

(b) 15 bar

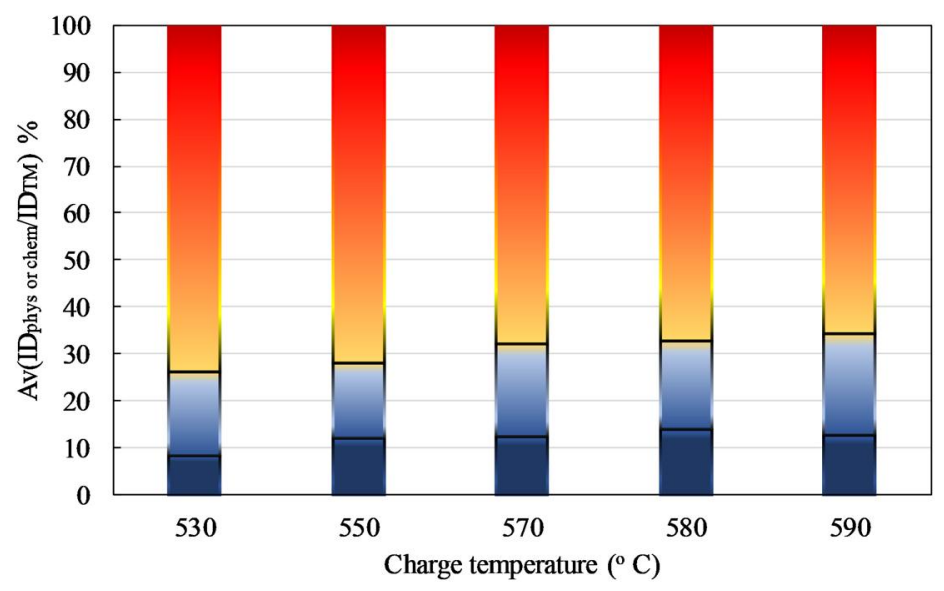

(c) 10 bar

Figure 5.14: The average physical and chemical ignition delay for all tested conditions 


\subsection{Total Ignition Delay Based on Pressure and Tem- perature Variations}

The total ignition delay, that is calculated from global pressure variations and local temperature variations as a function of the initial temperature at the start of injection, is shown in Figures 5.15 to 5.17. Each data point on the figures represents an average of 15 injection events. The ignition delay by temperature method $\left(I D_{T M}\right)$ is calculated at 24 locations in the main part of the chamber, as shown by the IQT icon in the figures. The solid lines in the figures represent the ID by pressure method versus the chamber skin temperature (charge air temperature), which is measured by a TC embedded on the chamber wall. The scatter symbols indicate the ID by temperature method versus the spatial measured temperature prior to fuel injection. Every three TC locations on the same plane are identified by a specific marker shape to show the agreement of the ID prediction locally based on temperature measurements with the ID calculation based on the pressure measurements.

The results show that the ID calculated by both methods increases with decreases in the temperature and pressure. As shown in Figure 5.15, the solid lines begin with a moderate ID increase and slopes are close to one, which indicate the onset of a negative temperature coefficient (NTC) regime with decreases in the ID time when temperatures decrease. This represents the reverse course of the ID with temperature, where as the temperature increases, the ID time becomes shorter. The slopes of the ID lines increase rapidly as the temperature decreases. The low charge pressure increases the ignition delay time and enables the air-fuel mixture to become more homogeneous, which can increase the chance of the NTC presence. The scatter points of the $I D_{T M}$ show excellent agreement with the $I D$ by pressure, particularly with the Bogin and DM methods. The

data at planes 9 and 10 are very close to the line of $I D_{I Q T}$, again showing that the autoignition starts in the area of planes 9 and 10 . 


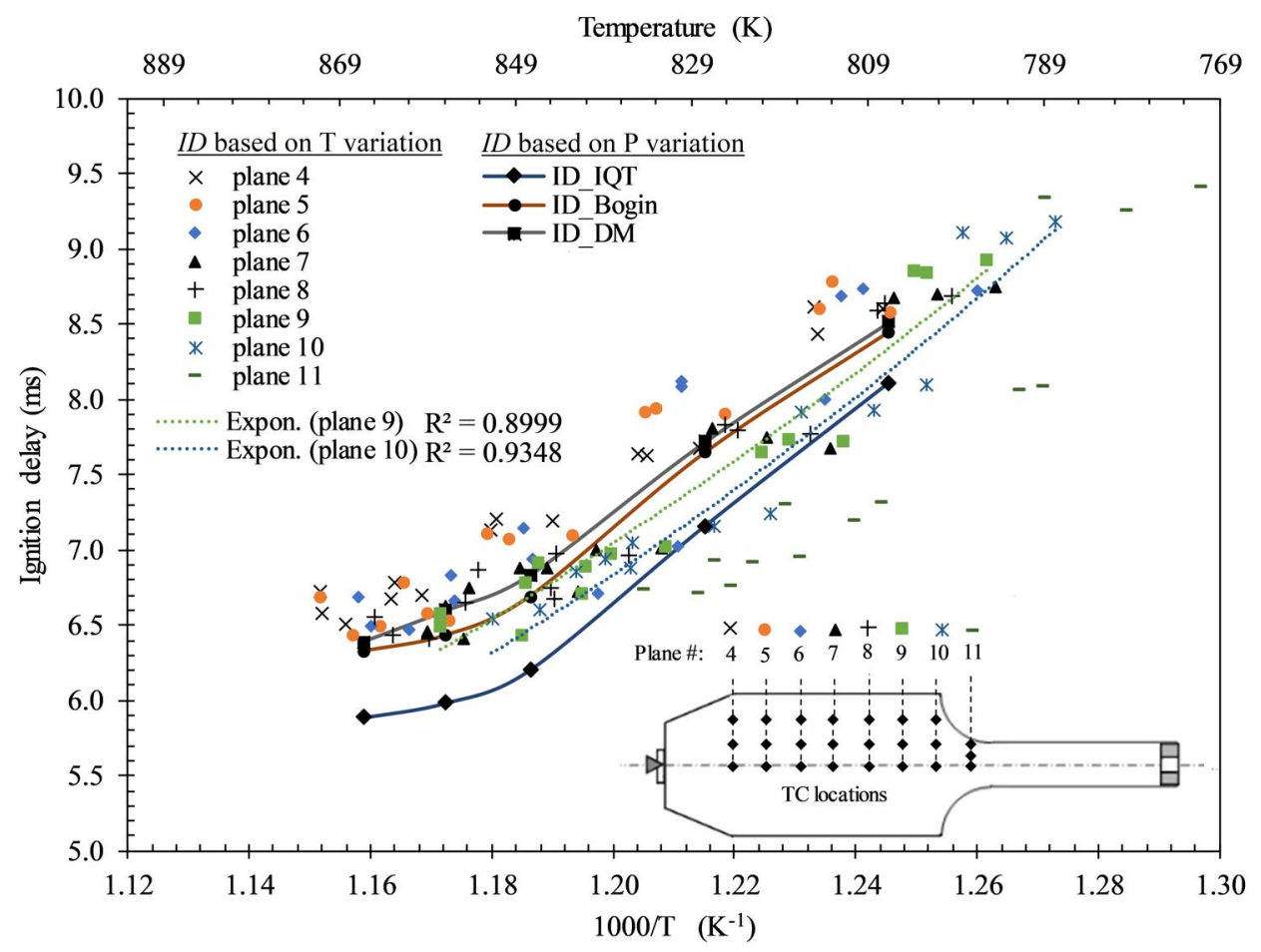

Figure 5.15: Comparison of the ignition delay based on pressure and temperature methods; charge pressure 10 bar

As the charge pressure increases to 15 bar and 21.4 bar (Figures 5.16 and 5.17), there is not enough time for the NTC to appear due to the relatively short ID period, and the predicted $I D_{T M}$ results are scattered around the ID by pressure. However, there is good agreement between the two methods. Two trend-lines of exponential form are added to each figure to represent the data at planes 9 and 10. This form of equation is used to represent the data, since the ID is usually indicated by the most popular model of this exponent form, which is known as Arrhenius model. High correlation coefficients are shown at 10 and 15 bar, and lower value at 21.4 bar. 


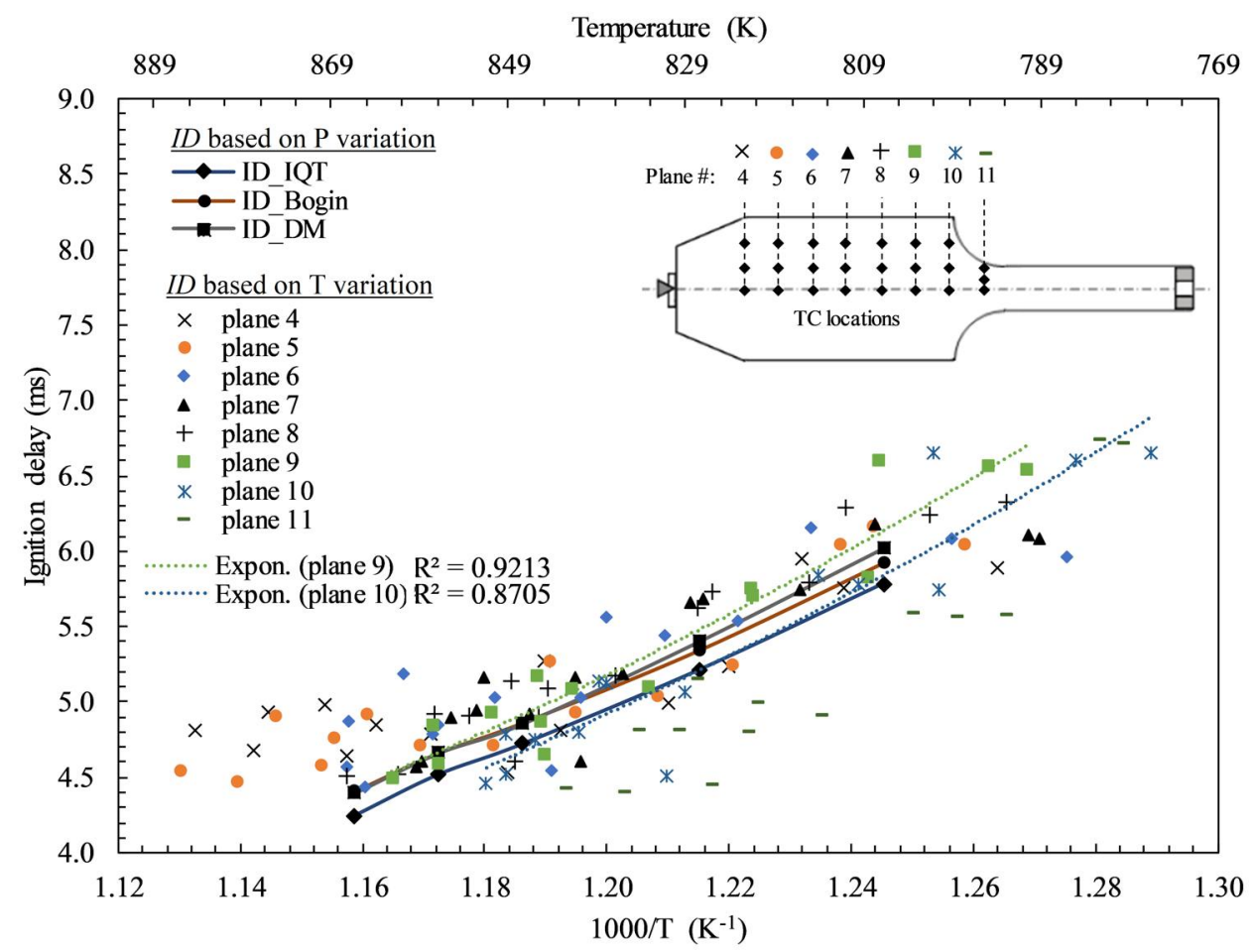

Figure 5.16: Comparison of the ignition delay based on pressure and temperature methods; charge pressure 15 bar

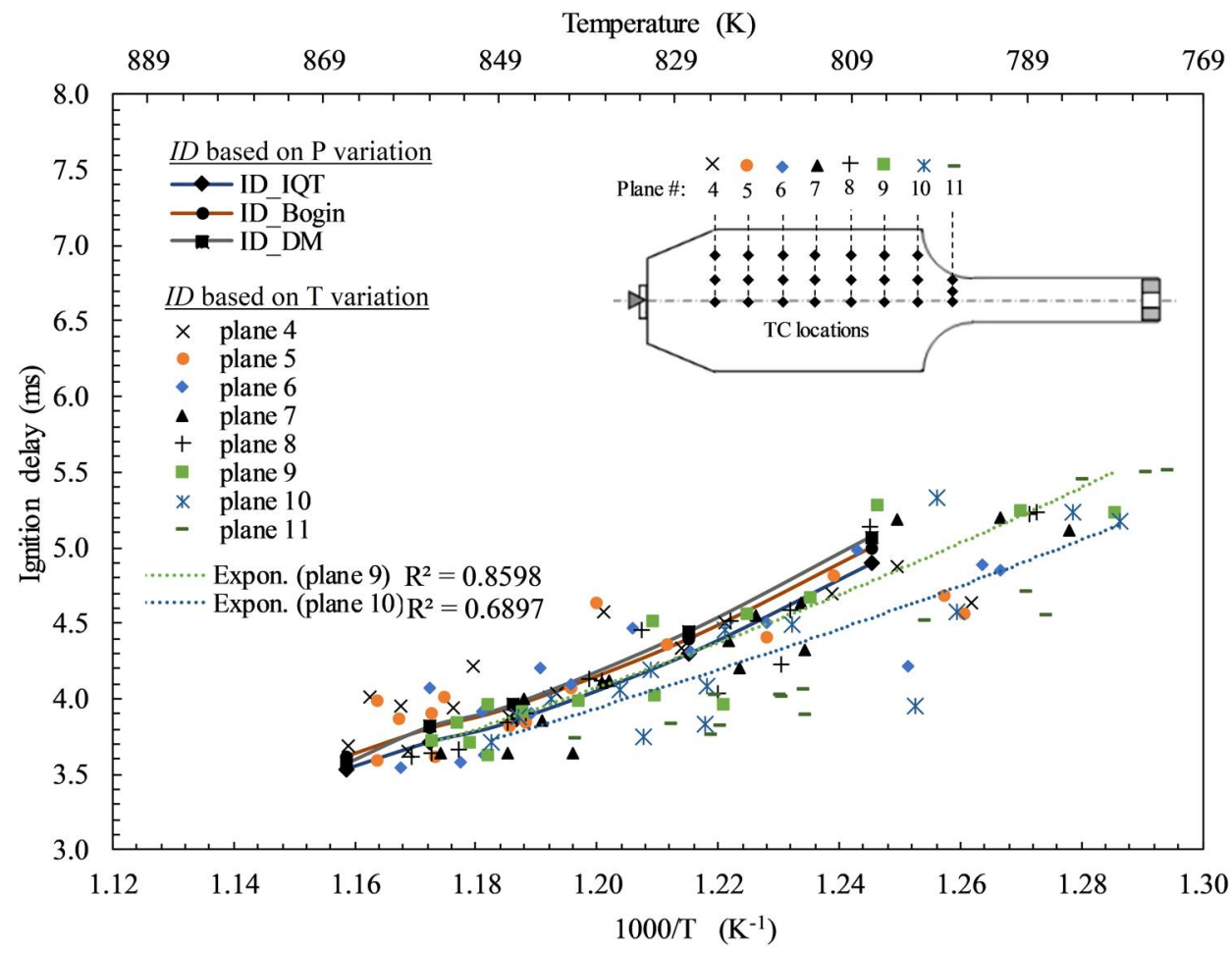

Figure 5.17: Comparison of the ignition delay based on pressure and temperature methods; charge pressure 21.4 bar 


\subsection{Spray Characteristics Results}

The spray characteristics (e.g. spray penetration, propagation speed, and spray cone angle) are typically investigated visually at room temperature under atmospheric pressure (in open space), or under high pressure in a constant volume chamber with a quartz or sapphire window on the chamber wall. In this work, the spray characteristics inside the $I Q T^{T M}$ chamber are investigated at elevated temperatures and pressures by spatial and temporal temperature variations.

\subsubsection{Estimation of Spray Penetration Length and Speed Prop- agation from Temperature Variation}

The macroscopic spray characteristics, which involve spray tip penetration, velocity, and spray cone angle, are often determined using high speed imaging techniques [121] -127 , and most characterization work was conducted by injecting the spray under atmospheric conditions. In this work, temperature variation measurements were used to determine the spray penetration length and velocity, in addition to the spray cone angle.

Spray penetration estimates are based on the elapsed time for the spray to reach the TCs, as explained in Figure 5.18. The figure indicates the variation (drop) in temperature as a ratio $\left(T(t) / T_{\text {initial }}\right)$ at different locations along the chamber centerline during the spray injection period $(\simeq 2 m s)$. The spray front traveling time to reach a particular TC starting from injector is determined when the temperature begins to drop below its initial value. The chamber centerline data was used for spray penetration and speed estimation, because the temperature drop was recorded first by the TCs at the centerline.

The spray speed calculations are explained by the example in Figure 5.18. Two lo- 
cations at $x_{1}=85 \mathrm{~mm}$ and $x_{2}=105 \mathrm{~mm}$ from nozzle injector plane along the chamber centerline were selected to verify this method. Although the data temperature measurements are taken at every $10 \mathrm{~mm}$ of longitudinal distance, which represents the intervals between each consecutive plane of the FTP TCs, it is preferable to use the data from two planes $20 \mathrm{~mm}$ apart to make the speed estimation more reliable. Thus, the spray speed at $105 \mathrm{~mm}$ (or at the time t2) from the injector is calculated based on the data at plane 8 (85 $\mathrm{mm}$ from injector) and plane 10 (105 $\mathrm{mm}$ from injector). Mathematically, the simple definition of speed as the distance traveled per unit time is used by this method to estimate the speed value. Thus, the predicted value of spray speed at $55 \mathrm{~mm}$ from injector is extracted from data at planes $5(55 \mathrm{~mm}$ from injector) and 2 (35 $\mathrm{mm}$ from injector $)$, and the value at $65 \mathrm{~mm}$ from injector is extracted from data at planes $6(65 \mathrm{~mm}$ from injector) and 4 (45 $\mathrm{mm}$ from injector), and so on. 


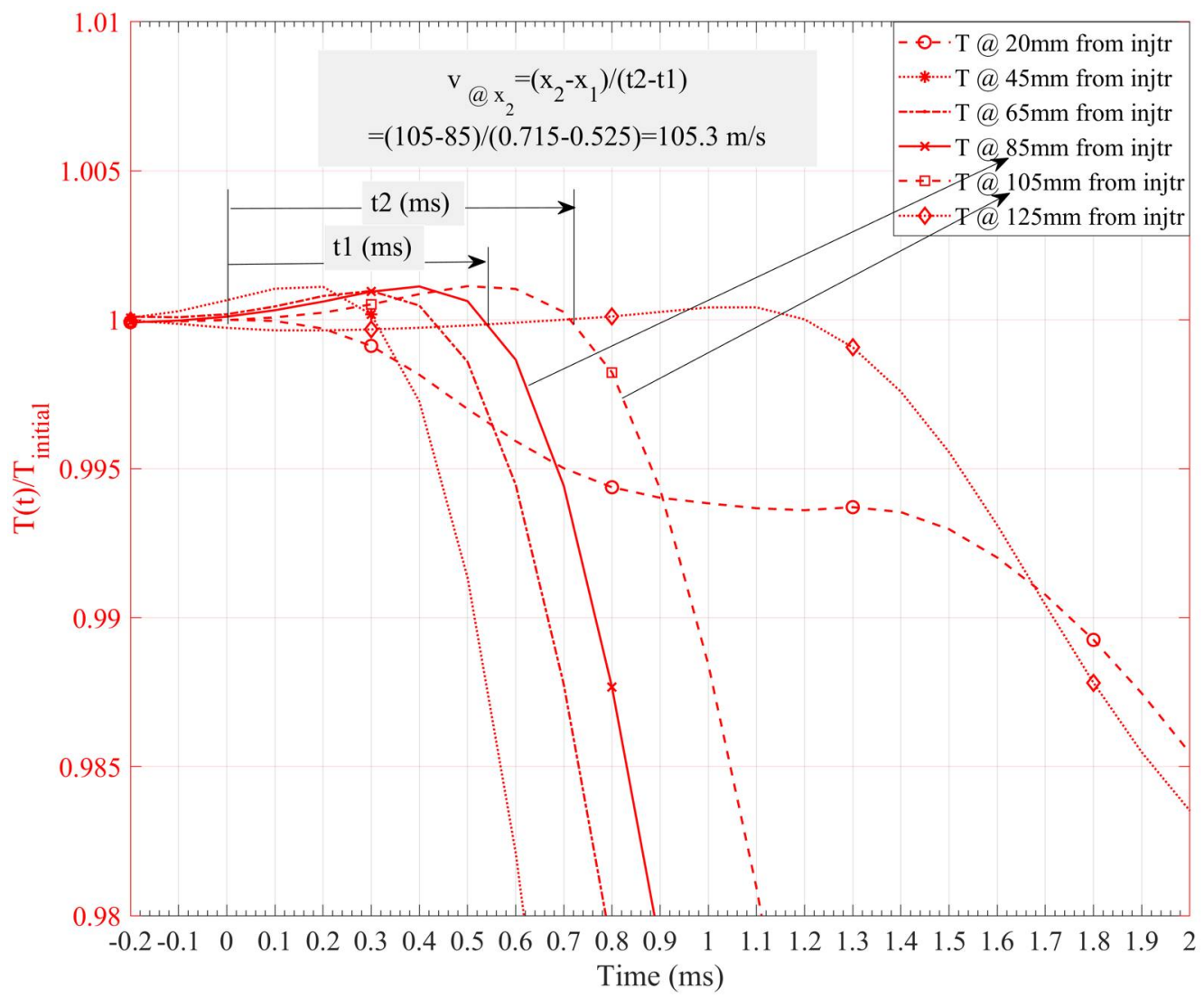

Figure 5.18: Explanation of the estimation of spray penetration and speed from temperature variation during spraying period, all locations are for TCs on the IQT chamber centerline, with 10 bar and $570{ }^{\circ} \mathrm{C}$

\subsubsection{Spray Penetration and Propagation Speed Results}

The spray penetration length and propagation speed were estimated from temperature measurements at 12 locations along the IQT chamber, from $20 \mathrm{~mm}$ to $135 \mathrm{~mm}$ from the injector plane. The calculations were conducted for all conditions and presented on six plots as shown in Figures 5.19 to 5.24

The experimental results of the spray characteristics were compared with the most widely used empirical correlations 128 of spray penetration length, velocity, and cone angle, first proposed by Hiroyasu et al. [129]. These correlations were the modified form which includes the conicity effect, and the spray penetration is described with two equa- 
tions. The equations are proportional to time, and incorporate the physical properties of injecting fluid, environment, and injector specifications, as shown in Equations 5.1 and 5.2 .

$$
\begin{gathered}
S(t)=\left(\frac{\rho_{f}}{\rho_{\text {air }}}\right)^{1 / 4} \sqrt{\frac{\rho_{\text {air }}^{1 / 3} \Delta P}{12 \rho_{f}} t^{3}} \quad \text { for } 0<t<t_{\text {break }} \\
S(t)=2.95\left(\frac{\triangle P}{\rho_{\text {air }}}\right)^{1 / 4} \sqrt{\left(C_{f}\right)^{Z} d_{o} t} \quad \text { for } t \geq t_{\text {break }}, C_{f}=\frac{d_{i}}{d_{0}},
\end{gathered}
$$

where $S$ is the penetration length, $\rho_{f}$ is the fuel density (n-heptane density at $50{ }^{\circ} \mathrm{C}$ ), $\rho_{\text {air }}$ is the density calculated from gas law based on charge air temperature and chamber air pressure at the time of fuel injection. In addition, $\triangle P$ is the pressure difference across the injector $\left(\triangle P=P_{i n j}-P_{a m b}\right), d_{i}$ and $d_{o}$ are the inner and outer diameters of the nozzle, and $Z$ is the power of the conicity parameter $\left(C_{f}\right)$ which equals one. The break-up time, $t_{\text {break }}$, is calculated by equating Equations 5.1 and 5.2 , and the spray tip velocity is obtained by differentiation of the spray penetration in Equations 5.1 and 5.2 .

$$
U_{s}(t)=1.475\left(\frac{\triangle P}{\rho_{\text {air }}}\right)^{1 / 4} \sqrt{\frac{\left(C_{f}\right)^{Z} d_{o}}{t}} \text { for } t \geq t_{\text {break }}
$$

Equations 5.1 to 5.3 are presented in Figures 5.19 to 5.24 for comparison with the experimental results.

Plots of spray penetration as a function of time for the ambient conditions are shown in Figures 5.19 to 5.21, as are the predicted penetration from Equations 5.1 and 5.2. The experimental results are presented at five different ambient temperatures from $530^{\circ} \mathrm{C}$ to $590^{\circ} \mathrm{C}$ on each plot. The momentum source of the spray comes from the injection pressure which remained at $17.93 \mathrm{MPa}$ with all ambient conditions. The ambient pressure acts as a momentum sink, while the ambient temperature (charge temperature) works as an evaporative energy source. The penetration is steeper at the time of injection, as the spray has high momentum and the droplet sizes are relatively large. At 


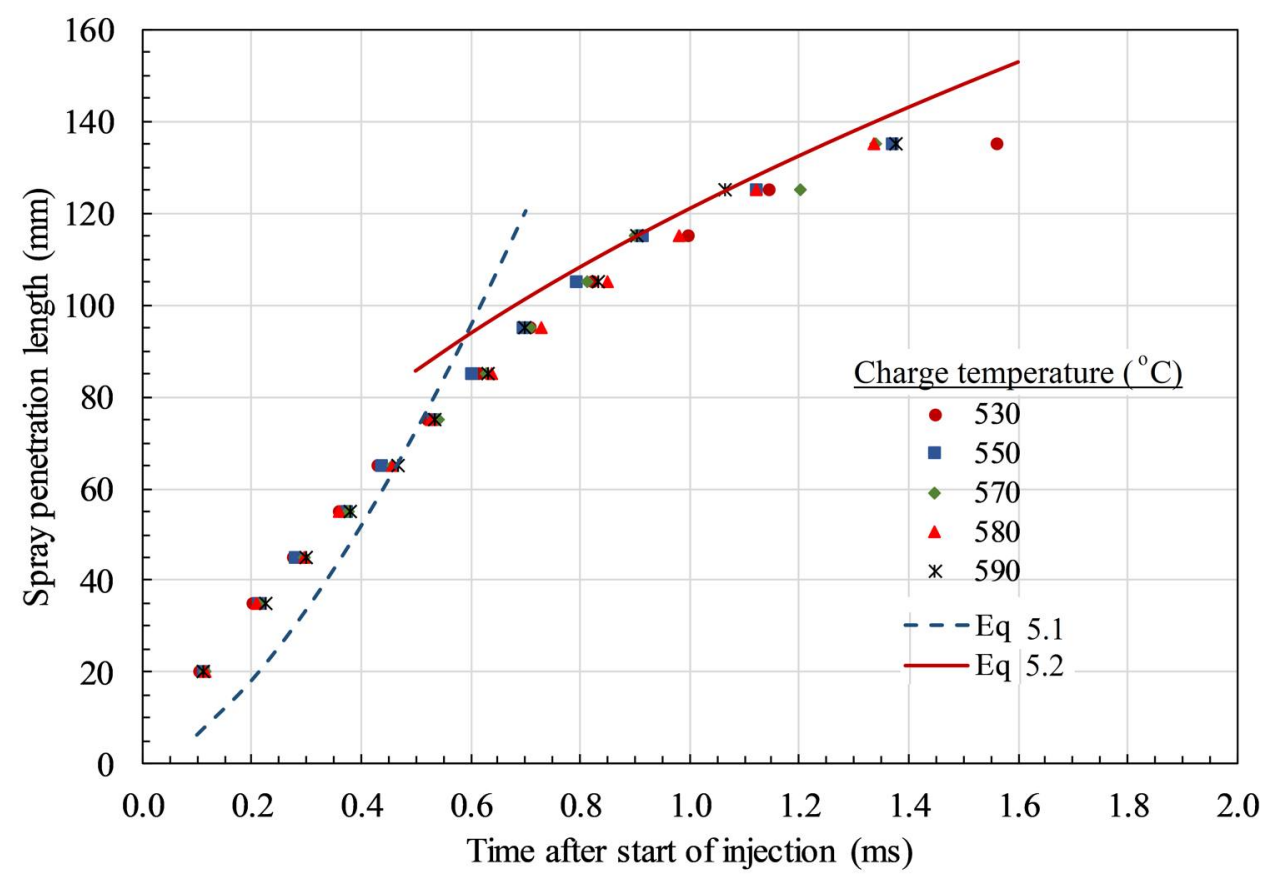

Figure 5.19: Comparison of experimental results of spray penetration length with Eqs 5.1 and 5.2. $P_{i n j}=17.93 \mathrm{MPa}$ and $P_{a m b}=1.0 \mathrm{MPa}$

some point the injection slows down due to loss of momentum caused by the secondary breakup (droplets become smaller), high turbulence and aerodynamic effects. The point of penetration slowdown is approximately $0.8 \mathrm{~ms}$ for ambient pressure at $1.0 \mathrm{MPa}$, and decreases to about $0.6 \mathrm{~ms}$ for the other two ambient pressures.

The ambient temperature seems to have minimal effect on the spray penetration, as clearly shown in Figure 5.19. This agrees with previously published work [122, [130]. As the ambient pressure increases the penetration becomes shorter, and flatter toward the end of chamber where the density increases with pressure and hinders the penetration. The predicted penetration from Equation 5.1 showed relatively high discrepancy with the experimental data where the spray penetrates more rapidly. The second penetration model equation correlates well with the measured data at $1.5 \mathrm{MPa}$ and $2.14 \mathrm{MPa}$. 


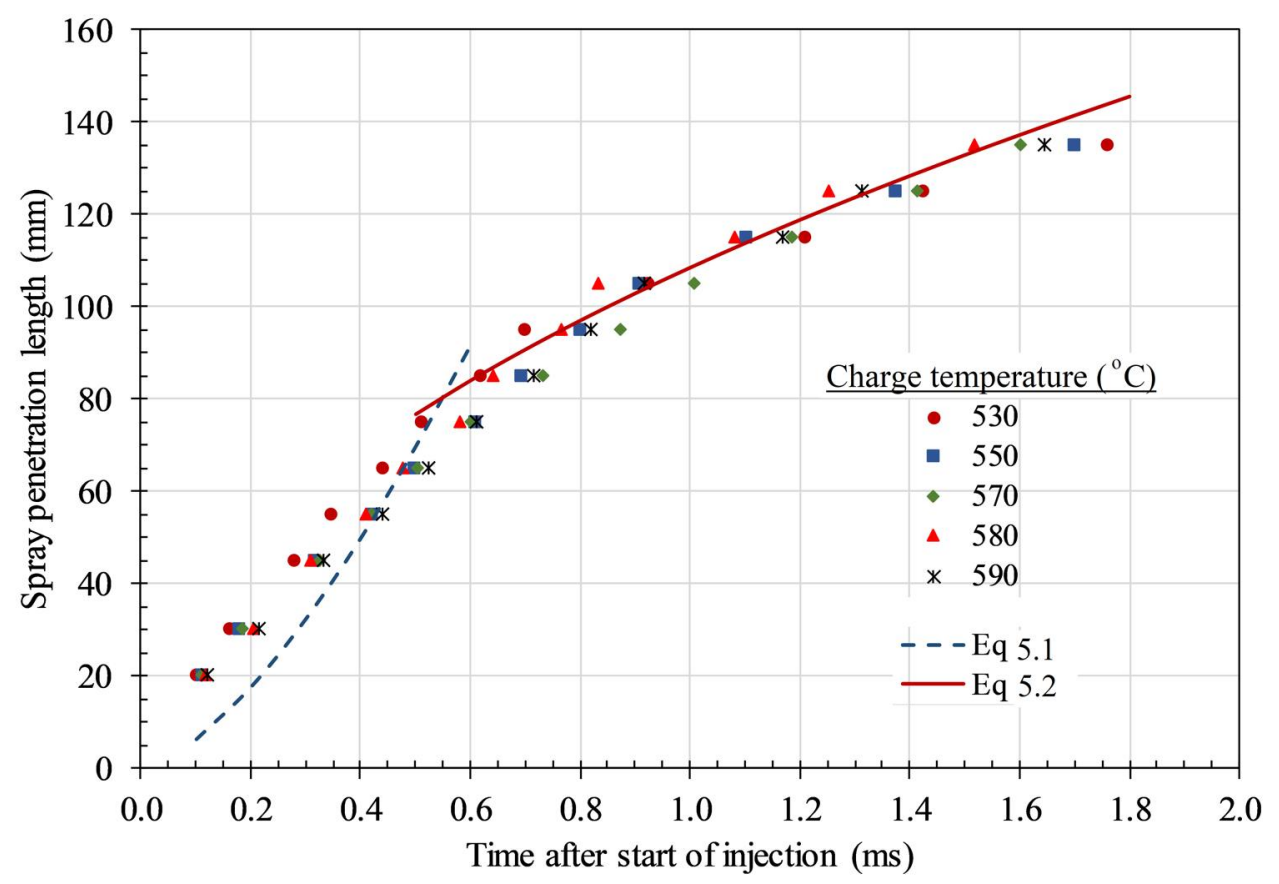

Figure 5.20: Comparison of experimental results of spray penetration length with Eqs 5.1 and 5.2 . $P_{i n j}=17.93 \mathrm{MPa}$ and $P_{a m b}=1.5 \mathrm{MPa}$

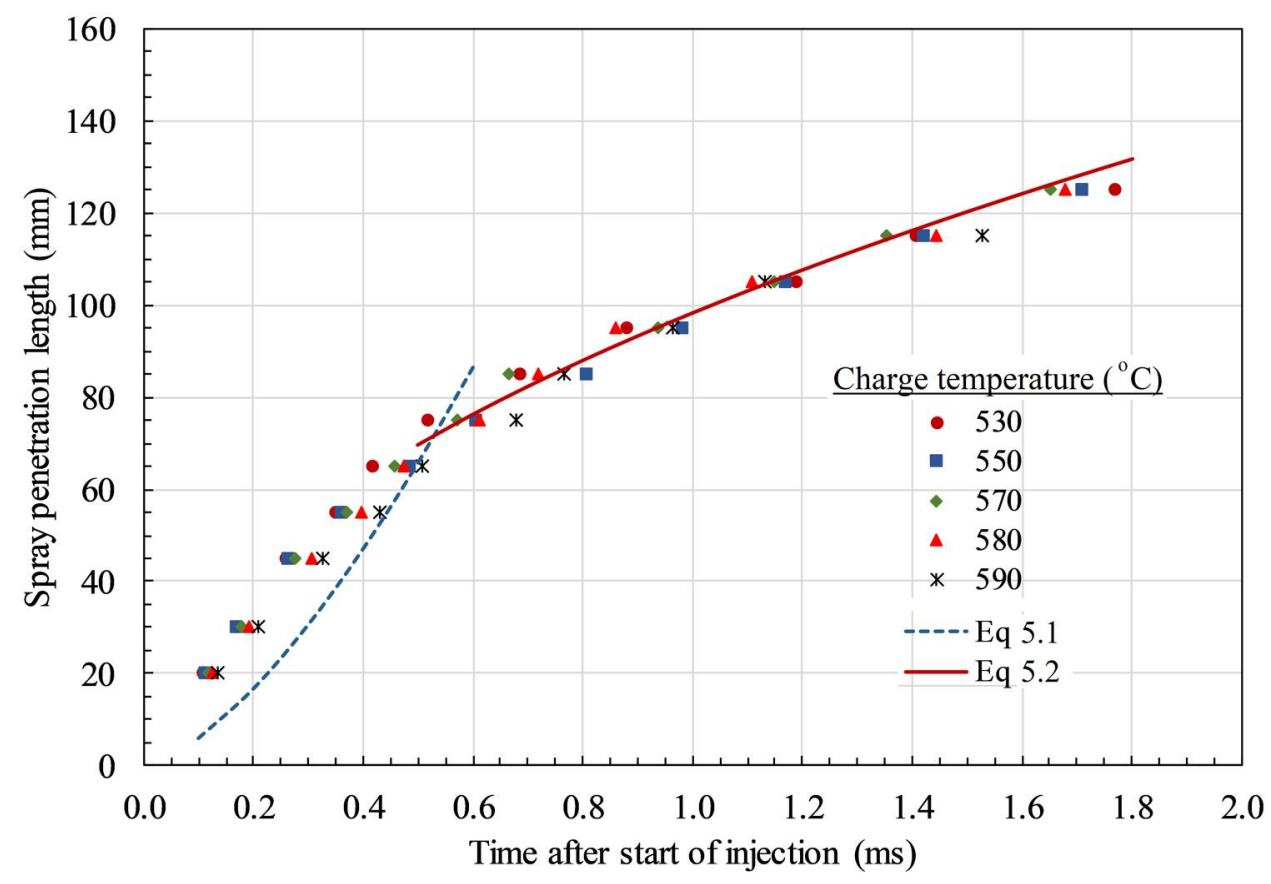

Figure 5.21: Comparison of experimental results of spray penetration length with Eqs 5.1 and 5.2. $P_{i n j}=17.93 \mathrm{MPa}$ and $P_{a m b}=2.14 \mathrm{MPa}$ 


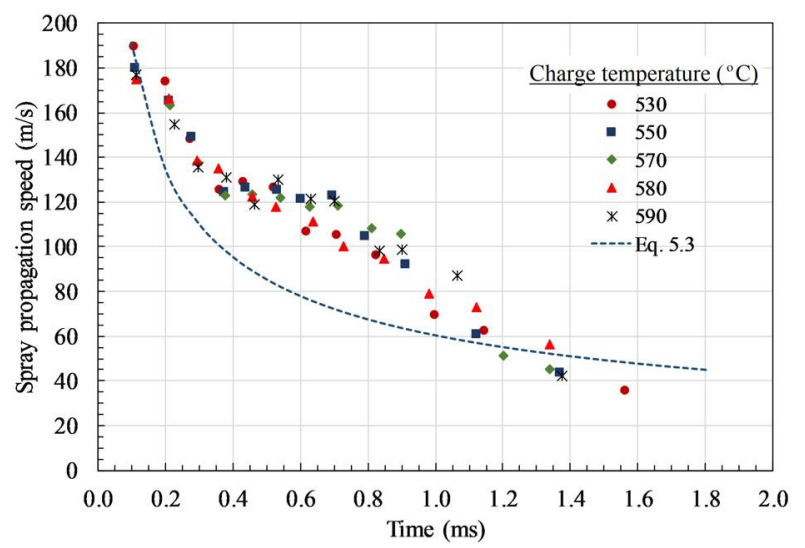

(a) Spray speed vs time

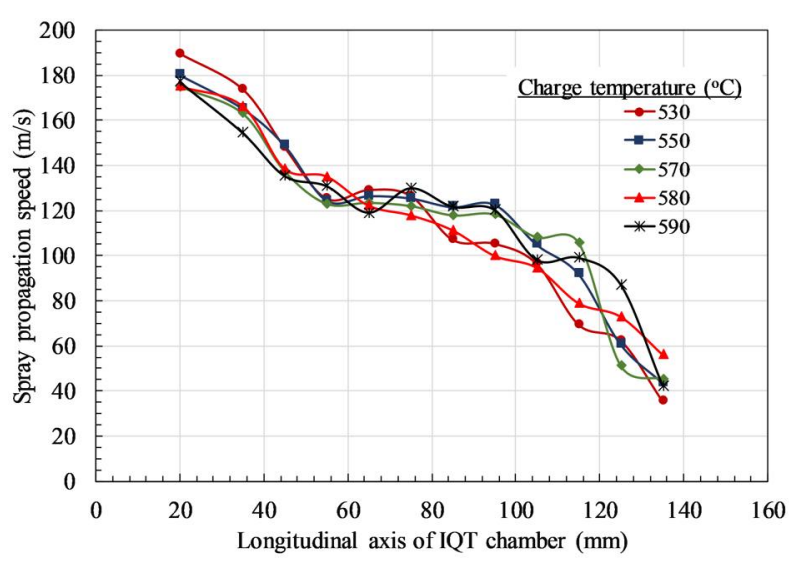

(b) Spray speed vs longitudinal axis

Figure 5.22: Spray penetration velocity profiles at $P_{a m b}=1.0 \mathrm{MPa}$

Figures 5.22 to 5.24 show the variation in spray tip penetration velocity versus time and longitudinal distance along the IQT chamber; the predicted spray velocity from Equation 5.3 is included in each figure. The results indicate that the spray speed drops almost linearly with the axial direction for high ambient pressure condition $(2.14 \mathrm{MPa})$ for different set points. At the other two ambient pressures (1.0 $\mathrm{MPa}$ and 1.5 $\mathrm{MPa}$ ) the spray speed decreases at the beginning, and remains almost constant in the main part of the chamber, then decreases again before reaching the end of the chamber. The predicted spray velocity from Equation 5.3 is close to the experimental data at the beginning and injection end periods, whereas there was a relatively high discrepancy was shown in between. 


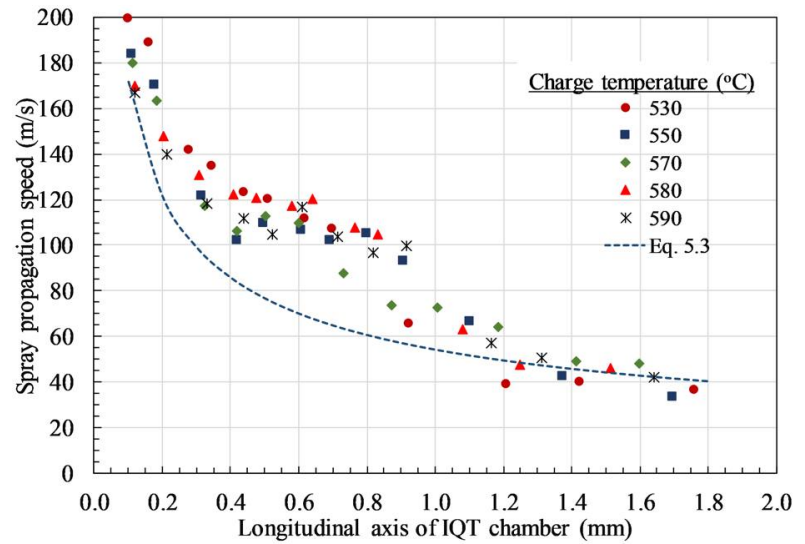

(a) Spray speed vs time

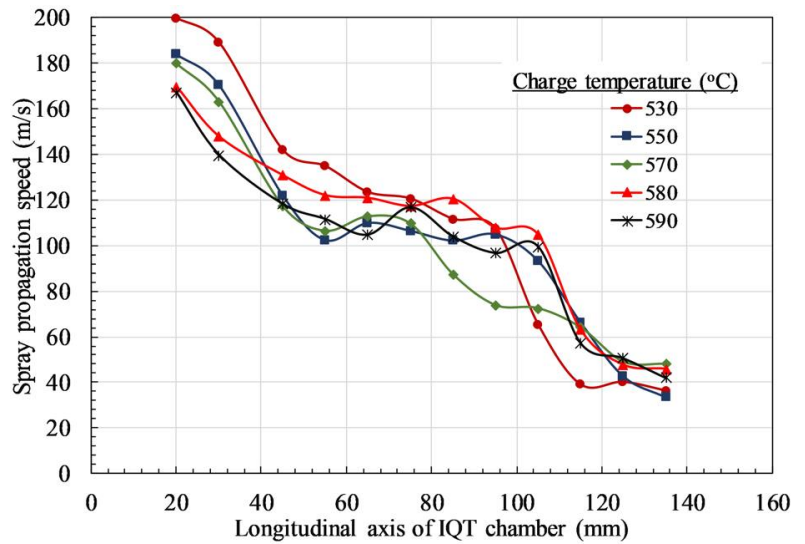

(b) Spray speed vs longitudinal axis

Figure 5.23: Spray penetration velocity profiles at $P_{a m b}=1.5 \mathrm{MPa}$

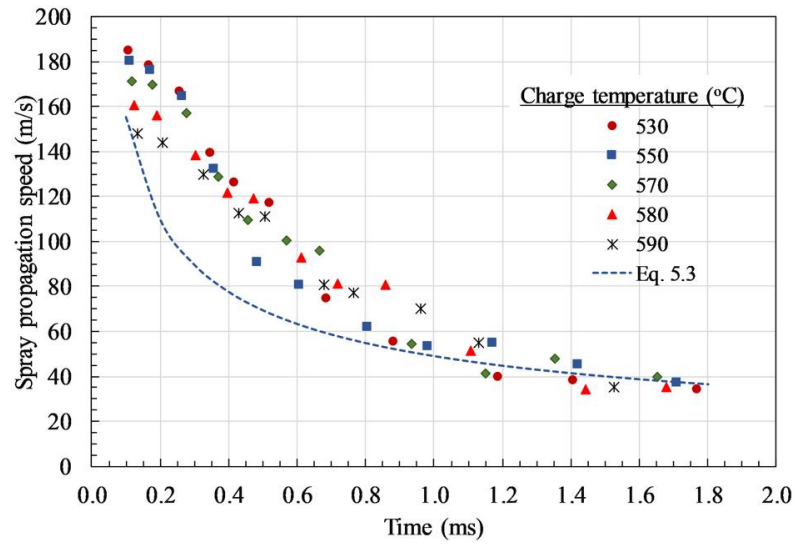

(a) Spray speed vs time

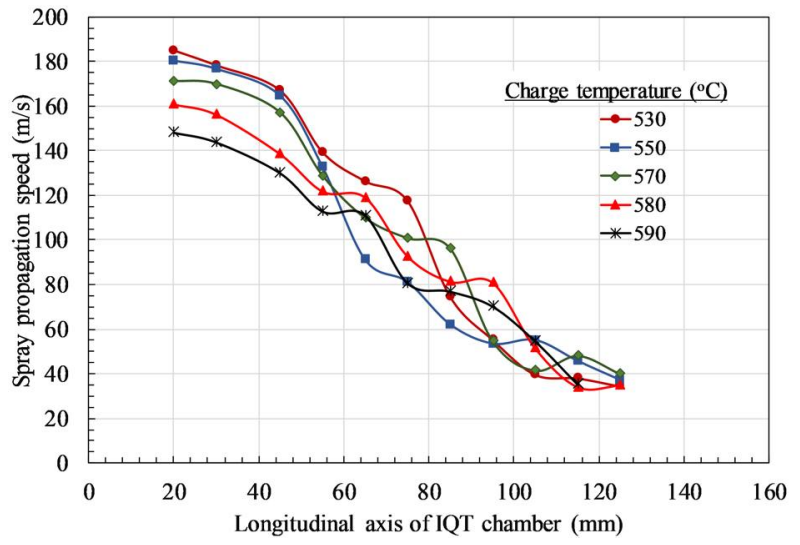

(b) Spray speed vs longitudinal axis

Figure 5.24: Spray penetration velocity profiles at $P_{a m b}=2.14 \mathrm{MPa}$ 


\subsubsection{Spray Cone Angle Estimation from Temperature Drop dur- ing Injection Period}

The spray cone angle, the third parameter of spray characterizations, is estimated from the map of temperature drop at measurement points during the fuel injection period, as shown in Figures 5.25 to 5.27. Three plots with three time intervals at 0.6, 1.2 and $1.8 \mathrm{~ms}$ after the start of injection (SOI) are included on each figure, and the results are given at three conditions of charge temperature and pressure. These conditions were lowest $\left(530^{\circ} \mathrm{C}\right.$ and $\left.10 \mathrm{bar}\right)$, intermediate $\left(570^{\circ} \mathrm{C}\right.$ and $\left.15 \mathrm{bar}\right)$ and highest $\left(590^{\circ} \mathrm{C}\right.$ and $\left.21.4 \mathrm{bar}\right)$.

The temperature drop shown on the vertical axis of the plots is the difference between the initial temperature and the temperature at the corresponding time on the plot.

As the pressure increases, the spray front becomes wider and more droplets spread in a radial direction, as indicated by the higher temperature drop particularly at $r=8 \mathrm{~mm}$ and less at $r=16 \mathrm{~mm}$. A slight drop was again recorded near the chamber wall, which could be due to evaporation cooling of smaller droplets near the wall. At the lowest condition, most injected fuel traveling near the chamber centerline reaches the end part of the chamber, as shown in Figure 5.25c. The spray angle based on the temperature drop scheme increases as the ambient conditions increase. It is calculated from the trigonometry of radial and axial dimensions, and is estimated to be in the range of $20^{\circ}$ and $45^{\circ}$. 


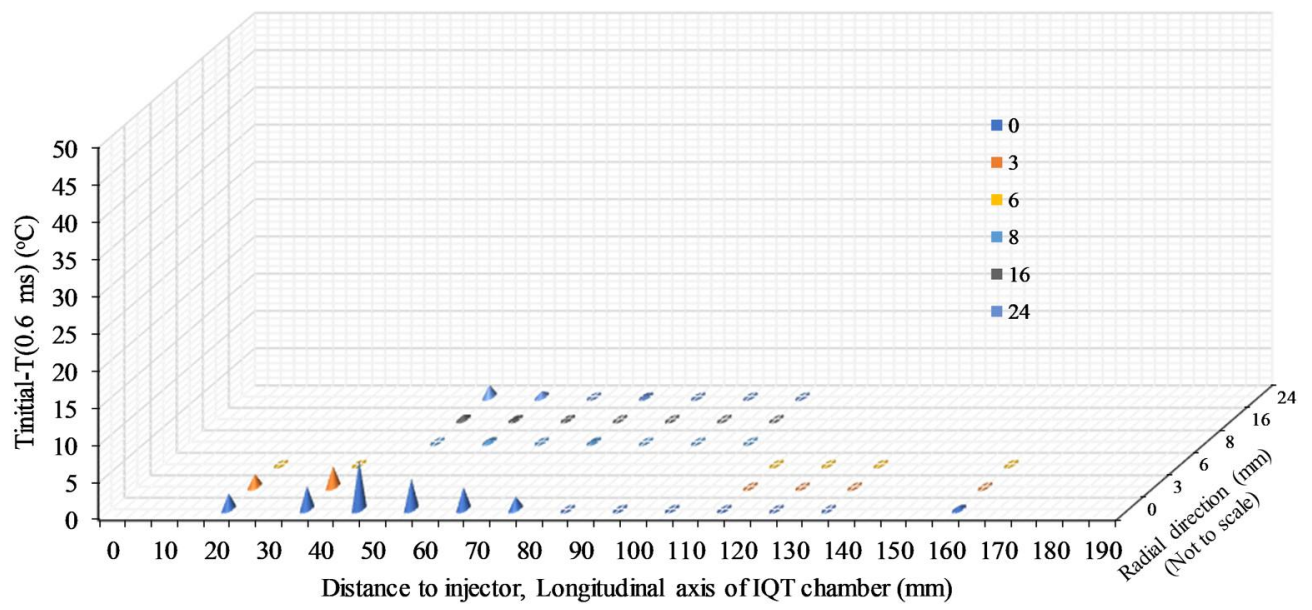

(a) after SOI by $0.6 \mathrm{~ms}$

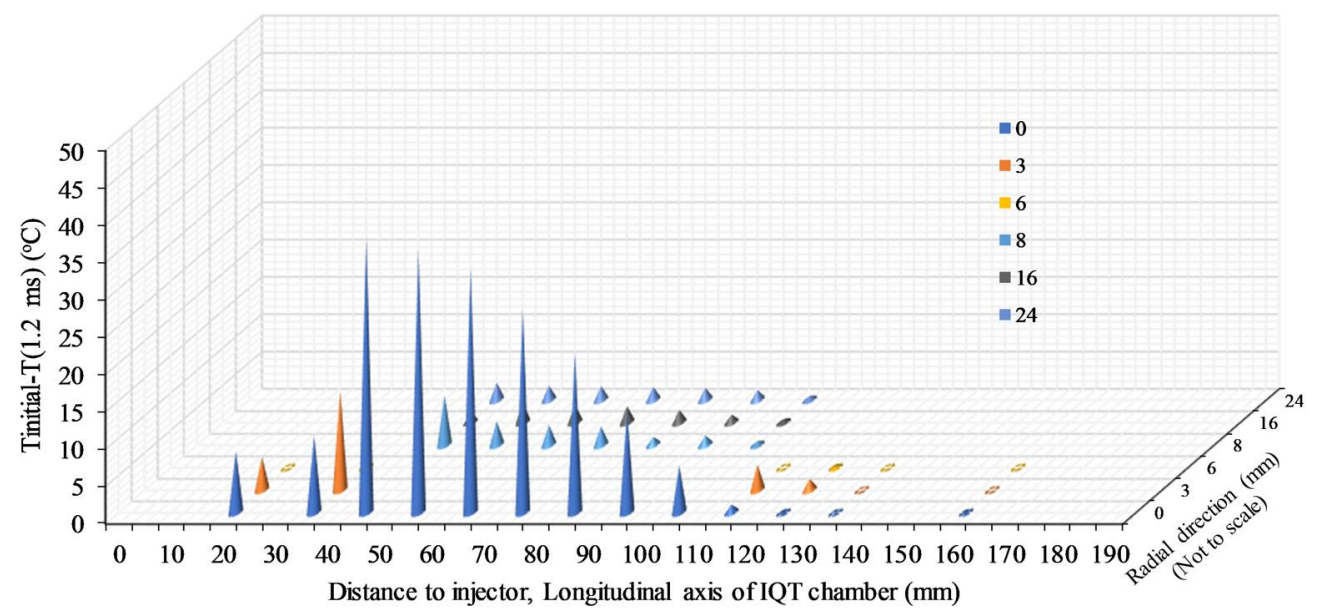

(b) after SOI by $1.2 \mathrm{~ms}$

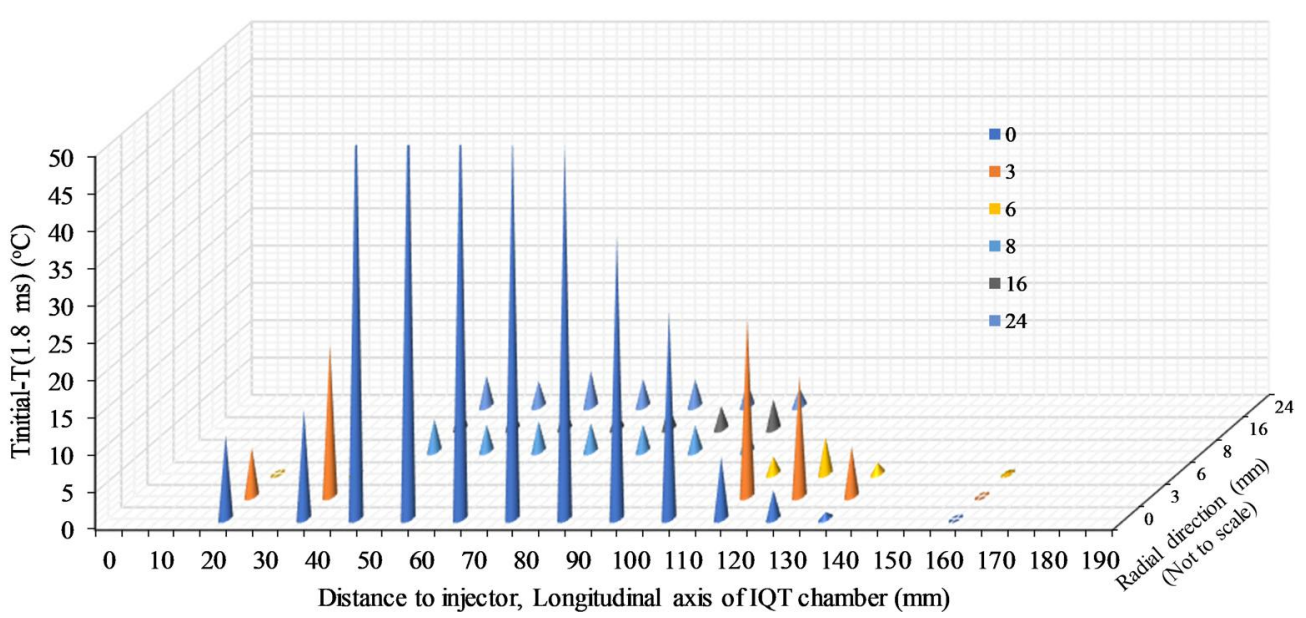

(c) after SOI by $1.8 \mathrm{~ms}$

Figure 5.25: Spray presented through temperature drop measurements, initial conditions: $530^{\circ} \mathrm{C}$ and $10 \mathrm{bar}$ 


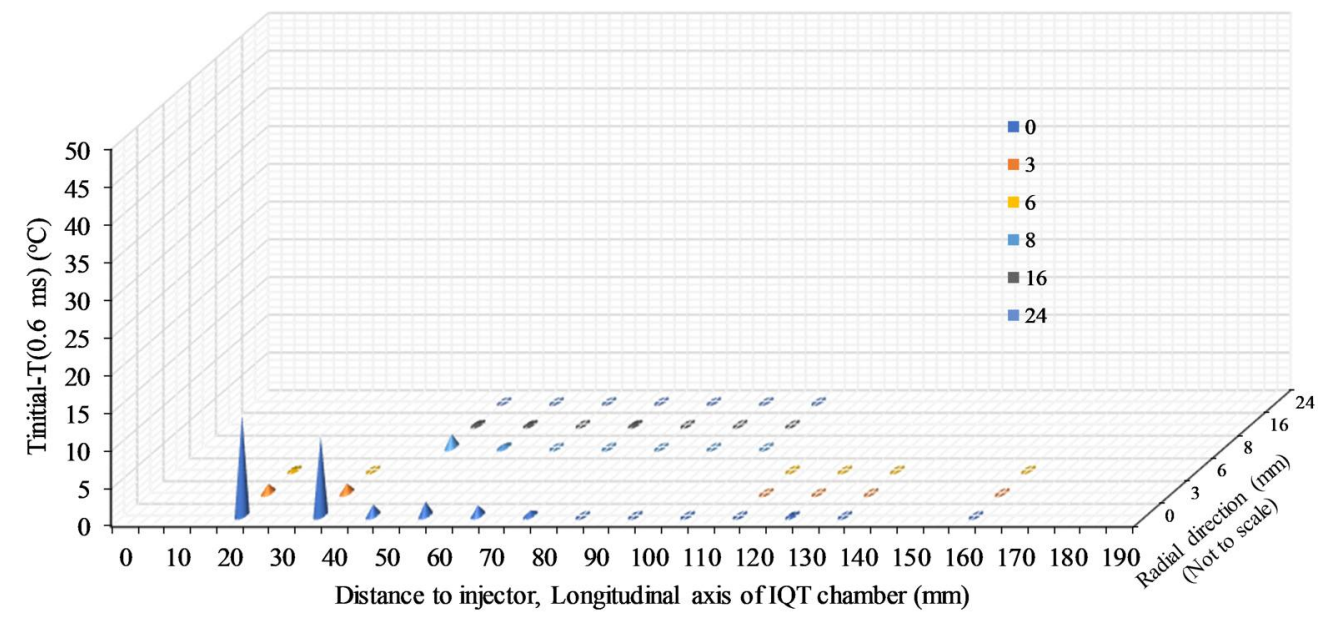

(a) after SOI by $0.6 \mathrm{~ms}$

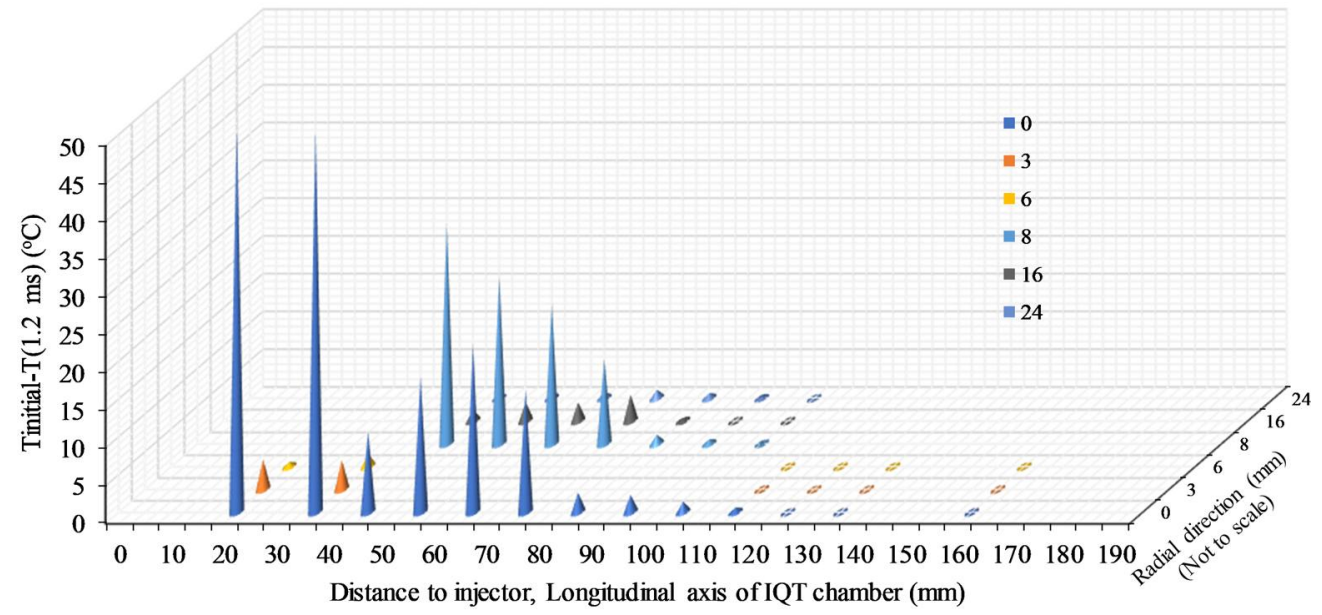

(b) after SOI by $1.2 \mathrm{~ms}$

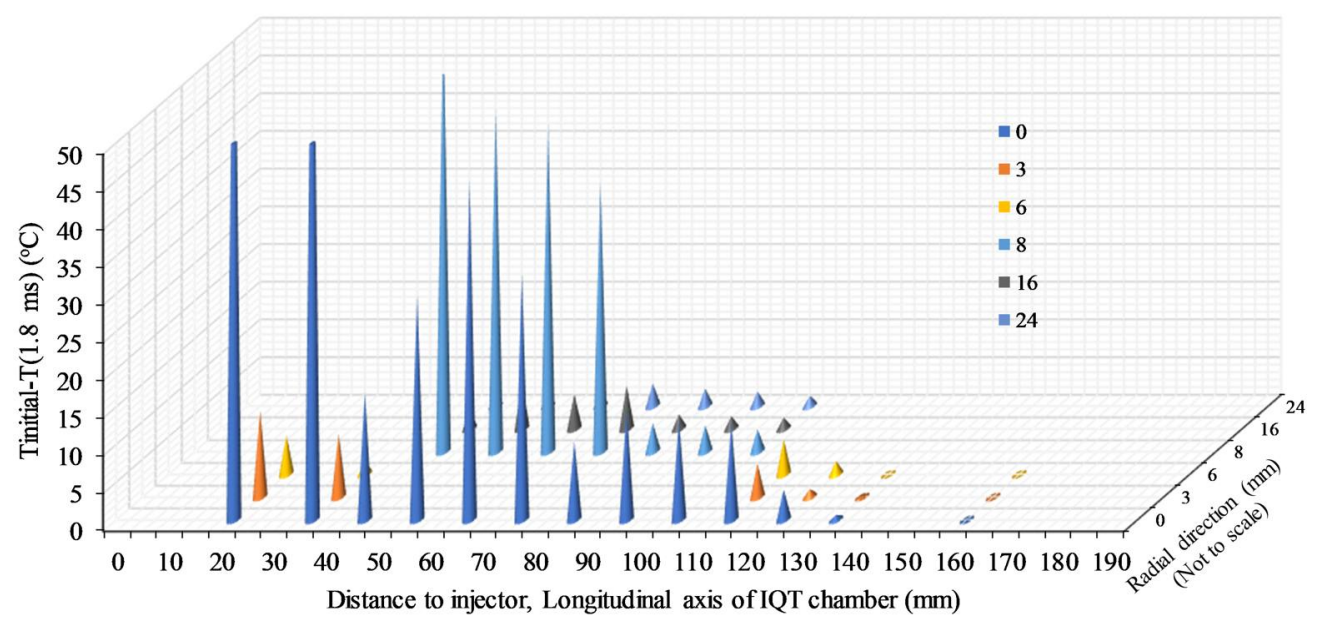

(c) after SOI by $1.8 \mathrm{~ms}$

Figure 5.26: Spray presented through temperature drop measurements, initial conditions: $570^{\circ} \mathrm{C}$ and $15 \mathrm{bar}$ 


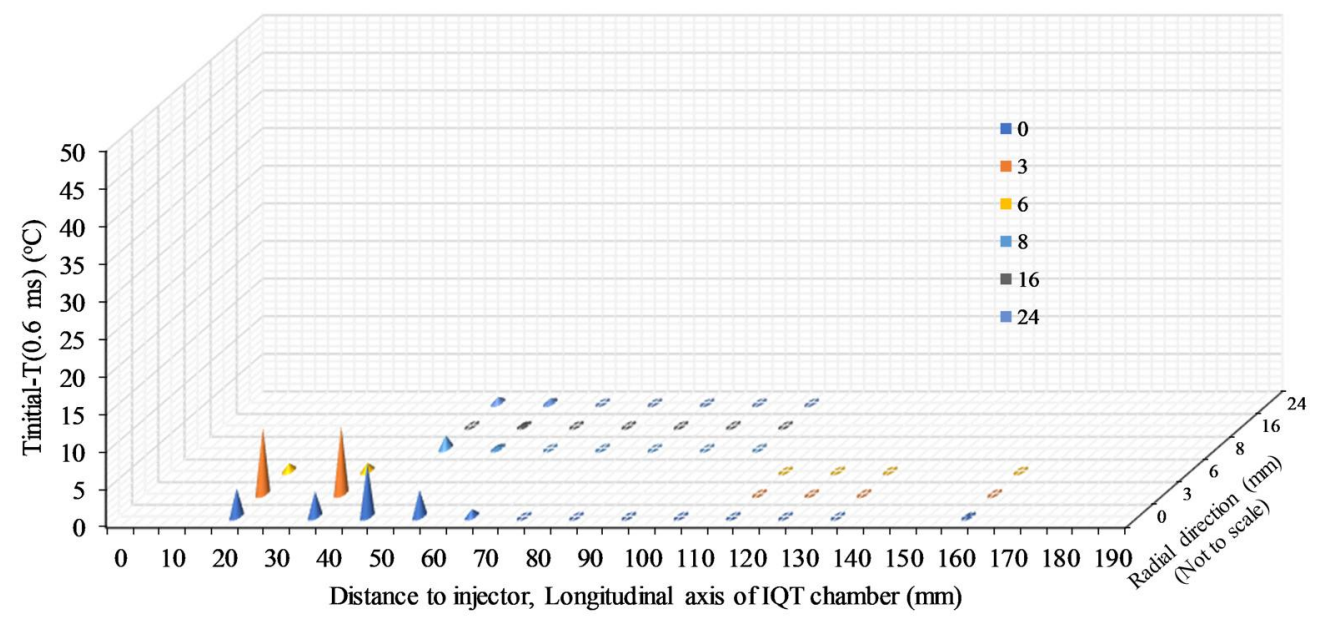

(a) after SOI by $0.6 \mathrm{~ms}$

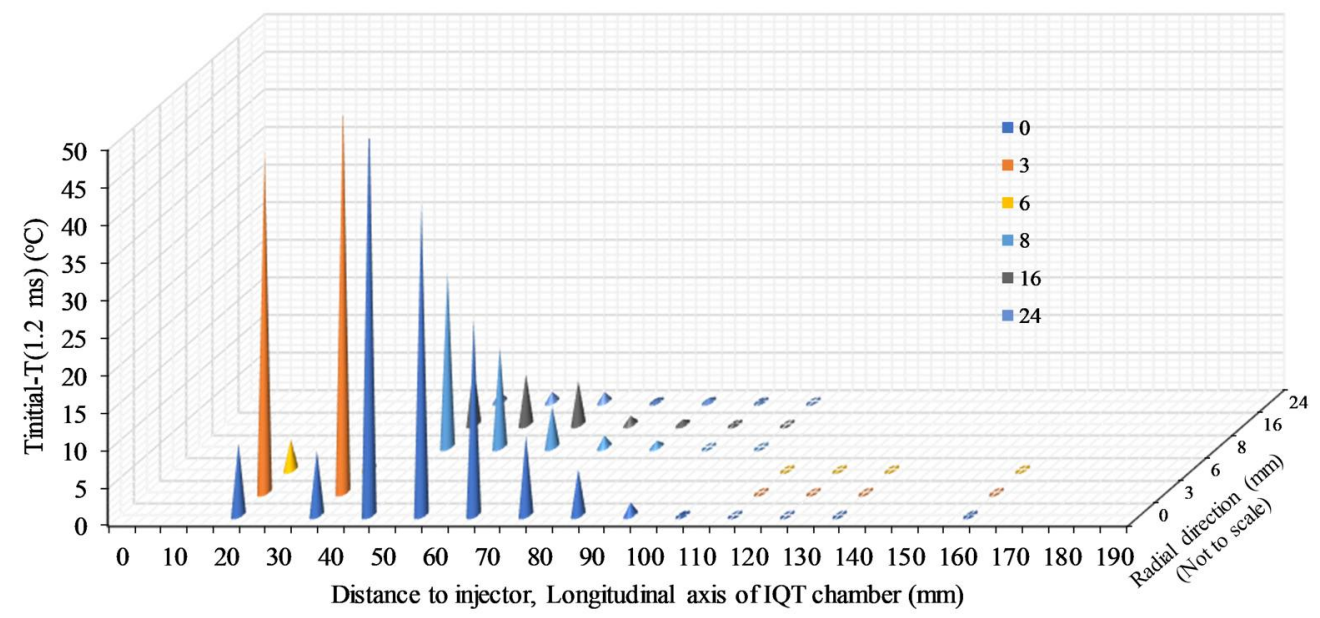

(b) after SOI by $1.2 \mathrm{~ms}$

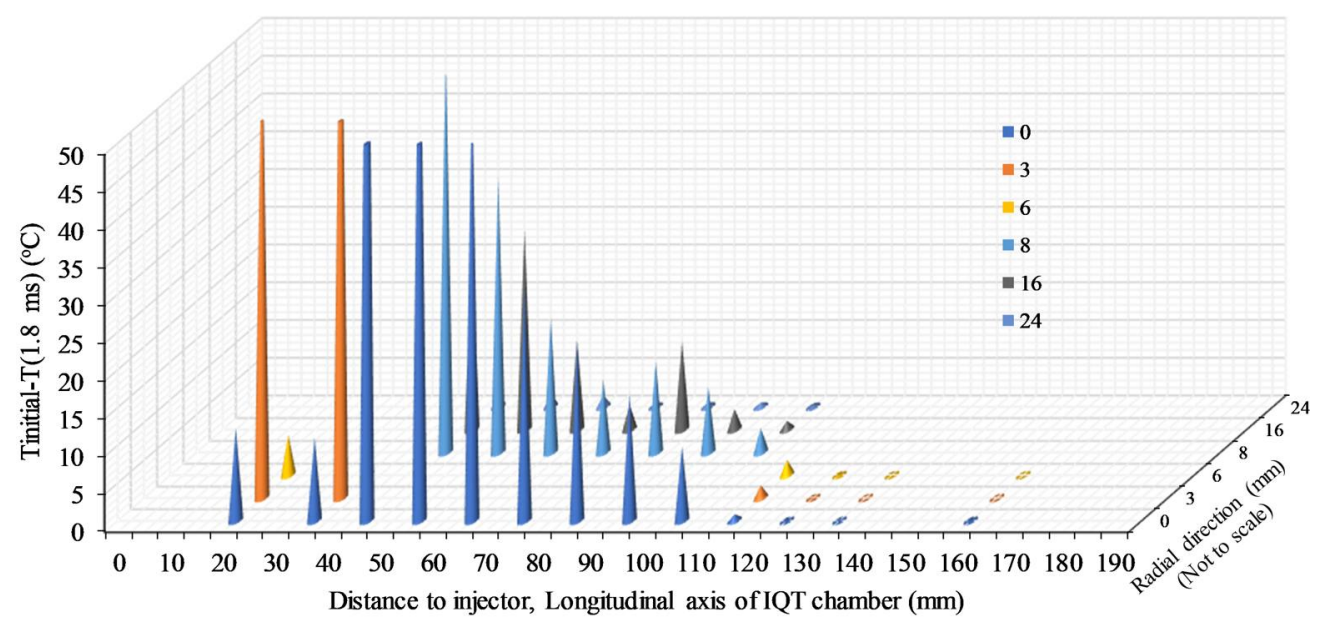

(c) after SOI by $1.8 \mathrm{~ms}$

Figure 5.27: Spray presented through temperature drop measurements, initial conditions: $590^{\circ} \mathrm{C}$ and $21.4 \mathrm{bar}$ 


\section{Chapter 6}

\section{Combustion Numerical Model}

Simulation of fuel spray and ignition in the $I Q T^{T M}$ is introduced in this chapter. Several numerical studies of the compression ignition in a constant volume chamber have been conducted using CFD software codes to create a computational model for spray break up, chemical kinetics, and combustion. This chapter gives an explanation

to such model through exploring the $I Q T^{T M}$ geometry, meshing, initial and boundary conditions, and the theory used in this simulation. ANSYS ICEM is used to create the geometry and mesh, and ANSYS Forte is used to implement the computational theory of combustion.

\subsection{IQT Geometry and Meshing}

The combustion chamber of IQT was drawn and meshed by using ANSYS ICEM computational fluid dynamics commercial software. The dimensions used in the isometric drawing of the chamber were extracted from the two dimensional sketches provided by Advanced Engine Technology. Then, the three dimensional drawing of the chamber was implemented on the ICEM after converting the dimensions into millimeters, as shown in Figure 6.1. The total volume of the drawn geometry is approximately $213 \mathrm{~cm}^{3}$. The chamber wall was partitioned into seven areas, f1 through f7, Figure 6.1, to include 


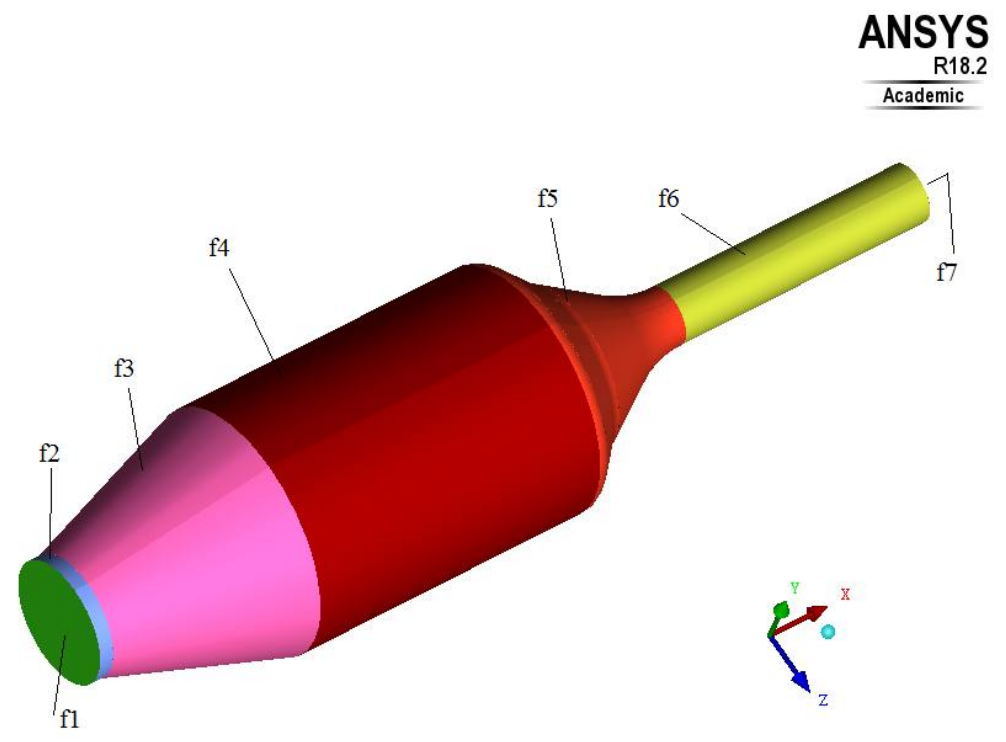

Figure 6.1: IQT combustion chamber isometric view with partitions

the initial temperature gradients along the chamber axis before fuel injection and to be compatible with the measured one. Then, the IQT geometry (domain) is pre-meshed as shown in Figure 6.2. Temperature distributions along the chamber axis were measured for pressurized and unpressurized chamber as shown in Figure 6.3.

The geometry domain of the IQT was meshed by using ANSYS ICEM. The structured grid was used in meshing the domain of the IQT as shown in Figure 6.2. This type of grid gives better convergence and higher resolution compared to unstructured grid [131], 132]. The mesh is refined at the injector tip area where there is a high density of fuel droplets moving with high velocity.

\subsection{Initial and Boundary Conditions}

The heated IQT chamber is pressurized with charge air through intake valve from a high pressure and ambient temperature air cylinder and kept for few seconds before fuel injection. Prior to the fuel injection, air pressure inside the IQT chamber is almost constant with a thermal gradient along the chamber due to cooling effects on both ends 


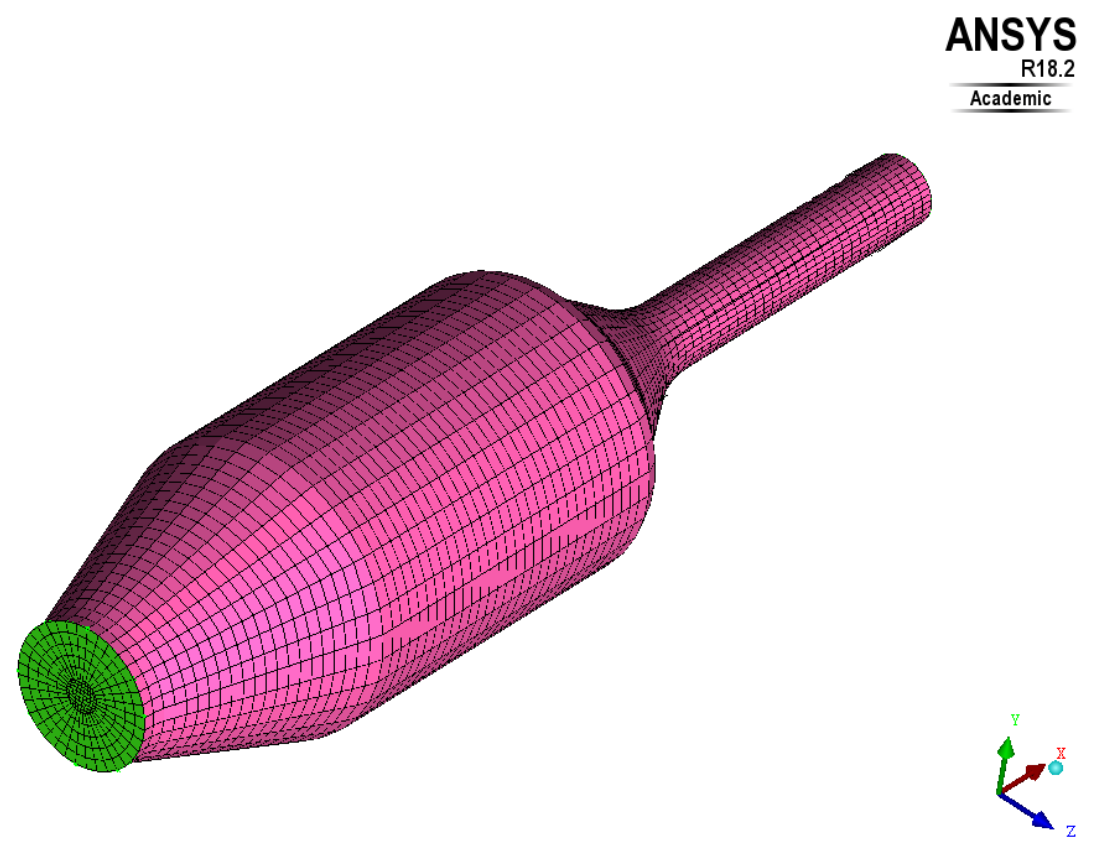

Figure 6.2: Initial structured mesh of the IQT

(injector and pressure transducer) of the IQT chamber. The chamber wall is heated up to a set point skin temperature while the injector and pressure transducer should be cooled and maintained at a temperature of $50^{\circ} \mathrm{C}$ and $130^{\circ} \mathrm{C}$, respectively. It is important to include this temperature distribution in the initial conditions of the CFD model.

The temperature along the chamber axis was measured at two heater settings with two air chamber pressure by inserting a thermocouple from pressure transducer port and fitting the pressure sensor on the inlet valve. The IQT control system disables chamber heaters for the period starting at the end of pressurizing the chamber with air up to the end of combustion. Thus, two heater settings (disabled and enabled) in that period were included in the temperature measurements as shown in the Figure 6.3a. The measured temperature distribution was showed high agreement with Metcalf et al. [76]. It is introduced as an initial condition for temperature to the modeling through a user defined function (UDF) used in ANSYS Forte. As a first guess to get the initial temperature distribution without using UDF, the chamber wall was divided longitudinally into 8 portions (Figure 6.1) and each portion was kept at a constant temperature through a 
setting in the boundary conditions of the Forte. The initial temperature distribution along chamber axis are shown in the dotted line with triangle markers in Figure 6.3a, which is very close to the experimental data.

The temperature distribution along chamber centerline prior to the fuel injection was collected from experimental measurements and used as an initial condition in the simulation. Figure 6.3b shows temperature distribution at chamber centerline for charge pressure and temperature at $21.4 \mathrm{bar}$ and $580{ }^{\circ} \mathrm{C}$, respectively. The temperature distribution is fitted as three lines. The three linear equations were used in a created Matlab code to get the initial condition data which is stored in a file with csv format. On the other hand, all chamber boundaries are kept adiabatic by setting heat transfer to zero. Switching walls to heat transfer case has no effects on combustion process [133 which lasts only a very short period.

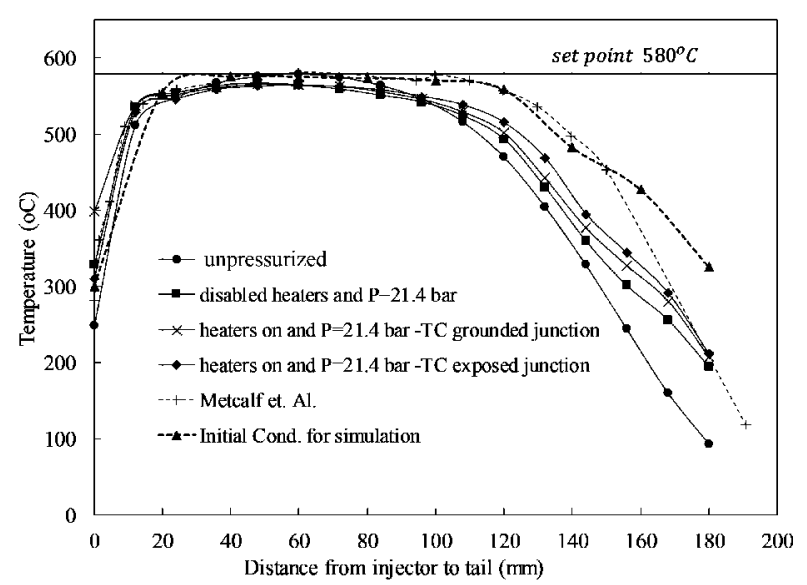

(a) measurement without combustion

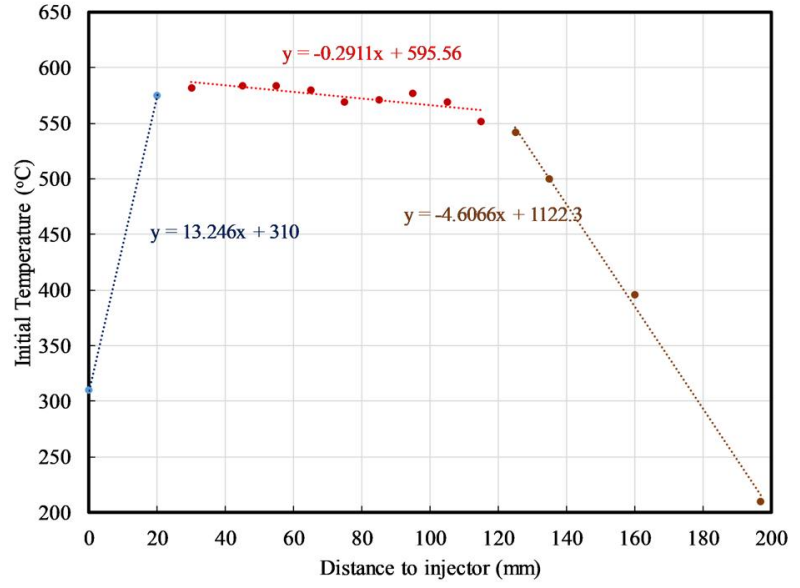

(b) measurement with combustion

Figure 6.3: Temperature distribution measurements at chamber centerline at pressure 21.4 bar and set point $580^{\circ} \mathrm{C}$ 


\subsection{Global Mesh Size and Maximum Time Step Sensi- tivity Analysis}

The created IQT geometry with pre-mesh is imported first to the ANSYS Forte. Then, mesh controls settings are applied on the pre-meshed geometry by selecting two inputs for two sub-nodes: material point and global mesh size (gms). Those two inputs are required for the case of automatic meshing. The material point should be selected properly within the computational domain for the automatic mesh generation to stay within the boundaries. The Cartesian coordinate of this point was decided to be at $(20,0,0 \mathrm{~mm})$ throughout the numerical study. The gms has an effect on the meshing and refinement over the computational domain. Thus, the simulation has been run and checked against experimental results at three different values of the gms $(2,4$, and $6 \mathrm{~mm})$. Temperature gradient is used to drive the solution adaptive mesh refinement. The mesh is refined automatically wherever there is a gradient in temperature at the running time step. The mesh refinement based on temperature gradient is well explained in Figure 6.4. 

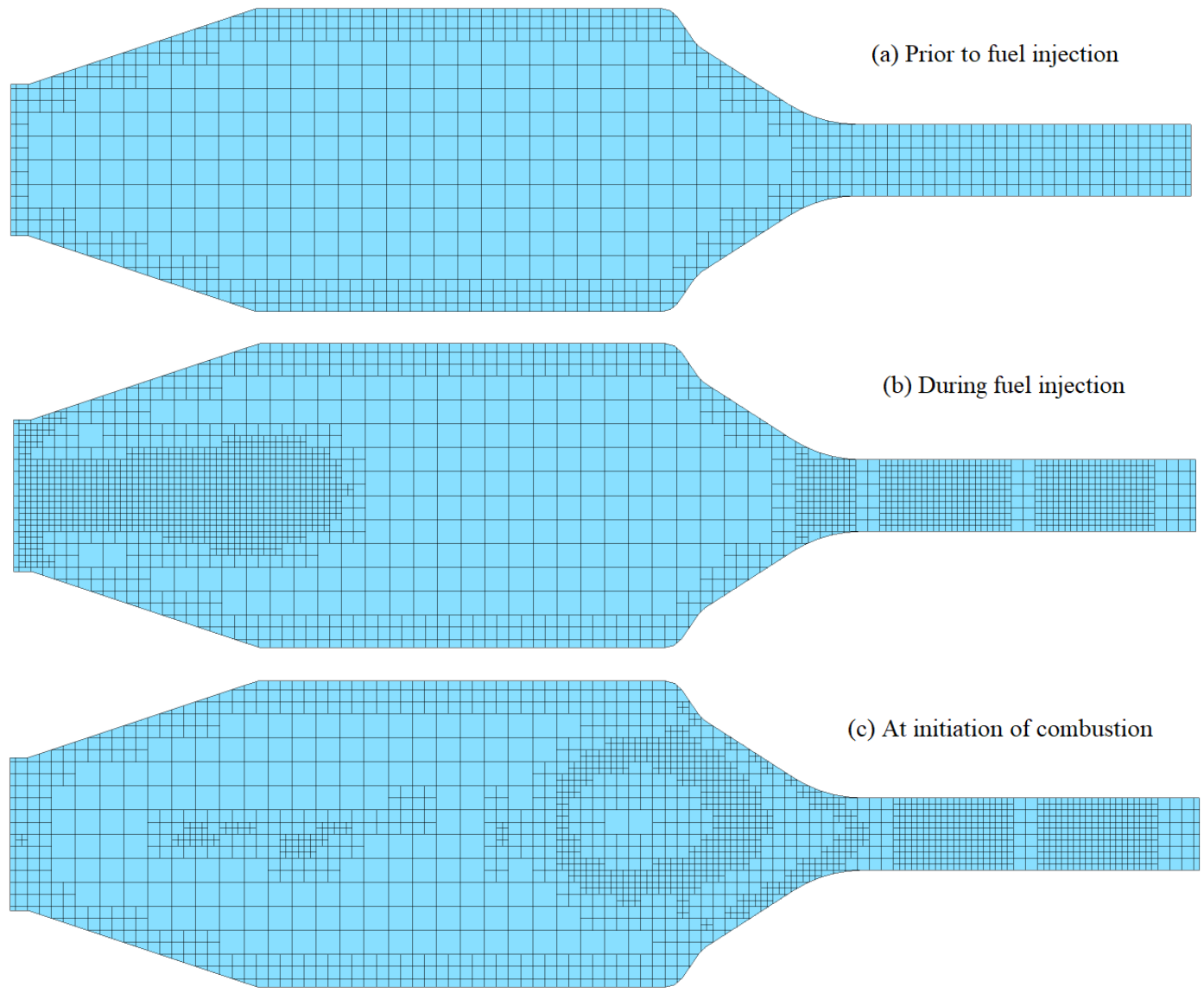

Figure 6.4: Mesh automatic refinement at milestones of simulation process of fuel injection and combustion

The maximum time step (mts) is used in Forte to restrict time-step growth, which can enhance convergence at the time of rapid change, like during droplet breakup and chemical reactions. The mts may be defined as a profile. However, it is defined as a constant value during simulation time. The simulation was checked at three values of the mts $(2,3$, and $5 \mu s)$. Thus, the simulation was run nine times at different values of gms and mts in order to obtain the best mts and gms. The advantage of splitting the calculations of the CFD and the chemical kinetics through using parallel platform with 2 processors was included in the implementation of the simulation. The total simulation run-time (the overall solution time and the time for chemistry) and the maximum number 


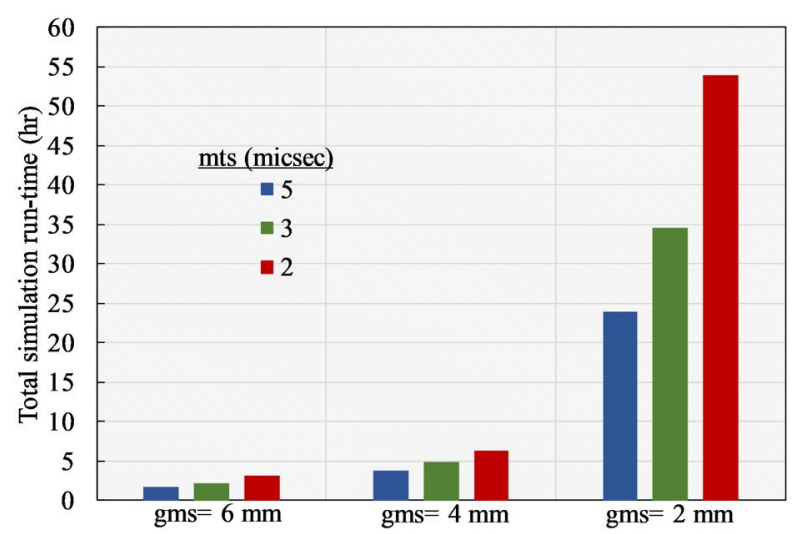

(a) Total simulation run-time

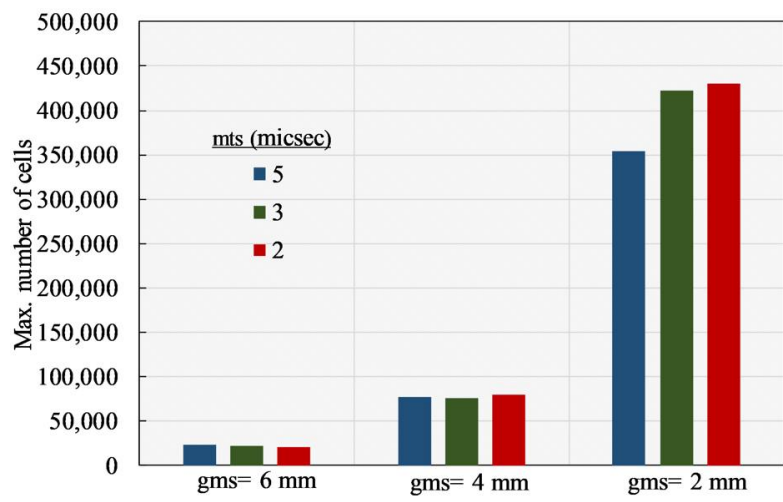

(b) Maximum number of cells

Figure 6.5: Comparison of total simulation run-time and Maximum number of cells at different values of mts and gms

of cells at different values of mts and gms are presented in Figure 6.5. The total simulation run-time and maximum number of cells increase significantly when the gms goes down beyond $4 \mathrm{~mm}$. Figure 6.6 shows the pressure variation with time for experimental and numerical results at 21 bar and $590^{\circ} \mathrm{C}$. The convergence study was conducted by using a skeletal mechanism of n-heptane with 35 species and 72 reactions [134]. The closest numerical results to experimental is when the gms and mts at $4 \mathrm{~mm}$ and $3 \mu s$, respectively. These values were used in the simulation for all conditions. 


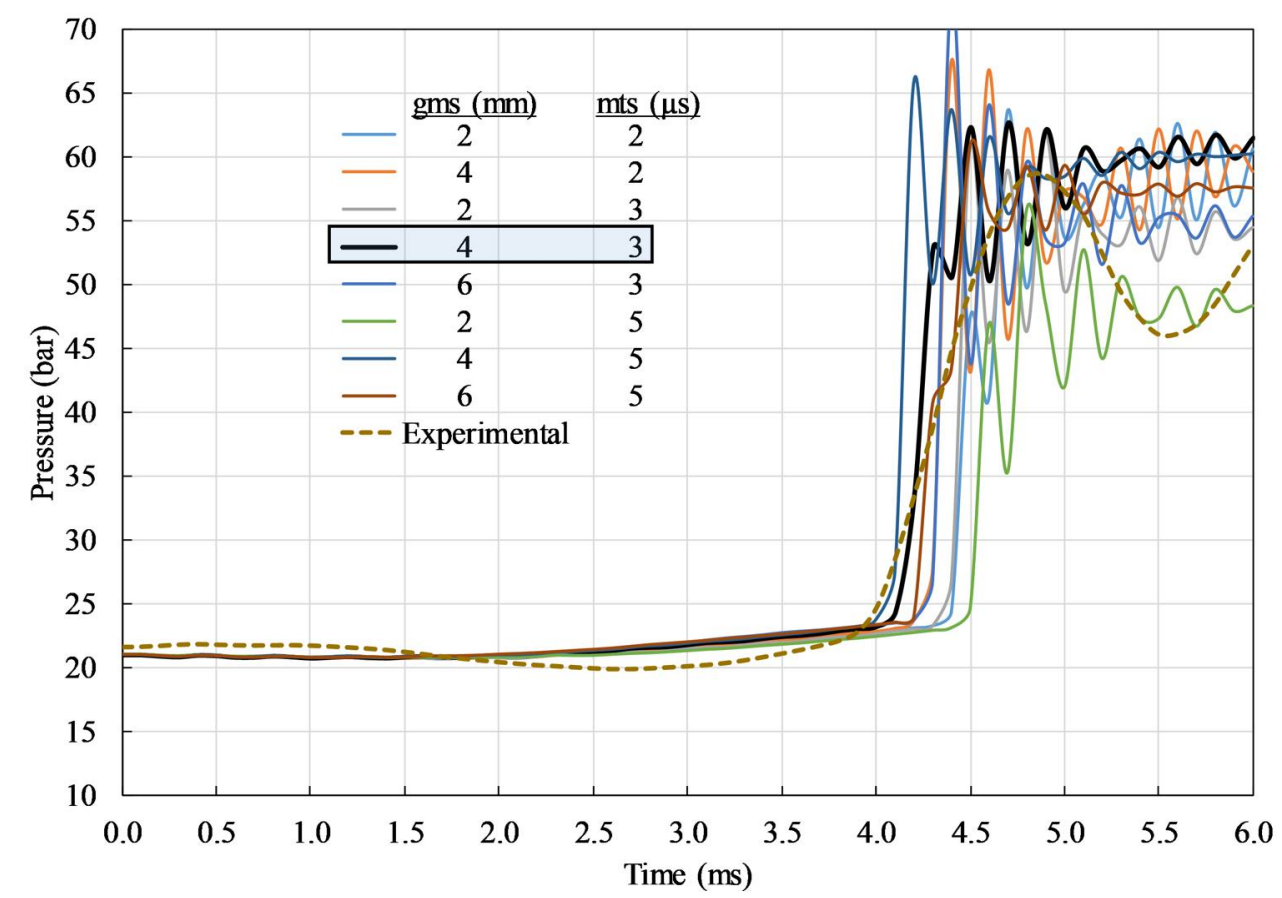

Figure 6.6: Verification of global mesh size and maximum time step

\subsection{Governing and Transport Equations in Combus- tion (Continuous Phase Governing Equations)}

In the CFD models, the standard conservation equations of mass, momentum and energy with enhanced sub-models such as turbulence and species transport are solved numerically at each cell of the discretized fluid domain. The solution of the conservation equations demonstrates thermodynamic state of the mixture spatially and temporally. More details on the turbulent models and governing equations can be found in the reference 135 . 


\subsubsection{Continuity Equation}

The unsteady conservation continuity equation with mass source term can be written in vector form as:

$$
\frac{\partial \rho}{\partial t}+\nabla \cdot(\rho \vec{v})=S_{m}
$$

Where $\rho$ and $\vec{v}$ are fluid density and velocity vector, respectively and $S_{m}$ is the mass source such as that one provided from the liquid droplet evaporation.

\subsubsection{Momentum Equation}

The unsteady 3D conservation momentum equation can be written in the form:

$$
\frac{\partial}{\partial t}(\rho \vec{v})+\nabla \cdot(\rho \vec{v} \vec{v})=-\nabla p+\nabla \cdot\left(\mu \nabla \vec{v}-\rho \overline{\mathbf{v}^{\prime} \mathbf{v}^{\prime}}\right)+\rho \vec{g}+\vec{F}
$$

Where $p$ is the static pressure, $\mu$ is the viscosity of the mixture gases, $\mathbf{v}^{\prime}$ is the fluctuating component of the velocity, $\rho \vec{g}$ is the gravitational body force which is usually

negligible because of its trivial effect comparing to the external body force $\vec{F}$ that usually comes from the interaction between spray droplets and continuous gas phase. The ideal mixing law and the kinetic theory models are used to calculate the viscosity of the gas mixture and their species, respectively. More details on the models used to calculate viscosity and other gas properties can be found in a reference 136 .

\subsubsection{Energy Equation}

The conservation energy equation is written as: 


$$
\frac{\partial}{\partial t}(\rho E)+\nabla \cdot(\vec{v}(\rho E+p))=\nabla \cdot\left(k_{e} \nabla T-\sum_{j}^{N} h_{j} \vec{J}_{j}+(\tau \cdot \vec{v})\right)+S_{s e}
$$

Where $E$ is the mixture internal energy as defined in the Equation 6.4, $k_{e}$ is the effective thermal conductivity of the mixture (summation of the species thermal conductivity and the turbulence thermal conductivity which is defined based on the turbulent model used), $h_{j}$ and $J_{j}$ are the specific enthalpy and the diffusion flux of the species $j$, respectively and $N$ is the total number of the chemical species in the mixture. $\tau$ is the viscous stress tensor and $S_{s e}$ is any defined volumetric heat source such as heat released from chemical reaction.

$$
E=h-\frac{p}{\rho}+\frac{v^{2}}{2}
$$

Where $h$ is the specific enthalpy of the ideal gases (mixture) which is defined as:

$$
h=\sum_{j}^{N} Y_{j} h_{j}
$$

Where $Y_{j}$ is the mass fraction of the species $j$.

\subsubsection{Species Transport Equations}

The solution of the species transport equations predicts the local mass fraction of each species, $Y_{j}$, in the mixture. The conservation form of the species transport equation for the $i^{t h}$ species can be written as:

$$
\frac{\partial}{\partial t}\left(\rho Y_{i}\right)+\nabla \cdot\left(\rho \vec{v} Y_{i}\right)=-\nabla \cdot \vec{J}_{i}+R_{i}+S_{i}
$$

Equation 6.6 is solved $N-1$ times for the fluid mixture consists of $N$ chemical species and with the sum of species fractions should equal one. The second term on the left 
side of Equation 6.6 represents the species convection due to velocity of the gases and the species convection due to mass concentration. Thermal gradients is presented by the first term $\left(-\nabla \cdot \overrightarrow{J_{i}}\right)$ on the right hand side of the equation. The diffusion flux, $\vec{J}_{i}$, in turbulent flow is defined as:

$$
\vec{J}_{i}=-\left(\rho D_{i, m}+\frac{\mu_{t}}{S c_{t}}\right) \nabla Y_{i}-D_{T h e r m, i} \frac{\nabla T}{T}
$$

Where $D_{i, m}$ and $D_{\text {Therm, } i}$ are mass and thermal diffusivity coefficients. In ANSYS Forte, they could be determined as constants for all species, constant for an individual species $i$, or polynomial function of temperature. Turbulence effects are included through the turbulent viscosity, $\mu_{t}$, and turbulent Schmidt number, $S c_{t}$. This number is defined as the ratio of the momentum to mass diffusivities and mathematically expressed as:

$$
S c_{t}=\frac{\mu_{t}}{\rho D_{t}}
$$

More details on the values of the $S c_{t}$ and its applications in the CFD analysis can be found in the references [137], [138]. The last two terms in Equation 6.6 are source terms and they are defined as: $R_{i}$ is the net chemical reaction rate source of species $i$ which is calculated as the summation of the Arrhenius rate of creation or destruction for all reactions that species $i$ takes part in; $S_{i}$ is a source defined by a user or the one that comes from liquid droplets evaporation.

\subsubsection{The RNG $\kappa-\varepsilon$ Turbulence Model}

The two equation $\kappa-\varepsilon$ turbulence model, which is based on the Reynolds-Averaged Navier-Stokes $(R A N S)$ equations, is the most widely used in the CFD simulation to describe the turbulence through two partial differential equations. One of these equations is for the turbulent kinetic energy $(\kappa)$ and the other is for the dissipation of the turbulent energy $(\varepsilon)$. In this study, the $\kappa-\varepsilon$ Renormalized Group $(\kappa-\varepsilon R N G)$ model is used to

predict the turbulent viscosity. More details on this model could be found in [139]. The 
turbulent kinetic energy $(\kappa)$ equation can be written as:

$$
\frac{\partial}{\partial t}(\rho \kappa)+\nabla \cdot(\rho \kappa \vec{v})=\nabla \cdot\left[\left(\alpha_{\kappa} \mu_{e f f}\right) \nabla \kappa\right]+\mu_{t} S^{2}-\rho \varepsilon
$$

and the dissipation rate $(\varepsilon)$ equation can be written as:

$$
\frac{\partial}{\partial t}(\rho \varepsilon)+\nabla \cdot(\rho \varepsilon \vec{v})=\nabla \cdot\left[\left(\alpha_{\varepsilon} \mu_{e f f}\right) \nabla \varepsilon\right]+C_{1 \varepsilon} \frac{\varepsilon}{\kappa} \mu_{t} S^{2}-C_{2 \varepsilon} \rho \frac{\varepsilon^{2}}{\kappa}-R_{\varepsilon}+S_{\varepsilon}
$$

Where $\alpha_{\kappa}$ and $\alpha_{\varepsilon}$ are the inverse effective Prandtl numbers for $\kappa$ and $\varepsilon$, respectively. They are defined as:

$$
\alpha_{\kappa}=\frac{\mu_{t}}{\sigma_{\kappa}} \quad \text { and } \quad \alpha_{\varepsilon}=\frac{\mu_{t}}{\sigma_{\varepsilon}}
$$

$\mu_{e f f}$ is the effective viscosity which is introduced in the $\kappa-\varepsilon R N G$ model to include the effects of low Reynolds number.

$S$ is the strain rate magnitude and it is defined in 3D as:

$$
S^{2}=2\left(\left(\frac{\partial u}{\partial x}\right)^{2}+\left(\frac{\partial v}{\partial y}\right)^{2}+\left(\frac{\partial w}{\partial z}\right)^{2}\right)+\left(\frac{\partial u}{\partial z}+\frac{\partial w}{\partial x}\right)^{2}+\left(\frac{\partial u}{\partial y}+\frac{\partial v}{\partial x}\right)^{2}+\left(\frac{\partial w}{\partial y}+\frac{\partial v}{\partial z}\right)^{2}
$$

$\sigma_{\kappa}, \sigma_{\varepsilon}, C_{1 \varepsilon}, C_{2 \varepsilon}$, and $C_{\mu}$ are adjustable constants and their values were calculated analytically and from experimental data over a wide range of turbulence flows [140]: $\sigma_{\kappa}=1.00, \sigma_{\varepsilon}=1.30, C_{1 \varepsilon}=1.44, C_{2 \varepsilon}=1.92$, and $C_{\mu}=0.09$.

$R_{\varepsilon}$ is an additional term in the $\kappa-\varepsilon R N G$ model compared to the Standard $\kappa-\varepsilon$ model. It is given by the equation below:

$$
R_{\varepsilon}=\frac{C_{\mu} \rho \eta^{3}\left(1-\eta / \eta_{o}\right)}{1+\beta \eta^{3}} \frac{\varepsilon^{2}}{\kappa}
$$


Where $\eta_{o}$ and $\beta$ are constants and $\eta$ is defined as:

$$
\eta=S \frac{\kappa}{\varepsilon}
$$

\subsection{Fuel injection and Discrete Phase Model Formula- tion}

Euler-Lagrange numerical approach is usually used to analyze the interaction between continuous and discrete phases such as spray injection into a continuous gas. The Lagrangian discrete phase model is used to solve the dispersed phase through tracking droplets in the flow field. The fuel core released from the nozzle experiences four processes in sequence throughout the combustion process; the primary breakup where the liquid core shreds into droplets, secondary breakup into smaller droplets, vaporization of the smaller droplets and mixing with air, and finally the chemical reaction and ignition of the mixture. The formulations of fuel spray breakup and tracking are explained briefly in the following subsections.

\subsubsection{Primary Breakup of liquid Fuel Core}

The primary breakup of liquid fuel represents the atomization of the intact liquid at nozzle outlet into relatively large droplets (but smaller than nozzle diameter) moving with high speed. The specifications of the nozzle used in diesel engines and so is the case in the $I Q T$, with the high pressure drop across the nozzle and high flow velocity bring the instantaneous static pressure close enough to the saturation pressure of the fuel. This leads to cavitation phenomena where local evaporation in the liquid occurs and voids are created. These voids collapse rapidly at nozzle outlet and breaking up the liquid core into droplets 141. 
There are four primary breakup regimes classified based on the liquid properties (density $\rho_{l}$, viscosity $\mu_{l}$, and surface tension $\sigma$ ), droplet diameter and liquid jet velocity at nozzle exit. These specifications are grouped into a non-dimensional number called Ohnesorge number $(O h)$ for the regimes to be presented in a quantitative manner as shown in the Ohnesorge diagram (Figure 6.7). Where Oh number relates the viscous force to the surface tension and inertial forces and also it is a function of Weber number $\left(W e_{l}\right)$ and Reynolds number $\left(R e_{l}\right)$. It can be written as:

$$
O h=\frac{\mu_{l}}{\sqrt{\rho_{l} d_{n} \sigma}}=\frac{\sqrt{W e_{l}}}{R e_{l}}
$$

$W e_{l}$ is defined as the ratio between inertial to surface tension forces and $R e_{l}$ is the inertial to viscous forces. They are written as:

$$
W e_{l}=\frac{v_{n}^{2} d_{n} \rho_{l}}{\sigma} \quad \text { and } \quad R e_{l}=\frac{v_{n} d_{n} \rho_{l}}{\mu_{l}}
$$

Where $v_{n}$ is liquid velocity at nozzle exit, $d_{n}$ is nozzle diameter, and the other properties were defined previously. It is clear from Figure 6.7 that for diesel like injection applications, the liquid core is atomized directly after emanating from the nozzle. Only atomization regime exists in the sprayed fuel which is spread in different directions to form a conical shape.

\subsubsection{Secondary Breakup}

Followed by the primary breakup is the secondary breakup. Where the droplets that produced from the atomization process break into smaller droplets due to aerodynamic forces which exist as a result of high velocity of the droplets. Experimental work has showed that the droplets of high velocity with $W e_{g}>100$ encounter a catastrophic breakup producing smaller droplets in the direction of their movement [143], [144]. The definition of gas phase Weber number $\left(W e_{g}\right)$ here is the same as in the primary breakup 


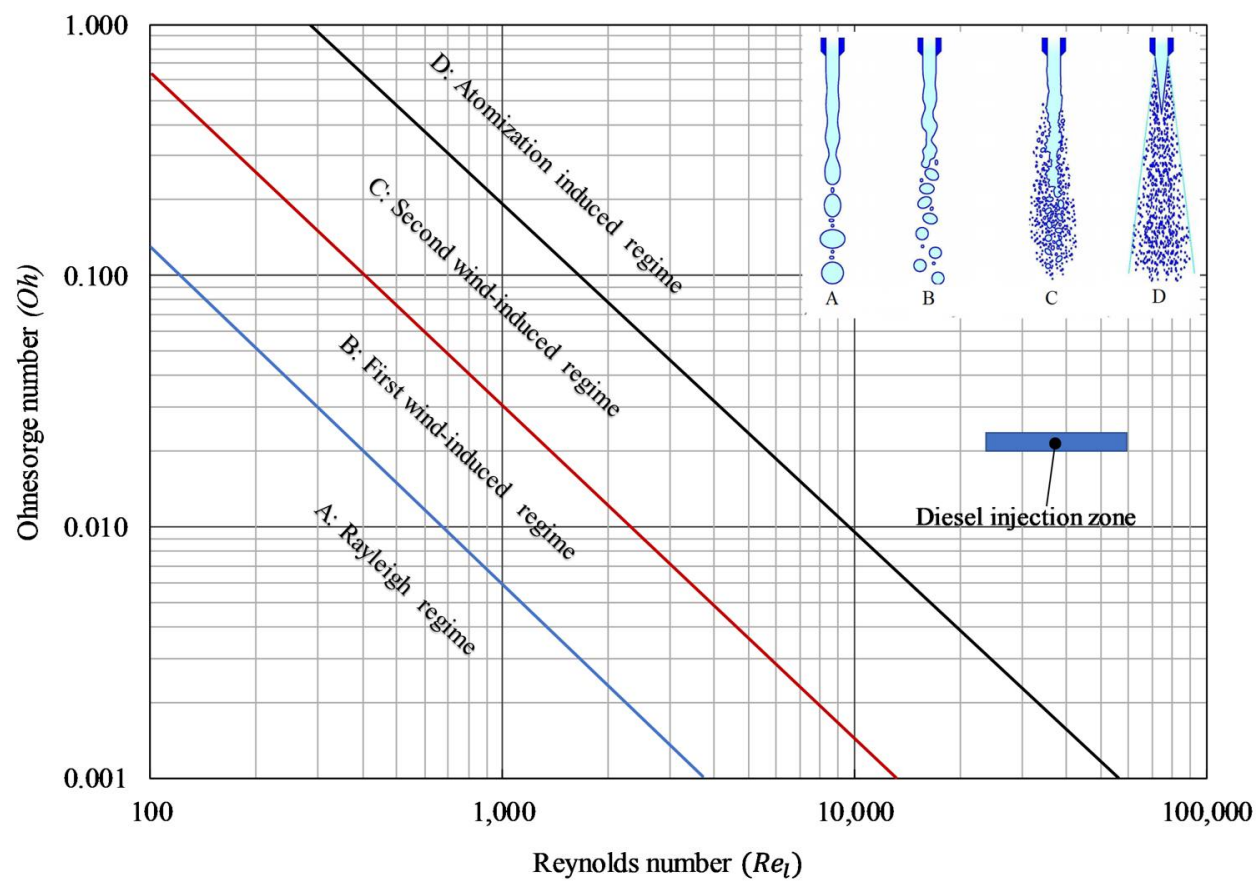

Figure 6.7: The four primary breakup regimes with diesel direct injection zone. Extracted from $[142$

except for the diameter which is replaced by the droplet diameter $\left(d_{\text {parent }}\right)$ before breakup instead of nozzle or jet diameter and the liquid velocity is replaced with the relative velocity $\left(v_{r e l}\right)$ between droplet and surrounding gas. It is given by:

$$
W e_{g}=\frac{v_{r e l}^{2} d_{\text {parent }} \rho_{g}}{\sigma}
$$

A combined Kelvin-Helmholtz / Rayleigh-Taylor $(K H-R T)$ model 85 will be used in the modeling to handle the secondary droplet breakup. The two models are working in a competing manner. The $K H$ model is applied to breakup droplets with bag breakup mode when $W e_{g}$ number is low and the $R T$ model is applied to breakup droplet with stripping breakup mode when $W e_{g}$ number is high [145].

The droplets experience vaporization and mixing with surrounding hot gases while traveling in a continuous phase. The heat is transferred from hot gases to the droplet mainly by convection. The radiative heat exchange and heat conduction within the droplet are neglected due to their slight effects. The laws of the droplet heating, rate of 
vaporization, and boiling are applied automatically in Forte when selecting droplet as a particle type 78 .

\subsection{Fuel Spray Settings}

To start the CFD calculations of the combustion model, the fuel spray parameters need to be initiated and determined in ANSYS Forte. The initial parameters are droplet diameter, cone type (hollow or solid) and angle, velocity profile, injection period, fuel total mass per injection, and fuel temperature. The spray model is enabled first to activate spray-model options which include droplet collision model, injector, nozzle, and injection. The Radius of Influence (ROI) collision model [146] with radius of influence at $0.2 \mathrm{~cm}$ was used to represent droplet collision. There are two options on injector type, either solid-cone or hollow-cone. The experimental work showed that the spray from the injector used in the IQT is close to hollow-cone shape than solid one. Thus, a hollowcone injector is created and adopted in the simulation. The fuel temperature is taken as $50^{\circ} \mathrm{C}$ based on the standard of the $\operatorname{IQT} T^{T M}(D 6890)$. The droplet velocity and diameter, and cone shape and angle were extracted from the experimental and visualization work of [72, [97]. The main injection period is around $2 \mathrm{~ms}$ as shown in Figure 4.3 and the injected mass is measured from the IQT. The fuel spray parameters and settings used in the simulation are presented in the Table 6.1 . 


\begin{tabular}{|c|c|}
\hline Fuel & n heptane \\
\hline Fuel temperature $\left({ }^{\circ} \mathrm{C}\right)$ & 50 \\
\hline Fuel injection pressure $(\mathrm{MPa})$ & 17.93 \\
\hline Injection shape & hollow cone \\
\hline Mean cone angle $\left({ }^{\circ}\right)$ & 35 \\
\hline Liquid jet thickness $\left(^{\circ}\right)$ & 15 \\
\hline Droplet size distribution & Rosin-Rammler distribution with shape \\
& parameter at 3.5 \\
\hline Nozzle diameter $(\mathrm{mm})$ & 0.257 \\
\hline Fuel discharge coefficient & 0.7 \\
\hline Total mass of injected fuel $(\mathrm{mg})$ & 8 \\
\hline Duration of injected fuel $(\mathrm{ms})$ & 2 \\
\hline Velocity profile shape & Square \\
\hline Spray break up model & Linearized instability sheet atomization (LISA) \\
& model $[147$ \\
\hline
\end{tabular}

Table 6.1: Fuel spray parameters for combustion modeling

\subsection{Chemical Kinetics Skeletal Mechanism}

As a starting point for the combustion modeling, the reduced chemical kinetics of previous work are applied to allow the model to be initiated and compared with current simulation work. It is notable that NASYS Forte efficiently managed the detailed and reduced chemical kinetics. Advanced solution strategies are used in the chemistry solution of ANSYS Forte, including a dynamic adaptive chemistry (DAC) method, a dynamic cell clustering (DCC) method and an advanced proprietary sparse-matrix solution methodology [148 -150]. The simulation was first run with detailed chemical kinetics of n-heptane [151], and validated against relevant experimental work in a wide range of temperature and pressure 152 . The results were then compared with the latest validated n-heptane skeletal (reduced) chemical kinetics of 106 species and 1738 reactions 153 155 in order to perform double confirmation and good agreement was recorded. 
This skeletal mechanism (106 species and 1738 reactions) was compared to three other skeletal mechanisms (29 and 52 [134], 35 and 41 [156], and 159 species and 770 reactions [157]) at different temperatures and pressures to determine which was closest to the experimental results. Implementing the simulation with the chemistry of the higher number of species (159) required more time and mesh cells, as shown in Figure 6.8. The time for chemistry calculations of the overall solution time increases as the number of species and reactions per skeletal mechanisms become higher. The maximum number of cells is approximately 60,000 , with the exception of the 159 species case where it is above 80,000 cells at $21 \mathrm{bar}$ and $590^{\circ} \mathrm{C}$.

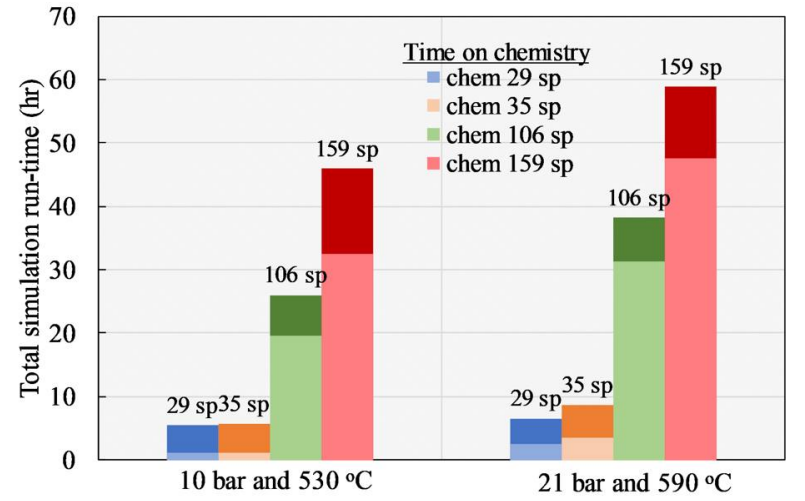

(a) Total simulation run-time at two conditions

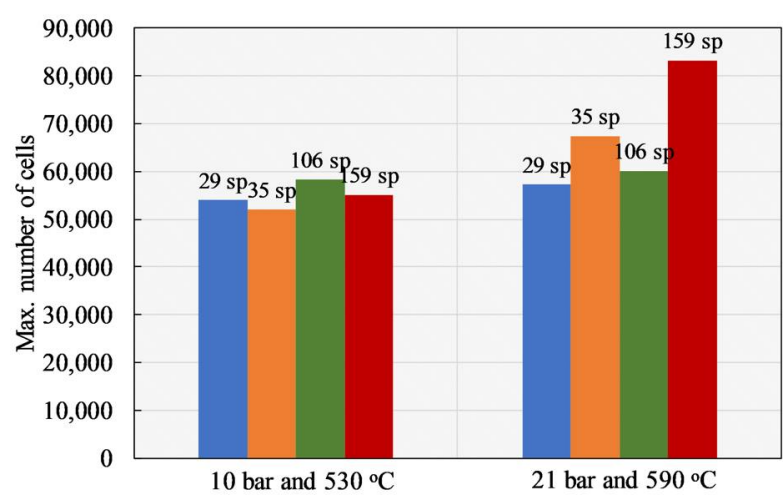

(b) Maximum number of cells at two conditions

Figure 6.8: Comparison of total simulation run-time and maximum number of cells at four skeletal chemical kinetics

The n-heptane mechanism with 106 species that was developed from a detailed nheptane mechanism over a wide range of operating conditions [155], predicted the ignition delay time closest to the experimental ignition delay time at both the highest and lowest pressure and temperature conditions used in the experiments, as shown in Figure 6.9. The predicted ID becomes closer to the experimental data as the initial pressure and temperature conditions increase. The implemented simulations at $10 \mathrm{bar}$ and $530^{\circ} \mathrm{C}$ with 


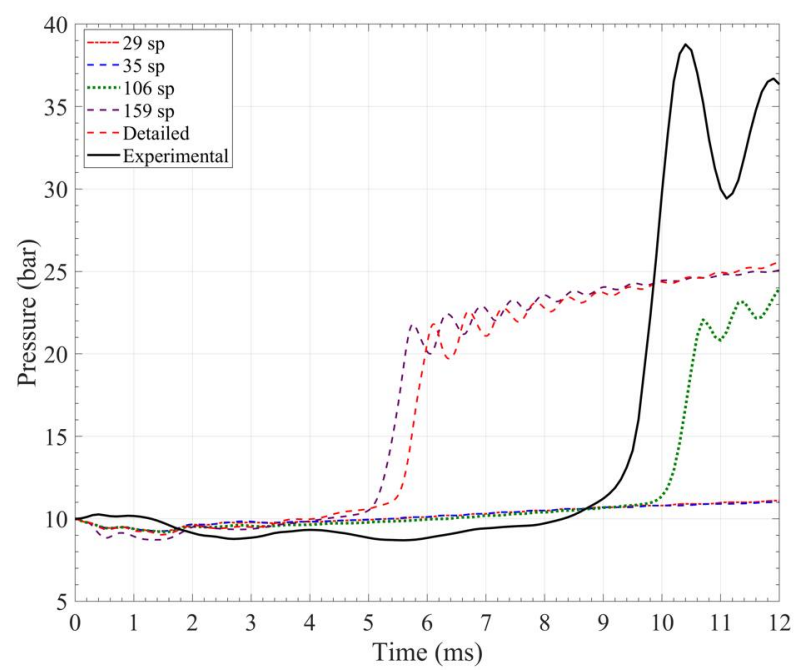

(a) $10 \mathrm{bar}$ and $530^{\circ} \mathrm{C}$

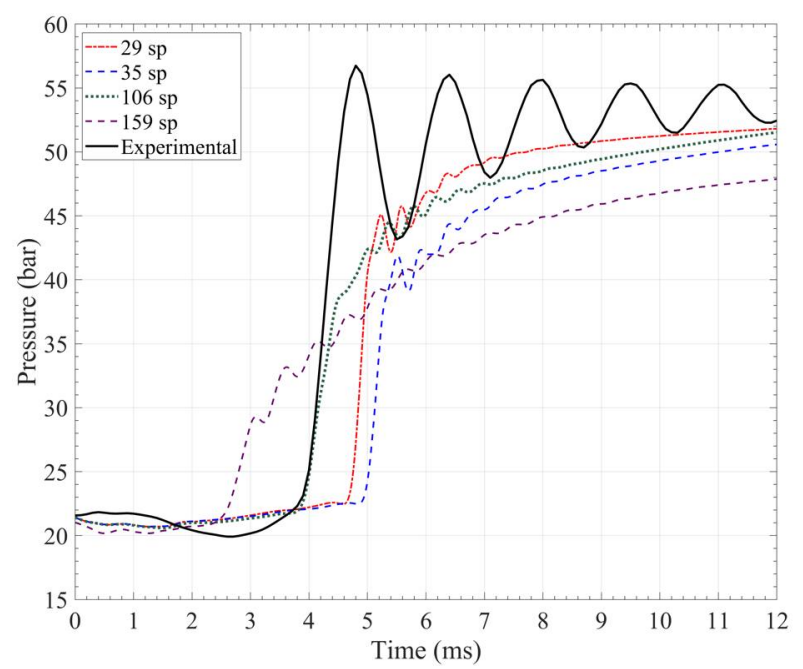

(b) 21 bar and $590^{\circ} \mathrm{C}$

Figure 6.9: Effects of skeletal and detailed mechanisms on the ignition delay at two conditions

29 species and 35 species did not show a significant increase in pressure and no combustion occurred during the simulation time, as shown in Figure 6.9a. This is because some of the low temperature reactions were eliminated while creating the two skeletal mechanisms. As indicated in Figure 6.9b, the predicted ignition delays from 29 species and 35 species at $21 \mathrm{bar}$ and $590^{\circ} \mathrm{C}$, is greater than those of the experiments by $\sim 0.8 \mathrm{~ms}$. The detailed mechanism, developed and used to study the oxidation of n-heptane in flow reactors, shock tubes and rapid compression machines [152, and the 159-species mechanism to be used for non-premixed system [157] developed from the detailed one of Curran et al. [152], predicted much shorter ignition delays than those in the experimental results. 


\section{Chapter 7}

\section{Validation of Simulation with Skeletal Mechanism}

In this chapter, the results of the numerical combustion simulation with a skeletal mechanism of 106 species and 1738 reactions are presented and validated against experimental data. All test conditions shown in Table 4.1 were simulated and the length of time modeled by the CFD model was $12 \mathrm{~ms}$ in order to include all the fuel spraying and combustion events.

\subsection{Auto-ignition Analysis through Temperature, Pres- sure and Fuel Mass Fraction Contours}

The characteristics of compression ignition can be analyzed by temporal tracing of the parameters that have significant effects on the combustion process, such as temperature, pressure and fuel vapor concentration (fuel mass fraction). Contour plots are the most effective way to graphically demonstrate variations in the chamber domain. The contour plots of temperature, pressure, and fuel vapor concentration are presented for three different set point conditions (charge or initial temperature) and pressures, as shown in Figures 7.1 to 7.9 . The fuel injection events and onset of combustion are illustrated by 
four plots on each figure, with the first two showing the effect of fuel spray at $1 \mathrm{~ms}$ (the middle of injection process), and $3 \mathrm{~ms}$ (approximately $1 \mathrm{~ms}$ after the end of injection). The third contour plots are at the initiation of combustion, and the fourth are during the combustion process. The highest values of the parameters of temperature, pressure and fuel mass fraction are depicted in red, and the lowest values are depicted in blue.

The spray cloud with a hollow cone shape, as determined by the settings, enters the chamber space with a temperature of approximately $50{ }^{\circ} \mathrm{C}$. The cooling effects of the propagated spray droplets reduce the temperature of the surrounding air when they move at high speed inside the IQT chamber, as shown in Figures 7.1 to 7.3 . The spray cloud becomes smaller when the initial surrounding conditions of pressure and temperature increase, since the smaller droplets at the spray edges evaporate before the bigger droplets. This evaporative cooling of the fuel spray continues after the end of fuel injection.

This is followed by the initiation of combustion, which largely depends on the initial conditions. Combustion starts at the end of the main area of the chamber with the rich mixture, while fuel at chamber tail entrance has not yet completely evaporated. It then spreads toward the regions of lower fuel concentration in the main area of the chamber, and autoignition begins at $10.1 \mathrm{~ms} \mathrm{~ms}$ for the lowest pressure and temperature initial conditions, as shown in Figure 7.1. Some fuel vapor is trapped in chamber tail, and autoignition does not occur there due to the relatively very low temperature. A smaller amount of fuel is also trapped in the chamber tail with the other two conditions, as depicted in Figures 7.2 and 7.3 . The combustion appears to be more homogeneous at higher pressure and temperature conditions. 


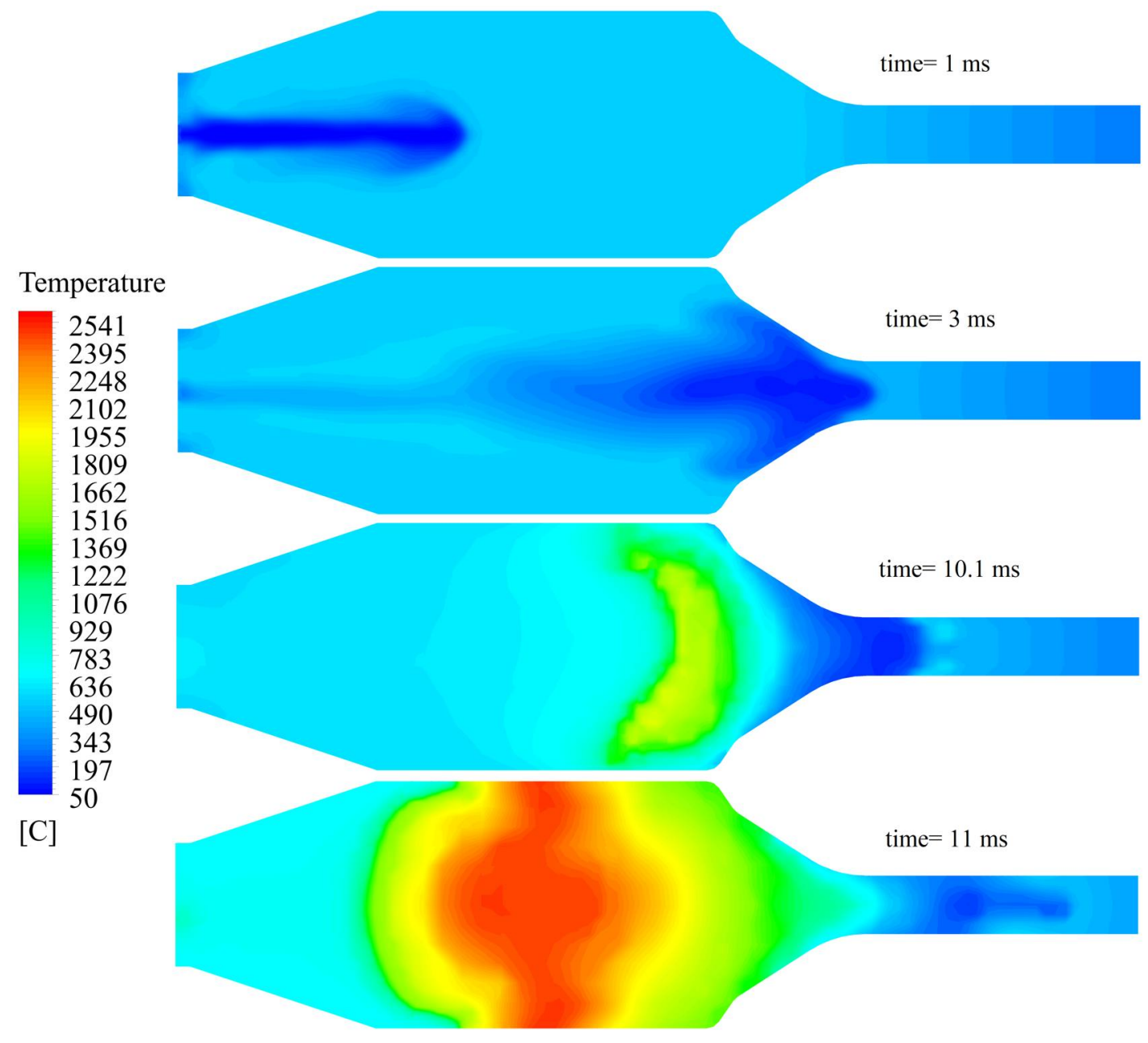

Figure 7.1: Temperature contour plots at different instances during injection and combustion processes for conditions $10 \mathrm{bar}$ and $530^{\circ} \mathrm{C}$ 


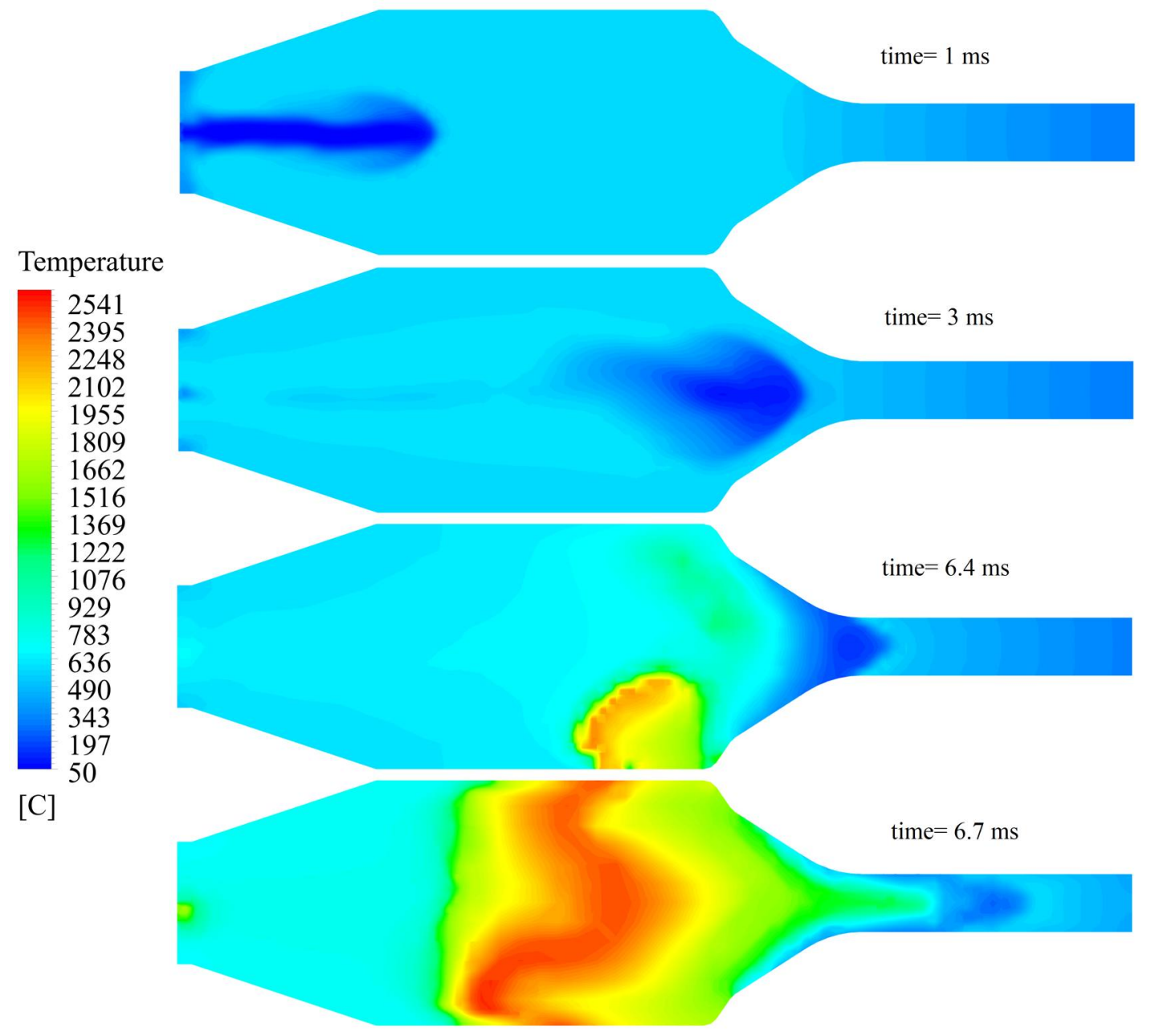

Figure 7.2: Temperature contour plots at different instances during injection and combustion processes for conditions 15 bar and $570{ }^{\circ} \mathrm{C}$ 


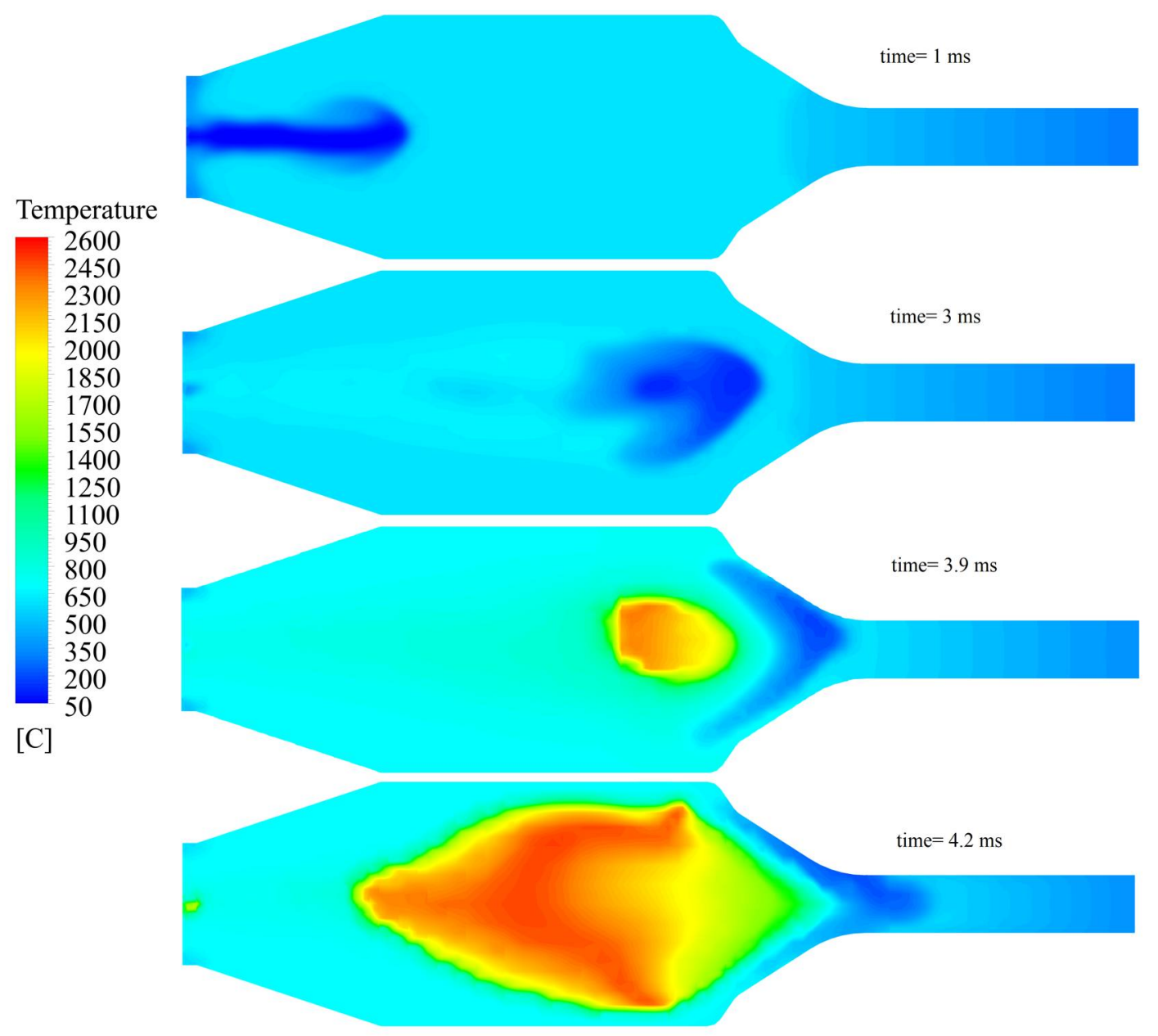

Figure 7.3: Temperature contour plots at different instances during injection and combustion processes for conditions $21.4 \mathrm{bar}$ and $590^{\circ} \mathrm{C}$

The variation in pressure during fuel injection (at $1 \mathrm{~ms}$ and $3 \mathrm{~ms}$ ) is of equalized nature as shown in Figures 7.4 to 7.6 . There is a slight drop in pressure in the chamber due to the cooling effects of the injected fuel. The heat is released when the chemical reactions start. Pressure waves are created at the location of autoignition and spread to both ends of the chamber, as shown in Figure 7.5 . 


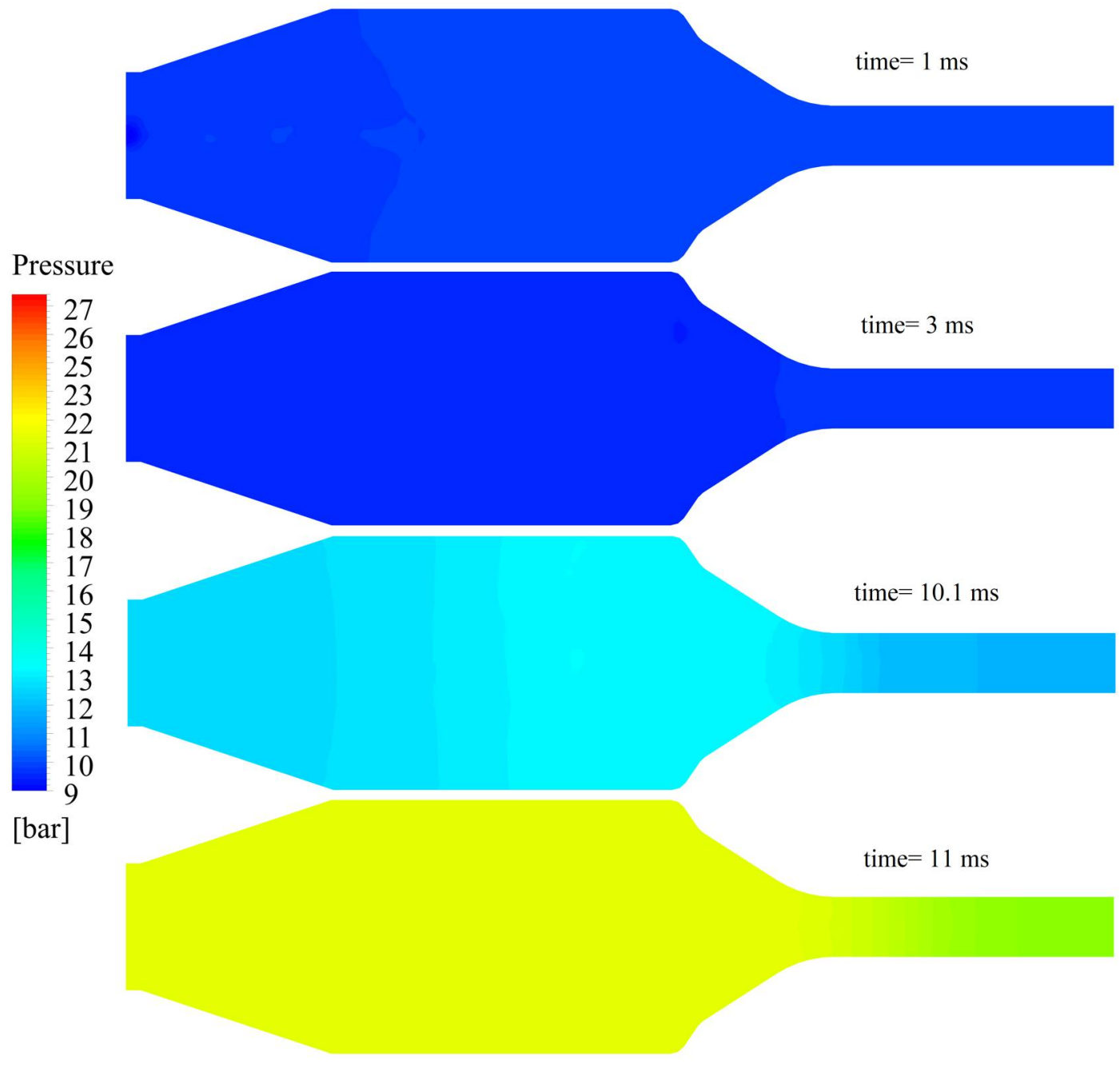

Figure 7.4: Pressure contour plots at different instances during injection and combustion processes for conditions $10 \mathrm{bar}$ and $530{ }^{\circ} \mathrm{C}$ 


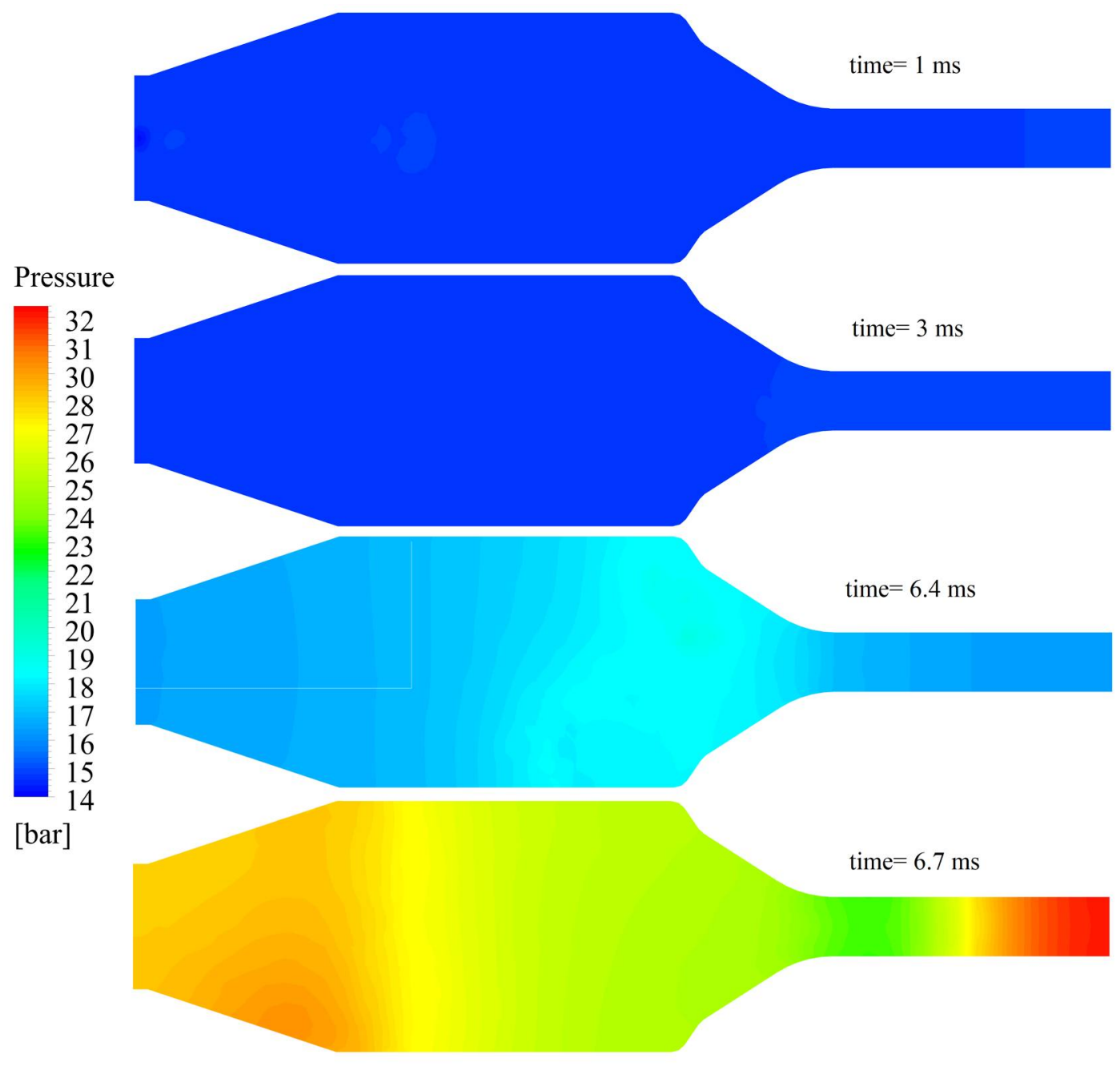

Figure 7.5: Pressure contour plots at different instances during injection and combustion processes for conditions 15 bar and $570^{\circ} \mathrm{C}$ 


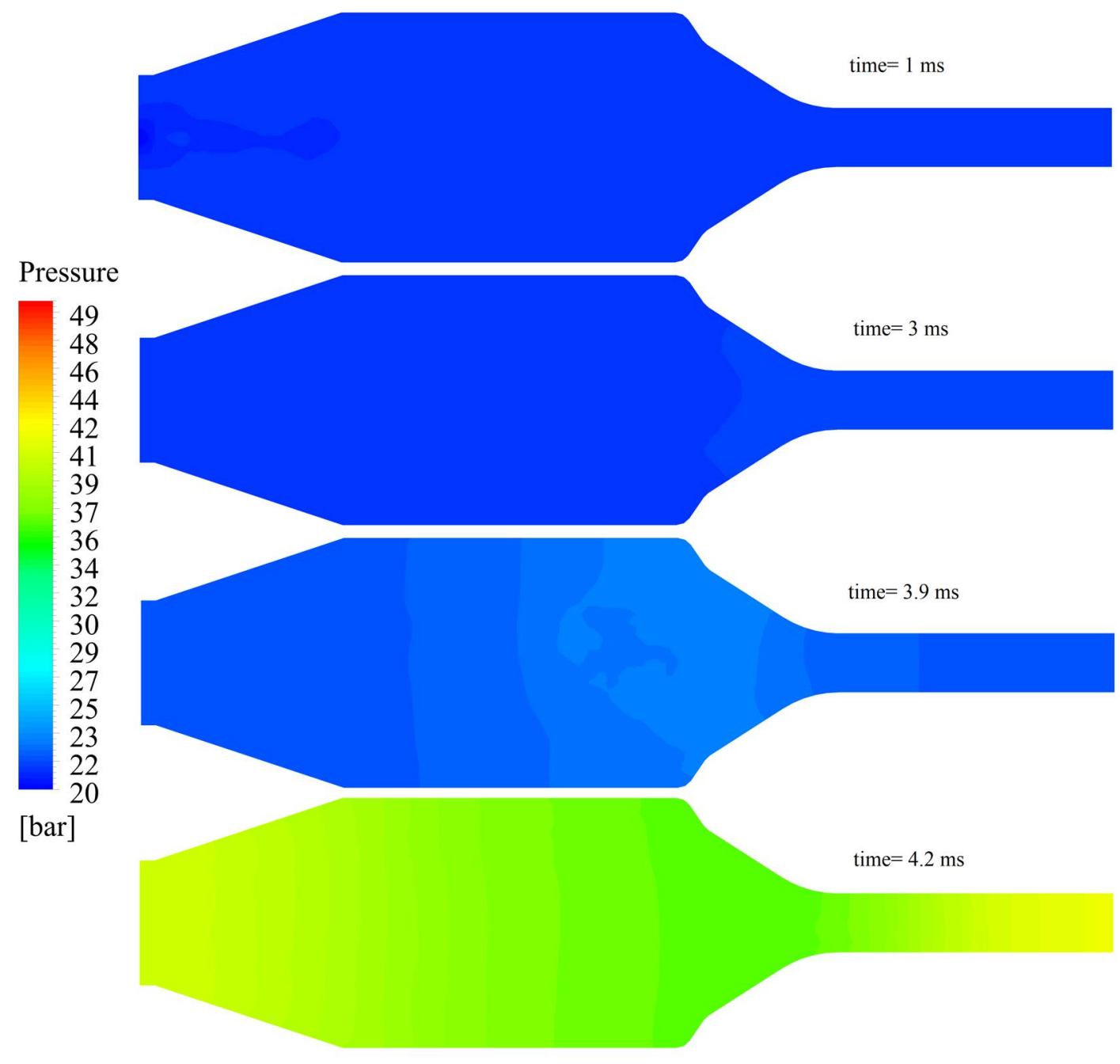

Figure 7.6: Pressure contour plots at different instances during injection and combustion processes for conditions $21.4 \mathrm{bar}$ and $590^{\circ} \mathrm{C}$

The n-heptane mass fraction is the third parameter presented in this section and is depicted in Figures 7.7 to 7.9 . The maximum values of n-heptane mass fraction are near the nozzle orifice, as shown by the $1 \mathrm{~ms}$ contour plots, and they decrease rapidly due to the mixing process with the surrounding air. The evaporated fuel is well mixed with air in the lower pressure and temperature condition compared to the higher pressure and temperature condition, as shown in Figures 7.7 and 7.9 . Prior to autoignition, most of the evaporated fuel and rich mixture zones are located at the end of the main part of the 


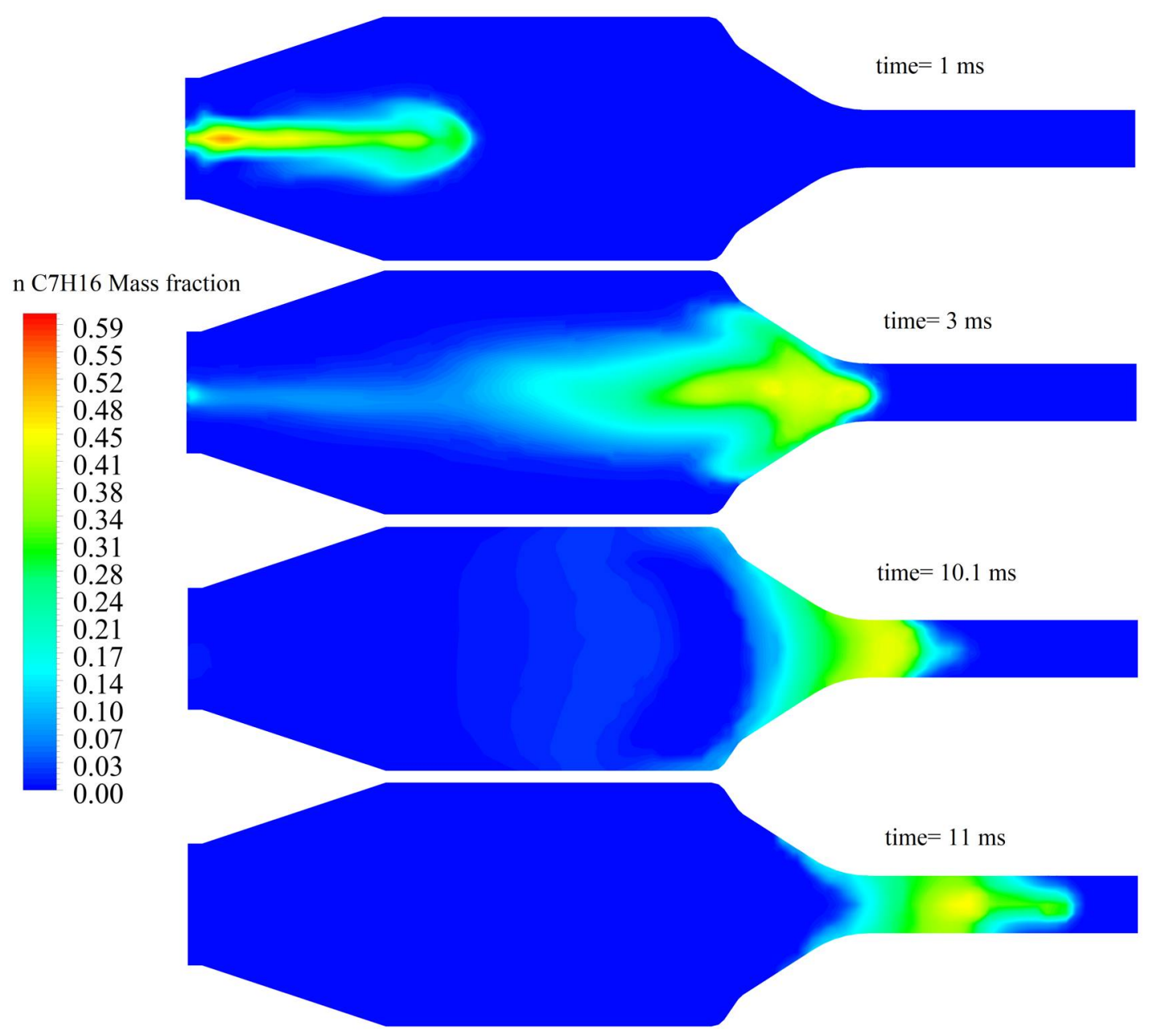

Figure 7.7: n-heptane mass fraction contour plots at different instances during injection and combustion processes for conditions 10 bar and $530{ }^{\circ} \mathrm{C}$

chamber, as shown by the $3 \mathrm{~ms}$ contour plots. Regardless of the initial conditions, the ignition is initiated at the same location (i.e. the end of the chamber). 


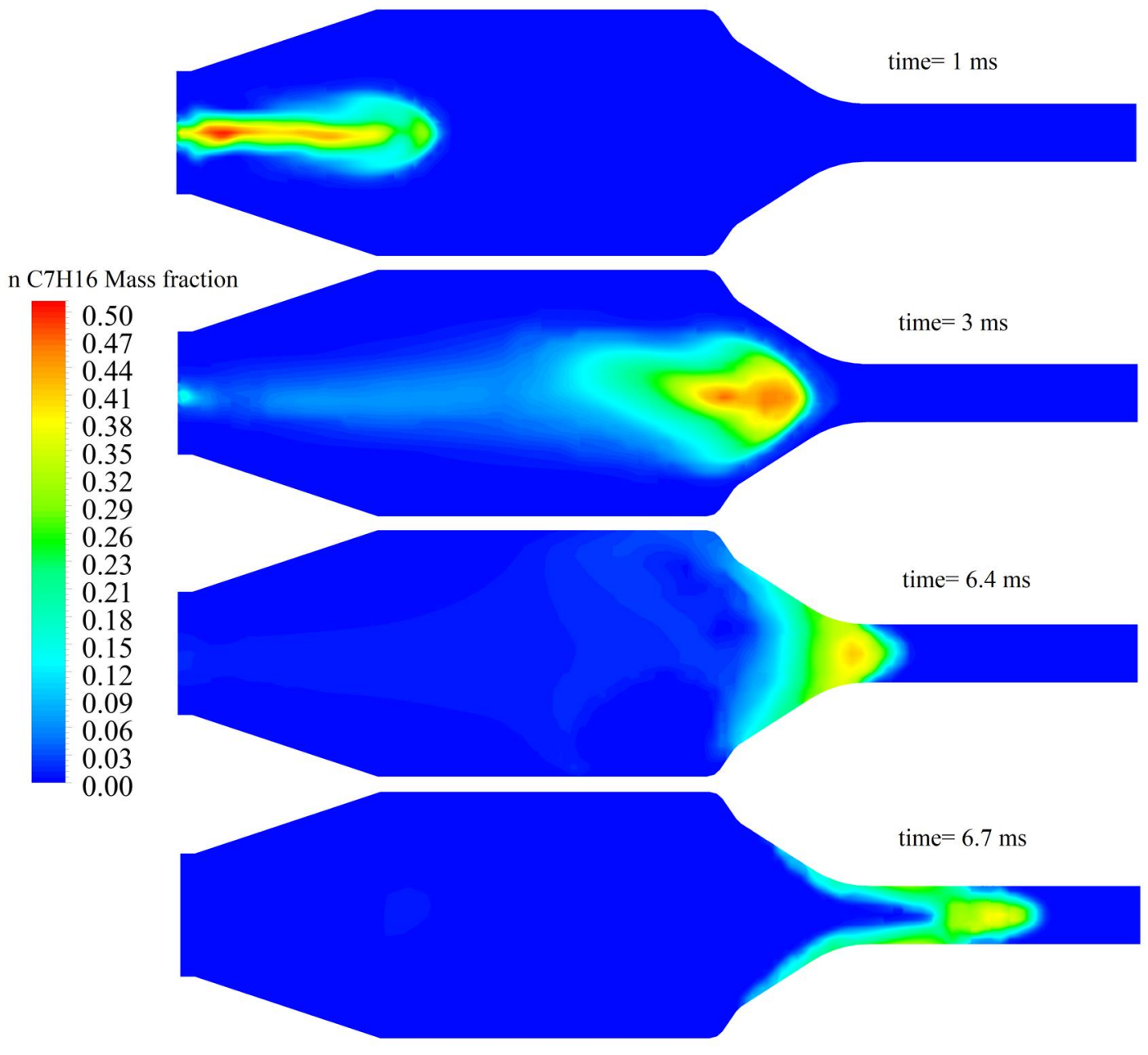

Figure 7.8: n-heptane mass fraction contour plots at different instances during injection and combustion processes for conditions 15 bar and $570^{\circ} \mathrm{C}$ 


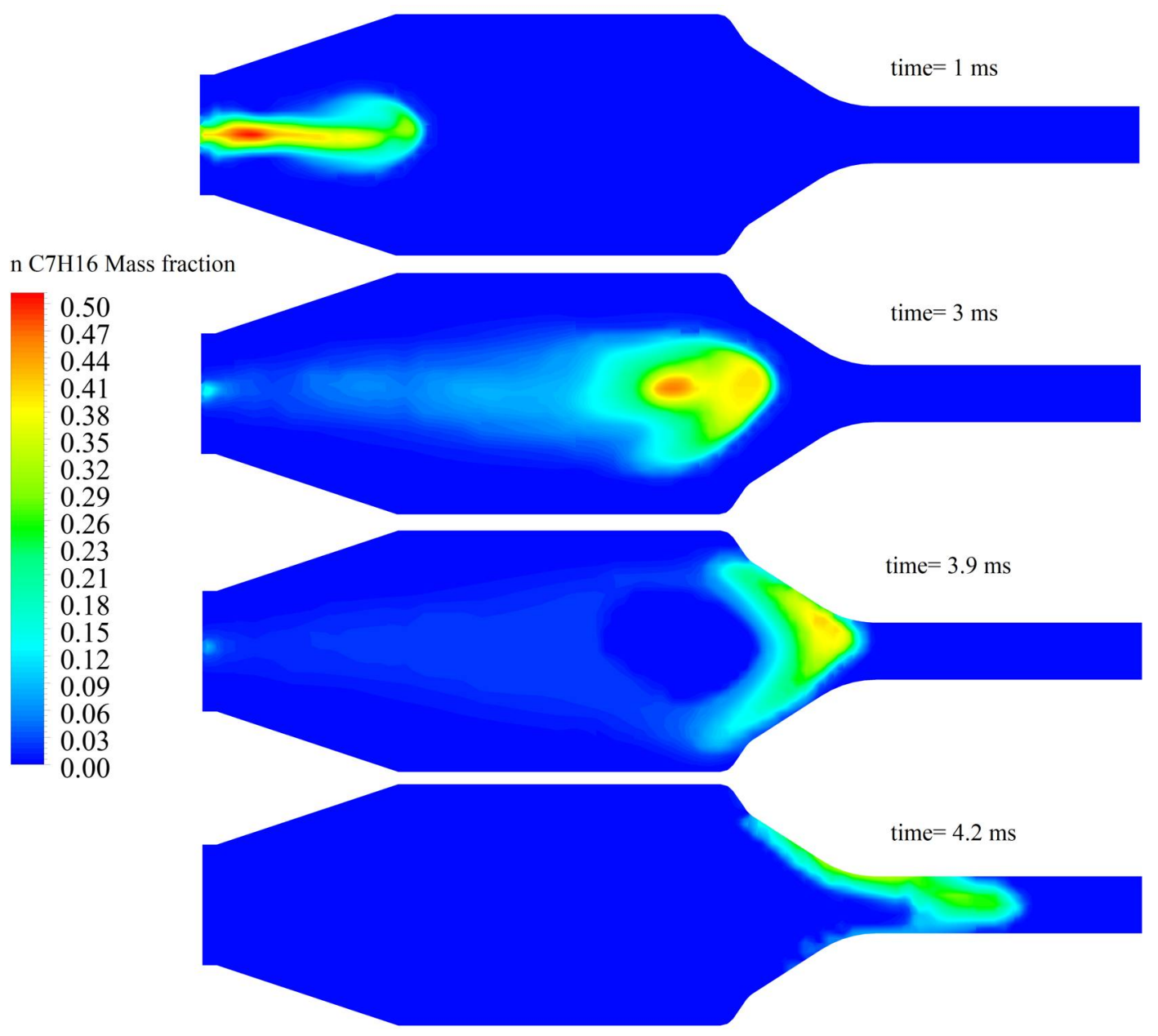

Figure 7.9: $\mathrm{n}$ heptane mass fraction contour plots at different instances during injection and combustion processes for conditions $21.4 \mathrm{bar}$ and $590^{\circ} \mathrm{C}$ 


\subsection{Comparison of Experimental and Numerical Igni- tion Delays}

The procedure of predicting ignition delay from temperature variation $\left(I D_{T M}\right)$ explained in Section 5.1, is also applied to the data in numerical simulation. The temperature method of the ID is shown on three plots with three different initial conditions, as shown in Figure 7.10. The temperature results used for the plots of both the numerical simulation and experimental work were on the chamber centerline, $105 \mathrm{~mm}$ from the injector. The temperature is presented as a ratio of the initial temperature prior to fuel injection, with the solid blue line representing numerical results and the red dashed line the experimental data. Two vertical axes that correspond to the type of results were used.

The variations in temperature (i.e. the decrease due to spray present and increase due to autoignition) for the numerical data occurs abruptly, since there is no response delay for measurement such as the recorded data sensed by TCs. The predicted experimental and numerical ID become closer to each other as the initial conditions of temperature and pressure increase. The difference $\left(\left|\left(I D_{T M}\right)_{N u m}-\left(I D_{T M}\right)_{E x p}\right|\right)$ is approximately $1 \mathrm{~ms}$ at $10 \mathrm{bar}$ and $530^{\circ} \mathrm{C}$, as shown in Figure $7.10 \mathrm{a}$, and $0.1 \mathrm{~ms}$ at $21.4 \mathrm{bar}$ and $590^{\circ} \mathrm{C}$.

The comparison of numerical and experimental ignition delay with the temperature method is shown in Figure 7.11. The data at eleven locations on the chamber centerline were selected, with the experimental data presented by red dashed lines and curves, and the numerical results by blue solid lines and curves. The horizontal red dashed lines

represent the average $I D_{I Q T}$ of the 11 runs at each point (or plane) on the centerline, and the horizontal blue solid lines represent the predicted $I D_{I Q T}$ based on the pressure variation from the simulation runs. Three plots at three charge temperatures $(530,570$, 


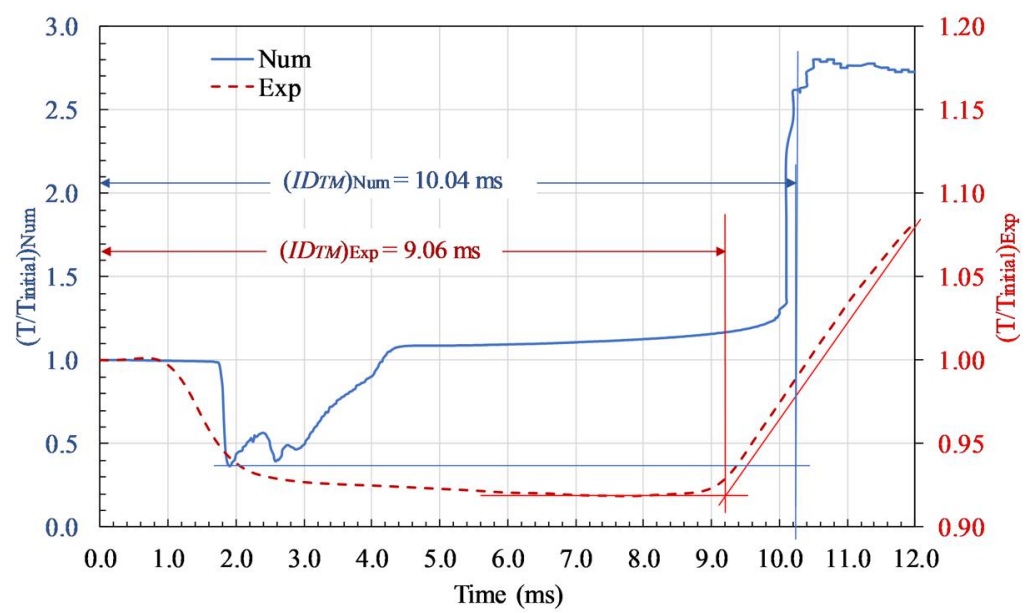

(a) $10 \mathrm{bar}$ and $530^{\circ} \mathrm{C}$

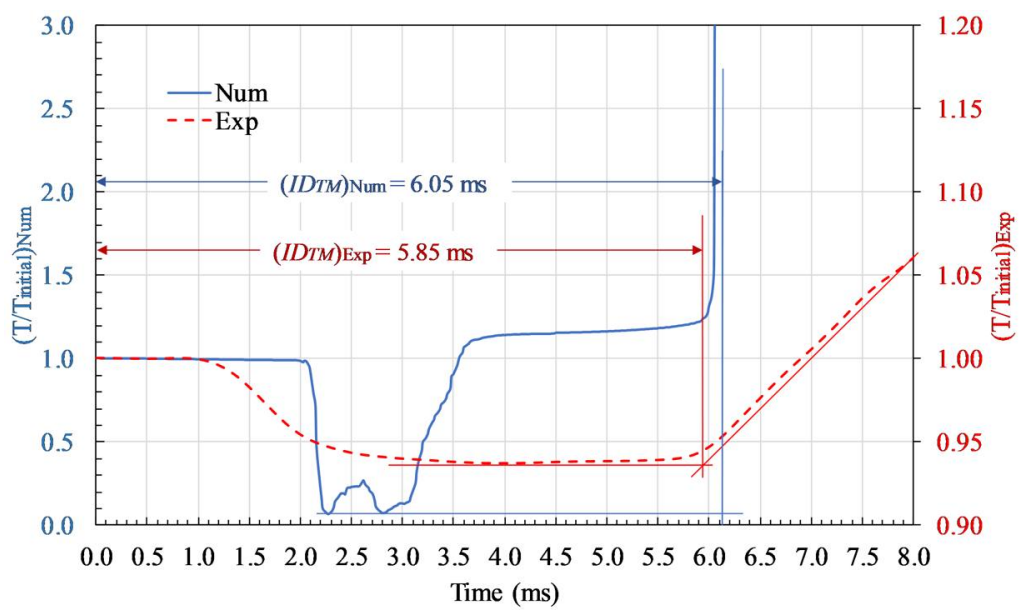

(b) $15 \mathrm{bar}$ and $550^{\circ} \mathrm{C}$

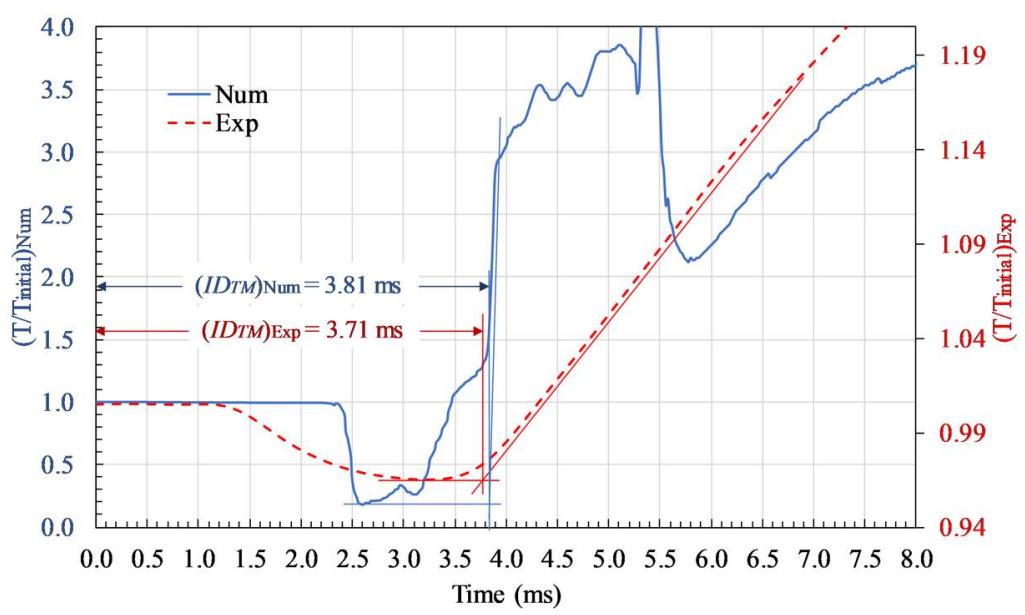

(c) $21.4 \mathrm{bar}$ and $590{ }^{\circ} \mathrm{C}$

Figure 7.10: Ignition delay prediction by temperature method on numerical and experimental data extracted from a point at chamber centerline and $105 \mathrm{~mm}$ from injector 
and $590{ }^{\circ} \mathrm{C}$ ) with three initial pressures at each plot were used to achieve the results.

As seen in Figure 7.11, there is good agreement between the estimated ignition delays experimentally and numerically by both the temperature and pressure methods $\left(I D_{T M}\right.$ and $\left.I D_{I Q T}\right)$ for all conditions in the figure, with the exception of the experimental results at 10 bar and $590^{\circ} \mathrm{C}$ where there is relatively high deviation as mentioned. The $\left(I D_{T M}\right)_{\text {Exp }}$ has approximately same value at the main part of the chamber which closest to the $\left(I D_{I Q T}\right)_{E x p}$, and it becomes higher at the end of the chamber. Similar trends have also been identified by the simulation results. In general, the ignition delay of the simulation data is higher than that of the experimental results at 10 bar and 15 bar, whereas at higher pressure $(21.4$ bar $)$ there is very good agreement between the numerical and experimental results. With the combustion modeling, the simulation at lower conditions (e.g. 10 bar and $530^{\circ} \mathrm{C}$ ) showed a delay in the autoignition compared to that at higher conditions (e.g. 21.4 bar and $590^{\circ} \mathrm{C}$ ). This could be due to omitting some important species and reactions from the detailed mechanism that start at relatively lower temperature and pressure, and initiate other reactions at higher conditions. 


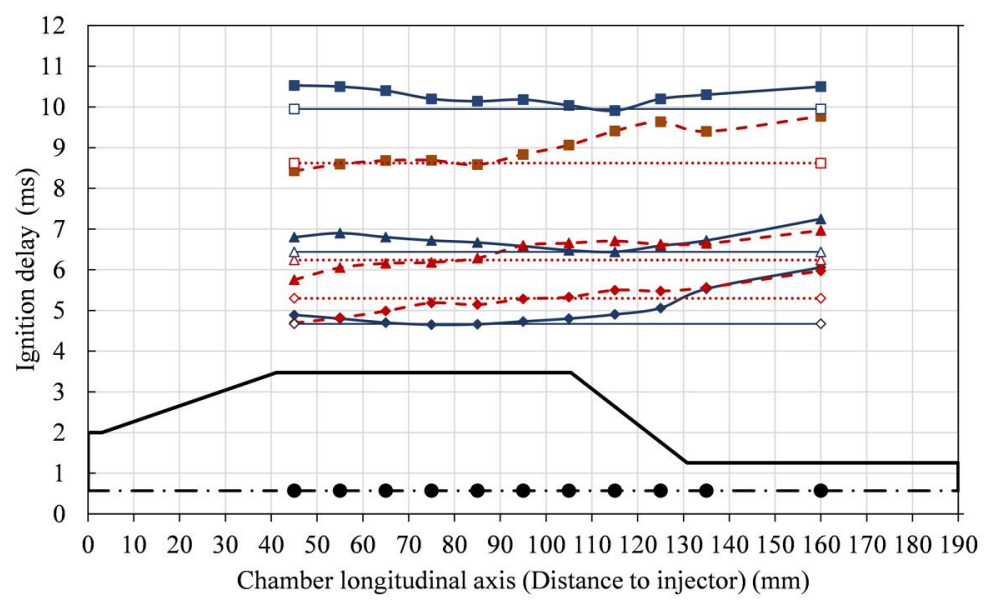

(a) Charge temperature $530^{\circ} \mathrm{C}$

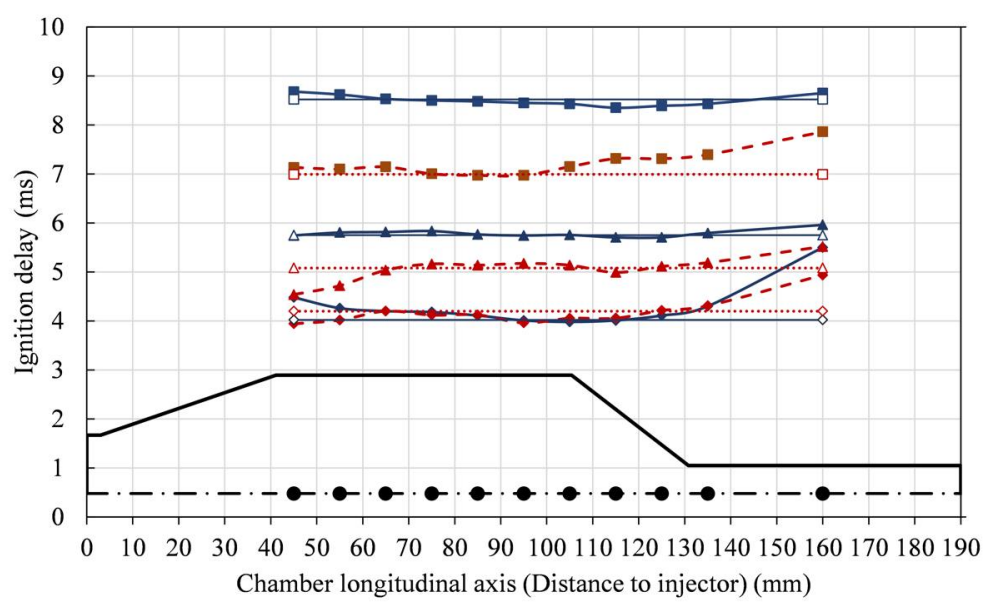

(b) Charge temperature $570^{\circ} \mathrm{C}$

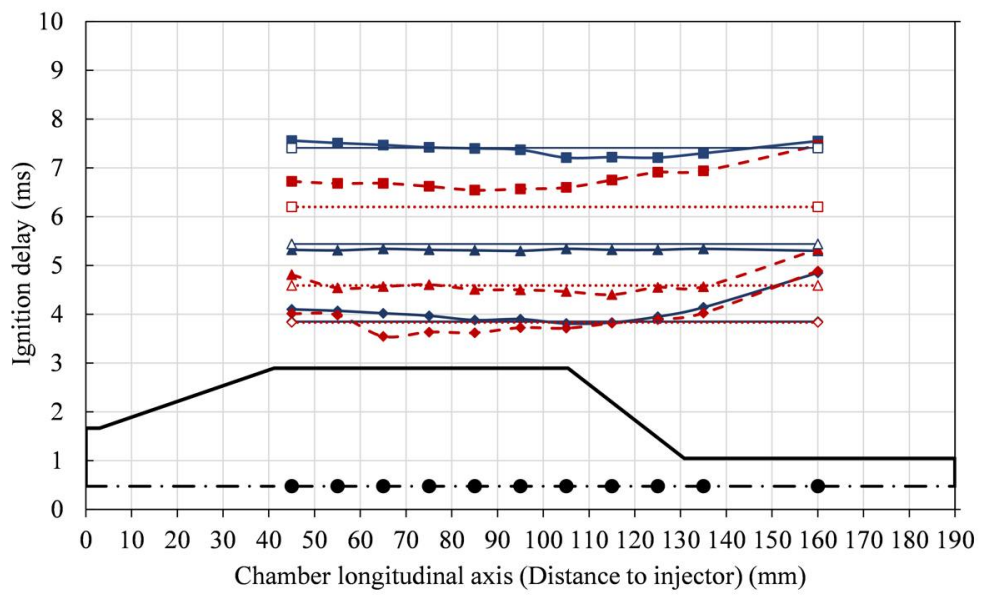

(c) Charge temperature $590^{\circ} \mathrm{C}$

Figure 7.11: Comparison of ignition delay experimentally (curves and lines with red colors) and numerically (curves and lines with blue colors). The solid markers $(\boldsymbol{\square}, \boldsymbol{\Delta}, \boldsymbol{\vee})$ are for $I D_{T M}$ at chamber centerline, and open markers $(\square, \triangle, \diamond)$ are for $I D_{I Q T}$. Markers $(\boldsymbol{\square}, \square)$ for $10 \mathrm{bar},(\boldsymbol{\Delta}, \triangle)$ for $15 \mathrm{bar}$ and $(\boldsymbol{\nabla}, \diamond)$ for $21.4 \mathrm{bar}$. 


\section{Chapter 8}

\section{Conclusions and Recommendations for}

\section{Future Work}

\subsection{Conclusions}

In this thesis, the temperature measurements inside the Ignition Quality Tester $\left(I Q T^{T M}\right)$ were used to analyze the spray and autoignition of n-heptane under 15 different initial temperature and pressure conditions. The measurements were carried out using a fine gauge type $\mathrm{K}$ thermocouple with a butt-welded hot junction end, and the temperature was recorded at 46 pre-selected locations in both radial and axial directions. Thirteen locations (i.e. planes) were selected for temperature measurements in the axial direction, starting from $20 \mathrm{~mm}$ to $160 \mathrm{~mm}$ from the injector with three $(r=0,3$, and $6 \mathrm{~mm})$ or four $(r=0,8,16$, and $24 \mathrm{~mm})$ radial locations per axial location. Robust and relatively high response temperature probes were prepared after set of tests on different sizes of thermocouple wires starting from finer gauges and finishing with the 0.01 inch TC wire that used in the experiments. The IQT combustion chamber was developed to accommodate the temperature probes and pressure sensor, and the connections were tailored to collect the data from all the sensors. The data of 15 repeated injections per 
run of 20 injections were filtered and averaged to report in the results.

It is concluded that the temperature results with the greatest decrease due to spray cooling effects was recorded by TCs at the chamber centerline, whereas almost no decrease was observed near the chamber walls except a slight drop at lower conditions (e.g. 10 bar and $530{ }^{\circ} \mathrm{C}$ ). Different levels of temperature decrease were found in the space between the chamber centerline and the wall. The maximum temperature recorded by TCs in the main part of the chamber was approximately $1300{ }^{\circ} \mathrm{C}$. The spray droplets did not reach the final location of $160 \mathrm{~mm}$ from the injector for all conditions, as there was no temperature decrease recorded. The temperature profiles for the same radius locations along the chamber were more uniform, and they had a very similar trend as moving toward the chamber wall, and also as the charge pressure and temperature decreased. The rate of increase in temperature recorded by TCs near the front port was inversely proportional to the initial temperature and pressure conditions. This indicates that the fuel and air are well mixed when the ignition delay time is relatively long at lower conditions.

Temperature variations during fuel injection and combustion periods were used to introduce a new method for estimating local physical and total ignition delays. In addition, the ID was predicted by three methods (i.e. standard IQT, Bogin et al, and differential) all of which are based on pressure variations. The end of the $\left(I D_{\text {phys }}\right)_{\text {local }}$ was determined by comparing the temperature drop line when injecting heptane into nitrogen with that when injecting into the air. It was predicted that this end (point) is located at the intersection point between the best fit line of temperature drop and the horizontal line at the minimum recorded temperature. The total ID was determined from the rise in temperature when injecting heptane into air, and is located at the intersection point between the best fit line of temperature rise due to combustion and the horizontal line at minimum temperature. It was found that the value of the local life span time of the spray droplets, or $\left(I D_{\text {phys }}\right)_{l o c a l}$, is different from one location to another in the IQT chamber, as there were higher values near the farthest end of the main part of the IQT 
chamber, approximately $100 \mathrm{~mm}$ from injector plane. There was no $\left(I D_{\text {phys }}\right)_{\text {local }}$ near the chamber wall, since there was no significant temperature drop there. The average percentage time of the physical ignition delay is $31 \%$ at $10 \mathrm{bar}$ and $47 \%$ at $21.4 \mathrm{bar}$. The average percentage time of the chemical ignition delay is higher at lower charge air pressure.

The modeled ID from temperature variations $\left(I D_{T M}\right)$ was illustrated in comparison with those from pressure variations. It was determined that at lower initial pressure and temperature conditions (i.e. when the $I D$ is relatively high) combustion is initiated almost evenly everywhere in the main part of the chamber, while as the initial conditions become higher (i.e. when the $I D$ is shorter) combustion is mainly initiated at the far end of the main part of the chamber. For all initial conditions, the higher value of the predicted ID combustion at the last region was at the chamber tail near the pressure transducer. At $10 \mathrm{bar}$, the results of the $I D_{T M}$ are much closer to the $I D_{\text {Bogin }}$ and $I D_{D M}$ methods than the $I D_{I Q T}$ method, which has a significant lower values. At the 15 and 21.4 bar pressure conditions, the results of the ID by pressure methods are close and in good agreement with the $I D_{I Q T}$ results.

In addition to the ignition delay predictions, the temperature measurements at the chamber centerline were also used to characterize the fuel spray, and the predicted results were validated against recognized correlations used to describe spray characteristics. The time for the spray to reach the TC was used to predict the spray velocity and penetration length. The results indicated that the ambient temperature has minimal effect on the spray penetration length, which is in good agreement with the published results based on the visualization work. The ambient pressure has a relatively significant effect on the propagation of the spray, since as it increases, the penetration length becomes shorter and steeper. The validation of the penetration length showed good agreement with wellknown empirical correlations, particularly at 15 and 21.4 bar. The spray penetration velocity versus the time and axial distance was resolved, and there are now two pro- 
files for penetration velocity based on ambient pressure. A linear decrease was predicted at 21.4 bar ambient pressure, and the profiles at 10 and 15 bar showed linear decreases with a constant velocity in the main part of the chamber. The empirical correlation is well-matched with experimental results at $1 \mathrm{~ms}$ from start of injection. The temperature decrease at the measurement points during the fuel injection process was used to investigate the spray cone angle, which was found to be in the range of $20^{\circ}$ and $45^{\circ}$.

To integrate the study, the injection and combustion processes were simulated numerically using ANSYS Forte software. The initial conditions from the experimental measurements, as well as the actual trace data of the nozzle needle lift, were applied to the IQT geometry with the actual dimensions. The model was first refined according to the global mesh size and maximum time step, and $4 \mathrm{~mm}$ and $3 \mu s$ respectively were then selected for all simulation runs. The second analysis before the final settings of the simulation file focused on the chemical kinetics. The simulation was first run with four n-heptane skeletal reduced mechanisms (i.e. 29 and 52, 35 and 41, 106 and 1738 and 159 species and 770 reactions) in addition to the detailed n-heptane mechanism. The mechanism with 106 species and 1738 reactions was used in the settings, as it had the highest agreement with the experimental data. The predicted $I D_{T M}$ from the numerical data also showed very good agreement to the experimental results at high pressure conditions.

\subsection{Recommendations for the Future Work}

Further investigation is recommended to expand and improve the quality of this research. Therefore, the following recommendations are suggested:

1. n-heptane is a high volatility fuel with relatively short ignition delay. It is also important to conduct experimental work on low volatility fuels, such as iso-octane 
and diesel type fuels.

2. Expand the initial conditions of temperature and pressure to include more engine conditions, and also investigate the effect of the fuel injected on the autoignition.

3. Insert more TCs inside the IQT chamber by creating additional ports in the side wall, thereby maintaining the pressure transducer in its standard position.

4. Use other types of TCs with higher temperature range durability in the experimental work, such as R, S and B types.

5. To simulate engine conditions, charge the chamber with the recirculation gas as well as air, and use different $\mathrm{O} 2$ percentages.

6. Develop an ignition delay model based on the temperature method, and validate it with the ignition delay methods. 


\section{Bibliography}

[1] A. Wang, G. Wang, Q. Chen, W. Yu, K. Yan, and H. Yang, "S-curve model of relationship between energy consumption and economic development", Natural Resources Research, vol. 24, no. 1, pp. 53-64, 2015.

[2] I. E. Agency, Key world energy statistics. International Energy Agency, 2016.

[3] O. o. E. S. o. S. D. U.S. Energy Information Administration and S. Integration, Monthly energy review, Apr. 2016.

[4] P. A. Lakshminarayanan and Y. V. Aghav, Modelling diesel combustion, English, 1. Aufl.;1st;1; Dordrecht;New York; Springer, 2010, ISBN: 9789048138852.

[5] D. Davidson, Y. Zhu, J. Shao, and R. Hanson, "Ignition delay time correlations for distillate fuels", Fuel, vol. 187, pp. 26-32, 2017.

[6] A. K. Agarwal, A. Dhar, J. G. Gupta, W. I. Kim, K. Choi, C. S. Lee, and S. Park, "Effect of fuel injection pressure and injection timing of karanja biodiesel blends on fuel spray, engine performance, emissions and combustion characteristics", Energy Conversion and Management, vol. 91, pp. 302-314, 2015.

[7] H. Y. Kim, J. C. Ge, and N. J. Choi, "Effects of fuel injection pressure on combustion and emission characteristics under low speed conditions in a diesel engine fueled with palm oil biodiesel", Energies, vol. 12, no. 17, p. 3264, 2019. 
[8] A. I. Standards, "Standard test method for cetane number of diesel fuel oil", in Annual Book of ASTM Standards, vol. 5.05, ASTM International, Feb. 2015, pp. 319.

[9] M. A. Fahim, T. A. Al-Sahhaf, and A. Elkilani, Fundamentals of petroleum refining. Elsevier, 2009.

[10] R. Hurn and K. Hughes, "Combustion characteristics of diesel fuels as measured in a constant-volume bomb-a report of the coordinating research council, inc.", SAE Technical Paper, Tech. Rep., 1952.

[11] T. W. Ryan and T. J. Callahan, "Engine and constant volume bomb studies of diesel ignition and combustion", SAE Technical Paper, Tech. Rep., 1988.

[12] A. I. Standards, "Standard test method for determination of ignition delay and derived cetane number ( $\mathrm{dcn}$ ) of diesel fuel oils by combustion in a constant volume chamber", in Annual Book of ASTM Standards, vol. 5.05, ASTM International, Feb. 2015, pp. 158-174.

[13] _ - "Standard test method for determination of derived cetane number (dcn) of diesel fuel oils- fixed range injection period, constant volume combustion chamber method", in Annual Book of ASTM Standards, vol. 5.05, ASTM International, Feb. 2015, pp. 175-187.

[14] — "Standard test method for determination of derived cetane number (den) of diesel fuel oils- ignition delay and combustion delay using a constant volume combustion chamber method", in Annual Book of ASTM Standards, vol. 5.05, ASTM International, Feb. 2015, pp. 158-174.

[15] J. Yanowitz, M. A. Ratcliff, R. L. McCormick, J. D. Taylor, and M. J. Murphy, "Compendium of experimental cetane numbers", NREL (National Renewable Energy Laboratory (NREL), Golden, CO (United States)), Tech. Rep., 2017. 
[16] Ignition quality tester (iqt), (Date last accessed 15-June-2017), 2017. [Online]. Available: http://aet.ca/index $\cdot$ php? section=20.

[17] Z. Zheng, T. Badawy, N. Henein, and E. Sattler, "Investigation of physical and chemical delay periods of different fuels in the ignition quality tester", Journal of engineering for gas turbines and power, vol. 135, no. 6, p. 061 501, 2013.

[18] W. J. Thoo, A. Kevric, H. K. Ng, S. Gan, P. Shayler, and A. La Rocca, "Characterisation of ignition delay period for a compression ignition engine operating on blended mixtures of diesel and gasoline", Applied Thermal Engineering, vol. 66, no. 1, pp. 55-64, 2014.

[19] Z. Liu and G. Karim, "The ignition delay period in dual fuel engines", SAE Technical Paper, Tech. Rep., 1995.

[20] J. Tausz and F. Schulte, "Determination of ignition points of liquid fuels under pressure", 1925.

[21] O. Holfelder, "Ignition and flame development in the case of diesel fuel injection", 1936.

[22] M. A. ELLIOTT, "Combustion of diesel fuel", SAE Technical Paper, Tech. Rep., 1949.

[23] K. Tsao, P. Myers, and O. Uyehara, "Gas temperatures during compression in motored and fired diesel engines", SAE Technical Paper, Tech. Rep., 1962.

[24] M. Burrows, S. Shimizu, P. Myers, and O. Uyehara, "The measurement of unburned gas temperatures in an engine by an infrared radiation pyrometer", in $S A E$ Technical Paper, SAE International, Jan. 1961. DOI: 10.4271/610043. [Online]. Available: http://dx.doi.org/10.4271/610043.

[25] T. W. Ryan, "Correlation of physical and chemical ignition delay to cetane number", SAE Technical Paper, Tech. Rep., 1985. 
[26] T. W. Ryan and B. Stapper, "Diesel fuel ignition quality as determined in a constant volume combustion bomb", 1987.

[27] K. J. Laidler, "The development of the arrhenius equation", Journal of Chemical Education, vol. 61, no. 6, p. 494, 1984.

[28] Z. Han, N. A. Henein, and W. Bryzik, "A new ignition delay formulation applied to predict misfiring during cold starting of diesel engines", SAE Technical Paper, Tech. Rep., 2000.

[29] S.-I. Kwon, M. Arai, and H. Hiroyasu, "Effects of cylinder temperature and pressure on ignition delay in direct injection diesel engine", Bull. MESJ, vol. 18, no. 1, pp. 3-16, 1990.

[30] J. Taylor, R. McCormick, and W. Clark, "Report on the relationship between molecular structure and compression ignition fuels, both conventional and hcci", National Renewable Energy Laboratory, Golden, CO, Report No. NREL/MP-54036726, 2004.

[31] J. Taylor, "Using iqt measurements, develop simplified kinetic expressions for ignition of fuels that could be used in heci engine models", NREL/MP-540-40755, National Renewable Energy Laboratory, Tech. Rep., 2006.

[32] S. Saravanan, G. Nagarajan, and S. Sampath, "A correlation for the ignition delay of a ci engine fuelled with diesel and biodiesel", International Journal of Green Energy, vol. 11, no. 5, pp. 542-557, 2014.

[33] F. Otto and C. KrÃACEger, "Simulation of combustion", English, in, C. S. GuÂšnter Merker and R. Teichmann, Eds. Berlin, Heidelberg: Springer Berlin Heidelberg, 2012, ch. 14, pp. 537-584, ISBN: 9783642029516;3642029515;

[34] J. Bittle, B. Knight, and T. Jacobs, "Interesting behavior of biodiesel ignition delay and combustion duration", Energy $\& 6$ Fuels, vol. 24, no. 8, pp. 4166-4177, 2010 . 
[35] E.-K. Mohammed and M. A. Nemit-allah, "Experimental investigations of ignition delay period and performance of a diesel engine operated with jatropha oil biodiesel", Alexandria Engineering Journal, vol. 52, no. 2, pp. 141-149, 2013.

[36] J. Petersen, D. Seivwright, P. Caton, and K. Millsaps, "Combustion characterization and ignition delay modeling of low-and high-cetane alternative diesel fuels in a marine diesel engine", Energy \& Fuels, vol. 28, no. 8, pp. 5463-5471, 2014.

[37] S. K. Berkhous, "Using a constant volume combustion chamber analyzer for predicting derived cetane number of aviation turbine fuels", IASH Paper, 2009.

[38] S. Kook, C. Bae, P. C. Miles, D. Choi, and L. M. Pickett, "The influence of charge dilution and injection timing on low-temperature diesel combustion and emissions", SAE Technical Paper, Tech. Rep., 2005.

[39] G. Bogin, A. M. Dean, M. A. Ratcliff, J. Luecke, and B. T. Zigler, "Expanding the experimental capabilities of the ignition quality tester for autoigniting fuels", $S A E$ International Journal of Fuels and Lubricants, vol. 3, no. 2010-01-0741, pp. 353$367,2010$.

[40] G. E. Bogin Jr, E. Osecky, M. A. Ratcliff, J. Luecke, X. He, B. T. Zigler, and A. M. Dean, "Ignition quality tester (iqt) investigation of the negative temperature coefficient region of alkane autoignition", Energy \& Fuels, vol. 27, no. 3, pp. 1632$1642,2013$.

[41] G. E. Bogin Jr, E. Osecky, J. Chen, M. A. Ratcliff, J. Luecke, B. T. Zigler, and A. M. Dean, "Experiments and computational fluid dynamics modeling analysis of large n-alkane ignition kinetics in the ignition quality tester", Energy $\&$ Fuels, vol. 28 , no. 7 , pp. $4781-4794,2014$.

[42] T. A. Barckholtz, "Modeling the negative temperature coefficient in the low temperature oxidation of light alkanes", Prepr. Pap.-Am. Chem. Soc., Div. Fuel Chem, vol. 48, no. 2, p. 518, 2003. 
[43] A. Cox, J. Griffiths, C. Mohamed, H. Curran, W. Pitz, and C. Westbrook, "Extents of alkane combustion during rapid compression leading to single-and two-stage ignition", in Symposium (International) on Combustion, Elsevier, vol. 26, 1996, pp. 2685-2692.

[44] Z. Zheng, T. Badawy, N. Henein, E. Sattler, and N. Johnson, "Effect of cetane improver on autoignition characteristics of low cetane sasol ipk using ignition quality tester", Journal of Engineering for Gas Turbines and Power, vol. 136, no. 8, p. $081505,2014$.

[45] S. Y. Yang, N. Naser, S. H. Chung, and K. Al-Qurashi, "Ignition delay and soot oxidative reactivity of mtbe blended diesel fuel", SAE Technical Paper, Tech. Rep., 2014.

[46] R. Karinen, V. Vindenes, I. Morild, L. Johnsen, I. Nygaard, and A. S. Christophersen, "Methyl tert-butyl ether (mtbe) detected in abnormally high concentrations in postmortem blood and urine from two persons found dead inside a car containing a gasoline spill", Journal of forensic sciences, vol. 58, no. 5, pp. 13931396, 2013.

[47] K. Zaidi, G. Andrews, and J. Greenhough, "Diesel fumigation partial premixing for reducing ignition delay and amplitude of pressure fluctuations", SAE Technical Paper, Tech. Rep., 1998.

[48] D. Assanis, Z. Filipi, S. Fiveland, and M. Syrimis, "A predictive ignition delay correlation under steady-state and transient operation of a direct injection diesel engine", Journal of Engineering for Gas Turbines and Power, vol. 125, no. 2, pp. 450-457, 2003. DOI: 10.1115/1.1563238.

[49] C. Jayakumar, Z. Zheng, U. Joshi, W. Bryzik, N. Henein, and E. Sattler, "Effect of intake pressure and temperature on the auto-ignition of fuels with different cetane number and volatility", SAE Technical Paper, Tech. Rep., 2012. 
[50] R. P. Rodríguez, R. Sierens, and S. Verhelst, "Ignition delay in a palm oil and rapeseed oil biodiesel fuelled engine and predictive correlations for the ignition delay period", Fuel, vol. 90, no. 2, pp. 766-772, 2011.

[51] W. F. Colban, P. C. Miles, and S. Oh, "Effect of intake pressure on performance and emissions in an automotive diesel engine operating in low temperature combustion regimes", SAE Technical Paper, Tech. Rep., 2007.

[52] M. Dahodwala, V. Nagaraju, K. Acharya, W. Bryzik, and N. Henein, "Effect of using biodiesel (b-20) and combustion phasing on combustion and emissions in a hsdi diesel engine", SAE Technical Paper, Tech. Rep., 2011.

[53] P. Schihl, L. Hoogterp-Decker, and E. Gingrich, "The ignition behavior of a coal to liquid fischer-tropsch jet fuel in a military relevant single cylinder diesel engine", SAE International Journal of Fuels and Lubricants, vol. 5, no. 2012-01-1197, pp. 785-802, 2012.

[54] D. Lata and A. Misra, "Analysis of ignition delay period of a dual fuel diesel engine with hydrogen and lpg as secondary fuels", International Journal of Hydrogen Energy, vol. 36, no. 5, pp. 3746-3756, 2011.

[55] U. Joshi, Z. Zheng, A. Shrestha, N. Henein, and E. Sattler, "An investigation on sensitivity of ignition delay and activation energy in diesel combustion", Journal of Engineering for Gas Turbines and Power, vol. 137, no. 9, p. 091 506, 2015.

[56] S. Y. Yang, N. Naser, S. H. Chung, and J. Cha, "Effect of temperature, pressure and equivalence ratio on ignition delay in ignition quality tester (iqt): Diesel, n-heptane, and iso-octane fuels under low temperature conditions", SAE International Journal of Fuels and Lubricants, vol. 8, no. 2015-01-9074, pp. 537-548, 2015.

[57] L. N. Allard, N. J. Hole, G. D. Webster, T. W. Ryan, D. Ott, A. Beregszazy, C. W. Fairbridge, J. Cooley, K. Mitchell, E. K. Richardson, et al., "Diesel fuel ignition 
quality as determined in the ignition quality tester (iqt)-part ii", SAE Technical Paper, Tech. Rep., 1997.

[58] O. A. Kuti, S. Y. Yang, N. Hourani, N. Naser, W. L. Roberts, S. H. Chung, and S. M. Sarathy, "A fundamental investigation into the relationship between lubricant composition and fuel ignition quality", Fuel, vol. 160, pp. 605-613, 2015.

[59] M. Waqas, N. Naser, M. Sarathy, K. Morganti, K. Al-Qurashi, and B. Johansson, "Blending octane number of ethanol in hcci, si and ci combustion modes", SAE International Journal of Fuels and Lubricants, vol. 9, no. 2016-01-2298, pp. 659$682,2016$.

[60] T. M. Foong, K. J. Morganti, M. J. Brear, G. da Silva, Y. Yang, and F. L. Dryer, "The octane numbers of ethanol blended with gasoline and its surrogates", Fuel, vol. 115, pp. 727-739, 2014.

[61] N. Rankovic, G. Bourhis, M. Loos, and R. Dauphin, "Understanding octane number evolution for enabling alternative low ron refinery streams and octane boosters as transportation fuels", Fuel, vol. 150, pp. 41-47, 2015.

[62] G. E. Bogin, J. Luecke, M. A. Ratcliff, E. Osecky, and B. T. Zigler, "Effects of isooctane/ethanol blend ratios on the observance of negative temperature coefficient behavior within the ignition quality tester", Fuel, vol. 186, pp. 82-90, 2016.

[63] E. M. Osecky, G. E. Bogin Jr, S. M. Villano, M. A. Ratcliff, J. Luecke, B. T. Zigler, and A. M. Dean, "Investigation of iso-octane ignition and validation of a multizone modeling method in an ignition quality tester", Energy \& Fuels, vol. 30, no. 11, pp. 9761-9771, 2016.

[64] B. T. Fisher, J. C. Allen, R. L. Hancock, and J. A. Bittle, "Evaluating the potential of a direct-injection constant-volume combustion chamber as a tool to validate chemical-kinetic models for liquid fuels", Combustion Science and Technology, vol. 189, no. 1, pp. 1-23, 2017. 
[65] N. Naser, S. Y. Yang, G. Kalghatgi, and S. H. Chung, "Relating the octane numbers of fuels to ignition delay times measured in an ignition quality tester (iqt)", Fuel, vol. 187, pp. 117-127, 2017.

[66] W. Cannella, M. Foster, G. Gunter, and W. Leppard, "Face gasolines and blends with ethanol: Detailed characterization of physical and chemical properties", $C R C$ Report No AVFL-24, 2014.

[67] A. Demirbas, M. Balubaid, A. Basahel, W. Ahmad, and M. Sheikh, "Octane rating of gasoline and octane booster additives", Petroleum Science and Technology, vol. 33, no. 11, pp. 1190-1197, 2015.

[68] G. T. Kalghatgi, K. Nakata, and K. Mogi, "Octane appetite studies in direct injection spark ignition (disi) engines", SAE Technical Paper, Tech. Rep., 2005.

[69] G. Kalghatgi, H. Babiker, and J. Badra, "A simple method to predict knock using toluene, n-heptane and iso-octane blends (tprf) as gasoline surrogates", $S A E$ International Journal of Engines, vol. 8, no. 2015-01-0757, pp. 505-519, 2015.

[70] A. A. Amsden, P. O'rourke, and T. Butler, "Kiva-ii: A computer program for chemically reactive flows with sprays", Los Alamos National Lab., NM (USA), Tech. Rep., 1989.

[71] A. Amsden, "Kiva3vrelease2. a block-structured kiva program for engines with vertical or canted valves", Los Alamos National Lab., NM (United States), Tech. Rep., 1999.

[72] Modeling the Fuel Spray and Combustion Process of the Ignition Quality Tester with KIVA-3V, National Renewable Energy Laboratory Golden, CO, 2010.

[73] G. E. Bogin Jr, A. DeFilippo, J. Y. Chen, G. Chin, J. Luecke, M. A. Ratcliff, B. T. Zigler, and A. M. Dean, "Numerical and experimental investigation of n-heptane autoignition in the ignition quality tester (iqt)", Energy 8 Fuels, vol. 25, no. 12, pp. 5562-5572, 2011. 
[74] H.-L. Tsai, J.-Y. Chen, and G. T. Chin, "Validation of a newly developed nheptane reduced chemistry and its application to simulations of ignition quality tester, diesel, and hcci combustion", Journal of Engineering for Gas Turbines and Power, vol. 136, no. 12, p. 121 505, 2014.

[75] A. Douaud and P. Eyzat, "Four-octane-number method for predicting the antiknock behavior of fuels and engines", SAE Technical Paper, Tech. Rep., 1978.

[76] O. J. Metcalf, A. Swarts, and A. Yates, "A study of the ignition-delay character of n-heptane in the iqtâc combustion bomb using cfd modelling", SAE Technical Paper, Tech. Rep., 2007.

[77] S. Som, D. Longman, Z. Luo, M. Plomer, and T. Lu, "Three dimensional simulations of diesel sprays using n-dodecane as a surrogate", in Fall technical meeting of the eastern states section of the combustion institute, 2011.

[78] Forte user's guide, 18.2, Canonsburg, PA 15317, Aug. 2017.

[79] S. K. Das and O. T. Lim, "Spray simulation of n-heptane in a constant volume combustion chamber over a wide range of ambient gas density and fuel temperature", Energy Procedia, vol. 105, pp. 1813-1820, 2017.

[80] S. J. M. Algayyim, A. P. Wandel, and T. Yusaf, "Experimental and numerical investigation of spray characteristics of butanol-diesel blends", in Proceedings of the 11th Asia-Pacific Conference on Combustion, Combustion Institute, 2017.

[81] C. Plengsa-ard and M. Kaewbumrung, "Cfd modelling wall heat transfer inside a combustion chamber using ansys forte", in IOP Conference Series: Materials Science and Engineering, IOP Publishing, vol. 297, 2018, p. 012036.

[82] J. Y. Tan, H. K. Ng, S. Gan, and F. Bonatesta, "Numerical simulations of constantvolume spray combustion of n-heptane with chemical kinetics", Indian Journal of Science and Technology, vol. 10, no. 7, 2017. 
[83] S. Subramaniam, "Lagrangian-eulerian methods for multiphase flows", English, Progress in Energy and Combustion Science, vol. 39, no. 2-3, pp. 215-245, 2013.

[84] M. A. Patterson and R. D. Reitz, "Modeling the effects of fuel spray characteristics on diesel engine combustion and emission", SAE Technical Paper, Tech. Rep., 1998.

[85] J. C. Beale and R. D. Reitz, "Modeling spray atomization with the kelvin-helmholtz/rayleightaylor hybrid model", Atomization and sprays, vol. 9, no. 6, 1999.

[86] S. R. Turns et al., An introduction to combustion, 3rd ed. McGraw-hill New York, 2014, vol. 287.

[87] C. K. Westbrook, W. J. Pitz, O. Herbinet, H. J. Curran, and E. J. Silke, "A comprehensive detailed chemical kinetic reaction mechanism for combustion of n-alkane hydrocarbons from n-octane to n-hexadecane", Combustion and Flame, vol. 156 , no. 1 , pp. 181-199, 2009.

[88] M. Mehl, W. J. Pitz, C. K. Westbrook, and H. J. Curran, "Kinetic modeling of gasoline surrogate components and mixtures under engine conditions", Proceedings of the Combustion Institute, vol. 33, no. 1, pp. 193-200, 2011.

[89] J.-Y. Chen, "Automatic generation of reduced mechanisms and their applications to combustion modeling", China Academy of Aeronautics and Astronautics, vol. 33, no. 2, pp. 59-67, 2001.

[90] H. Ciezki and G. Adomeit, "Shock-tube investigation of self-ignition of n-heptaneair mixtures under engine relevant conditions", Combustion and flame, vol. 93, no. 4, pp. 421-433, 1993.

[91] T. Turanyi, A. Tomlin, and M. Pilling, "On the error of the quasi-steady-state approximation", The Journal of Physical Chemistry, vol. 97, no. 1, pp. 163-172, 1993.

[92] M. Mehl, H. Curran, W. Pitz, and C. Westbrook, "Chemical kinetic modeling of component mixtures relevant to gasoline", in European Combustion Meeting, 2009. 
[93] T. W. Ryan III, "Development of a portable fuel cetane quality monitor", DTIC Document, Tech. Rep., 1992.

[94] L. N. Allard, G. D. Webster, N. J. Hole, T. W. Ryan, D. Ott, and C. W. Fairbridge, "Diesel fuel ignition quality as determined in the ignition quality tester (iqt)", SAE technical paper, Tech. Rep., 1996.

[95] L. N. Allard, G. D. Webster, T. W. Ryan, G. Baker, A. Beregszaszy, C. W. Fairbridge, A. Ecker, and J. Rath, "Analysis of the ignition behaviour of the astm d-613 primary reference fuels and full boiling range diesel fuels in the ignition quality tester (iqtâф)-part iii”, SAE Technical Paper, Tech. Rep., 1999.

[96] L. N. Allard, G. D. Webster, T. W. Ryan, A. C. Matheaus, G. Baker, A. Beregszaszy, H. Read, K. Mortimer, and G. Jones, "Diesel fuel ignition quality as determined in the ignition quality tester (iqtậ) - part iv", in SAE Technical Paper, SAE International, Sep. 2001. DOI: 10.4271/2001-01-3527. [Online]. Available: http://dx.doi.org/10.4271/2001-01-3527.

[97] S. G. Daviault, "Characterization of the fuel injection process within the ignition quality tester (iqt)", Master's thesis, Carleton University, 2011.

[98] M. M. Karakolis, "Experimental analysis of the fuel injection system of the ignition quality tester (iqt)", Master's thesis, Carleton University, 2010.

[99] A. E. T. Ltd., Iqttm user manual, 2009.

[100] Kistler charge output pressure sensor model 601b, 2017. [Online]. Available: http: //www.process-controls.com/intertechnology/Kistler/Pressure_Model_ 601B.htm.

[101] B. N. A. C. Monitoring, $3300 x l$ 8mm proximity transducer system, 2016.

[102] 1-mhz, 16-bit usb data acquisition modules, (Date last accessed 25-July-2017), 2017. [Online]. Available: http://www . omega.ca/pptst_eng/OMB - DAQ-3000 . html. 
[103] P. Childs, J. Greenwood, and C. Long, "Review of temperature measurement", Review of scientific instruments, vol. 71, no. 8, pp. 2959-2978, 2000.

[104] A. Tong, "Improving the accuracy of temperature measurements", Sensor Review, vol. 21, no. 3, pp. 193-198, 2001.

[105] C. S. McEnally, Ü. Ö. Köylü, L. D. Pfefferle, and D. E. Rosner, "Soot volume fraction and temperature measurements in laminar nonpremixed flames using thermocouples", Combustion and Flame, vol. 109, no. 4, pp. 701-720, 1997.

[106] K. Farahmand and J. W. Kaufman, "Experimental measurement of fine thermocouple response time in air", Experimental heat transfer, vol. 14, no. 2, pp. 107$118,2001$.

[107] P. Auerkari, Mechanical and physical properties of engineering alumina ceramics. Technical Research Centre of Finland Espoo, 1996.

[108] Dry block calibrator, https://www.omega.com/pptst/CL-780A.html, (Date last accessed 14-January-2019). [Online]. Available: https://www.omega.com/pptst/ CL-780A.html.

[109] Thermocouple response time, Apr. 2017. [Online]. Available: https://www. omega. ca/en/resources/thermocouples-response-time.

[110] J. T. Nakos, Uncertainty analysis of thermocouple measurements used in normal and abnormal thermal environment experiments at Sandia's Radiant Heat Facility and Lurance Canyon Burn Site. United States. Department of Energy, 2004.

[111] R. Dieck, W. Steele, and G. Osolsobe, "Test uncertainty. asme ptc 19.1-2005", American Society of Mechanical Engineers, New York, NY, 2005.

[112] H. W. Coleman and W. G. Steele, "Engineering application of experimental uncertainty analysis", AIAA journal, vol. 33, no. 10, pp. 1888-1896, 1995.

[113] A. C. E.-2. on Temperature Measurement, Manual on the use of thermocouples in temperature measurement. ASTM International, 1981, vol. 470. 
[114] O. Ramadan, G. Webster, L. Menard, A. Wilcox, M. Kellen, and E. Matida, "Diesel fuel totally automated laboratory model of the ignition quality tester technology updates, part-1: Iqtâф-talm description and micro intra-laboratory study ( $\mu$ ils) results", SAE Technical Paper, Tech. Rep., 2014.

[115] O. Ramadan, G. Webster, L. Menard, A. Wilcox, C. Webster, and J. Larocque, "Ignition quality tester (iqtâc) precision improvements from using the totally automated laboratory model (talm) technology: Technology update, part-2: Mini inter-laboratory study using the iqtâф-talm", SAE Technical Paper, Tech. Rep., 2015.

[116] O. Ramadan, L. Menard, D. Gardiner, A. Wilcox, and G. Webster, "Performance evaluation of the ignition quality testers equipped with talm precision package (talm-iqtâф) participating in the astm neg cetane number fuel exchange program", SAE Technical Paper, Tech. Rep., 2017.

[117] T. Kollie, J. Horton, K. Carr, M. Herskovitz, and C. Mossman, "Temperature measurement errors with type k (chromel vs alumel) thermocouples due to shortranged ordering in chromel", Review of Scientific Instruments, vol. 46, no. 11, pp. 1447-1461, 1975.

[118] G. W. Burns and M. G. Scroger, The calibration of thermocouples and thermocouple materials, 35. US Department of Commerce, National Institute of Standards and Technology, 1989, vol. 250.

[119] C. Gu, Smoothing spline ANOVA models. Springer Science \& Business Media, 2013, vol. 297.

[120] A. I. Standards, ANNUAL BOOK OF ASTM STANDARDS. ASTM International, 2012, vol. 5.05. 
[121] M. Jaasim, A. Elhagrasy, M. Sarathy, S.-H. Chung, and H. G. Im, "Auto-ignition and spray characteristics of n-heptane and iso-octane fuels in ignition quality tester", SAE Technical Paper Series, 2018.

[122] R. Payri, J. P. Viera, V. Gopalakrishnan, and P. G. Szymkowicz, "The effect of nozzle geometry over the evaporative spray formation for three different fuels", Fuel, vol. 188, pp. 645-660, 2017.

[123] X. Wang, Z. Huang, O. A. Kuti, W. Zhang, and K. Nishida, "Experimental and analytical study on biodiesel and diesel spray characteristics under ultra-high injection pressure", International journal of heat and fluid flow, vol. 31, no. 4, pp. 659$666,2010$.

[124] Ö. O. Taşkiran and M. Ergeneman, "Experimental study on diesel spray characteristics and autoignition process", Journal of Combustion, vol. 2011, 2011.

[125] J. Kostas, D. Honnery, and J. Soria, "Time resolved measurements of the initial stages of fuel spray penetration", Fuel, vol. 88, no. 11, pp. 2225-2237, 2009.

[126] K. Lee and R. D. Reitz, "Investigation of spray characteristics from a low-pressure common rail injector for use in a homogeneous charge compression ignition engine", Measurement Science and Technology, vol. 15, no. 3, p. 509, 2004.

[127] R. Klein-Douwel, P. Frijters, L. Somers, W. De Boer, and R. Baert, "Macroscopic diesel fuel spray shadowgraphy using high speed digital imaging in a high pressure cell", Fuel, vol. 86, no. 12-13, pp. 1994-2007, 2007.

[128] H. Hiroyasu and M. Arai, "Structures of fuel sprays in diesel engines", SAE transactions, pp. 1050-1061, 1990.

[129] H. Hiroyasu, "Supplementary comments: Fuel spray characterization in diesel engines", Combustion modeling in reciprocating engines, pp. 369-408, 1980. 
[130] R. Payri, J. Gimeno, G. Bracho, and D. Vaquerizo, "Study of liquid and vapor phase behavior on diesel sprays for heavy duty engine nozzles", Applied Thermal Engineering, vol. 107, pp. 365-378, 2016.

[131] C. C. Douglas, J. Hu, M. Kowarschik, U. Rüde, and C. Weiß, "Cache optimization for structured and unstructured grid multigrid", Electronic Transactions on Numerical Analysis, vol. 10, pp. 21-40, 2000.

[132] J. F. Thompson and N. P. Weatherill, "Structured and unstructured grid generation.", Critical reviews in biomedical engineering, vol. 20, no. 1-2, pp. 73-120, 1992.

[133] C. Kraus, L. Selle, T. Poinsot, C. M. Arndt, and H. Bockhorn, "Influence of heat transfer and material temperature on combustion instabilities in a swirl burner", Journal of Engineering for Gas Turbines and Power, vol. 139, no. 5, p. 051503 , 2017.

[134] A. Patel, S.-C. Kong, and R. D. Reitz, "Development and validation of a reduced reaction mechanism for hcci engine simulations", SAE Technical Paper, Tech. Rep., 2004.

[135] T. Echekki and E. Mastorakos, "Turbulent combustion: Concepts, governing equations and modeling strategies", in Turbulent Combustion Modeling, Springer, 2011, pp. 19-39.

[136] B. E. Poling, J. M. Prausnitz, J. P. O'connell, et al., The properties of gases and liquids. Mcgraw-hill New York, 2001, vol. 5.

[137] C. Gualtieri, A. Angeloudis, F. Bombardelli, S. Jha, and T. Stoesser, "On the values for the turbulent schmidt number in environmental flows", Fluids, vol. 2, no. 2, p. 17, 2017. 
[138] Y. Tominaga and T. Stathopoulos, "Turbulent schmidt numbers for cfd analysis with various types of flowfield", Atmospheric Environment, vol. 41, no. 37, pp. 8091-8099, 2007.

[139] A. Fluent, "12.0 theory guide", Ansys Inc, vol. 5, pp. 114-118, 2009.

[140] H. K. Versteeg and W. Malalasekera, An introduction to computational fluid dynamics: the finite volume method. Pearson Education, 2007.

[141] S. Sazhin, "Spray formation and penetration", in Droplets and Sprays, Springer, 2014, pp. 9-48.

[142] A. H. Lefebvre and V. G. McDonell, Atomization and sprays. CRC press, 2017.

[143] S. Hwang, Z. Liu, and R. D. Reitz, "Breakup mechanisms and drag coefficients of high-speed vaporizing liquid drops", Atomization and Sprays, vol. 6, no. 3, 1996.

[144] S. A. Krzeczkowski, "Measurement of liquid droplet disintegration mechanisms", International Journal of Multiphase Flow, vol. 6, no. 3, pp. 227-239, 1980.

[145] L. Bravo and C.-B. Kweon, "A review on liquid spray models for diesel engine computational analysis", ARMY RESEARCH LAB ABERDEEN PROVING GROUND MD, Tech. Rep., 2014.

[146] Y. Shi, Y. Wang, and R. D. Reitz, "Computational fluid dynamic modelling a heavy-duty compression-ignition engine fuelled with diesel and gasoline-like fuels", International Journal of Engine Research, vol. 11, no. 5, pp. 355-373, 2010.

[147] D. P. Schmidt, I. Nouar, P. Senecal, C. Rutland, J. Martin, R. D. Reitz, and J. A. Hoffman, "Pressure-swirl atomization in the near field", SAE Technical Paper, Tech. Rep., 1999.

[148] L. Liang, J. G. Stevens, and J. T. Farrell, "A dynamic adaptive chemistry scheme for reactive flow computations", Proceedings of the Combustion Institute, vol. 32, no. 1, pp. 527-534, 2009. 
[149] _ _ "A dynamic multi-zone partitioning scheme for solving detailed chemical kinetics in reactive flow computations", Combustion Science and Technology, vol. 181, no. 11, pp. 1345-1371, 2009.

[150] L. Liang, J. G. Stevens, S. Raman, and J. T. Farrell, "The use of dynamic adaptive chemistry in combustion simulation of gasoline surrogate fuels", Combustion and flame, vol. 156, no. 7, pp. 1493-1502, 2009.

[151] H. J. Curran, E. M. Fisher, P.-A. Glaude, N. M. Marinov, W. Pitz, C. Westbrook, D. Layton, P. F. Flynn, R. P. Durrett, A. Zur Loye, et al., "Detailed chemical kinetic modeling of diesel combustion with oxygenated fuels", Sae Transactions, pp. 514-521, 2001.

[152] H. J. Curran, P. Gaffuri, W. J. Pitz, and C. K. Westbrook, "A comprehensive modeling study of n-heptane oxidation", Combustion and flame, vol. 114, no. 1-2, pp. 149-177, 1998.

[153] A. Stagni, A. Cuoci, A. Frassoldati, T. Faravelli, and E. Ranzi, "Lumping and reduction of detailed kinetic schemes: An effective coupling", Industrial \& Engineering Chemistry Research, vol. 53, no. 22, pp. 9004-9016, 2013.

[154] E. Ranzi, A. Frassoldati, A. Stagni, M. Pelucchi, A. Cuoci, and T. Faravelli, "Reduced kinetic schemes of complex reaction systems: Fossil and biomass-derived transportation fuels", International Journal of Chemical Kinetics, vol. 46, no. 9, pp. 512-542, 2014.

[155] A. Stagni, A. Frassoldati, A. Cuoci, T. Faravelli, and E. Ranzi, "Skeletal mechanism reduction through species-targeted sensitivity analysis", Combustion and Flame, vol. 163, pp. 382-393, 2016.

[156] M. Yao and Z. Zheng, "An investigation on a new reduced chemical kinetic model of n-heptane for hcci combustion", Proceedings of the Institution of Mechanical 
Engineers, Part D: Journal of Automobile Engineering, vol. 220, no. 7, pp. 991$1002,2006$.

[157] R. Seiser, H. Pitsch, K. Seshadri, W. Pitz, and H. Gurran, "Extinction and autoignition of n-heptane in counterflow configuration", Proceedings of the Combustion Institute, vol. 28, no. 2, pp. 2029-2037, 2000.

[158] Cid 510 - cetane ignition delay, (Date last accessed 18-June-2017). [Online]. Available: http://www.paclp.com/lab_instruments/cid_510_-_cetane_ignition_ delay/. 
Appendix A 


\section{Appendix A}

\section{Cetane Number Scale Standards}

In addition to the (ASTM D6890) IQT ${ }^{T M}$ standard test method for Cetane Number determination of diesel fuel oil, there are three other standard test methods used to evaluate the characteristics of compression ignition fuels. Those standards are ASTM D613 by the Cooperative Fuel Research (CFR) engine, ASTM D7170 by Fuel Ignition Tester (FIT) and ASTM D7668 by CID 510-Cetane Ignition Delay [158]. Main features of all test methods are summarized in the Table A.1.

Table A.1: Characteristics of Cetane Number Scales, 120

\begin{tabular}{|c|c|c|c|c|c|}
\hline & $\begin{array}{l}\text { Method } \\
\Rightarrow \Longrightarrow \\
\text { Features } \Downarrow\end{array}$ & D613-10a & D6890-17 & D7170-11 & D7668-10 \\
\hline 1 & $\begin{array}{l}\text { Rated } \\
\text { fuels }\end{array}$ & $\begin{array}{l}\text { Conventional } \\
\text { diesel oils }\end{array}$ & $\begin{array}{c}\text { diesel oils } \\
\text { with and } \\
\text { without } \\
\text { additives, } \\
\text { blends } \\
\text { with } \\
\text { biodiesel, } \\
\text { oil-sand } \\
\text { based } \\
\text { fuels, high } \\
\text { paraffinic } \\
\text { fuels }\end{array}$ & $\begin{array}{c}\text { diesel oils } \\
\text { with and } \\
\text { without } \\
\text { additives, } \\
\text { blends } \\
\text { with } \\
\text { biodiesel }\end{array}$ & $\begin{array}{c}\text { diesel oils } \\
\text { with and } \\
\text { without } \\
\text { additives, } \\
\text { blends with } \\
\text { biodiesel }\end{array}$ \\
\hline
\end{tabular}


Table A.1: Characteristics of Cetane Number Scales, [120]

\begin{tabular}{|c|c|c|c|c|c|}
\hline 2 & $\begin{array}{c}\text { Combustion } \\
\text { chamber }\end{array}$ & $\begin{array}{l}\text { Single cyl. } \\
\text {, 4stroke, } \\
\text { comp. } \\
\text { ratio }(8: 1 \\
\text { to } 36: 1)\end{array}$ & $\begin{array}{l}\text { Constant } \\
\text { volume } \\
\text { combus- } \\
\text { tion } \\
\text { chamber } \\
\text { (CVCC) }\end{array}$ & CVCC & CVCC \\
\hline & $\begin{array}{c}\text { Method } \\
\Rightarrow \Longrightarrow \\
\text { Features } \Downarrow\end{array}$ & D613-10a & D6890-17 & D7170-11 & D7668-10 \\
\hline 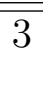 & $\begin{array}{l}\text { Injection } \\
\text { type }\end{array}$ & $\overline{\text { Indirect }}$ & Direct & Direct & Direct \\
\hline 4 & $\begin{array}{l}\text { Precise } \\
\mathrm{CN} / \mathrm{DCN} \\
\text { covered } \\
\text { range }\end{array}$ & $30-65$ & $34.4-62$ & $37.3-56-5$ & $35-60$ \\
\hline 5 & $\begin{array}{c}\text { Fuel } \\
\text { sample } \\
\text { and ap- } \\
\text { proximate } \\
\text { test time }\end{array}$ & $\begin{array}{c}400- \\
500 \mathrm{~mL} \\
5-10 \mathrm{~min}\end{array}$ & $\begin{array}{c}100 \mathrm{~mL}, \\
17 \mathrm{~min}\end{array}$ & $\begin{array}{c}220 \mathrm{~mL}, \\
20 \mathrm{~min}\end{array}$ & $\begin{array}{l}370 \mathrm{~mL}, \\
30 \mathrm{~min}\end{array}$ \\
\hline 6 & $\begin{array}{l}\text { Fuel flow } \\
\text { into } \\
\text { system }\end{array}$ & $\begin{array}{l}\text { Due to } \\
\text { gravity }\end{array}$ & $\begin{array}{c}\text { Under N2 } \\
\text { Pressure } \\
(345 \pm 35 \mathrm{kPa})\end{array}$ & $\begin{array}{l}\text { Under air } \\
\text { pressure }\end{array}$ & $\begin{array}{l}\text { Under N2 } \\
\text { pressure }\end{array}$ \\
\hline 7 & $\begin{array}{l}\text { Calibration } \\
\text { reference } \\
\text { materials } \\
\text { (min. } \\
\text { purity } \\
\text { \%by vol.) }\end{array}$ & $\begin{array}{c}\text { No specific } \\
\text { blends }\end{array}$ & $\begin{array}{c}1 . \\
\text { Heptane } \\
99.5 \% 2 . \\
\text { Methylcyclo- } \\
\text { hexane } \\
(\mathrm{MCH}) \\
99 \%\end{array}$ & $\begin{array}{c}1 . \\
\text { Heptane } \\
99.5 \% 2 . \\
\text { MCH } 99 \%\end{array}$ & $\begin{array}{l}\text { 1. Mix. } 50: 50 \\
\text { by W. of: } \\
\text { a)Hexadecane } \\
99 \% \text { b) } \\
\text { Heptameth- } \\
\text { ylnonane } 98 \% \\
\text { 2. MCH } 99 \%\end{array}$ \\
\hline 8 & $\begin{array}{l}\text { Number of } \\
\text { runs at } \\
\text { calibration }\end{array}$ & - & $\begin{array}{c}\text { 1. } 3 \text { runs } \\
\text { of Heptane } \\
I D_{a v}= \\
3.78 \pm \\
0.01 \mathrm{~ms} 2 . \\
2 \text { runs of } \\
\mathrm{MCH} \\
I D_{a v}= \\
10.4 \pm \\
0.5 \mathrm{~ms}\end{array}$ & $\begin{array}{c}\text { 1. } 3 \text { runs } \\
\text { of Heptane } \\
I D_{a v}= \\
3.15 \pm \\
0.02 \mathrm{~ms} \\
\text { 2. } 2 \text { runs of } \\
\mathrm{MCH} \\
I D_{a v}= \\
10.1 \pm \\
0.5 \mathrm{~ms}\end{array}$ & $\begin{array}{c}\text { 1. until } \\
\text { getting av. } \\
\text { Delay within } \\
\text { ID \&CD } \\
\text { ranges. } \\
2.2 \\
\text { succeeded } \\
\text { runs of MCH }\end{array}$ \\
\hline
\end{tabular}


Table A.1: Characteristics of Cetane Number Scales, [120]

\begin{tabular}{|c|c|c|c|c|c|}
\hline 9 & $\begin{array}{l}\text { \# of injec- } \\
\text { tions/run }\end{array}$ & $\begin{array}{c}\text { Engine: } \\
900 \pm 9 \text { rpm } \\
\text {, 4stroke }\end{array}$ & $\begin{array}{c}15 \text { pre } \\
+32 \text { test }\end{array}$ & 2 pre +25 test & 5 pre +15 test \\
\hline 10 & $\begin{array}{l}\text { O2 \% by } \\
\text { vol. in } \\
\text { charged air }\end{array}$ & - & $20.9 \pm 1.0$ & $20.9 \pm 1.0$ & $20 \pm 0.5$ \\
\hline 11 & $\begin{array}{c}\text { Charged } \\
\text { air Pres- } \\
\text { sure(MPa) }\end{array}$ & - & $2.137 \pm 0.007$ & $2.400 \pm 0.02$ & $2.00 \pm 0.02$ \\
\hline 12 & $\begin{array}{l}\text { Charged } \\
\text { air temp. } \\
(0 \mathrm{C})\end{array}$ & ambient & $545 \pm 30$ & $510 \pm 50$ & $535-600$ \\
\hline \multirow[t]{2}{*}{13} & $\begin{array}{c}\text { Warm up } \\
\text { time }(\min ) \approx\end{array}$ & 60 & 30 & - & 40 \\
\hline & $\begin{array}{l}\text { Method } \\
\Rightarrow \Longrightarrow \\
\text { Features } \Downarrow\end{array}$ & D613-10a & D6890-17 & D7170-11 & D7668-10 \\
\hline$\overline{14}$ & $\begin{array}{c}\text { CN/DCN } \\
\text { Calcula- } \\
\text { tion } \\
\text { eq. } \\
\text { ID: } \\
\text { Ignition } \\
\text { Delay, CD: } \\
\text { Combus- } \\
\text { tion } \\
\text { Delay }\end{array}$ & $\mathrm{CN}|\overline{8}|$ & $\begin{array}{c}D C N= \\
4.46+\frac{186.6}{I D}\end{array}$ & $\begin{array}{l}D C N= \\
171 \times \frac{1}{I D}\end{array}$ & $\begin{array}{l}D C N= \\
-5245 \times \\
I D-0.2566 \times \\
I D^{2}+ \\
0.1932 \times C D- \\
.001993 C D^{2}+ \\
46.857 \times \\
\frac{I D}{C D}+39.903\end{array}$ \\
\hline 15 & $\begin{array}{c}\text { Combustion } \\
\text { chamber } \\
\text { size } \\
\text { (Lit.) }\end{array}$ & $\begin{array}{c}\text { Cylinder: } \\
D s p l=0.612\end{array}$ & $0.213 \pm 0.002$ & $0.6 \pm 0.03$ & $0.473 \pm 0.05$ \\
\hline 16 & $\begin{array}{c}\text { Nozzle } \\
\text { opening } \\
\text { pressure } \\
(\mathrm{MPa})\end{array}$ & $10.3 \pm 0.34$ & $17.93 \pm 0.344$ & & $100 \pm 1.5$ \\
\hline 17 & $\begin{array}{l}\text { Approximate } \\
\text { Injection } \\
\text { period } \\
(\mathrm{ms})\end{array}$ & & $1.8-2$ & $5 \pm 0.25$ & $0.8-1.5$ \\
\hline
\end{tabular}

